ESTUDO DE PROVENIÊNCIA SEDIMENTAR DE SEQUÊNCIAS NEOPROTEROZOICAS AO LONGO DO LINEAMENTO PATOS (PROVÍNCIA BORBOREMA, NE DO BRASIL)

John Mauricio Rico Bautista

Orientadora: Profa ${ }^{a}$ Dra. Maria Helena Bezerra Maia de Hollanda

DISSERTAÇÃO DE MESTRADO

Programa de Pós-Graduação em Geoquímica e Geotectônica

VERSÃO CORRIGIDA 
UNIVERSIDADE DE SÃO PAULO

INSTITUTO DE GEOCIÊNCIAS

\section{"PROVENIÊNCIA SEDIMENTAR DE SEQUÊNCIAS NEOPROTEROZÓICAS AO LONGO DO LINEAMENTO PATOS (PROVÍNCIA BORBOREMA, NE DO BRASIL)" \\ JOHN MAURÍCIO RICO BAUTISTA}

Orientador: Profa. Dra. Maria Helena Bezerra Maia de Hollanda

DISSERTAÇÃO DE MESTRADO

COMISSÃO JULGADORA

Nome

Dra. Maria Helena Bezerra Maia de Holanda (Orientador)

Dr. Miguel Angelo Stipp Basei

(GMG/IGc/USP)

Dr. Ticiano José Saraiva dos Santos

(UNICAMP)

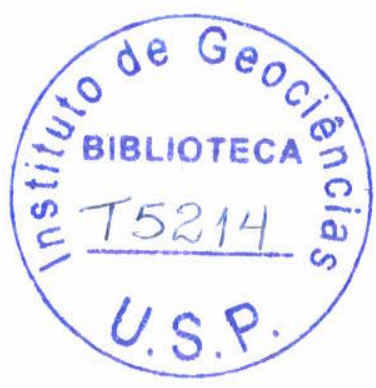

Assinatura

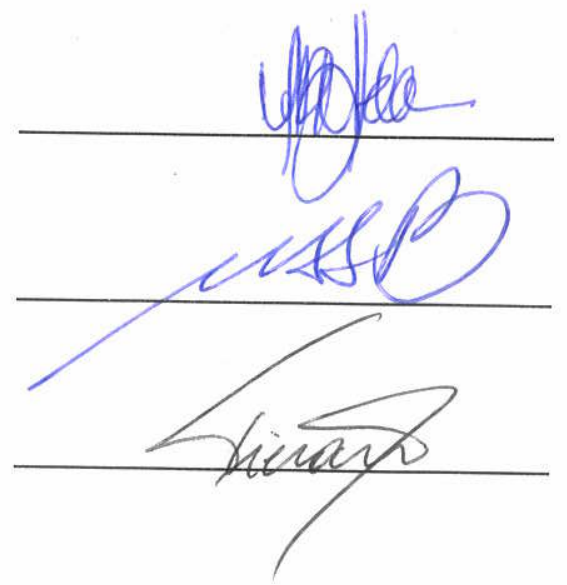

DEDALUS - Acervo - IGC

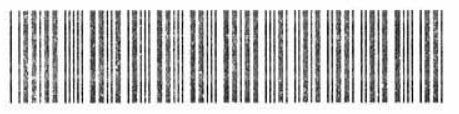

30900031216

SÃO PAULO

2012

Versão original 


\title{
ESTUDO DE PROVENIÊNCIA SEDIMENTAR DE SEQUÊNCIAS NEOPROTEROZOICAS AO LONGO DO LINEAMENTO PATOS (PROVÍNCIA BORBOREMA, NE DO BRASIL)
}

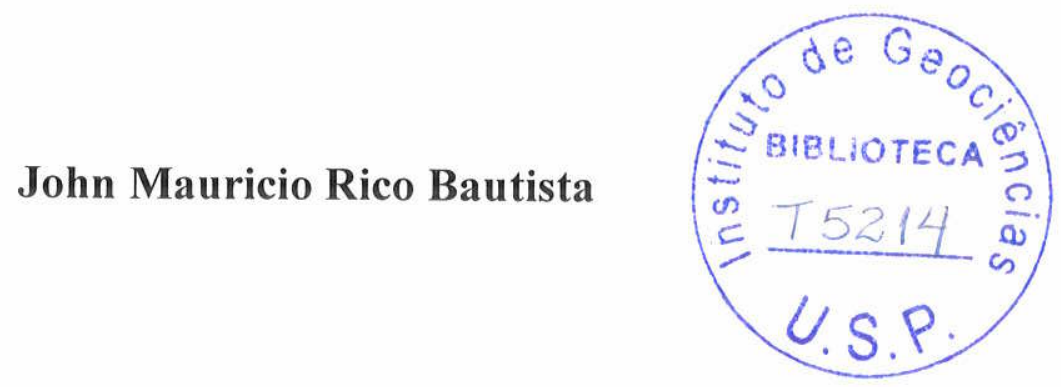 \\ Orientadora: Prof ${ }^{\mathrm{a}}$. Dra . Maria Helena Bezerra Maia de Hollanda \\ Dissertação de Mestrado elaborada junto ao \\ Programa de Pós-Graduação em Geoquímica e Geotectônica \\ do Instituto de Geociências da Universidade de São Paulo \\ na área de Geocronologia e Geologia Regional para obtenção \\ do Titulo do Mestre em Geociências.
}

\author{
DISSERTAÇÃO DE MESTRADO \\ Programa de Pós-Graduação em Geoquímica e Geotectônica \\ VERSÃO CORREGIDA
}

SÃO PAULO 
Ficha catalográfica preparada pelo Servico de Biblioteca e Documentação do Instituto de Geociências da Universidade de São Paulo

Rico Bautista, John Mauricio

Estudo de Proveniência Sedimentar de Sequências Neoproterozoicas ao Longo do Lineamento Patos, Província Borborema, NE do Brasil./ John Mauricio Rico Bautista. - São Paulo, 2012

70 p.: il + anexos

Dissertação (Mestrado) : IGc/USP

Orient.: Bezerra Maia de Hollanda, Maria Helena

1. Grupo Seridó 2. Formação Lavras da Mangabeira 3. Província Borborema 4. Geocronologia 5. Proveniência I. Título 
"Dedicado em memória de meu pai Israel Rico e meu irmão Omar Rico" 
"Man finds God behind every door that does open science" Albert Einsten 1879-1955. 


\section{AGRADECIMENTOS}

Primeiramente, gostaria de agradecer a Deus pela sonhada oportunidade de fazer o mestrado no Brasil e por ter colocado em meu caminho tanta gente que nos tratou muito bem a mim e a minha esposa, Johanna Mendez Duque. A meus irmãos Luis, Gladys e Elizabeth que sempre me apoiaram e me animaram, e a minha mãe Isbelia Bautista de Rico que sempre me incentivou a trabalhar forte em procura de meus sonhos, sempre me lembrando o valor da honestidade, responsabilidade e respeito.

A minha orientadora, Prof ${ }^{a}$. Dr ${ }^{a}$. Maria Helena Bezerra Maia de Hollanda por me dar a oportunidade de realizar o mestrado baixo sua orientação, sua grande ajuda profissional, excelentes conselhos e sugestões na interpretação dos dados e pela paciência em tudo momento.

Ao professor Dr. Carlos Jose Archanjo por sua colaboração e pelos comentários construtivos em campo e em todas as etapas de elaboração desta dissertação.

A toda a equipe dos laboratórios de Geocronologia (CPgeo), especialmente a Vazco Lois, Mauricio de Souza (Gaucho), Roberto Siqueira, Walter Sprosser, por suas valiosa ajudas nas etapas de preparação, análise, interpretação isotópica dos resultados, alem da solução de problemas técnicos.

Ao professor Dr. Daniel Atencio pela revisão do texto e colaboração na descrição petrográfica.

Ao professor Dr. André Oliveira Sawakuchi, agradeço principalmente por sua amizade, e por ter nos recebido a mim e a Johanna quase que como filhos, nos oferecendo sua hospitalidade e ajuda incondicional a todo instante. Seremos gratos a ele pelo resto de nossas vidas.

A Ilana Fichberg pelo apoio desde o primeiro momento no Brasil e pela amizade e incondicional ajuda.

Ao Instituto de Geociências e a CAPES pelo apoio financeiro por ter possibilitado a realização desta pesquisa. 
Ao Leonardo Pressi pela sua ajuda sincera amizade e colaboração en tudo momento.

Aos meus amigos Omar Camilo Montenegro e Alba Suárez pela confiança depositada em mim na execução deste projeto.

Aos parceiros Oscar Romero e Felipe Lamus, por serem bons amigos e também por serem "tan lámparas".

A meu parceiro de campo Luis Gustavo Viegas pela amizade, apoio na primera etapa de campo e sua multiples conselhos profesionais e colaborações.

A minha melhor amiga Geane Carolina Cavalcante por sua constante ajuda na revisão de textos, amizade, confiança e bom momentos compartidos.

A minha amiga Claudia Tokashiki por sua valiosa colaboracao na preparação das amostras e revisão dos textos da tese, e pela amizade.

Aos meus companheros de sala Bernardo e Vinicius por sua companhia e inumerables dicas e conselhos. A Donald Emmanuel Ngonge por sua colaboração na revisão dos textos da tese e conselhos.

Aos amigos do bloco, Eduardo Sartori, Angela Meira, Felipe Meira, Andréia Beleque, Nívea Magalhães e Nazaré Almeida pelo apoio, amizade e bons momentos compartidos.

A minha esposa Johanna Mendez Duque por sua valiosa e incansável companhia, sua grande paciência, seu constante ânimo, e o amor incondicional que me deu a mim durante todos estes anos e em especial o tempo no Brasil. Por seus valiosos e imnumeraveis conselhos profesionais e grande colaboração durante a elaboração desta dissertação, e por não me deixar desistir em nenhum momento e alegrar minha vida sempre.

Finalmente e não menos importante, a minha amada filha Anna Isabella que está a caminho de alegrar ainda mais minha vida.

Se me esqueci de alguém, por favor me desculpe. 


\section{SUMARIO}

\section{CAPÍTULO 1}

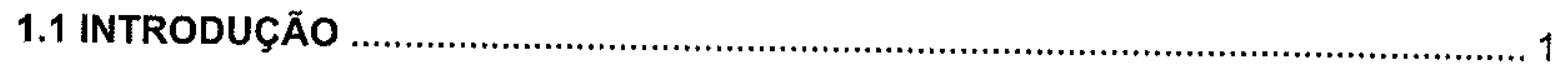

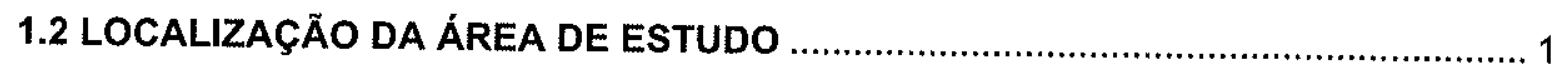

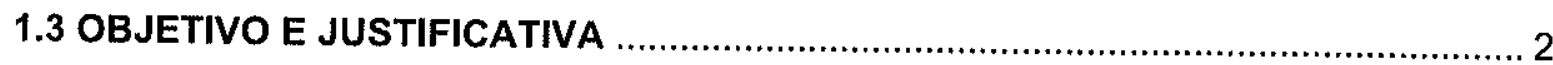

\section{CAPÍTULO 2}

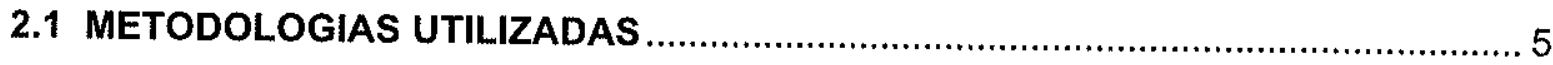

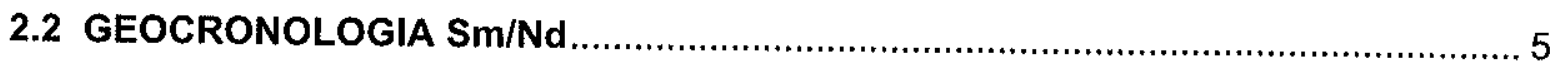

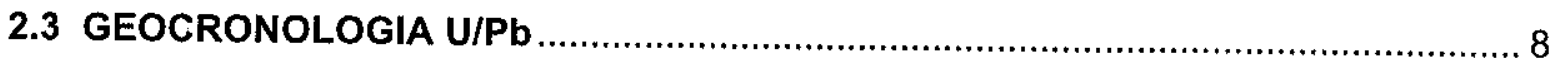

2.4 Tratamento Estatístico de Dados U/Pb por LA- ICP-MS .........................................10

CAPÍTULO 3

3.1 INTRODUÇÃO

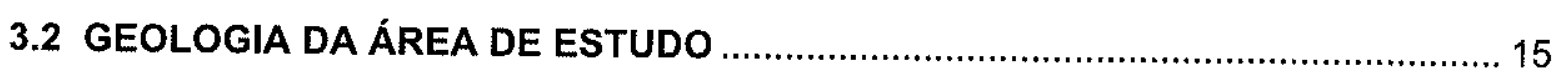

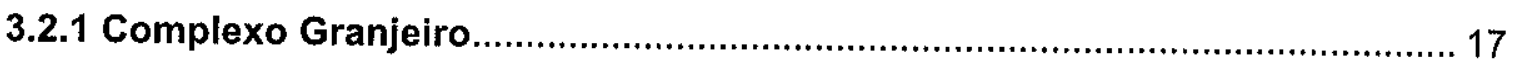

3.2.2. Sequência Supracrustal Lavras da Mangabeira …………………………..... 17

3.2.3 O Grupo Seridó e seu Embasamento .............................................................. 18

3.2.4. Sucessões Sedimentares Eo-Paleozoicas .................................................... 20

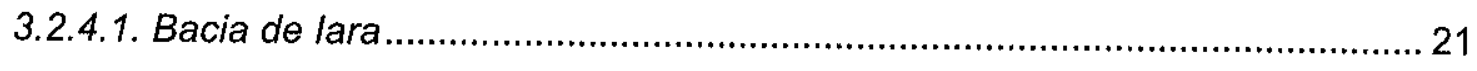

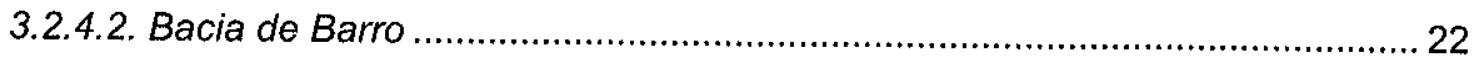

\section{CAPÍTULO 4}

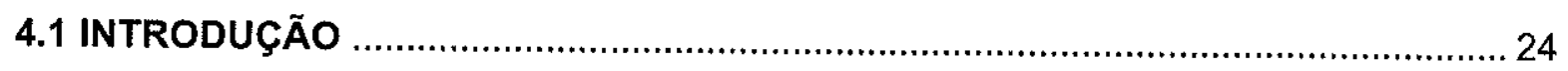

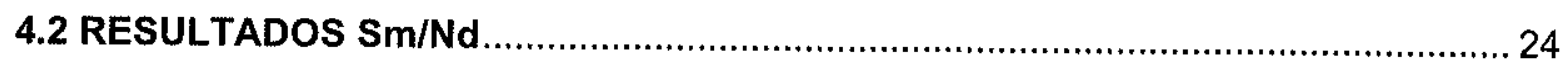

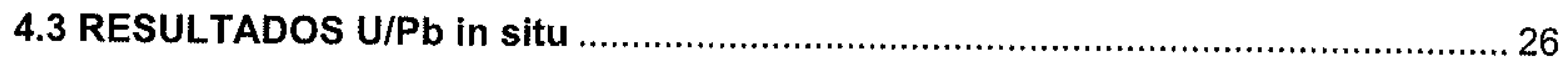

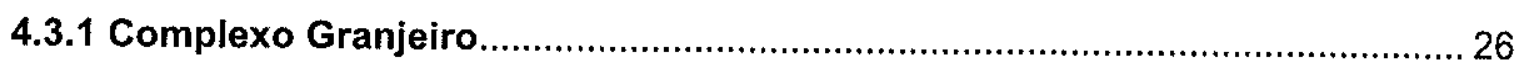

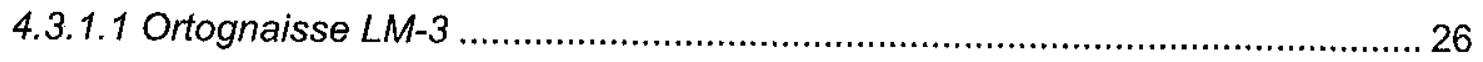

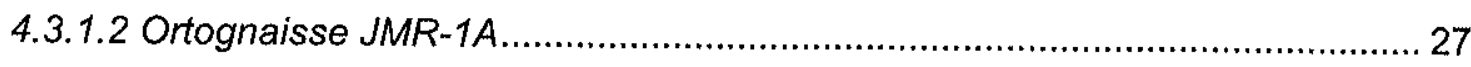

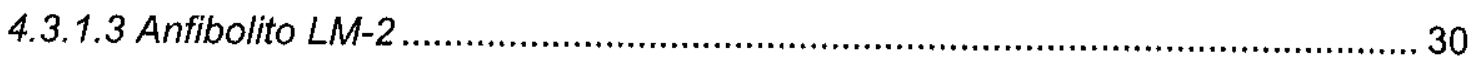

4.3.2 Sequência Metasedimentar Lavras da Mangabeira ……………...................... 31 


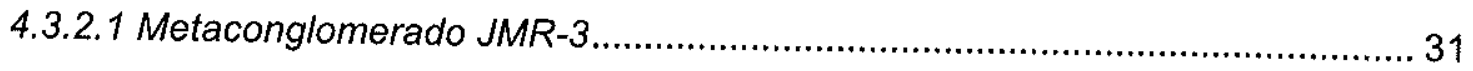

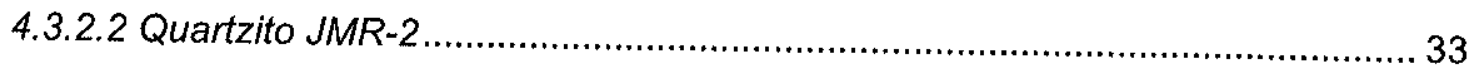

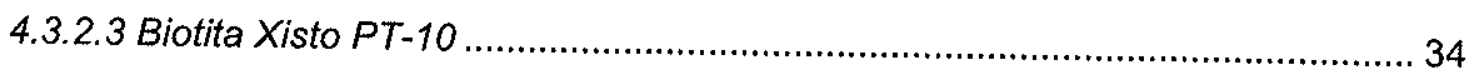

4.3.3 Sequência Metasedimentar Seridó ............................................................... 36

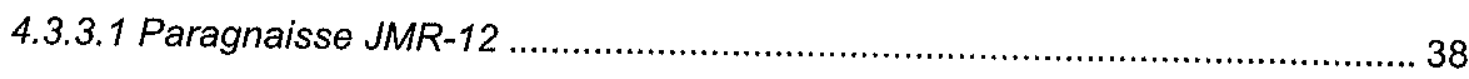

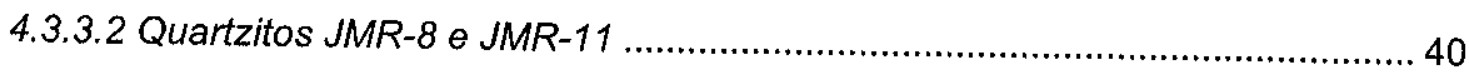

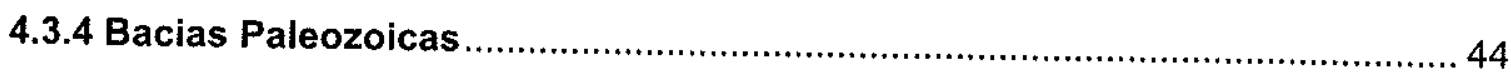

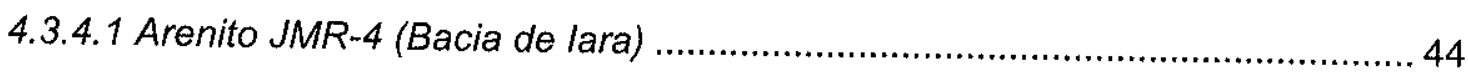

4.3.4.2 Arenito JMR-5 (Bacia de Barro) ............................................................ 46

\section{CAPÍTULO 5}

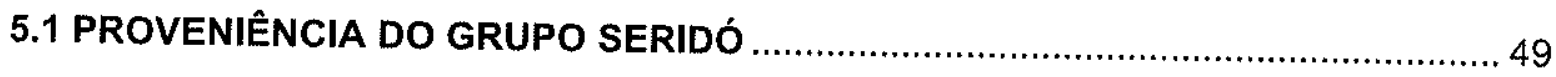

5.2 CORRELAÇÃO ENTRE AS SEQUÊNCIAS METASEDIMENTARES ESTUDADAS E O GRUPO SERIDÓ

5.3 ORIGEM PARA AS PROVÁVEIS FONTES DO GRUPO SERIDÓ .51

5.4 A TRANSIÇÃO NEOPROTEROZOICO-PALEOZOICO 53

5.5 CONCLUSÕES 54

Referências bibliográficas. .56 Anexos 


\section{SUMARIO DE FIGURAS}

\section{CAPÍTULO 1}

Figura 1.1. Mapa tectônico da Província Borborema

Figura 1.2.Mapa geológico das áreas de estúdo mostrando as zonas de cisalhamento e as unidades litologicas estudadas e a localizacao, das amostras coletadas

\section{CAPÍTULO 2}

Figura 2.1. Gráficos de "brancos", "padrões" e "razões" obtidos no tratamento estatístico pelo pacote $R \otimes$.

Figura 2.2. Diagramas Concórdia e histograma gerado pelo pacote $R \circledast$ 13

\section{CAPÍTULO 3}

Figura 3.1 Compartimentacão do setor norte da Província Borborema 16

Figura 3.2. Aspecto de campo dos afloramentos amostrados para análise de proveniência U/Pb in situ na regiāo de Coremas e Lavras da Mangabeira.

Figura 3.3 Aspecto de campo dos afloramentos das bacias eo-paleozoicas estudadas para análise $\mathrm{U} / \mathrm{Pb}$ in situ.

\section{CAPÍTULO 4}

Figura 4.1. Diagrama de evolução $\varepsilon N d$ versus tempo

Figura 4.2. Imagens de luz transmitida (A) e de catodoluminescência (B) dos zircões do ortognaisse LM-3.

Figura 4.3. Diagramas Concórdia para o ortognaisse LM-3.

Figura 4.4. Imagens de luz transmitida e catodoluminescência das populações de zircões do ortognaisse JMR-1A.

Figura 4.5. Diagrama Concórdia e histograma de densidade de probabilidade para o ortognaisse JMR-1A mostrando.

Figura 4.6. Imagens de luz transmitida (A) e de catodoluminescência (B) dos zircões do anfibolito LM2. 
Figura 4.8. Imagens de catodoluminescência ( $A$ a E) dos zircões do metaconglomerado JMR-3. .... 32 Figura 4.9. Diagramas Concórdia e histograma de densidade de probabilidade para o metaconglomerado JMR-3 33

Figura 4.10.Imagens de catodoluminescência ( $A$ a E) dos zircões do quartzito JMR-2. 35

Figura 4.11. Diagramas Concórdia e histograma de densidade de probabilidade para o quartzito JMR-2 36

Figura 4.12. Imagens de catodoluminescência (A a F) dos zircões do biotita xisto PT-10. 37

Figura 4.13. Diagramas Concórdia e histograma de densidade de probabilidade para o biotita xisto PT-10 38

Figura 4.14. Imagens de catodoluminescência (A a D) dos zircões do paragnaisse JMR-12. 39

Figura 4.15. Diagramas Concórdia e histograma de densidade de probabilidade para o paragnaisse JMR-12 .40

Figura 4.16. Imagens de catodoluminescência $(A$ a $D)$ dos zircões dos quartzitos JMR-8 e JMR-11. 42

Figura 4.17. Imagens de catodoluminescência $(A$ a $D)$ dos zircões do quartzitos JMR-11. 43

Figura 4.18. Diagramas Concórdia e histograma de densidade de probabilidade para os quartzitos JMR-8 e JMR-11: 44

Figura 4.19. Imagens de catodoluminescência ( $A$ a D) dos zircões do arenito JMR-4. 45

Figura 4.20. Diagramas Concórdia e histograma de densidade de probabilidade para o arenito JMR-4 46

Figura 4.21. Imagens de catodoluminescência (A a D) dos zircões do arenito JMR-5. 47

Figura 4.22. Diagramas Concórdia e histograma de densidade de probabilidade para o arenito JMR-5 48

\section{CAPÍTULO 5}

Figura 5.1. Correlação dos padrões de proveniência sedimentar entre as sequências CajazeirasCoremas, Lavras da Mangabeira e bacias eo-paleozoicas. 


\section{SUMARIO DE TABELAS}

Tabela 1. Amostras coletadas nos Estados de Paraíba e Ceará para análises isotópicos Sm-Nd e U$\mathrm{Pb}$ 


\section{RESUMO}

A Provincia Borborema corresponde a um domínio crustal localizado no nordeste do Brasil, cuja configuração tectônica é resultado da acresção de blocos crustais ao longo de zonas de cisalhamento. Dentre essas zonas destaca-se a de Patos, que corresponderia a uma das principais suturas originadas do Ciclo Brasiliano. Essa estrutura é caracterizada pela presença de milonitos diversos e ortognaisses migmatíticos com direção predominante $E-W$, mas também inclui a ocorrência de rochas supracrustais conhecidas regionalmente como a Formação Lavras da Mangabeira e uma sequência que ocorre na região de CajazeirasCoremas (PB) que é interpretada como análoga ao Grupo Seridó. A sul desta zona de cisalhamento localizam-se algumas bacias eo-paleozoicas dentre as quais as de lara e Barro, depositadas sobre metapelitos neoproterozoicos do Grupo Cachoeirinha. A sequência de embasamento na área de estudo é denominada Complexo Granjeiro. Apresenta uma grande variedade composicional, incluindo ortognaisses, biotita gnaisses parcialmente migmatizados e rochas máficas e meta-ultramáficas. As idades modelo tom em ortognaisses deste complexo variam entre 2,7 e 2,6 Ga enquanto que as idades de cristalização (U/Pb em zircão) definem um intervalo entre c. 3,1 - 2,35 $\mathrm{Ga}$, incluindo neste conjunto os resultados de anfibolitos. Repousando em discordância sobre o embassamento encontra-se os metasedimentos da Formacão Lavras da Mangabeira. Compreende metaconglomerados e quartzitos na base, passando ao topo para micaxistos e filitos. Os metaconglomerados e quartzitos apresentam assinaturas de proveniência com idades modelo $t_{D M}$ entre 2,7 - 2,5 $\mathrm{Ga}$, e padrões de proveniência U/Pb em zircão detritico definidos por populações de idades entre c. 3,4 e 2,0 Ga, com pico principal em c. 2,2 Ga. Por outro lado, os zircões das litologias metapelíticas exibem idades $U / P b$ dominantemente neoproterozoicas entre 1,1 . $0,55 \mathrm{Ga}$, com picos máximos de proveniência em c. 0,65 e c. 0,73 Ga. O Grupo Seridó na área de estudo é definido como em sua área-tipo na Faixa Seridó, incluindo os paragnaisses e mármores da Formação Jucurutu, quartzitos da Formação Equador e os metaturbiditos da Formação Seridó. Nos paragnaisses os zircões detríticos forneceram idades entre 1,1 - 0,6 $\mathrm{Ga}$, incluindo contribuições menores de populações paleoproterozoicas e arqueana. Ao contrário, os quartzitos da Formação Equador apresentam idades modelo tom entre 2,7 e 2,5 $\mathrm{Ga}$, com zircões detríticos mostraram idades paleoproterozoicas a arqueanas, similares àquelas obtidas na sequência basal da Formação Lavras da Mangabeira. Esse padrão de proveniência é fortemente sugestivo de que as rochas metasedimentares estudadas (Lavras da Mangabeira e a sequência Cajazeiras-Coremas) devam fazer parte de uma única bacia que, juntamente com o Grupo Seridó na sua área-tipo, tenha sido desmembrada pelo deslocamento transcorrente da Zona de Cisalhamento Patos. Os arenitos arcosianos das bacias eo-paleozoicas, por sua vez, apresentam populações de zircões neoproterozoicos, mas também com aportes de zircões paleoproterozoicos e arquenos. Esses resultados 
indicam que as bacias podem ter sido preenchidas por fontes diversas ou mesmo por sedimentos provenientes da erosão das sequências metasedimentares neoproterozoicas, mais antigas. A presença de zircões mais jovens que c. $0,62 \mathrm{Ga}$ indica a participação de rochas ígneas brasilianas também como fonte para a sedimentação dessas bacias. 


\begin{abstract}
The Borborema Province is a crustal domain located in northeastern Brazil, with a tectonic configuration that resulted from the accretion of crustal blocks along shear zones. The Patos Shear Zone, among the important ones, is one of the main sutures produced by the Brasilian Cycle. This structure is characterized by the presence of $E-W$-trending diverse milonites and migmatitic orthogneisses, including the regionally known Lavras da Mangabeira supercrustal formation and a sequence in the Cajazeiras-Coremas $(P B)$ region considered as analogous to the Serido Group. At the south of this shear zone are localized some Eo-Paleozoic basins such as the Lara and Barro, deposited on Neoproterozoic metapelites of the Cachoeirinha Group. The basement sequence of the area studied is called the Granjeiro Complex. It has a varied composition of orthogneisses, partially migmatized biotite gneisses and mafic and ultramafic rocks. Model $T_{D M}$ ages in orthogneisses of this complex varies between 2,7 and 2,6 Ga while the crystallization ages (U/Pb in zircon) define an interval between c. 3,1 and 2,35 Ga, including the results from amphibolites. Metasediments of the Lavras da Mangabeira Formation are discordant on the basement. It comprises of metaconglomerates and quartzites at the base and micaschists and phyllites at the top. The metaconglomerates and quartzites have provenance signatures with model $T_{D M}$ ages between 2,7 - 2,5 Ga, and $\mathrm{U} / \mathrm{Pb}$ in detritic zircon provenance model defined by populations with ages between $\mathrm{c}, 3,4$ and 2,0 Ga, with main peak at c. 2,2 Ga. The zircons from the metapelitic lithologies show $\mathrm{U} / \mathrm{Pb}$ ages dominantly Neoproterozoic between $1,1-0,55 \mathrm{Ga}$, with maximum peaks of provenance at c. 0,65 and c. 0,73 Ga.

The Serido Group in the studied area is defined as an area-type in the Serido Belt, including paragneisses and marbles of the Jucurutu Formation, quartzites from the Equador Formation and the metaturbidites of the Seridó Formation. Detritic zircons in the paragneisses give ages between $1,1-0,6 \mathrm{Ga}$, including minor contributions from the Archean and Paleoproterozoic populations. On the contrary, the the quartzites from the Equador Formation give model TDM ages between 2,7 e 2,5 Ga, with detritic zircons having Archean to Paleoproterozoic ages similar to those obtained in the basal sequence of the Lavras da Mangabeira Formation. This provenance model is strongly suggestive in the fact that the studied metasedimentary rocks (Lavras da Mangabeira and the Cajazeiras-Coremas sequence) are supposed to be part of a unique basin which together with the Serido Group in its area-type, was isolated by the transcurrent deslocation of the Patos Shear Zone.

On the other hand, the arkosic sandstones of the Eo.Paleozoic basins have Neoproterozoic zircon populations with Archean and Paleoproterozoic contributions. These results indicate that the basins could have been filled by sediments of diverse sources or from the erosion of the older Neoproterozoic metasediments. The presence of zircons younger than c. $0,62 \mathrm{Ga}$
\end{abstract}


indicate a participation of igneous rocks of the Brasilian orogeny which also is the source of the sediments of these basins. 


\section{CAPÍTULO 1}

\subsection{INTRODUÇÃO}

O conhecimento atual sobre a história evolutiva da Província Borborema como uma entidade geológica neoproterozoica resulta de um acervo significativo de dados cartográficos (com ênfase na definição de padrões estruturais e empilhamento estratigráfico), estudos petrológicos e levantamentos geofísicos. Apesar do reconhecido avanço em geocronologia no Brasil, alavancado nos últimos anos, são ainda de caráter pontual os dados existentes para as unidades geológicas que constituem essa importante província.

As primeiras tentativas de separar a Província Borborema em sub-unidades tectônicas tiveram como base o conceito de domínios estruturais, aos quais já estão hoje incorporadas informações geocronológicas precisas. Assim sendo, os grandes domínios tectônicos - Setentrional, Central, Meridional - propostos e discutidos em Santos et al. (1997, 2000) e Brito Neves et al. (2000), bem como em diversas outras referências anteriores, representam um modelo de compartimentação consolidado para a província. Muito ainda precisa ser feito quando o foco passa aos setores internos de cada domínio, com suas evoluções particulares no tempo e espaço. Nesse sentido, uma das questões mais básicas do ponto de vista geológico é reconhecer a extensão lateral das unidades litoestratigráficas regionais dentro desses domínios. É nesse aspecto que a geocronologia tem potencial para contribuir, quando as observações diretas de campo são prejudicadas face ao grau de tectonismo, má exposição ou registro pouco preservado dos objetos de interesse.

Essa dissertação de Mestrado tem por objetivo trazer um conjunto de dados geocronológicos $(\mathrm{Sm} / \mathrm{Nd}$ e $\mathrm{U} / \mathrm{Pb}$ ) obtidos em rochas metasedimentares que afloram no dominio Setentrional da Província Borborema, aqui usados como ferramenta de correlação litoestratigráfica lateral. A comparação é feita com base nos padrões de proveniência observados para cada uma da sucessões estudadas, e os resultados discutidos à luz do contexto geodinâmico regional atualmente reconhecido para esse setor da província.

\subsection{LOCALIZAÇÃO DA ÁREA DE ESTUDO}

A área está localizada na região nordeste do Brasil, circunscrita entre os meridianos $37^{\circ} 30^{\prime} \mathrm{W}$ e $39^{\circ} 30^{\prime} \mathrm{W}$ e os paralelos $6^{\circ} 15^{\prime} \mathrm{S}$ e $7^{\circ} 20^{\prime} \mathrm{S}$. Geologicamente, está dentro dos limites da Província Borborema, englobando a parte centro-ocidental da Zona de Cisalhamento Patos (Figura 1.1). Essa estrutura corresponde a uma zona de transcorrência dúctil de direção E-W, com cinemática destral, tendo aproximadamente $450 \mathrm{~km}$ de comprimento desde a costa leste até a Bacia do Araripe, e largura variando entre 20-30 km. Sua ocorrência em campo é marcada pela presença de milonitos de alta e baixa temperatura, 
além de migmatitos, desenvolvidos essencialmente em rochas supracrustais (quartzitos, xistos) e ortognaisses, os quais marcam o limite entre o domínio Rio Grande do Norte, a norte, e os vários terrenos que caracterizam a Zona Transversal, a sul (Vauchez et al., 1995).

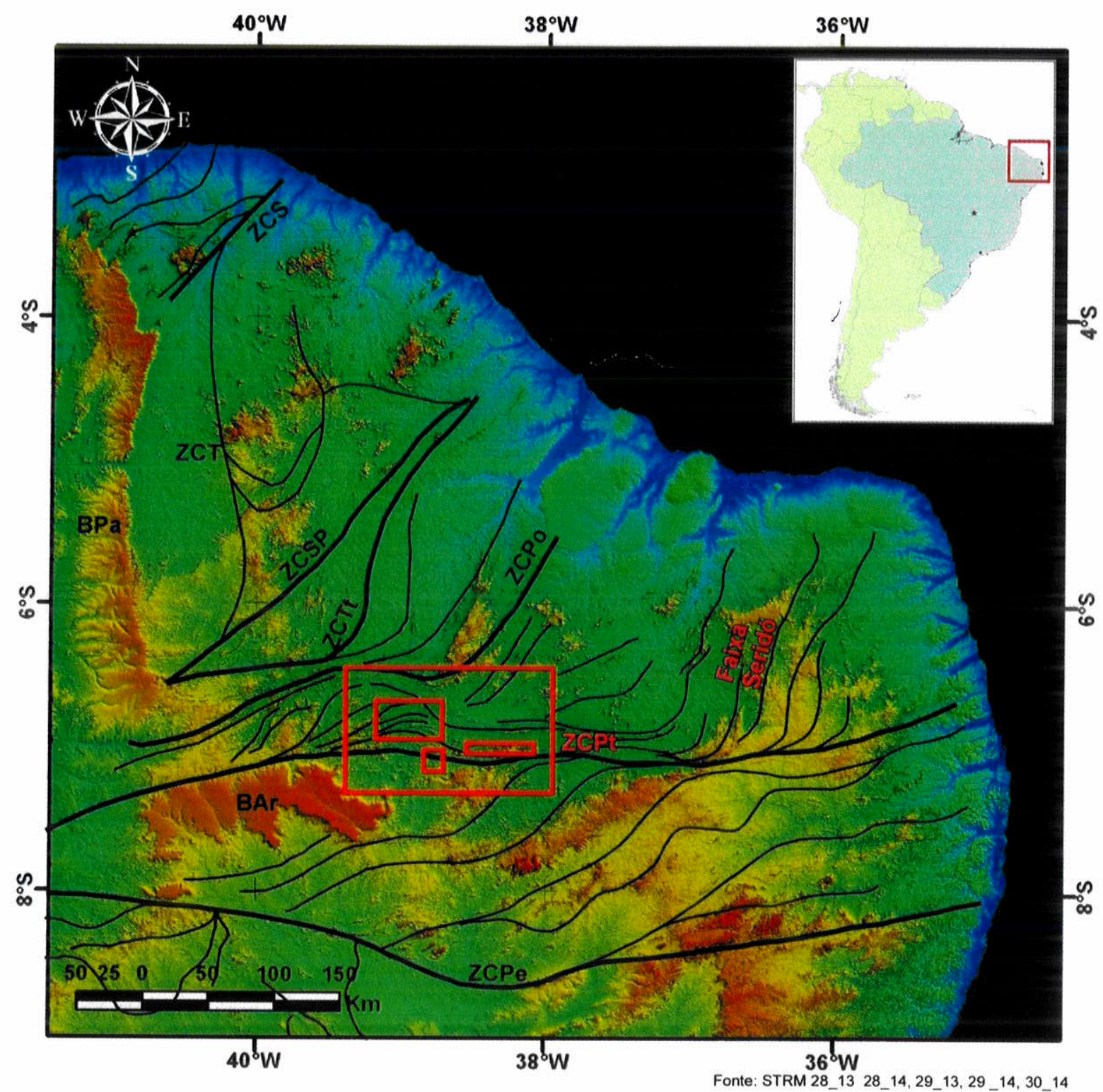

Figura 1.1. Mapa tectônico da Província Borborema. Abreviações: Zona de Cisalhamento Patos (ZCPt); Zona de Cisalhamento Pernambuco (ZCPe); Zona de Cisalhamento Senador Pompeu (ZCSP); Zona de Cisalhamento Tatajuba (ZCTt); Zona de Cisalhamento Portalegre (ZCPo); Zona de Cisalhamento Sobral (ZCS); Zona de Cisalhamento Taúa (ZCT); Bacia do Parnaiba (BPa); Bacia do Araripe (BAr). O quadrado vermelho identifica a área de estudo. Adaptado de STRM 28_13, 26_14, 29_13, 29_14, 30_14.

\subsection{OBJETIVO E JUSTIFICATIVA}

O objetivo principal desta dissertação de Mestrado é estabelecer a assinatura de proveniência das rochas metassedimentares (quartzitos, paragnaisses, xistos) que ocorrem ao longo da Zona de Cisalhamento Patos, entre as cidades de Cajazeiras e Coremas 
(Paraíba - PB), bem como daquelas que afloram na região de entorno da cidade de Lavras da Mangabeira (Ceará - CE) (Figura 1.2). Para atingir esse objetivo utilizou-se ferramentas metodológicas em Geologia Isotópica que consistiram em idades modelo $\mathrm{Sm} / \mathrm{Nd}\left(\mathrm{t}_{\mathrm{DM}}\right)$ e idades U/Pb in situ em zircão pela técnica LA-ICP-MS, as quais vêm sendo amplamente aplicadas em estudos de sequências metasedimentares antigas.

A justificativa para a presente abordagem esteve embasada na possibilidade de comparar a assinatura de proveniência das unidades metasedimentares estudadas ao longo do lineamento Patos com o padrão hoje reconhecido para as unidades do Grupo Seridó Formações Jucurutu, Equador e Serido, na região do Seridó (RN-PB). A comparação é especialmente importante para fins de correlação litoestratigráfica entre essas unidades visto que as mesmas encontram-se separadas por dezenas de quilômetros e seus contatos originais fortemente afetados por diferentes graus de milonitização. Ainda, os resultados permitirão discutir aspectos quanto a reconstrução paleogeográfica da paleobacia Seridó, buscando entender o papel da Zona de Cisalhamento Patos em condicionar a atual configuração espacial desta bacia. 


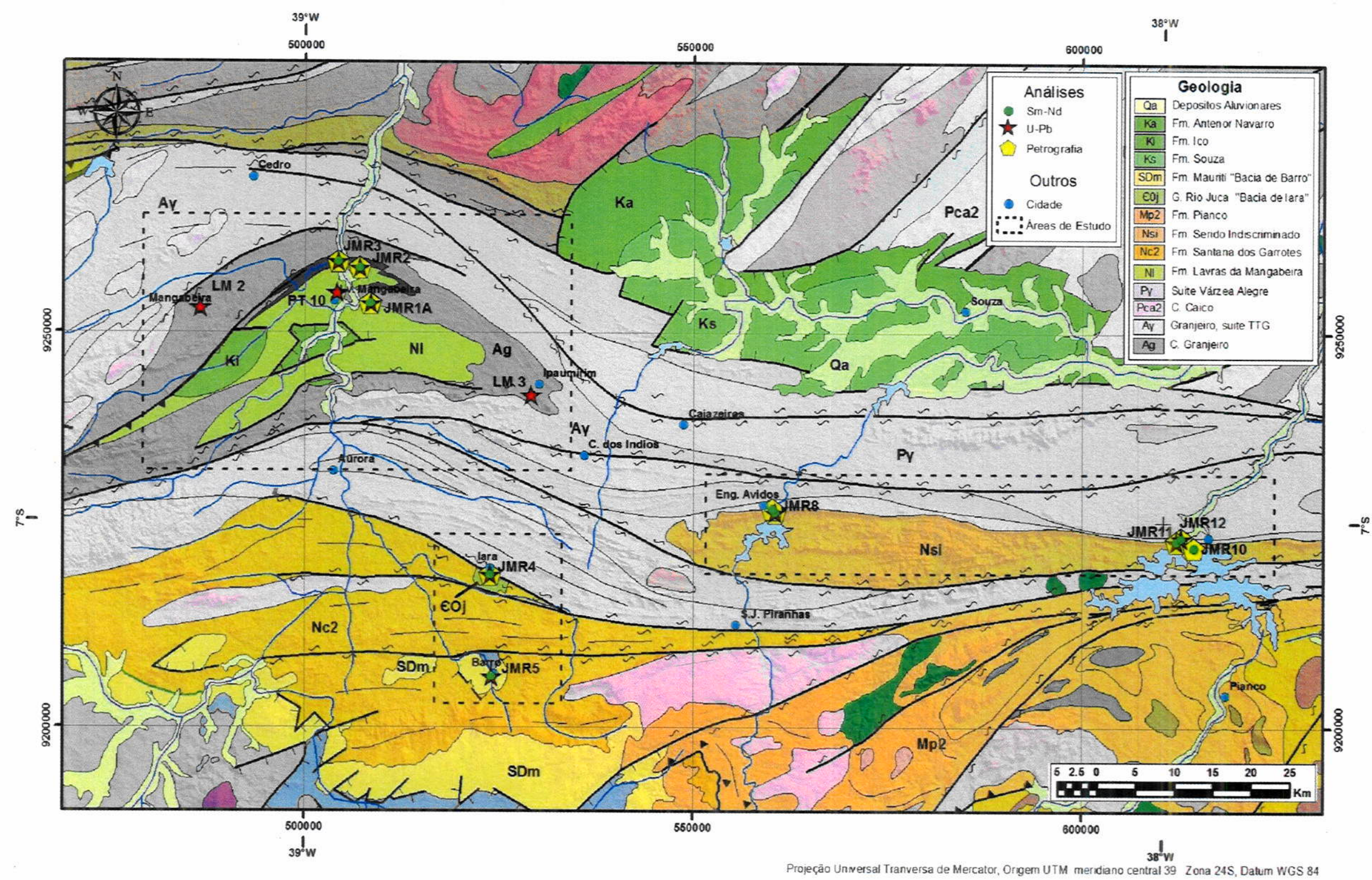

Figura 1.2. Mapa geológico das áreas de estudo mostrando as zonas de cisalhamento e as unidades litológicas estudadas e a localização, das amostras coletadas. Adaptado da Folha SB.24-Z Jaguaribe-SE e Folha SB.24-Y Jaguaribe-SW. Escala 1:500000. CPRM. 2000. 


\section{CAPÍTULO 2}

\subsection{METODOLOGIAS UTILIZADAS}

As atividades realizadas no âmbito deste projeto de Mestrado incluiram o reconhecimento regional da geologia da área, coleta de amostras, análises isotópicas pelos métodos $\mathrm{Sm} / \mathrm{Nd}$ e U/Pb in situ, tratamento estatístico de dados. O trabalho de campo teve duração de sete dias, conduzido com base nos mapas geológicos da CPRM (Folha Souza 1:250.000; folhas Jaguaribe Leste e Jaguaribe Oeste, ambas em escala 1:500.000). Para o método $\mathrm{Sm} / \mathrm{Nd}$ buscou-se coletar, na medida do possível, amostras com grau incipiente de alteração intempérica; no caso dos metapelitos de maior grau metamórfico, foi priorizada a coleta de amostras em niveis com menor concentração de granada para evitar qualquer influência maior deste mineral nos valores das razões ${ }^{147} \mathrm{Sm} /{ }^{144} \mathrm{Nd}$ em rocha-total.

Para o método $\mathrm{U} / \mathrm{Pb}$ a coleta foi feita em todas as unidades de interesse. Somente os metapelitos ao longo da Zona de Cisalhamento Patos (entre Cajazeiras-Coremas, PB) não forneceram material suficiente para o estudo, motivo pelo qual o padrão de proveniência desta unidade não está incluido neste trabalho.

$\mathrm{Na}$ Tabela 1 estão listadas as localizações das amostras coletadas e a sua distribuição está ilustrada no mapa da Figura 1.2

\subsection{GEOCRONOLOGIA Sm/Nd}

Sm e Nd são elementos do grupo dos Elementos Terras Raras (leves) apresentando características comuns que incluem o número de valência $(+3)$ e a dimensão de seus raios iônicos $(0,96 \AA$ e $1 \AA$, respectivamente), o que thes confere comportamentos geoquímicos similares. $O$ decaimento de um dos isótopos radioativos de $\mathrm{Sm}\left({ }^{147} \mathrm{Sm}\right)$ para 0 isótopo radiogênico ${ }^{143} \mathrm{Nd}$ ocorre por emissão de uma partícula $\alpha$, a uma meia-vida de 106 Ga e constante $\lambda$ de $6,54^{*} 10^{-12}$ ano ${ }^{-1}$, permitindo a aplicação do método como ferramenta para datação de rochas antigas. No entanto, a contribuição mais significativa do método $\mathrm{Sm} / \mathrm{Nd}$ tem sido a discriminação de rochas-fonte de magmas de origem crustal ou manto-derivados, fundamentada no parâmetro $\varepsilon_{\mathrm{Nd}}$. Não menos importante é a utilização da idade modelo $T_{\mathrm{DM}}$ que pode ser interpretada como a idade em que magma e fonte se diferenciaram, para casos em que a idade de cristalização se aproxima do valor $T_{D M}$ calculado, ou ainda como uma estimativa da idade da fonte quando a idade de cristalização do magma é significativamente mais jovem que a idade $T_{D M}$ (Arndt\& Goldstein,1987). $O$ cálculo da idade modelo $T_{D M}$ é definido pela equação [1]: 


$$
\begin{gathered}
T_{D M}=\frac{1}{\lambda} \ln \left[\frac{\left(\frac{143_{N d}}{144_{N d}}\right)_{A m o s t r a}-\left(\frac{143_{N d}}{144_{N d}}\right)_{D M}}{\left(\frac{147_{S m}}{144_{N d}}\right)_{A m o s t r a}-\left(\frac{147_{S m}}{144_{N d}}\right)_{D M}}+1\right], \text { Onde }\left(\frac{143_{N d}}{144_{N d}}\right)_{D M}=0.513144 \\
\text { e } \quad\left(\frac{147_{N d}}{144_{N d}}\right)_{D M}=0.222
\end{gathered}
$$

A representação gráfica de dados isotópicos $\mathrm{Sm} / \mathrm{Nd}$ é normalmente feita em um diagrama binário que relaciona tempo e a razão radiogênica ${ }^{143} \mathrm{Nd} /{ }^{144} \mathrm{Nd}$ normalizada para o valor estimado desta razão para o reservatório 'manto condrítico' (CHUR), conforme a equação [2]. Nesse gráfico é também representada a curva de evolução de $\mathrm{Nd}$ estabelecida para o'manto empobrecido' (DM), como proposto por De Paolo \& Wasserburg (1976). A união entre $\circ$ valor de $\varepsilon_{N d}$ hoje $(t=0)$ e o valor de $\varepsilon_{N d}$ calculado para o tempo $t$ de cristalização (a partir da equação [2]) definirá a reta de evolução isotópica de $\mathrm{Nd}$ na amostra, cuja inclinação é fortemente controlada pela razão ${ }^{147} \mathrm{Sm} /{ }^{144} \mathrm{Nd}$ medida na amostra. A interseção da reta na curva DM e seu prolongamento atẻ o eixo $t$ fornecerá a idademodelo $t_{D M}$.

$$
\varepsilon N d(t)=\left[\frac{\left(\frac{143_{N d}}{144_{N d}}\right)_{\text {Amostra }}}{\left(\frac{143_{N d}}{144_{N d}}\right)_{C H U R}}-1\right] * 10^{4} \text {, Onde }\left(\frac{143_{N d}}{144_{N d}}\right)_{C H U R}=0.512638 \text { [2] }
$$

Neste trabalho o método $\mathrm{Sm} / \mathrm{Nd}$ foi utilizado para caracterizar o padrão de proveniência das rochas metasedimentares de interesse a partir da interpretação das idades $t_{D M}$ como valores mistos indicativos de contribuições de fontes com idades e proporções distintas durante a deposição. Com base nos resultados dessa primeira aproximação foram selecionadas as amostras para análise U/Pb in situ nos zircões detríticos para quantificar a proporção de contribuição das diferentes fontes identificadas.

A preparação das amostras (rocha total) para análise $\mathrm{Sm} / \mathrm{Nd}$ envolveu sua fragmentação inicial em um pilão de aço para tamanhos de aproximadamente $0,5 \mathrm{~cm}$. Os fragmentos foram pulverizados em um moinho de anéis com revestimento de tungstênio durante um tempo médio de 2-3 minutos que foi regulado em função da quantidade e dureza do material trabalhado.

O procedimento de cromatografia de troca iônica com diluição isotópica foi realizado conforme a rotina descrita em Petronilho (2009; modificado de Sato et al., 1995). Cerca de $100 \mathrm{mg}$ de cada amostra pulverizada foram cuidadosamente pesados e postos para dissolver em meio ácido ( $\left.\mathrm{HF}: \mathrm{HNO}_{3} 3: 1\right)$, com temperatura e tempo controlados. Às amostras foram adicionadas quantidades conhecidas de um traçador misto ${ }^{149} \mathrm{Sm}-{ }^{150} \mathrm{Nd}$, como premissa da técnica de diluição isotópica. A separação dos elementos terras raras da matriz 


\begin{tabular}{|c|c|c|c|c|c|}
\hline \multicolumn{6}{|c|}{ COORDENADAS } \\
\hline AMOSTRA & LESTE & NORTE & $\begin{array}{c}\text { ALTITUDE } \\
\text { (metros) }\end{array}$ & LITOLOGIA & LOCALIDADE \\
\hline \multicolumn{6}{|l|}{ Complexo Granjeiro } \\
\hline $\begin{array}{c}\text { JMR1A } \\
\text { JMR1B } \\
\text { LM2 } \\
\text { LM3 }\end{array}$ & $\begin{array}{l}508518 \\
508403 \\
486534 \\
529148\end{array}$ & $\begin{array}{l}9253606 \\
9253635 \\
9253122 \\
9242040\end{array}$ & $\begin{array}{r}284 \\
286 \\
288 \\
321 \\
\end{array}$ & $\begin{array}{c}\text { Biotita Ortognaisse } \\
\text { Biotita Ortognaisse } \\
\text { Ortognaisse } \\
\text { Anfibolito }\end{array}$ & $\begin{array}{l}\text { Lavras da Mangabeira (CE) } \\
\text { Lavras da Mangabeira (CE) } \\
\text { Mangabeira (CE) } \\
\text { Ipaumirim (CE) }\end{array}$ \\
\hline $\begin{array}{c}\text { JMR3 } \\
\text { JMR2 } \\
\text { PT10 } \\
\text { Sequência Metasedime }\end{array}$ & $\begin{array}{r}504321 \\
507129 \\
504126 \\
\text { tar Seridó }\end{array}$ & $\begin{array}{l}9258954 \\
9258147 \\
9255054 \\
\text { (Região en }\end{array}$ & $\begin{array}{c}239 \\
237 \\
260 \\
\text { re Cajazeiras }\end{array}$ & $\begin{array}{l}\text { Muscovita Quartzito } \\
\text { Muscovita Quartzito } \\
\text { Biotita Xisto } \\
\text { Coremas-PB) }\end{array}$ & $\begin{array}{l}\text { Lavras da Mangabeira (CE) } \\
\text { Lavras da Mangabeira (CE) } \\
\text { Lavras da Mangabeira (CE) }\end{array}$ \\
\hline $\begin{array}{c}\text { Formação Jucur } \\
\text { JMR12 } \\
\text { Formação Equad } \\
\text { JMR8 } \\
\text { JMR9 } \\
\text { JMR11 } \\
\text { Formação Serido } \\
\text { JMR10 } \\
\text { Bacias Paleozoicas }\end{array}$ & $\begin{array}{l}612829 \\
6 r \\
560496 \\
560169 \\
612213 \\
614537\end{array}$ & $\begin{array}{l}9224050 \\
9227216 \\
9227694 \\
9223643 \\
9222860\end{array}$ & $\begin{array}{l}235 \\
\\
369 \\
335 \\
234 \\
\\
251\end{array}$ & $\begin{array}{c}\text { Granada Biotita Xisto } \\
\text { Muscovita-Quartzito } \\
\text { Muscovita-Quartzito } \\
\text { Muscovita-Quartzito } \\
\text { Biotita Xisto }\end{array}$ & $\begin{array}{c}\text { Coremas (PB) } \\
\text { Engenheiro Ávidos (PB) } \\
\text { Engenheiro Ávidos (PB) } \\
\text { Coremas (PB) } \\
\text { Coremas (PB) }\end{array}$ \\
\hline $\begin{array}{l}\text { Bacia de lara } \\
\text { JMR4 } \\
\text { Bacia de Barro } \\
\text { JMR5 }\end{array}$ & 523864 & 9219259 & 373 & $\begin{array}{l}\text { Arenito Lítico } \\
\text { Arenito Arcosiano }\end{array}$ & $\begin{array}{c}\text { lara (PB) } \\
\text { Barro (PB) }\end{array}$ \\
\hline
\end{tabular}


foi feita em uma coluna primária empacotada com aproximadamente $250 \mathrm{ml}$ de resina RESpec, através de sucessivas etapas de eluiçăo. A alíquota contendo esses elementos passou por nova etapa cromatográfica, onde $\mathrm{Sm}$ e $\mathrm{Nd}$ foram separados dos demais elementos terras raras; o procedimento foi feito em uma coluna secundária empacotada com resina $\mathrm{LN}-\mathrm{Spec}$. Sm e Nd foram coletados em alíquotas separadas e depositados em filamentos de tungstênio para análise por espectrometria de massa de ionização termal (TIMS). As concentrações e razões isotópicas $\mathrm{Sm} / \mathrm{Nd}$ estão listadas na Tabela 2 (Ver ANEXO 1).

\subsection{GEOCRONOLOGIA U/Pb}

Esse método está fundamentado no decaimento por emissão a e $\beta$ dos isótopos radioativos ${ }^{238} \cup\left(t_{1 / 2}=4,468.10^{9}\right.$ anos; $\left.\lambda_{238}=1,55125.10^{-10}\right) e^{235} \cup\left(t_{1 / 2}=0,704.10^{9}\right.$ anos; $\lambda_{235}=9,84485 \cdot 10^{-10}$ ) para os isótopos radiogênicos ${ }^{206} \mathrm{~Pb}$ e ${ }^{207} \mathrm{~Pb}$, respectivamente, as oferecendo dois importantes cronômetros independentes. O método é especialmente aplicado na datação de zircão $\left(\mathrm{ZrSiO}_{4}\right)$ dada a fácil substituição do íon $\mathrm{Zr}^{4+}$ (radio iônico de $0,87 \AA)$ pelos íons $U^{4+}(1,05 \AA)$ e $T^{4+}(1,10 \AA)$ na estrutura do mineral, muito embora outros minerais também sejam amplamente considerados na geocronologia U/Pb (badeleíta, titanita, monazita, rutilo). As equações [3] e [4] ilustramos parâmetros relacionados para o cálculo de idades U/Pb.

$$
\begin{aligned}
& \frac{207_{p b}}{235_{U}}=\left(e^{\lambda_{285 t}}-1\right) \\
& \frac{206_{p b}}{238_{U}}=\left(e^{\lambda_{288} t}-1\right)
\end{aligned}
$$

As equações acima estão relacionadas na Curva Concórdia definida por Wetherill (1956) que representa um arranjo geométrico onde as razões (ou idades) ${ }^{206} \mathrm{~Pb} /{ }^{238} \mathrm{U}$ e ${ }^{207} \mathrm{~Pb} /{ }^{235} \mathrm{U}$ em um sistema mineral permaneceram proporcionalmente equivalentes para um determinado tempo $t$, ou seja, concordantes. A obtenção de idades concordantes em zircão tem sido facilitada com o desenvolvimento de técnicas analíticas pontuais em geocronologia $\mathrm{U} / \mathrm{Pb}$, donde destacam-se LA-ICP-MS e SHRIMP. Essas técnicas priorizam o conhecimento prévio da estrutura interna do zircão permitindo reconhecer história simples (crescimento ígneo contínuo, recristalização completa) ou multifásica (crescimento ígneo - recristalização parcial tardi- e pós-magmática, núcleos herdados, metamitização, p. ex.) em escala micrométrica.

Em geocronologia U/Pb o uso da técnica de imageamento por catodoluminescência tem auxiliado na caracterização da história de crescimento registrada no mineral. O princípio 
baseia-se na resposta de luminescência emitida por um mineral quando é excitado por um feixe de elétrons primários de alta energia ( $>20 \mathrm{KeV})$ gerado por um tubo catodo. $O$ feixe de elétrons impacta sobre a superfície da amostra (que se comporta como um semicondutor) transferindo energia para a estrutura cristalina do mineral, causando uma imediata retrodispersão de elétrons (backscattering). A energia dos elétrons primários e retroespalhados pode ser transferida como calor (temperaturas de até $600^{\circ}-700^{\circ} \mathrm{C}$ ) e raios$X$, gerando elétrons secundários. Estes elétrons são fótons que apresentam um espectro de energia de vários eV, que pode ser visto no campo visível do espectro eletromagnético refletindo a imagem do mineral analisado (Nasdala et al., 2003).

As diferenças em tons de cinza típicas de imagens de catodoluminescência refletem variações composicionais (normais e 'anômalas') relacionadas àpresença de íons terras raras $^{2+3+}, \mathrm{Hf}^{4+}, \mathrm{Pb}^{2+}, \mathrm{Th}^{4+}$ e $\mathrm{U}^{4+}$ quando comparados diferentes setores no grão. Por exemplo, o zonamento oscilatório ígneo tipicamente observado em zircão indica variações na concentração desses íons, interpretadas como mudanças composicionais na interface cristal-magma devido o estado de oxidação e taxa local de difusão-cristalização (Koppel e Sommerauer, 1974; Corfu et al., 2003). Também, durante eventos metamórficos a recristalização expressa-se regularmente por altos níveis de luminescência (baixo $U$ ), enquanto que processos hidrotermais tendem estar relacionados a altas concentrações de $U$ e, por tanto, baixa luminiscência (Nasdala et al., 2003).

O procedimento prévio à análise $\mathrm{U} / \mathrm{Pb}$ in situ adotado neste trabalho iniciou com a separação mecânica do zircão a partir da rocha total ao longo de em várias etapas que incluem britagem, peneiramento, separação magnética e por densidade, e purificação em lupa binocular. A primeira etapa consistiu em preparar a amostra em um britador de mandíbulas utilizando-se uma quantidade aproximada de $5 \mathrm{~kg}$, e reduzindo-se a amostra até aproximadamente $1 \mathrm{~cm}$. Uma fração mais fina foi obtida em moinho de disco para que o material possa ser, a seguir, peneirado em um conjunto composto por malhas de 60, $100 \mathrm{e}$ 250 mesh. A fração de 100 e 250 mesh foi depositada em uma mesa vibratória tipo Wiffley com objetivo de separar, por fluxo aquoso, os minerais leves (quartzo, feldspatos, micas) dos minerais pesados (anfibólios, piroxênios, granada, monazita, rutilo, zircão, apatita, magnetita, ilmentita, etc.). A fração de minerais pesados foi submetida à separação magnética inicial com um imã de mão e, em seguida, em um equipamento tipo Frantz® com controle na regulagem da inclinação da calha e amperagem da corrente. A intenção foi obter um concentrado mais puro possível de zircão. A etapa final de purificação foi feita utilizandose líquidos densos, bromofórmio -densidade $2,82 \mathrm{~g} / \mathrm{cm}^{3}$ e iodeto de metileno - densidade $3,32 \mathrm{~g} / \mathrm{cm}^{3}$ (Loios., 2009). 
Cerca de 200-300 grãos de zircão foram selecionados para montagem em discos de resina epoxy $(2,5 \mathrm{~cm}$ diâmetro e $0,5 \mathrm{~cm}$ de altura) o qual foi, em seguida, polido até aproximadamente a metade dos grãos para expor sua estrutura interna. As imagens de catodoluminescência desses grãos foram tomadas em microscópio eletrônico de varredura FEI Quanta 250, com detector de catodoluminescência CENTAURUS. As análises isotópicas foram realizadas em um ICP-MS multicoletor Neptune (Thermo Scientific) com laser Excimer Ar-F (193nm) com $5 \mathrm{~mJ} / \mathrm{cm}^{2}$ e frequência de $6 \mathrm{~Hz}$, e diâmetro do spot de 29 $\mu \mathrm{m}$. As intensidades das massas isotópicas de ${ }^{202} \mathrm{Hg},{ }^{204} \mathrm{~Pb}$ comum, ${ }^{206} \mathrm{~Pb},{ }^{207} \mathrm{~Pb},{ }^{208} \mathrm{~Pb}$ e ${ }^{238} \mathrm{U}$ foram adquiridos em 50 ciclos de 1 segundo, obedecendo uma sequência de 2 brancos, 3 análises do padrão internacional GJ-1 (idade média de $601 \pm 3,5 \mathrm{Ma}$ ), 13 analises pontuais de amostras, 2 brancos e 2 padrões. Para maiores detalhes sobre o procedimento analítico rotineirizado no CPGeo para datação U/Pb em zircões detríticos ver Sato et al.(2009).

\subsection{Tratamento Estatístico de Dados U/Pb por LA- ICP-MS}

Os dados U/Pb in situ obtidos por LA-ICP-MS incorporam alguns erros sistemáticos e instrumentais que devem ser eliminados ou atenuados por meio de uma avaliação matemática e estatística prévia. Nessa dissertação o tratamento dos dados U/Pb foi feito usando um software desenvolvido em linguagem Python, o qual utiliza as ferramentas estatísticas e gráficas do software $R \otimes$ para avaliação do comportamento de brancos e padrões durante o procedimento. Esse programa foi desenvolvido no CPGEO pelo técnico Roberto Siqueira, estando disponível gratuitamente no link http://10.44.5.171/wiki/TratamentoDeDadosICPMS. A seguir, é apresentado breve resumo das etapas envolvidas no processo de tratamento dos dados, comentados com base na Figura 2.1. Os resultados tratados foram manipulados no pacote Isoplot 4.1 (Ludwig, 2003) para apresentação dos gráficos Concórdia e histogramas de densidade de probabilidade.

1. A calibração dos brancos e padrões em cada um dos isótopos ${ }^{202} \mathrm{Hg},{ }^{204} \mathrm{~Pb},{ }^{206} \mathrm{~Pb},{ }^{207} \mathrm{~Pb}$, ${ }^{208} \mathrm{~Pb},{ }^{232} \mathrm{Th}$ e ${ }^{238} \mathrm{U}$ é feita por meio da eliminação dos "outliers" presentes nos dados brutos (cor verde), usando a função mediana móvel (runmed) do programa $R \circledast$. O resultado corrigido é destacado em cor preta. Além disso, pode ser visualizado em cor azul as regressões lineares ou exponenciais obtidas com a ferramenta Im de $\mathbf{R}($ (Figura 2.1A).

2. No gráfico dos padrões é possível observar a variação do sinal à medida que o laser penetra no grão, no intervalo de tempo decorrido entre os 50 ciclos feitos a cada spot, além do efeito da subtração do $\mathrm{Hg}$ (presente no gás de arraste) e do $\mathrm{Pb}$ comum (eventualmente presente na amostra; inferido via equação de (Stacey and Kramers, 1975) (Figura 2.1B). 
3. Dos valores corrigidos nos brancos e padrões, procede-se a extração aritmética do Padrão os quantidades isotópicas corrigidas nos brancos assim (Padrões - Brancos). Depois procede-se a calcular as razoes isotópicas ${ }^{206} \mathrm{~Pb} /{ }^{238} \mathrm{U},{ }^{207} \mathrm{~Pb} /{ }^{235} \mathrm{U},{ }^{206} \mathrm{~Pb} /{ }^{207} \mathrm{~Pb}$, ${ }^{208} \mathrm{~Pb} /{ }^{232} \mathrm{Th}$, onde em cada gráfico as 50 repetições encontra-se protadas sem a compensação do fracionamento e com compensação ao fracionamento. No grafico apresenta-se uma curva gaussiana horizontal, feita com a função density de $R \otimes$, cuja media representa a idade isotópica compensada ao fracionamento para cada razão isotópica. (Figuras $2.1 \mathrm{C}, \mathrm{D}$ ).

4. O mesmo tratamento mencionado no item 3, acima, é realizado para todas as análises (grãos) em cada amostra. Cada análise é então plotada em um diagrama Concórdia individual (Figura $2.2 \mathrm{~A}, \mathrm{~B}$ ), com os 50 ciclos (repetições) representados por curvas de isovalores (cor verde) traçadas com a finalidade de gerar a elipse de confiança (com a função ellipse do pacote $R \otimes$; cor púrpura), em vez de apenas utilizar as covariâncias obtidas das razões ${ }^{206} \mathrm{~Pb} /{ }^{238} \mathrm{U}$ e ${ }^{207} \mathrm{~Pb} /{ }^{235} \mathrm{U}$, como se faz no IsoplotQ (Figura 2.2B). Posteriormente é construído um histograma de densidade de probabilidade, com curvas gaussianas para cada uma das diferentes razões isotópicas ${ }^{206} \mathrm{~Pb} /{ }^{238} \mathrm{U},{ }^{207} \mathrm{~Pb} /{ }^{235} \mathrm{U}$, ${ }^{206} \mathrm{~Pb} /{ }^{207} \mathrm{~Pb} e^{208} \mathrm{~Pb} /{ }^{232} \mathrm{Th}$ (Figura $2.2 \mathrm{C}$ ). Finalmente, toda a informação analítica é gerada em formato texto para ser importada para o ExcekB. 


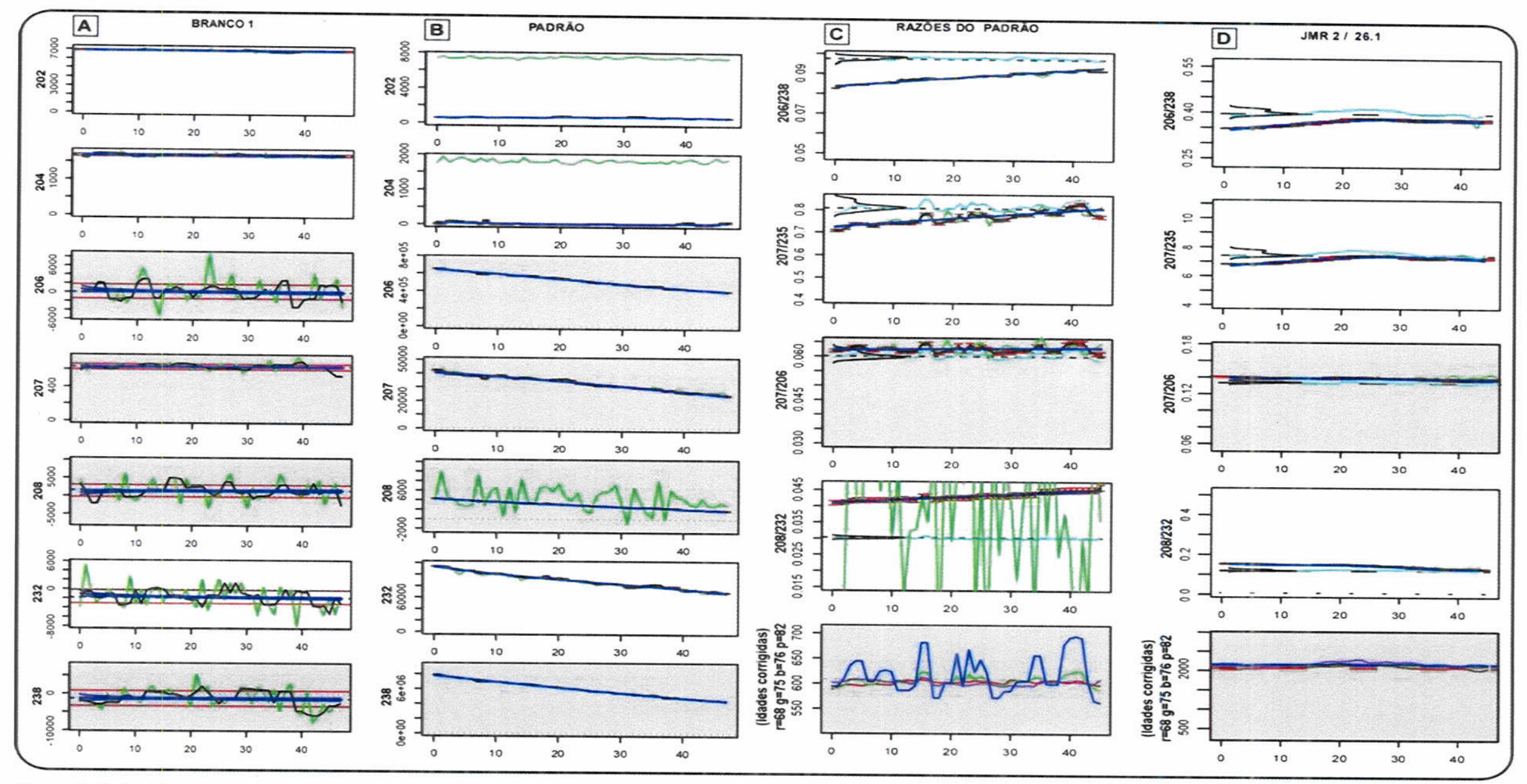

Figura 2.1. Gráficos de "brancos", "padrões" e "razões" obtidos no tratamento estatístico pelo pacote R囚. (A) BRANCOS: Observa-se em cor verde os dados brutos para cada isótopo, os quais depois de serem corrigidos ficam na cor preta. As barras em vermelho indicam o desvio padrão e a linhas azuis representam as regressões feitas com os dados já corrigidos. (B) PADRÕES: Pode-se observar que as maiores correções são feitas no ${ }^{202} \mathrm{Hg},{ }^{204} \mathrm{~Pb} ; \operatorname{como}^{200} 0$ ${ }^{208} \mathrm{~Pb}$ é muito ruidoso, ele é calculado sinteticamente a partir de ${ }^{206} \mathrm{~Pb} \mathrm{e}^{207} \mathrm{~Pb}$. (C) e (D) RAZÕES: Pode-se observar em cada uma das razões que o conjunto de dados, depois de serem corrigidos o seu fracionamento e a sua intensidade (pelos valores do padrão), transforma-se na linha azul claro (melhor resolução $\mathrm{em}^{206} \mathrm{~Pb} /{ }^{207} \mathrm{~Pb}$ ). $\mathrm{O}$ último diagrama de baixo plota todas as razões em unidades de idade $(\mathrm{Ma})$, para fins de comparação. 


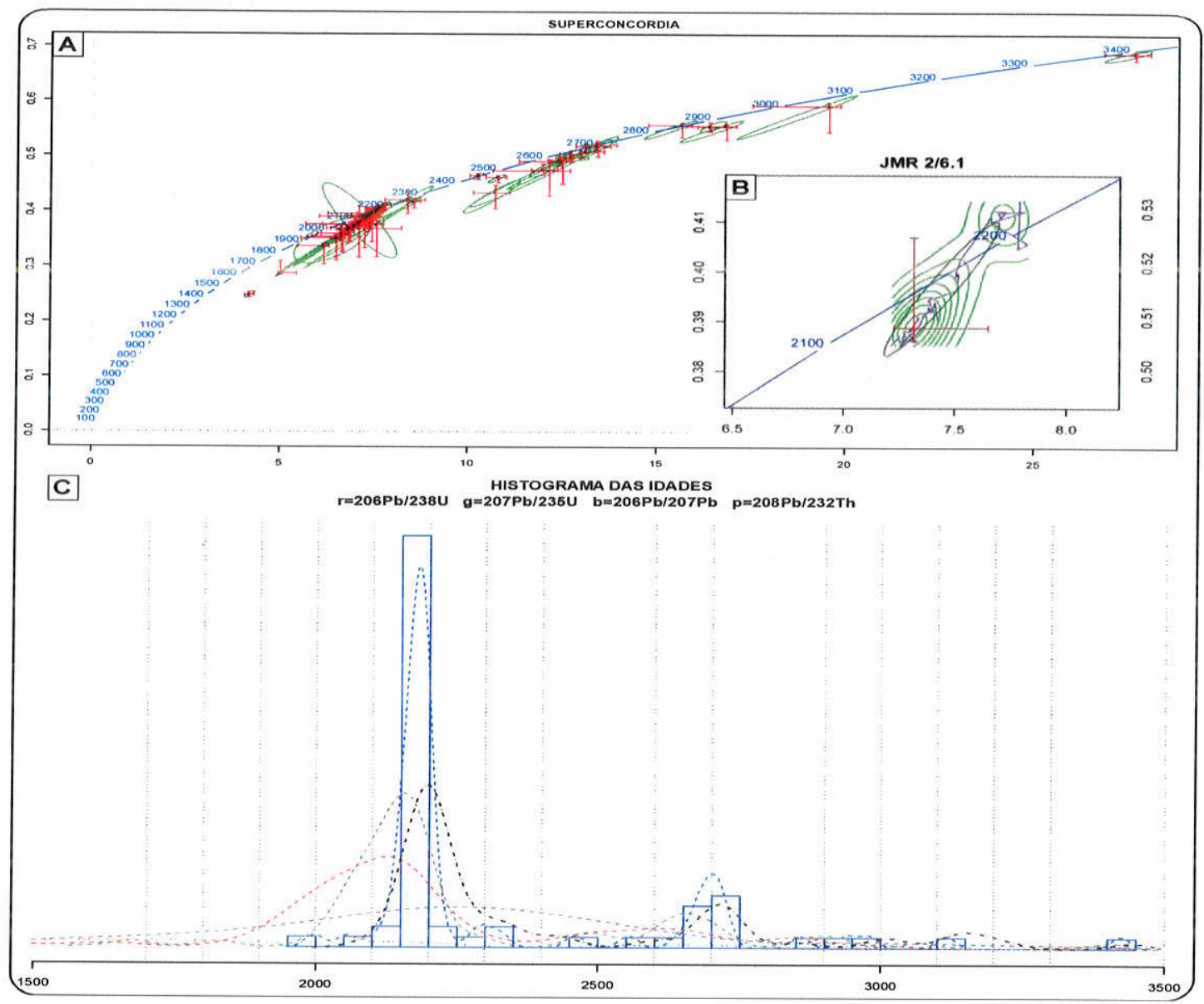

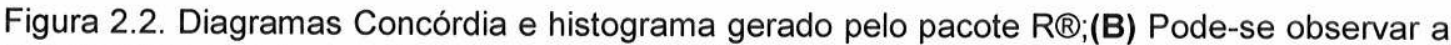
'trilha' obtida a partir dos 50 ciclos em uma análise (linha cor púrpura), e as linhas de isovalores (cor verde) que indicam a distribuição espacial das idades do grão. Ainda é possível ilustrar que a elipse de confiança construída é assimétrica, diferente ao padrão de covarianças ${ }^{206} \mathrm{~Pb}$ e ${ }^{207} \mathrm{~Pb}$ fornecido pelo/soplot. (C) Histograma de densidade de probabilidade com as curvas gaussianas para as idades ${ }^{206} \mathrm{~Pb} /{ }^{207} \mathrm{~Pb}$ em cor azul, ${ }^{206} \mathrm{~Pb} /{ }^{238} \mathrm{U}$ em cor vermelho, ${ }^{207} \mathrm{~Pb} /{ }^{235} \mathrm{U}$ em cor verde $\mathrm{e}^{208} \mathrm{~Pb} /{ }^{232} \mathrm{Th}$ em cor púrpura. 


\section{CAPÍTULO 3 - GEOLOGIA REGIONAL}

\subsection{INTRODUÇÃO}

A Província Borborema como definida por Almeida et al. $(1977,1981)$ está representada em boa parte da região nordeste do Brasil englobando os estados do Ceará, Rio Grande do Norte, Paraíba, Pernambuco e Alagoas. Corresponde a um domínio de crosta precambriana deformada por processos geológicos relacionados ao Ciclo Brasiliano que, mesmo no âmbito da província, teve comportamento diacrônico (c. 630 - 570 Ma). Seus limites se dão a sul com o Cráton São Francisco e com as bacias fanerozoicas do Tucano e Jatobá, a oeste com os sedimentos paleozoicos da Bacia do Parnaíba, e a norte, leste e sudeste com os sedimentos mesozoicos das bacias costeiras Potiguar, PernambucoParaíba e Sergipe-Alagoas, respectivamente. Figura 3.1

Um dos produtos mais representativos do Ciclo Brasiliano na Província Borborema é representado pelas extensas zonas de cisalhamento de cinemática transcorrente dúctil que seccionam toda a província em domínios tectônicos distintos, muitas das quais com deslocamentos de escala continental (Caby e Arthaud, 1986; Caby et al., 1991; Vauchez et al., 1991, 1995). Os domínios individualizados pelo arranjo dessas zonas caracterizam-se por evoluções tectono-estratigráficas constrastantes, embasando a proposição de modelos de compartimentação em sub-unidades propostas desde a década de 70 (ver Brito Neves, 1975; Almeida et al., 1976; Brito Neves, 1978, 1983; Santos e Brito Neves, 1984; Santos et al., 1984) até mais recentemente (Jardim de Sá, 1994; Van Schmus et al., 1995; Santos et al., 1997, 2000; Brito Neves et al., 2000). De forma geral, os autores subdividem a província em três domínios maiores que, de norte para sul, são reconhecidos como: Setentrional representado pelos sub-domínios Médio Coreaú, Ceará Central e Rio Grande do Norte, Central - a Zona Transversal, e Meridional - representado pelos sub-domínios Pernambuco-Alagoas, Sergipano e Riacho do Pontal. O setor setentrional é caracteristicamente dominado pela extensa ocorrência de rochas paleoproterozoicas (c. 2.3 - 2.1 Ga; Hackspacher et al., 1990; Dantas, 1992; Souza et al., 1993, 2008) como embasamento de faixas móveis marginal (Martinópolis) e intraplaca (Seridó) neoproterozoicas, cuja deposição é sugerida em c. 650 - 630 Ma. Núcleos arquenos de menor expressão regional são ainda preservados na porção mais oriental (São José do Campestre; Dantas et al., 2004) e central (Complexo Granjeiro; Silva et al., 1997). A Zona Transversal, limitada a norte pelo lineamento Patos e a sul pelo lineamento Pernambuco, configura-se como um conjunto de terrenos paieo- meso- e neoproterozoicos separados por zonas de cisalhamento que definem um arranjo sigmoidal adquirido durante o ciclo Brasiliano. De leste para oeste inclui os "terrenos" tectono-estratigráficos Rio Capibaribe, Alto Moxotó, Alto Pajeú e Faixa Cachoeirinha (p.ex., Santos, 1995; Brito Neves et al., 2000; 
Medeiros, 2002). Por fim, o setor meridional encerra domínios gnáissico (PernambucoAlagoas) e metavulcanosedimentares (Paulistana-Monte Orebe, Canindé-Marancó) com evolução mesoproterozoica em c. 1,1 - 1,0 Ga, além de faixa móveis neoproterozoicas marginais ao Cráton do São Francisco (Riacho do Pontal, Sergipana) (Bizzi et al., 2003). Figura 3.1

\subsection{GEOLOGIA DA ÁREA DE ESTUDO}

As unidades litoestratigráficas que foram alvo neste trabalho ocorrem no setor setentrional da Província Borborema, mais especificamente ao longo do limite sul deste setor que corresponde à extensão da Zona de Cisalhamento Patos (Figura 3.1). Em termos geológicos, a área está inserida no Domínio Rio Grande do Norte que inclui as faixas OrósJaguaribe (mesoproterozoica) e Seridó e Martinópolis (neoproterozoicas), e os terrenos de embasamneto arqueano-paleoproterozoico Rio Piranhas, São José do Campestre e Granjeiro. Esse domínio limita-se a norte e leste pela Bacia Potiguar e coberturas costeiras recentes, respectivamente, a sul pela Zona de Cisalhamento Patos e a oeste pela Zona de Cisalhamento Tatajuba (Bizzi et al., 2003).

A porção mais ocidental da área de estudo encerra uma unidade antiga (neoarquena, segundo Silva et al., 1997) representada por duas associações litoestratigráficas (supracrustais e metaplutônicas intrusivas) que, juntas, constituem o Complexo Granjeiro (Prado et al., 1980; Vasconcelos et al., 1997). Essas rochas são o embasamento regional de uma unidade metasedimentar (ainda pouco estudada, mas provavelmente de idade neoproterozoica, Medeiros et al., 2008) representada pela Formação Lavras da Mangabeira (Prado et al., 1980; Caby et al., 1995). Na continuação a leste, aflora uma outra sequência metasedimentar que, segundo Medeiros et al. (2008), é correlacionada ao Grupo Seridó (de idade neoproterozoica) que aflora em sua área-tipo na região do Seridó (RN-PB; ver, p.ex., Jardim de Sá, 1994). Por fim, ainda incluimos como alvos duas sucessões sedimentares eopaleozoicas instaladas ao longo da Zona de Cisalhamento Patos (bacias de lara e Barro) definidas dominantemente por rochas siliciclásticas continentais (p.ex., Teixeira et al., 2004).

Todas as unidades meta- (neoproterozoicas) e sedimentares (paleozoicas) foram estudadas para fins de estabelecer o padrão de proveniência com base em idades $t_{D M} e$ idades U/Pb in situ em grãos de zircões detríticos. As unidades (meta)ígneas foram também analisadas para esses dois métodos geocronológicos, mas com objetivo de definir suas idades de formação por considerarmos serem estas candidatas prováveis como áreas-fonte para a sedimentação mais jovem na região. 


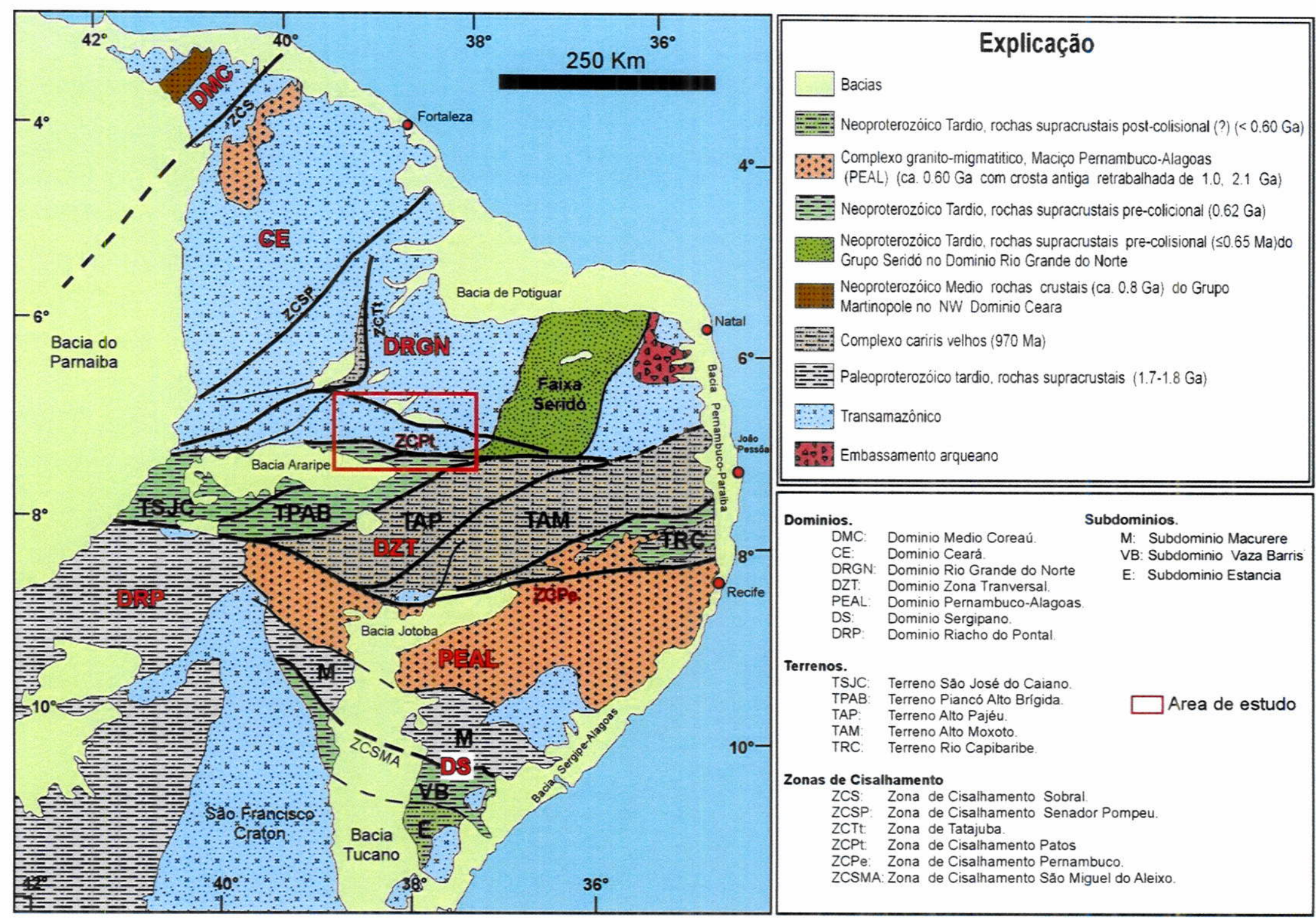

Figura 3.1 Compartimentacão do setor norte da Província Borborema. Domínios e terrenos são adoptados de Van Schmus (2003, 2011). 


\subsubsection{Complexo Granjeiro}

Compreende o conjunto de unidades litoestratigráficas que ocorrem confinadas entre o lineamento Patos e a Zona de Cisalhamento Tatajuba-Potengi, configurando uma espécie de terreno desmembrado (disrupted terrane) de direção predominantemente E-W que se inflete para NE-SW na sua porção mais ocidental. Corsini et al. (1996) sugerem que a geometria em duplexes que caracteriza essa região resultaria da acomodação de esforço devido a essa mudança na direção de E-W para NE-SW. O limite a norte do Complexo Granjeiro é feito com a zona de cisalhamento Malta e a faixa móvel Orós-Jaguaribe.

Informações gerais referentes ao Complexo Granjeiro estão sintetizadas em Bizzi et al. (2003) que citam um arcabouço litoestratigráfico composto por duas associações: uma de origem metavulcanosedimentar, com características químico-exalativas, compreendendo rochas metamáficas e metaultramáficas intercaladas com quartzitos, mármores e BIFs, e outra de origem metaplutônica, intrusiva, representada por ortognaisses tonalíticos a granodioríticos com idade estimada em c. 2,55 Ga (U/Pb SHRIMP por Silva et al., 1997; $\mathrm{Pb} / \mathrm{Pb}$ evaporação por Vasconcelos et al., 1997). Essa idade foi obtida em uma amostra de biotita-hornblenda gnaisse tonalítico da associação metaplutônica, sendo a única informação geocronológica disponível para o complexo. Idades modelo $t_{D M}$ para rochas do Complexo Granjeiro entre c. 2,7 - 2,5 Ga sugerem tratar-se de crosta juvenil neoarqueana (Fetter, 1999).

O Complexo Granjeiro parece representar o fragmento de crosta arquena mais jovem mapeado na parte setentrional da Província Borborema, quando comparado com as idades disponíveis para os maciços de Tróia (c. 2,9 a 2,7 Ga; Fetter, 1999) de São José do Campestre (c. 3,45 a 2,7 Ga; Dantas et al., 2004). Em conjunto, essas unidades constituem apenas uma pequena fração do embasamento mais antigo da província, ainda preservado.

\subsubsection{Sequência Supracrustal Lavras da Mangabeira}

São poucos os trabalhos geológicos específicos sobre a sequência metasedimentar Lavras da Mangabeira (CE), quase sempre mencionada em textos explicativos de mapas geológicos regionais (Prado et al., 1980, 1981; Santos et al., 1984) quando Ihe teria sido atribuída a qualificação de "Complexo". Já na síntese de Caby et al. (1995) sobre as unidades supracrustais brasilianas da PB, essa sequência é tratada como Formação Lavras da Mangabeira representada por quartzitos e metaconglomerados basais e metapelitos com lentes de calciosilicáticas no topo, designação essa que será adotada neste trabalho.

A Formação Lavras da Mangabeira está disposta discordantemente sobre o embasamento Granjeiro e é composta, na base, por um conjunto de quartzitos conglomeráticos e níveis de metaconglomerados com seixos de quartzo e polimíticos moderadamente deformados, que passam para quartzitos com estratificação plano-paralela 
ainda preservada e eventuais seixos de quartzitos (basais) retrabalhados (Figura 3.2D). Todo esse pacote está em contato gradacional com metapelitos com biotita+andalusita+estaurolita \pm granada indicando metamorfismo em condições de facies anfibolito para a sequência (ver Caby et al., 1995). Medeiros et al. (2008) descrevem a ocorrência de filitos e/ou sericita-clorita xistos com posição estratigráfica pouco conclusiva, mas assumida por estes como a parte superior da unidade. Esses autores sugerem a correlação litoestratigráfica da Formação Lavras da Mangabeira com as unidades psamítica (Formação Equador) e pelítica (Formação Seridó) do Grupo Seridó.

\subsubsection{O Grupo Seridó e seu Embasamento}

O atual conhecimento sobre a Faixa Seridó preconiza que o empilhamento litoestratigráfico seria representado por um substrato de embasamento gnáissicomigmatítico paleoproterozoico (c. 2,2 Ga), cuja definição é o Complexo Caicó. Esse complexo é representado por uma sequência metavulcanosedimentar, pouco preservada, que inclui paragnaisses e anfibolitos com lentes de kinzigitos, quartzitos, formações ferríferas e, mais raramente, mármores e rochas calciossilicáticas (p. ex., Souza, 1991; Dantas, 1992). Essa unidade é intrudida por rochas metaplutônicas de composição tonalítica-granítica interpretadas como produtos de diferenciação de magmas parentais com afinidade cálcio-alcalina alto-K. A assinatura geoquímica-isotópica dessas rochas indica derivação a partir da fusão parcial de um manto litosférico enriquecido em LILE representado por espinélio- ou granada-Iherzolitos (Souza, 1991; Souza et al., 1993; Jardim de Sá, 1994; Souza et al., 2007). Valores tanto negativos (Dantas, 1997) quanto positivos (Souza et al., 2007) para o parâmetro عNd sugerem a consolidação do substrato Caicó a partir de sucessivos episódios de colagem entre arcos magmáticos oceânicos e continentais, estes últimos resultaria da reciclagem de um substrato mais antigo de idade arqueana (Dantas et al., 2004).

Intrusões tabulares e corpos batolíticos de granitóides porfiríticos gnaissificados (os augen gnaisses tipo "G2" de Jardim de Sá et al., 1981) são cartografados especialmente no embasamento ocidental da faixa, e têm sido interpretados à luz de duas correntes de pensamento antagônicas: (i) representariam marcadores estrutural e cronológico de uma orogênese paleoproterozoica (c. 2,0 - 1,95 Ga Transamazônico) na Faixa Seridó (Macedo et al., 1984; Jardim de Sá et al., 1987, 1995; Legrand et al., 1991; Jardim de Sá, 1994), ou (ii) representariam intrusões anorogênicas, pré-Brasilianas, intrusivas nos ortognaisses Caicó, igualmente integrando o substrato de embasamento para a paleobacia Seridó (Caby, 1985, 1989; Archanjo e Salim, 1986). Dados U/Pb SHRIMP em zircão de vários corpos de augen gnaisses considerados como os tipo G2 mostraram que esse magmatismo ocorreu em grande parte contemporâneo, ou mesmo precedendo, a colocação dos protólitos dos 
ortognaisses Caicó face às idades obtidas em c. 2,35 - 2,15 Ga (Hollanda et al., 2011). Ainda, uma idade c. 1,75 Ga foi obtida em um dos corpos estudados ("G2" Serra Negra) indicando que o magmatismo anorogênico estateriano da faixa Orós-Jaguaribe se estende para o embasamento ocidental da faixa.

As rochas supracrustais do Grupo Seridó são representadas por uma sequência metavulcanossedimentar depositada discordantemente sobre o embasamento Caicó, todos deformados durante o Ciclo Brasiliano e extensivamente afetados pela intrusão de inúmeros corpos granitóides neoproterozoicos que têm seu alojamento controlado por zonas de cisalhamento transcorrentes N-NE. Devido os efeitos da deformação brasiliana os contatos entre as unidades são quase sempre marcados por zonas de cisalhamento dificultando a observação de aspectos originais como, por exemplo, o empilhamento litoestratigráfico. Essa condição levou à proposição de duas colunas para explicar o arcabouço litoestratigráfico da faixa. Jardim de Sá e Salim (1980) incluíram todas as unidades metasedimentares dentro do Grupo Seridó, representado da base para o topo pelas formações Jucurutu, Equador e Seridó, depositadas dentro de um intervalo único de sedimentação. O trabalho de Archanjo e Salim (1986) trouxe a proposta de organizar a faixa nas formações Jucurutu e Equador (Grupo Jucurutu), na base, sobrepostas pelas formação Parelhas e Seridó (Grupo Seridó), separados por uma importante discordância regional. Na concepção de Archanjo e Salim (1986), e também Caby et al. (1995), o hiato entre a deposição dos grupos Jucurutu e Seridó representaria um intervalo de c. 1,4 bilhões de anos, sendo o Grupo Jucurutu um depósito cratônico ou pericratônico disposto imediatamente sobre o embasamento paleoproterozoico, enquanto a deposição do Grupo Seridó estaria relacionada aos efeitos da subsidência do embasamento durante o Neoproterozoico. O estudo pioneiro de proveniência sedimentar com base em geocronologia $\mathrm{U} / \mathrm{Pb}$ em zircões detríticos publicado por Van Schmus et al. (2003) (também M.H.B.M.Hollanda, dados inéditos) para as unidades Jucurutu e Seridó indicou idade neoproterozoica para sua deposição, não superior a $c .650 \mathrm{Ma}$, com populações de idades $\mathrm{U} / \mathrm{Pb}$ muito similares para as duas unidades. A assinatura de proveniência $\mathrm{Sm} / \mathrm{Nd}$ mostrou rejuvenescimento típico das idades $t_{D M}$ em direção ao topo da sequência, se consideradas apenas as unidades Jucurutu (base, $t_{D M}$ 1,6 -1,4 Ga) e Seridó (topo, $t_{D M}$ 1,3-1,2 Ga), o que foi acompanhado pelas idades U/Pb em zircões detríticos agrupadas em 670-630 Ma, 780$710 \mathrm{Ma}, 860-810 \mathrm{Ma}, 970-930 \mathrm{Ma}$ e 1100-1000 Ma. Um pequeno conjunto de dados apresenta idades mais antigas (meso- a paleoproterozoicas). Esses resultados sugerem fortemente a deposição das unidades Jucurutu e Seridó em um ciclo de sedimentação única como defendido por Jardim de Sá et al. (1984) e Jardim de Sá (1995), muito embora com idade significativamente mais jovem que aquela paleoproterozoica proposta pelos autores. 
Recentemente, Hollanda et al. (2010) apresentaram dados de proveniência U/Pb in situ em zircões detríticos dos quartzitos e metaconglomerados da Formação Equador, a unidade intermediária do Grupo Seridó. Ao contrário, a assinatura de proveniência obtida para essas rochas é dominada por idades $t_{D M}$ e idades $U / P b$ mais antigas indicando a contribuição exclusiva de fontes arqueanas a paleoproterozoicas ( $t_{D M}>2,5 \mathrm{Ga}$; U/Pb in situ > 2,0 Ga); zircões meso - ou neoproterozoicos não foram encontrados.

Esse trabalho irá adotar a coluna litoestratigráfica tríplice de Jardim de Sá e colaboradores para efeito de correlação com as unidades metasedimentares estudadas ao longo da Zona de Cisalhamento Patos e na região de Lavras da Mangabeira. Essas unidades seriam então representadas por: (i) Formação Jucurutu, basal, constituída dominantemente por biotitatepidoto paragnaisses, contendo intercalações de mármores e rochas calciossilicatadas, micaxistos, quartzitos, formações ferríferas, e metavulcânicas (Figura 3.2A); (ii) Formação Equador, intermediária e lateralmente descontínua, composta por quartzitos e metaconglomerados mono- e polimíticos, além de raras intercalações de micaxistos e rochas calciossilicatadas (Figura 3.2B,C); e (iii) Formação Seridó, no topo, constituída dominantemente por micaxistos feldspáticos ou aluminosos, com intercalações subordinadas de mármores, rochas calciossilicatadas, paragnaisses, metavulcânicas, quartzitos e metaconglomerados.

Entre c. $600 \mathrm{Ma}$ até $520 \mathrm{Ma}$ toda a Faixa Seridó foi intrudida por inúmeros corpos granitóides (magmatismo bimodal) e pegmatíticos marcando os vários estágios pré-, sin- e pós-colisional da orogenia brasiliana (Baumgartner et al., 2006; Archanjo et al., 2012; M.H.B.M.Hollanda, dados inéditos).

\subsubsection{Sucessões Sedimentares Eo-Paleozoicas}

Após o Ciclo Brasiliano um conjunto de pequenas bacias se desenvolveu ao longo das grandes zonas de cisalhamento que se implantaram na Província Borborema durante o Neoproterozoico, assim marcando a transição Proterozoico-Fanerozoico (Brito Neves et al., 2000). Essa ocorrência foi especialmente comum no setor setentrional da província. O padrão de sedimentação foi caracterizado pelo desenvolvimento de sucessões clásticas imaturas compostas por conglomerados, arenitos e folhelhos continentais, em alguns casos associadas a magmatismo ácido a básico (Teixeira et al., 2004). 

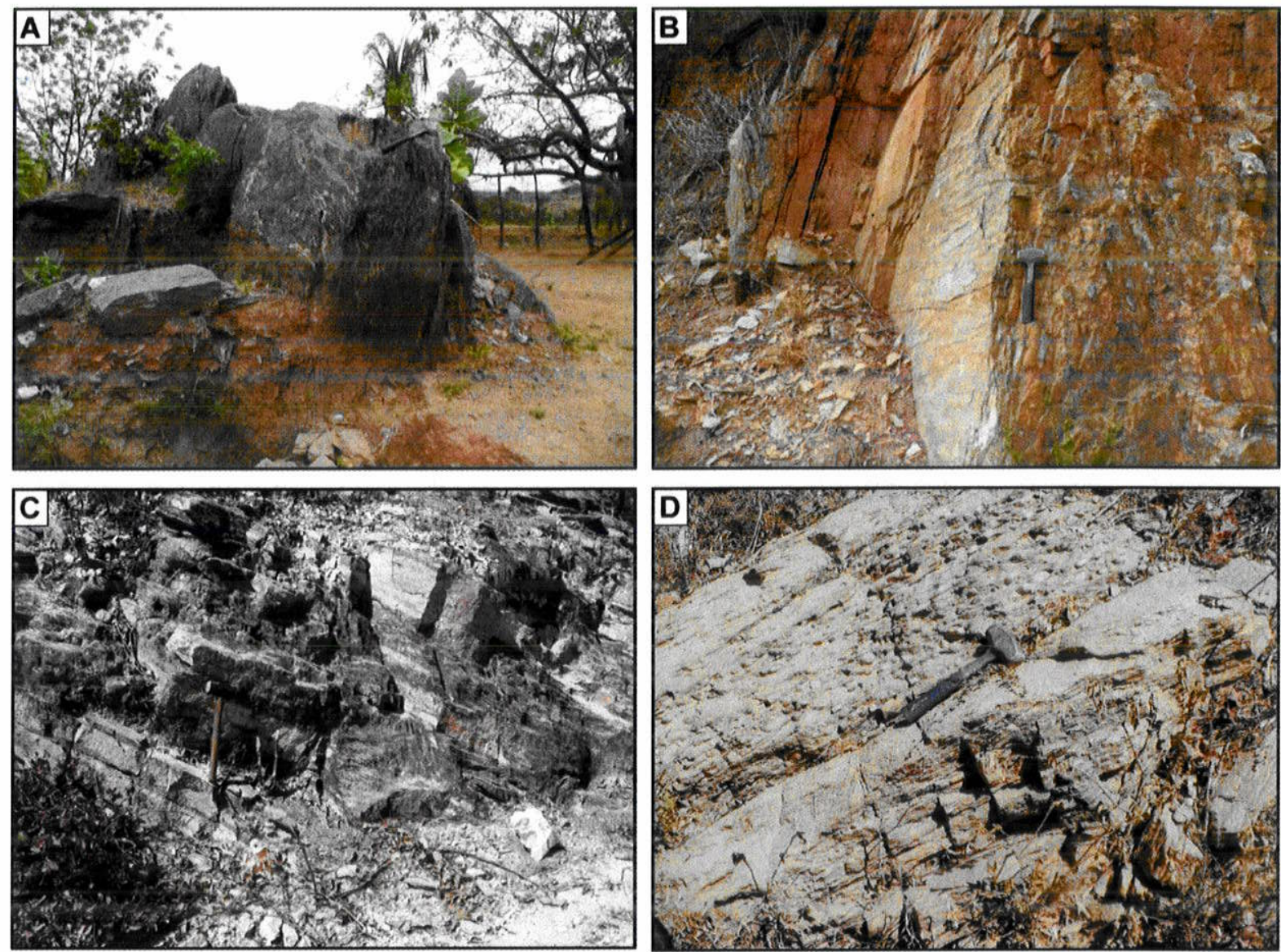

Figura 3.2. Aspecto de campo dos afloramentos amostrados para análise de proveniência U/Pb in situ na região de Coremas e Lavras da Mangabeira. A. Paragnaisse da Formação Jucurutu na barragem do açude de Coremas (PB); B. Quartzito da Formação Equador na barragem do açude de Coremas (PB); C. Quartzito da Formação Equador no barragem do açude de Bom Jesus perto a cidade de Engenhero Avidos (PB); D. Metaconglomerado da Formação Lavras da Mangabeira.

Nesse trabalho foram incluídas duas sucessões eo-paleozoicas cartografadas na Província Borborema setentrional, que ocorrem como preenchimento das bacias de lara e Barro (CE), implantadas no substrato precambriano a sul do lineamento Patos. O objetivo é verificar o padrão de proveniência sedimentar durante o período transicional Neoproterozoico-Eo-Paleozoico na região. A abordagem metodológica foi a mesma adotada para as unidades neoproterozoicas.

\subsubsection{Bacia de lara}

Essa bacia está localizada na porção sul do estado do Ceará, com área aflorante de aproximadamente $15 \mathrm{~km}^{2}$ e cuja geometria E-W definida por um sistema de (semi)grabens preenchidos por uma sucessão litológica tipicamente vulcanosedimentar (Parente et al., 1984, 1990; Teixeira et al., 2004). Seu embasamento é representado pelos metapelitos do Grupo Cachoeirinha, cuja idade máxima de deposição é c. 650 Ma (Van Schmus et al., 2011), deformados e metamorfizados durante o evento Brasiliano a c. $580 \mathrm{Ma}$, mas seu limite norte é feito com as rochas do Complexo Granjeiro. 
Parente et al. (1990) descrevem a sedimentação na Bacia de lara em duas fases distintas, ambas relacionadas à fases transtensionais de reativação das zonas de cisalhamento de lara e Cuncas que a limitam. Segundo esses autores a sequência basal é representada por paraconglomerados polimíticos (seixos de quartzo, milonitos e granitóides em matriz grauváquica) que gradam ao topo para arenitos arcosianos intercalados com siltitos e vulcânicas bimodais. Essa sucessão estaria discordantemente superposta por uma sucessão clástica imatura composta por brechas polimíticas e arenitos vulcanogênicos que, também associados com vulcanismo (extrusivo e efusivo) básico a intermediário, marcariam uma outra fase deposicional na bacia. Figura 3.3A

\subsubsection{Bacia de Barro}

Essa bacia está localizada na borda leste da Bacia do Araripe, abrangendo uma área de aproximadamente $15 \mathrm{~km}^{2}$. A exemplo das inúmeras bacias interiores menores da parte setentrional da Província Borborema, seu desenvolvimento está condicionado ao funcionamento de falhas normais em arranjos tipo semi-grabens, especialmente evidentes em suas bordas norte e oeste, provavelmente representando reativações tardias do lineamento Patos (Ponte e Appi, 1990). Seu embasamento é representado pelos metapelitos de baixo grau do Grupo Cachoeirinha.

Estão notadamente ausentes trabalhos voltados exclusivamente à geologia da Bacia de Barro. Algumas informações muito pontuais podem ser encontradas em relatórios técnicos e sínteses regionais da CPRM e Petrobras que superficialmente mencionam a correlação litoestratigráfica das sucessões nessa bacia com outras de maior expressão - por exemplo, Araripe e Jatobá (Ponte et al., 1991; Assine., 1992; Carvalho, 1996; Arai, 2006). Nesse aspecto é especialmente controversa a idade da unidade basal que aflora não só na Bacia de Barro como em outras bacias menores adjacentes. Essa unidade tem similaridade litológica com unidades indubitavelmente siluro-devonianas das bacias do Parnaíba (Grupo Serra Grande) e Jatobá (Formação Tacaratu), e tem sido mencionada como "Conglomerado Basal", Formação Cariri ou ainda Formação Mauriti (ver síntese em Arai, 2006 e referências ali relacionadas).

A sedimentação na Bacia de Barro é dominantemente continental, com leques aluviais restritos ao seu limite meridional (SE-SW), com lagos efêmeros estabelecidos na borda setentrional (Carvalho, 1996). A assembléia litológica é dominada por, na sua porção basal, arenitos conglomeráticos com seixos de quartzo e líticos que gradam para arenitos feldspáticos a quartzosos com seixos dispersos ou, ainda, com níveis delgados de conglomerados quartzosos. Sobre essa sucessão estão depositados pelitos representados por folhelhos e argilitos vermelhos, intercalados localmente com arenitos finos a médios, que passam para uma unidade caracteristicamente homogênea representada por arenitos 
quartzosos, ligeiramente feldspáticos e/ou cauliníticos (Assine, 1992). Esse registro sedimentar superior é correlacionado com as formações Brejo Santo e Missão Velha da Bacia do Araripe, de idade mesozoica (juro-neocomiana)( Figura 3.3B).
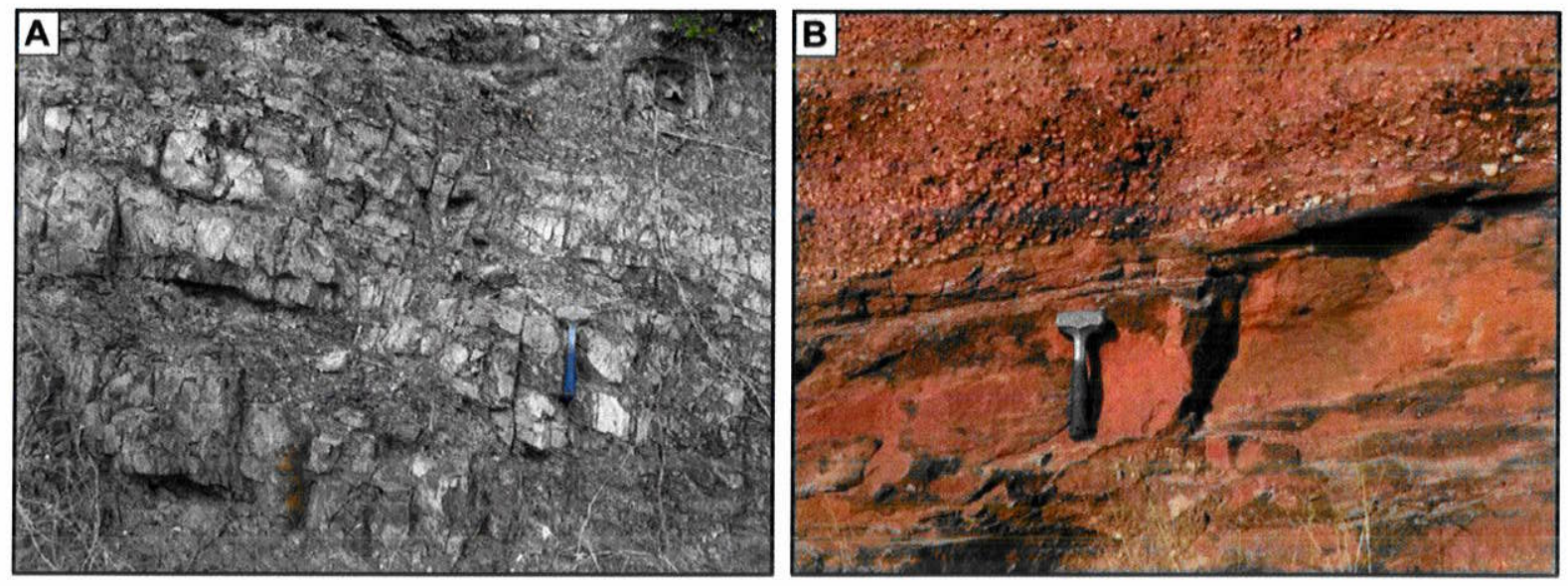

Figura 3.3 Aspecto de campo dos afloramentos das bacias eo-paleozoicas estudadas para análise $\mathrm{U} / \mathrm{Pb}$ in situ. A. Arenito arcosiano da Bacia de lara; B. Alternância de arenitos grossos e conglomerados da Conglomerado Basal da Bacia de Barro. 


\section{CAPÍTULO 4}

\subsection{INTRODUÇÃO}

Este capitulo traz os resultados isotópicos $\mathrm{Sm} / \mathrm{Nd}$ em rocha total de onze amostras que representam as unidades litoestratigráficas estudadas: o Complexo Granjeiro, a sequência metasedimentar Lavras da Mangabeira, a sequência metasedimentar que aflora ao longo da Zona de Cisalhamento Patos e as unidades basais das bacias de lara e Barro. Também serão apresentados os dados geocronológicos $\mathrm{U} / \mathrm{Pb}$ in situ de zircões detríticos que foram selecionados de cada uma dessas unidades litoestratigráficas. A distribuição geográfica das amostras coletadas pode ser vista na (Figura 1.2); os dados $\mathrm{Sm} / \mathrm{Nd}$ e U/Pb estão relacionados no ANEXO 1 e 2 .

\subsection{RESULTADOS $\mathrm{Sm} / \mathrm{Nd}$}

Duas amostras do Complexo Granjeiro foram analisadas pelo método $\mathrm{Sm} / \mathrm{Nd}$ amostras JMR-1A e JMR-1B. Dessas somente a amostra JMR-1A foi datada pelo método $\mathrm{U} / \mathrm{Pb}$ uma vez que ambas foram coletadas no mesmo afloramento, mas em pontos diferentes distantes em aproximadamente 200 metros. Petrograficamente consistem em biotita ortognaisses com composição granodiorítica. As duas amostras apresentaram valores para razão ${ }^{143} \mathrm{Nd} /{ }^{144} \mathrm{Nd}$ muito radiogênicos, refletindo valores de $\varepsilon \mathrm{Nd}_{(2,36)}$ de $-2,22$ (JMR-1A) e -1,98 (JMR-1B) calculados para a idade de cristalização U/Pb em zircão obtida em JMR-1A (ver adiante). As idades modelo $t_{D M}$ calculadas foram 2,7-2,6 Ga indicando contribuição crustal na gênese dessas rochas.

Em apenas duas amostras da Formação Lavras da Mangabeira foram determinados dados $\mathrm{Sm} / \mathrm{Nd}$ sendo que ambas representam a unidade quartzítica - amostras JMR-2 e JMR-3. Os resultados são muito semelhantes mostrando idades modelo $t_{D M}$ em 2,7 e 2,5 Ga indicando a participação de fonte(s) dominantemente antiga(s) que seria(m) arqueana(s) ou combinação de idades paleoproterozoicas e arquenas. Esse mesmo padrão é encontrado nas amostras de quartzitos da sequência metasedimentar que aflora ao longo da Zona de Cisalhamento Patos (JMR-8, JMR-9, JMR-11), cujas idades modelo $t_{D M}$ são também calculadas entre 2,7 e 2,5 Ga. Valor mais jovem para a idade $t_{D M}$ foi obtido no biotita xisto JMR-10 que representa a unidade de topo dessa sequência, em 1,2 $\mathrm{Ga}$, sugerindo a inegável participação de fontes neoproterozoicas. Para a amostra do paragnaisse basal (JMR-12), no entanto, a idade $t_{D M}$ tem valor anômalo de $2,7 \mathrm{Ga}$ interpretada como resultado de fracionamento entre $\mathrm{Sm}$ e $\mathrm{Nd}$ na amostra, dada a razão ${ }^{147} \mathrm{Sm} /{ }^{144} \mathrm{Nd}$ muito elevada de 0,1360 .

Por fim, para as unidades eo-paleozoicas das bacias de lara e Barro as idades modelo são em parte semelhantes àquelas dos quartzitos estudados com valores em $2,7 \mathrm{Ga}$ 
(amostra JMR-4, Bacia de lara) e 1,9 Ga (amostra JMR-5, Bacia de Barro). Considerando que a razão ${ }^{147} \mathrm{Sm} /{ }^{144} \mathrm{Nd}$ na amostra JMR-4 foi igualmente elevada, de 0,1572 , interpretamos o valor de 2,7 Ga como também um valor anômalo influenciado pelo fracionamento entre $\mathrm{Sm}$ e Nd em escala de amostra.

$\mathrm{Na}$ Figura 4.1 estão plotadas as curvas de evolução de $\mathrm{Nd}$ em todas as amostras analisadas. Foram excluídas as amostras do paragnaisse JMR-12 e do arenito JMR-5 visto que os valores anômalos para a razão ${ }^{147} \mathrm{Sm} /{ }^{144} \mathrm{Nd}$ levam à uma inclinação muito baixa das curvas obviamente indicando idades modelo espúrias. No conjunto, nota-se que as curvas de evolução para os quartzitos plotam no mesmo campo que as amostras do embasamento gnáissico (Complexo Granjeiro); apenas a amostra JMR-1A tem assinatura inicial de $\mathrm{Nd}$ pouco mais radiogênica como indicado pelo valor de $\varepsilon N d(0)$ em c. -42 . Esse padrão é estritamente semelhante às assinaturas isotópicas de $\mathrm{Nd}$ obtidas de quartzitos da Formação Equador na região do Seridó (RN) e gnaisses daquele embasamento (Caicó) disponíveis na literatura (Hollanda et al., 2003, 2011; Dantas et al., 2004; Souza et al., 2008).

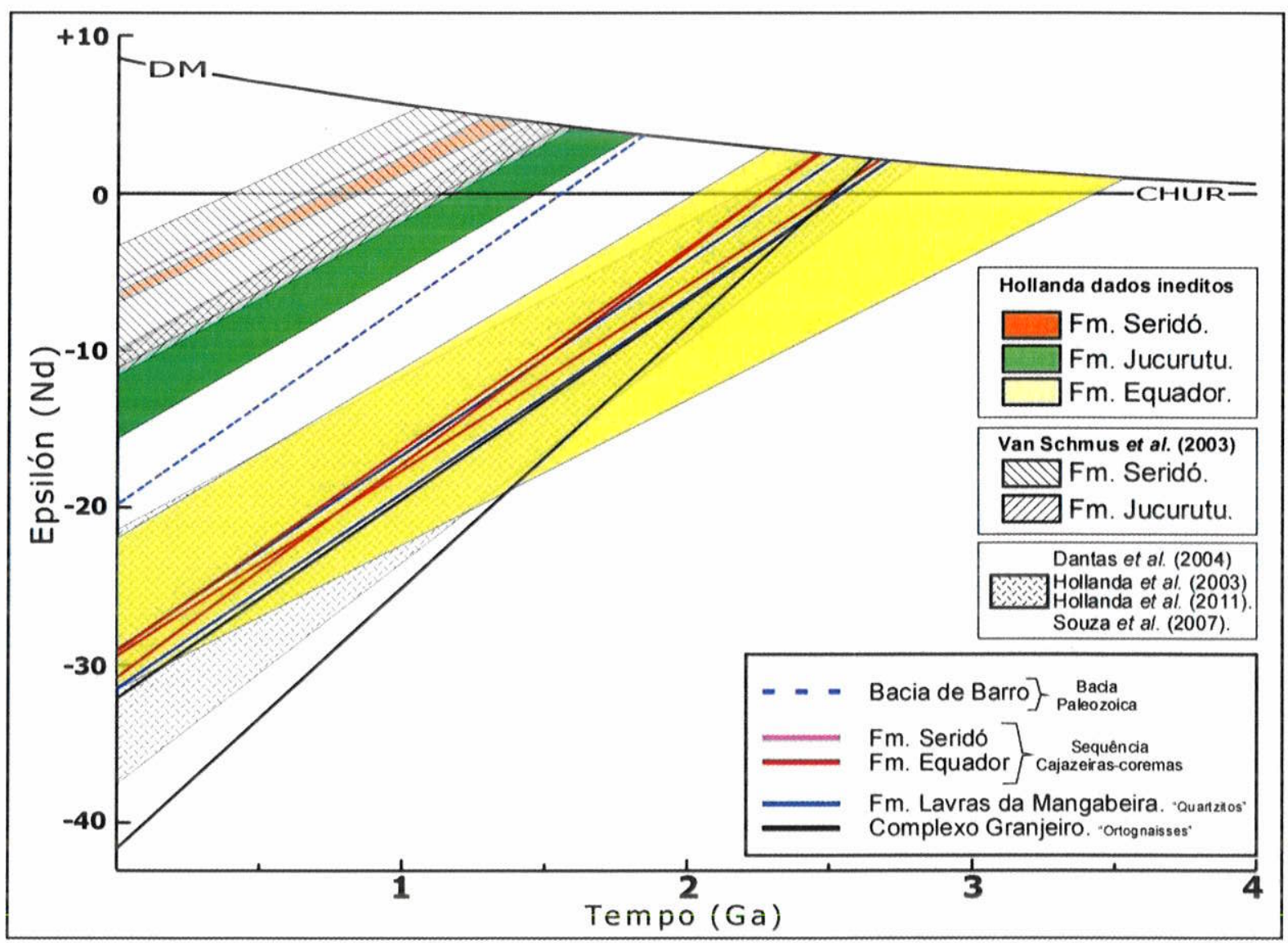

Figura 4.1. Diagrama de evolução $\varepsilon N d$ versus tempo. Dados $\mathrm{Sm} / \mathrm{Nd}$ das amostras analisadas e o campo de dados da literatura (Van Schmus et al., 2003; Hollanda et al., 2003, 2011; Dantas et al., 2004; Souza et al., 2008) referentes às unidades de ocorrência regional na Província Borborema setentrional. 
Apesar do número muito limitado de análises para os metapelitos, quando comparados aos dados das unidades Seridó e Jucurutu (Van Schmus et al., 2003; M.H.Hollanda, dados inéditos), nota-se a semelhança no padrão da amostra JMR-10 (biotita xisto) com a assinatura dos metapelitos da Formação Seridó, e a tendência intermediária da curva de evolução do arenito paleozoico JMR-5 entre os campos definidos para quartzitos da Formação Equador e os paragnaisses da Formação Jucurutu, sugerindo que suas fontes poderiam representar proporções distintas entre aquelas definidas para cada uma destas unidades de referência.

\subsection{RESULTADOS U/Pb in situ}

Em todas as amostras a escolha dos grãos analisados para o estudo de proveniência foi direcionada a aqueles com setores ígneos bem desenvolvidos (largura $\geq 50 \mu \mathrm{m}$ ) evitando-se setores com fraturamento, sobrecrescimento e/ou núcleo metamitizados. Não foram objeto deste estudo bordas (sobrecrescimentos) sugestivas de origem metamórfica, apesar de serem relativamente comuns nas amostras. Em apenas duas amostras, a idade de metamorfismo foi tentativamente estimada por análise dessas bordas (ver amostras JMR-4 e JMR-11).

Todas as idades $\mathrm{U} / \mathrm{Pb}$ obtidas em cada amostra foram plotadas em diagramas Concórdia para ilustrar o padrão de distribuição das várias populações presentes, independente se concordantes ou não. Quando a concordância entre as razões ${ }^{206} \mathrm{~Pb} /{ }^{238} \mathrm{U}$ e ${ }^{207} \mathrm{~Pb} /{ }^{235} \mathrm{U}$ foi superior a $90 \%$, as análises foram consideradas concordantes e plotadas em histogramas de densidade de probabilidade. Para grãos com idade inferior a $1200 \mathrm{Ma}$ a estatística foi feita com as idades ${ }^{206} \mathrm{~Pb} /{ }^{238} \mathrm{U}$, enquanto que para grãos mais antigos que $1200 \mathrm{Ma}$ foi considerada a idade ${ }^{207} \mathrm{~Pb} /{ }^{206} \mathrm{~Pb}$.

\subsubsection{Complexo Granjeiro}

Três amostras dessa unidade foram analisadas sendo duas delas ortognaisses (LM3 e JMR-1A) e a outra um anfibolito (LM-2). O ortognaisse LM-3 foi coletado em um corte da BR-116 1,6 km a sudoeste do município de Ipaumirim (CE), enquanto que o ortognaisse JMR-1A foi coletado em um corte ao longo da BR-230, cerca de $3 \mathrm{~km}$ do município de Lavras da Mangabeira (CE). O anfibolito LM-2 foi também coletado na BR-230 dentro da área urbana da cidade de Mangabeira (CE).

\subsubsection{Ortognaisse $L M-3$}

A amostra consiste em um biotita ortognaisse com textura granoblástica, composto por quartzo $(32 \%)$, plagioclásio $(11 \%)$, feldspato alcalino $(9 \%)$, biotita $(30 \%)$ e hornblenda $(15 \%)$, titanita $(1 \%)$, tendo minerais opacos, zircão, epidoto e apatita como minerais 
acessórios. Cerca de 30 grãos de zircão foram montados para serem imageados por catodoluminescência, sendo que onze grãos foram analisados em dois deles feitos centro e borda (\#4, \#6).

Os grãos têm razão comprimento:largura entre 1:1 e 3:1 e terminações arredondadas, internamente caracterizados por zonação oscilatória que, em alguns deles, são truncados pelo desenvolvimento de setores mais externos onde o aspecto zonado não é tão evidente (p.ex., grãos \#2 e \#3) (Figura 4.2A, B). Discreto sobrecrescimento de forte luminescência provavelmente relacionado à recristalização metamórfica é observado em poucos grãos.

As análises foram preferencialmente feitas nos sítios dos grãos com zonação presente, mas o comportamento geral é discordante (Figura 4.3). A melhor discórdia é definida pelo alinhamento de dez pontos analíticos cujo intercepto superior forneceu idade de $3136 \pm 30 \mathrm{Ma}(M S W D=2,1 ; n=10)$, tendendo a um intercepto inferior de idade neoproterozoica (Figura 4.3B).

\subsubsection{Ortognaisse JMR-1A}

A amostra consiste em um biotita ortognaisse com textura granoblástica e assembléia mineral semelhante ao ortognaisse LM-3. É composto principalmente por quartzo $(30 \%)$, plagioclásio $(12 \%)$, álcali-feldspato $(10 \%)$, biotita $(35 \%)$, hornblenda $(10 \%)$, titanita (2\%), tendo epidoto, zircão, apatita e minerais opacos como fases modais acessórias.
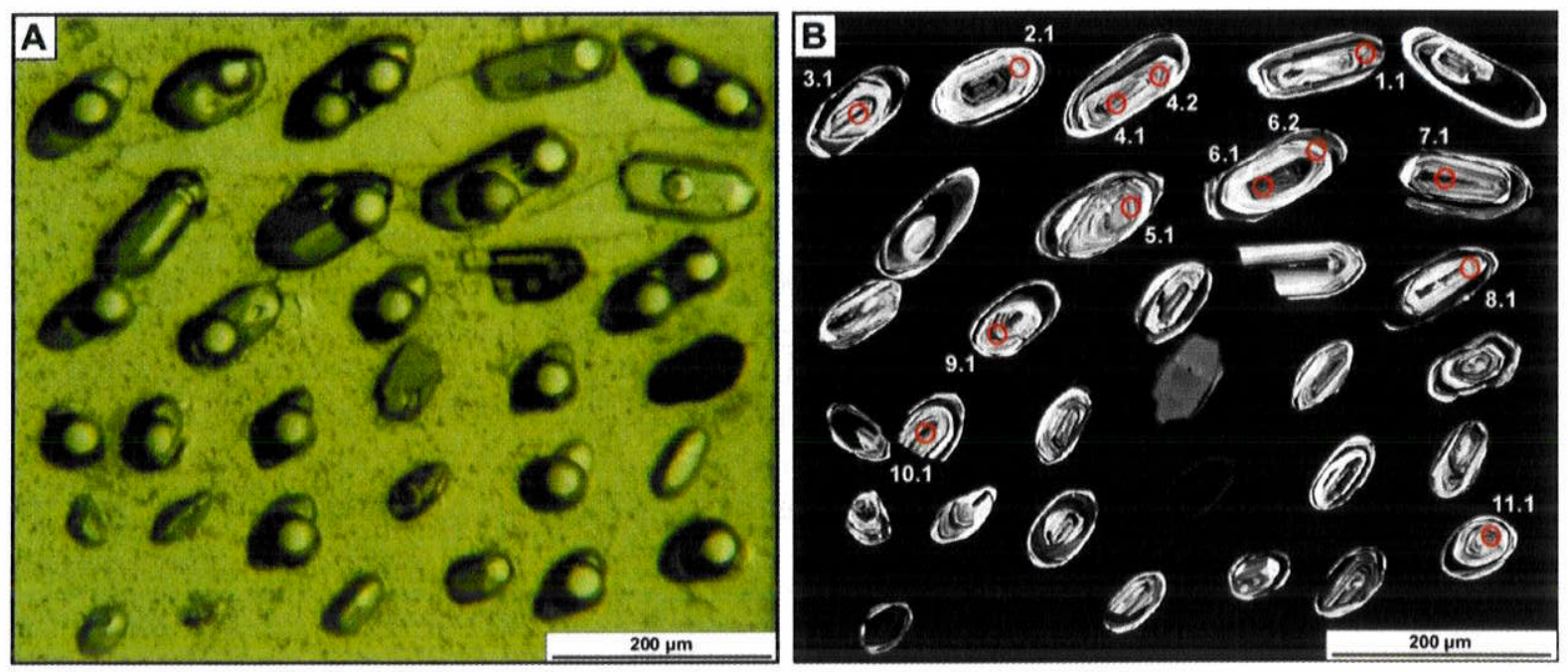

Figura 4.2. Imagens de luz transmitida $(A)$ e de catodoluminescência $(B)$ dos zircões do ortognaisse LM-3. 


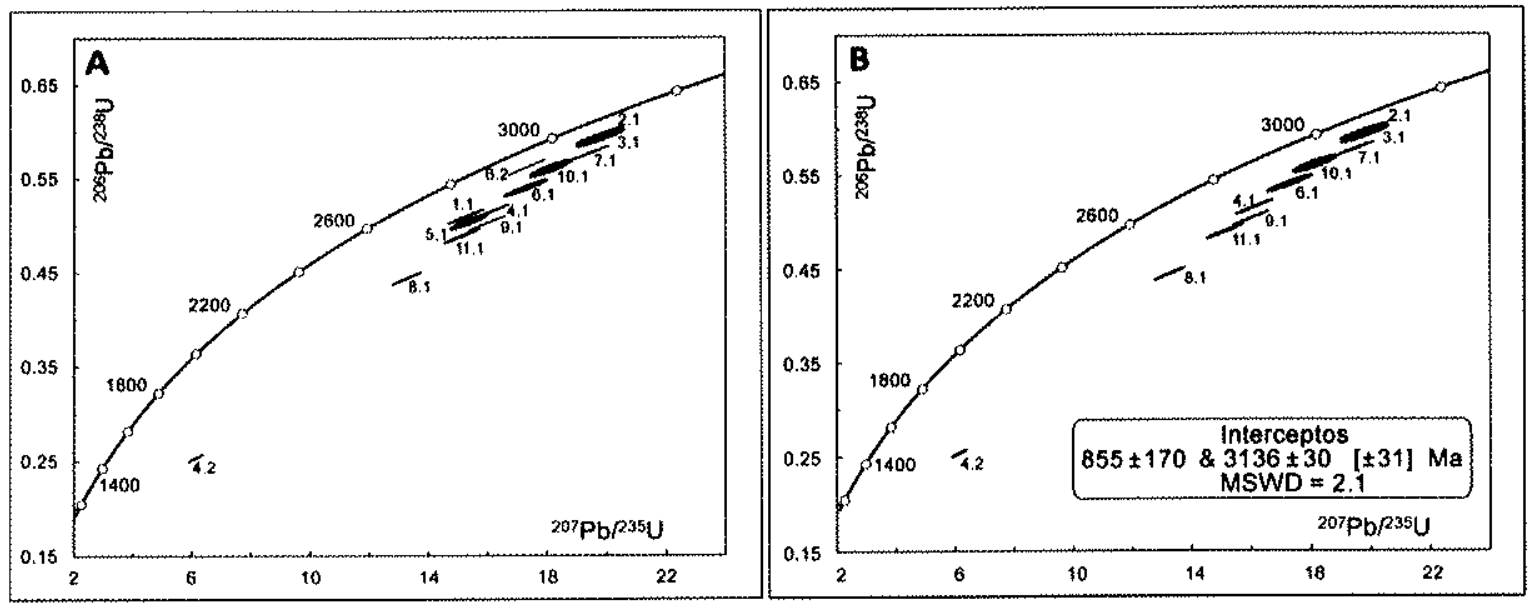

Figura 4.3. Diagramas Concórdia para o ortognaisse LM-3. A. Distribuição das treze análises realizadas no ortognaisse LM-3, e a discórdia calculada a partir do alinhamento de dez dos pontos analíticos (\#2.1, \#3.1, \#4.1, \#4.2, \#6.1, \#7.1, \#8.1, \#9.1, \#10.1 e \#11.1) cujo intercepto superior indica idade mesoarqueana (em B).

Cerca de 100 grãos de zircão foram montados e imageados por catodoluminescência. Duas populações foram discriminadas:

a) zircões euedrais a sub-euedrais com razão comprimento:largura entre 2:1 e 3:1, fortemente metamitizados, alguns deles apresentando discreto sobrescrescimento de baixa luminescência provavelmente de origem metamórfica (Figura 4.4A). Apesar de sua representativade na amostra, só um grão dessa população foi analisado (análise \#2.1) fornecendo idade ${ }^{207} \mathrm{~Pb} /{ }^{206} \mathrm{~Pb}$ discordante de $2129 \pm 190 \mathrm{Ma}$.

b) zircões euedrais a sub-euedrais com razão 2:1 (e, em menor grãos prismaticos em proporção, 3:1) exibindo terminações bi-piramidais. As imagens de catodoluminescência mostram a presença de zonação ígnea bem desenvolvida, com padrão oscilatório ou setorizado (sector zoning). Em alguns grãos os setores zonados têm baixa luminescência podendo ser confundidos com recristalização de origem metamórfica, uma vez que a rocha está fortemente deformada. No entanto, as análises feitas em alguns desses sítios (\#1.1, \#3.1, \#4.1, \#11.1, \#12.1) forneceram idades similares àquelas de setores onde a estrutura ígnea é evidente (Figura 4.4A, B).

Além do grão \#1 mais 25 zircões da população descrita em (b) foram analisados. No diagrama Concórdia as razões ${ }^{206} \mathrm{~Pb} /{ }^{238} \mathrm{U}$ e ${ }^{207} \mathrm{~Pb} /{ }^{235} \mathrm{U}$ se agrupam próximas à Concórdia, definindo uma discórdia com intercepto superior é $2356 \pm 12$ Ma (MSWD $=0,08 ; n=26$ ) estritamente similar à idade média ${ }^{207} \mathrm{~Pb} /{ }^{206} \mathrm{~Pb}$ calculada para o conjunto em $2351 \pm 15 \mathrm{Ma}$ (excluindo a análise \#2.1; Figura 4.5A, B). 

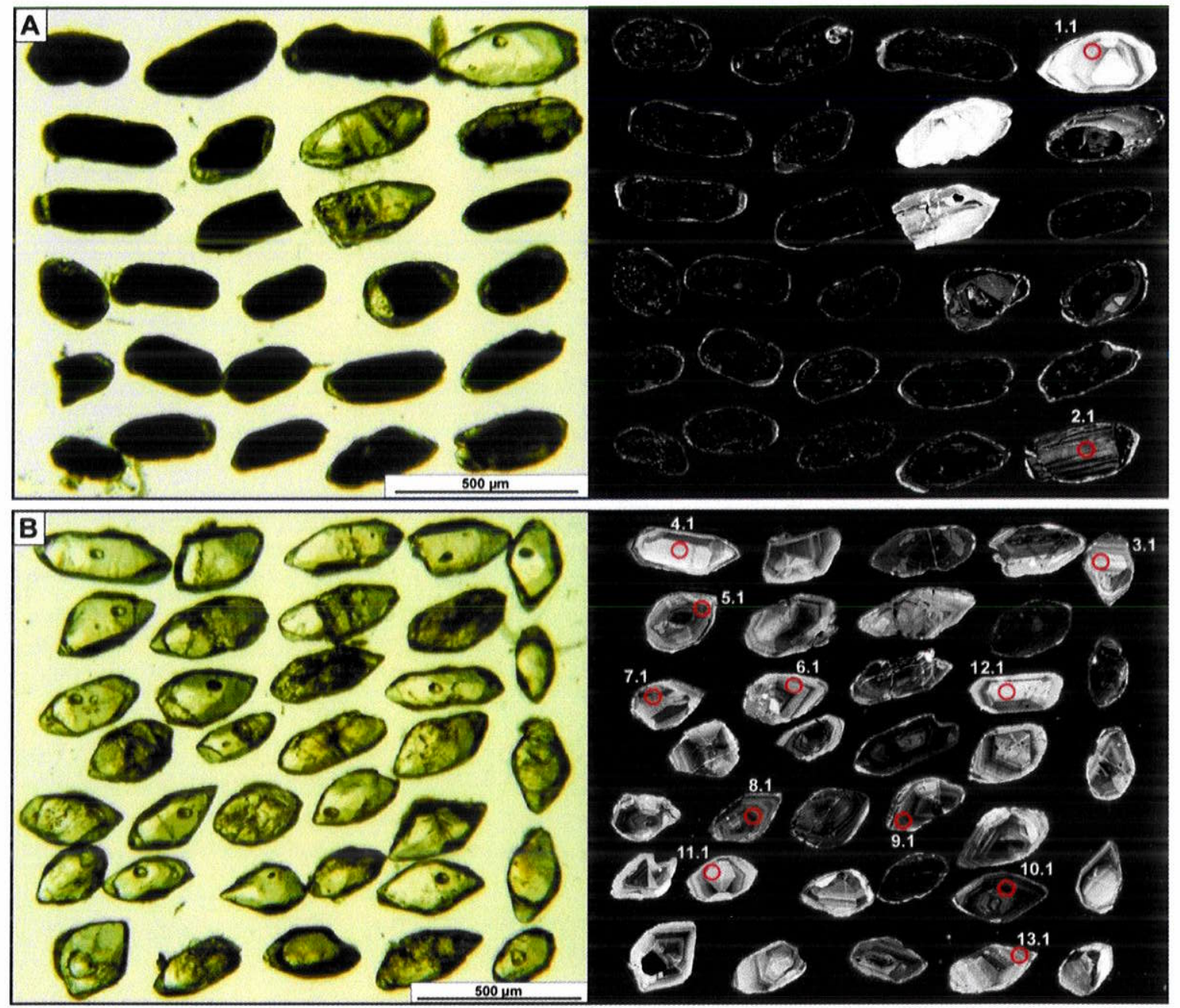

Figura 4.4. Imagens de luz transmitida e catodoluminescência das populações de zircões do ortognaisse JMR-1A. (A) População de zircões metamitizados, onde somente o grão \#2 forneceu idade representativa, paleoproterozoica; (B) População de zircões bi-piramidais mostrando zonações ígneas bem preservadas.
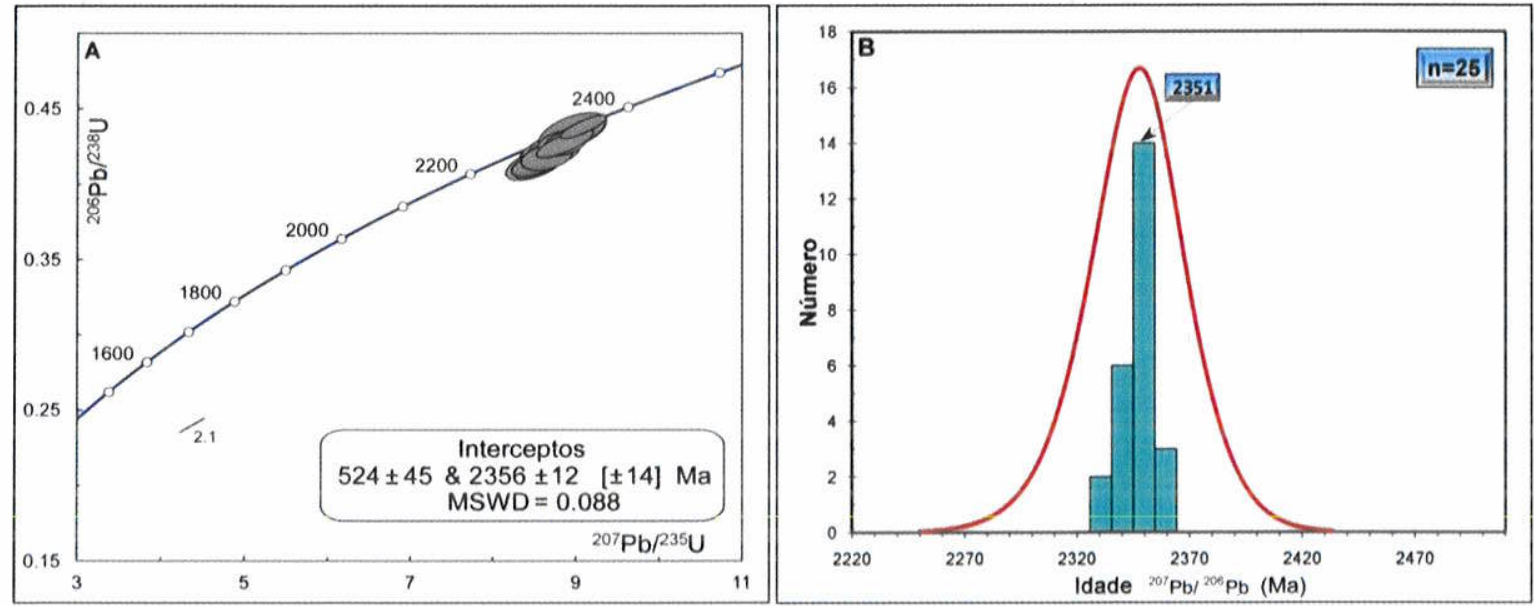

Figura 4.5. Diagrama Concórdia e histograma de densidade de probabilidade para o ortognaisse JMR-1A mostrando. Distribuição do conjunto de análises feitas no ortognaisse JMR-1A e a discórdia calculada apontando para idade paleoproterozoica (em A), e histograma de densidade de probabilidade ilustrando o padrão das idades ${ }^{207} \mathrm{~Pb} /{ }^{206} \mathrm{~Pb}$ com média em $2351 \pm 15 \mathrm{Ma}$ (em B). 


\subsubsection{Anfibolito LM-2}

Devido o forte grau de alteração da amostra não foi possível observar detalhes de sua petrografia. A amostra está inserida na unidade de anfibolítica cartografada e descrita na Folha SB-24-ZA Souza, como parte do Complexo Granjeiro (Medeiros et al., 2008) cuja constituição mineralógica essencial é representada por anfibólio, plagioclásio e clinopiroxênio.

Cerca de 30 grãos foram recuperados mas apenas 11 foram analisados uma vez que os demais apresentaram forte metamitização/fraturamento. De forma geral os grãos são sub-euedrais, com terminações bi-piramidais ou levemente arredondadas, e razões comprimento:largura variando entre $2: 1$ e 3:1.

As imagens de catodoluminescência mostraram ser grãos de estrutura interna complexa com núcleos de alto $U$, parcial ou completamente metamitizados, circundados por setores com zonação ígnea definida pela alternância de bandas com teores variáveis de $U$ quando comparadas entre si. Esses setores estão (em geral) bem preservados, muito embora possam mostrar-se afetados por microfraturas propagadas a partir do núcleo metamitizado. É comum a presença de sobrecrescimento mais externo de origem metamórfica (Figura 4.6A, B).

Quando plotadas no diagrama Concórdia as análises mostraram forte dispersão dada pela perda significativa de $\mathrm{Pb}$ (Figura 4.7A). A melhor discórdia foi traçada pelo alinhamento dos pontos \#1.1, \#1.2, \#4.1, \#5.1, \#7.1 e \#9.2 com intercepto superior de idade $2892 \pm 22 \mathrm{Ma}(\mathrm{MSWD}=0,87 ; \mathrm{n}=6)$, e intercepto inferior indicando idade neoproterozoica em c. $775 \mathrm{Ma}$ (Figura 4.7B).
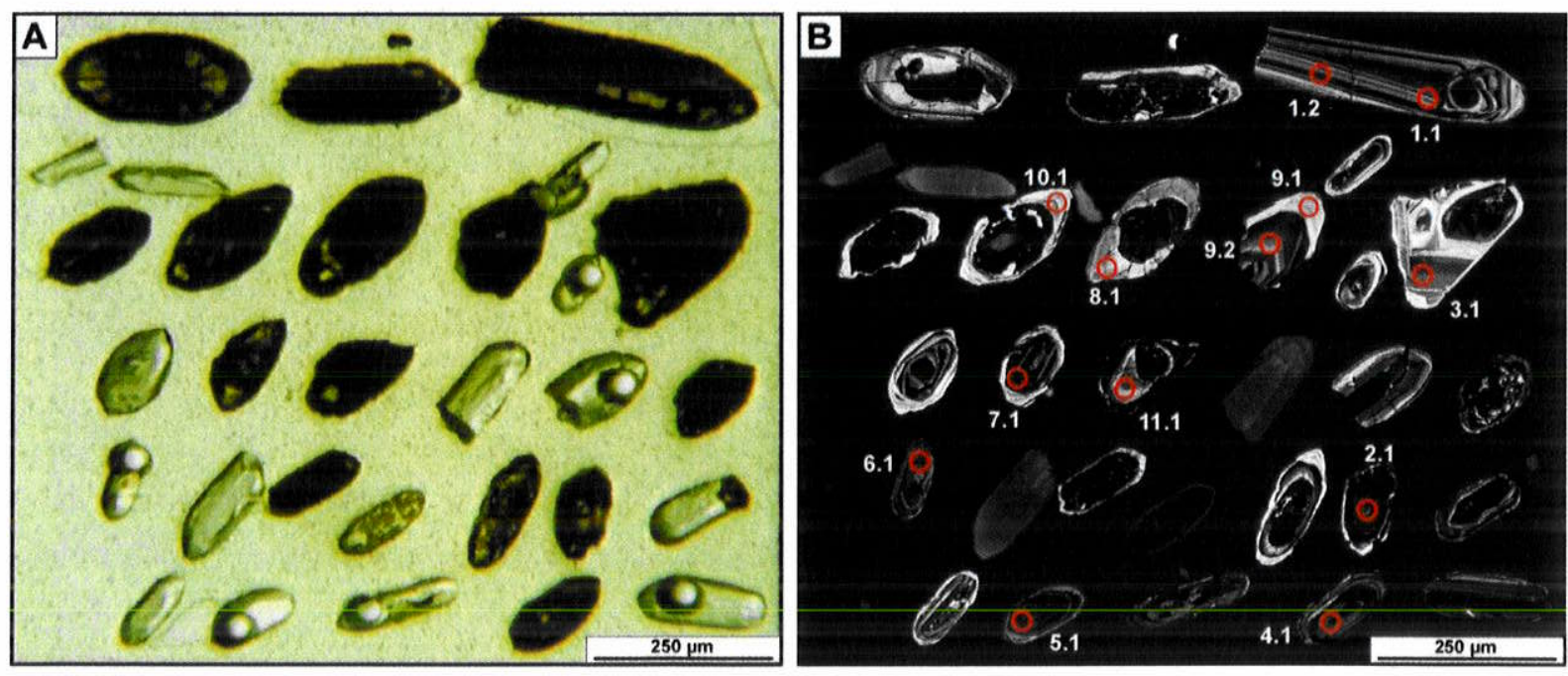

Figura 4.6. Imagens de luz transmitida $(A)$ e de catodoluminescência (B) dos zircões do anfibolito LM-2. 

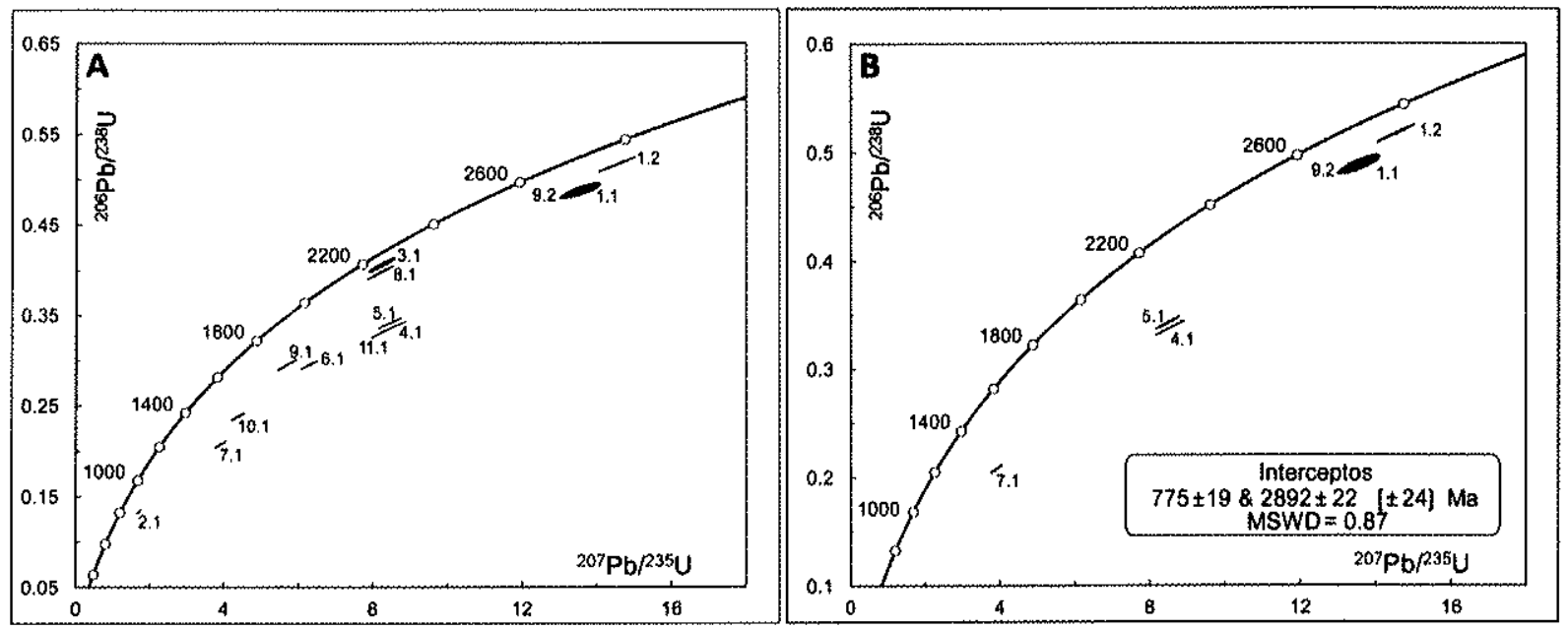

Figura 4.7. Diagramas Concórdia para o anfibolito LM-2: (A) Distribuição de todas as análises realizadas no anfibolito LM-2. (B) Discórdia definida com seis análises com intercepto superior indicando idade neoarqueana.

\subsubsection{Sequência Metasedimentar Lavras da Mangabeira}

\subsubsection{Metaconglomerado JMR-3}

A amostra representa a matriz de um metaconglomerado coletado cerca de $5 \mathrm{~km}$ a norte da cidade de Lavras da Mangabeira, indo pela estrada que leva ao Rio Salgado. Petrograficamente a amostra é representada por um muscovita quartzito com textura granolepidoblástica, incluindo quartzo $(90 \%)$ e muscovita $(8 \%)$ como fases principais, além de turmalina, minerais opacos, titanita, zircão e biotita como acessórios. A muscovita distribuise em bandas definindo a foliação na rocha.

Aproximadamento 170 grãos foram recuperados, exibindo morfologias que variam desde tipos prismáticos até fortemente arredondados. As estruturas internas observadas por catodoluminescência são as mais diversas, predominando tipos ígneos com zonação com padrões oscilatório ou setorizado (Figura 4.8A-E). Grãos metamitizados e microfraturas são comuns, bem como sítios de alta luminescência (baixo $U$ ) sugerindo recristalização completa (p. ex., \#14.1, \#18.1, \#53.1) ou parcial (p. ex., \#44.1, \#48.1, \#55.1). Do conjunto de grãos montados 60 foram analisados e suas razões ${ }^{206} \mathrm{~Pb} /{ }^{238} \mathrm{U}$ e ${ }^{207} \mathrm{~Pb} /{ }^{235} \mathrm{U}$ plotadas no diagrama Concórdia (Figura 4.9A), as quais definiram três arranjos independentes com razoável discordåncia: (i) um grupo de oito análises alinharam-se ao longo de uma discórdia com intercepto superior de $2252 \pm 17 \mathrm{Ma}$ (MSWD =0,11; Figura 4.9B), (ii) um grupo principal definiu uma discórdia com intercepto superior em $2496 \pm 11 \mathrm{Ma}$ (MSWD $=0,49 ; n$ = 24; Figura $4.9 \mathrm{C}$ ) e (iii) uma população de sete análises forneceu uma discórdia com intercepto superior em $2727 \pm 18 \mathrm{Ma}$ (MSWD $=0,22$; Figura 4.9D). O histograma de densidade de probabilidade gerado para as análises com concordância superior ou igual a 
$90 \%$ confirma a dominância de grãos com idades paleoproterozoicas a neoarqueanas entre C. 2,8 e $2,2 \mathrm{Ga}$ (Figura $4.9 \mathrm{E}$ ).
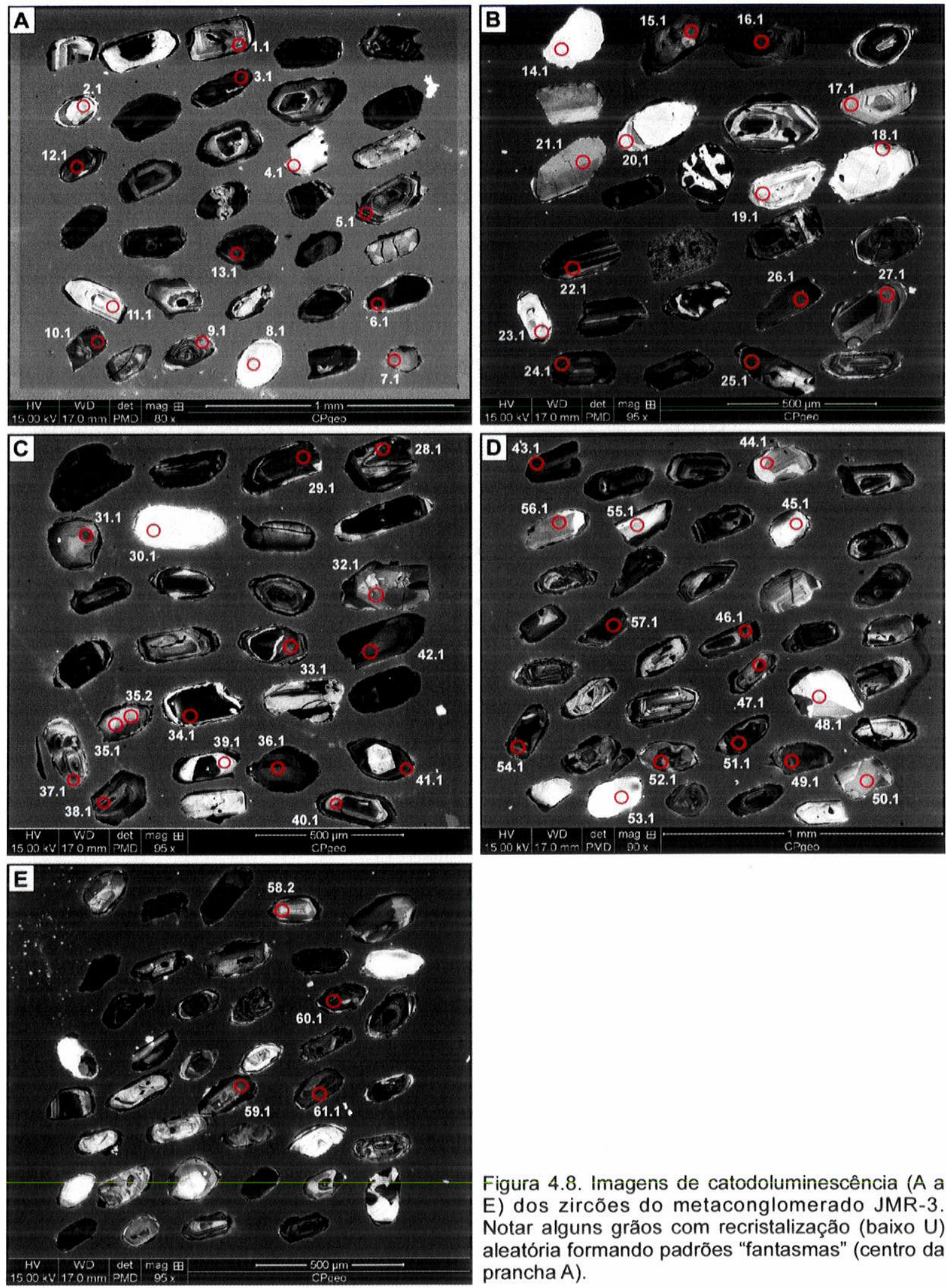

Figura 4.8. Imagens de catodoluminescência (A a E) dos zircões do metaconglomerado JMR-3. Notar alguns grãos com recristalização (baixo U) aleatória formando padrões "fantasmas" (centro da prancha A). 

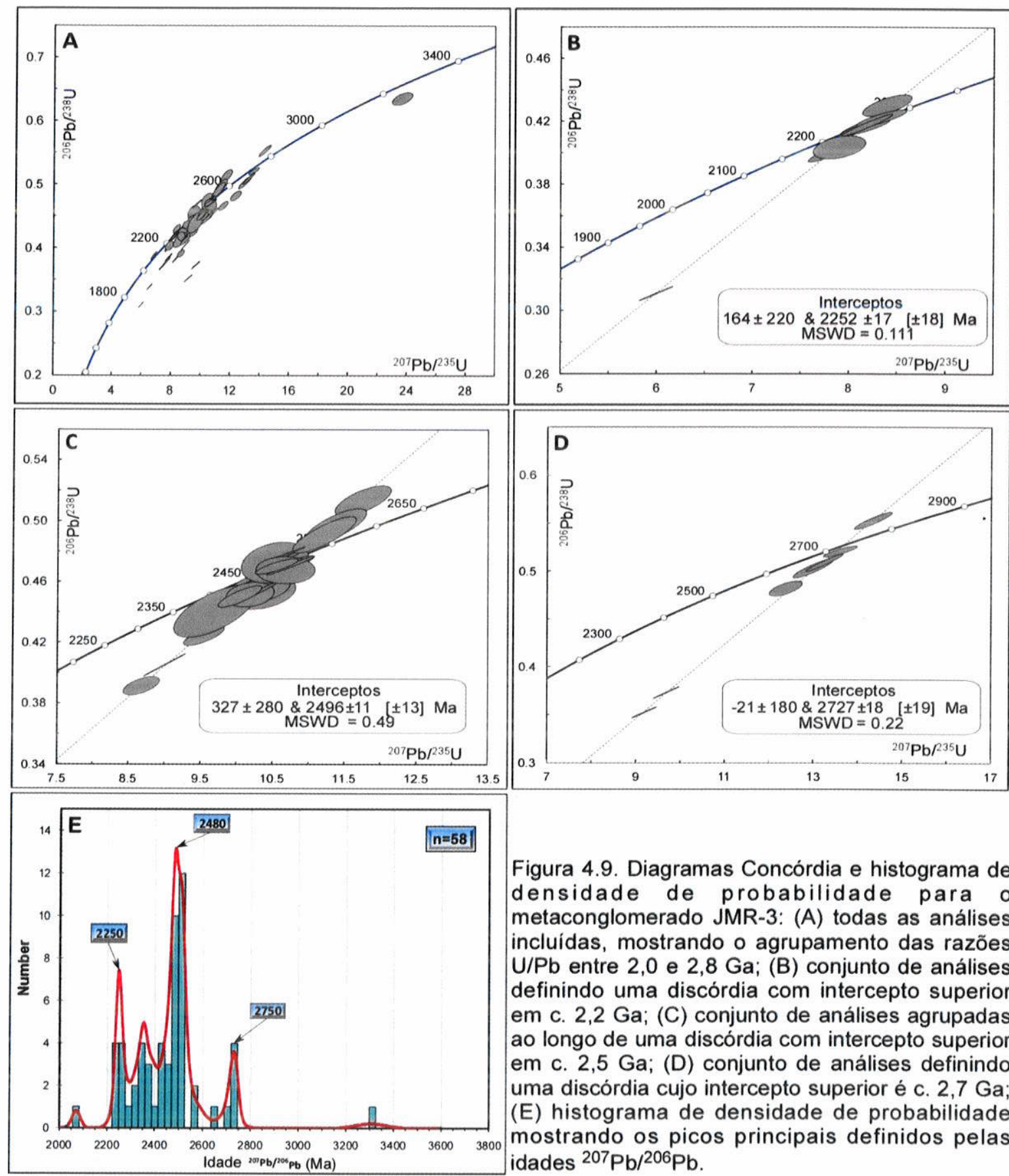

Figura 4.9. Diagramas Concórdia e histograma de densidade de probabilidade para o metaconglomerado JMR-3: (A) todas as análises incluídas, mostrando o agrupamento das razões $\mathrm{U} / \mathrm{Pb}$ entre 2,0 e 2,8 Ga; (B) conjunto de análises definindo uma discórdia com intercepto superior em c. 2,2 Ga; (C) conjunto de análises agrupadas ao longo de uma discórdia com intercepto superior em c. 2,5 Ga; (D) conjunto de análises definindo uma discórdia cujo intercepto superior é c. $2,7 \mathrm{Ga}$; (E) histograma de densidade de probabilidade mostrando os picos principais definidos pelas idades ${ }^{207} \mathrm{~Pb} /{ }^{206} \mathrm{~Pb}$.

\subsubsection{Quartzito JMR-2}

A amostra foi coletada em uma estrada secundária construída na parte leste da Serra do Boqueirão, a noroeste do município de Lavras da Mangabeira (CE). Em seção delgada a amostra consiste em um muscovita-feldspato quartzito com textura granolepidoblástica, constituído por quartzo (60\%), feldspato potássico (19\%), plagioclásio $(10 \%)$ e muscovita $(10 \%)$, tendo biotita (cloritizada), epidoto, apatita, zircão e minerais opacos como fases acessórias. A foliação é principalmente definida pela orientação preferencial da muscovita. 
Cerca de 110 grãos de zircão foram recuperados e montados para serem imageados por catodoluminescência, incluindo desde tipos com morfologia prismática até tipos com moderado grau de arredondamento. Desses, 63 grãos foram analisados e a grande maioria mostrou zonação oscilatória; alguns poucos mostram sobrecrescimento com forte luminescência (p. ex., \#33) e/ou núcleos metamitizados com micro-fraturas radiais (p. ex., \#3) (Figura 4.10A-E).

O padrão de distribuição das análises no diagrama Concórdia é em parte semelhante a aquele da matriz do metaconglomerado JMR-3, com pontos analíticos concordantes ou semi-concordantes alinhados segundo arranjos independentes (Figura 4.11A). Os pontos analíticos definem duas discórdias cujos interceptos superiores forneceram idades de 2193 $\pm 9,8 \mathrm{Ma}(\mathrm{MSWD}=0,31 ; \mathrm{n}=43$; Figura 4.11B) e $2716 \pm 28 \mathrm{Ma}(\mathrm{MSWD}=0,43 ; \mathrm{n}=10$; Figura $4.11 \mathrm{C}$ ), em ambos os casos os interceptos inferiores tendem à idades neoproterozoicas. Zircões com idades ${ }^{207} \mathrm{~Pb} /{ }^{206} \mathrm{~Pb}$ intermediárias entre essas duas populações princiapais não foram encontrados, ao contrário da amostra JMR-3 que apresentou grãos com idades c. $2,5 \mathrm{Ga}$. Alguns grãos tiveram idades ${ }^{207} \mathrm{~Pb} /{ }^{206} \mathrm{~Pb}$ mais antigas, também discordantes, entre 3,4 e 2,6 Ga (análises \#14.1, \#20.1, \#27.1, \#36.1, \#39.1, \#48.1, \#54.1). Quando plotadas apenas as análises com concordância $\geq 90 \%$ no histograma de densidade de probabilidade (Figura 4.11D) a presença das duas populações é confirmada.

\subsubsection{Biotita Xisto PT-10}

A amostra foi coletada aproximadamente $2 \mathrm{~km}$ a sul da cidade de Lavras da Mangabeira ( $C E$ ), na estrada que liga esta com a cidade de Aurora (PB). Consiste em um granada-biotita xisto com textura lepidoblástica, constituído por biotita (50\%), feldspatos+quartzo (45\%) e granada (4\%), tendo como acessórios identificados zircão, apatita, muscovita e clorita.

Cerca de 160 grãos foram recuperados e imageados. O padrão interno é principalmente definido por domínios com zonação oscilatória e, mais raramente, convoluta (Figura 4.12A-F). Um total de 63 grãos foi analisado e as idades ${ }^{206} \mathrm{~Pb} /{ }^{238} \mathrm{U}$ obtidas são dominantemente concordantes, distribuídas entre 1100 e 550 Ma (Figura 4.13A, B, C). Apresenta-se grãos neoproterozoicos com picos principais em c. 650 e 730 Ma (Figura 4.13C). Menos que $10 \%$ dos grãos analisados apresentaram idades mais antigas que 2,2 Ga (\#25.1, \#37.1, \#48.1, \#49.1). O análises concordantes feito no grão \#7.1, forneceu idades ${ }^{206} \mathrm{~Pb} /{ }^{238} \mathrm{U}$ entre de $663 \mathrm{Ma}$, sendo este resultado concordante com Archanjo et al., (2012). 

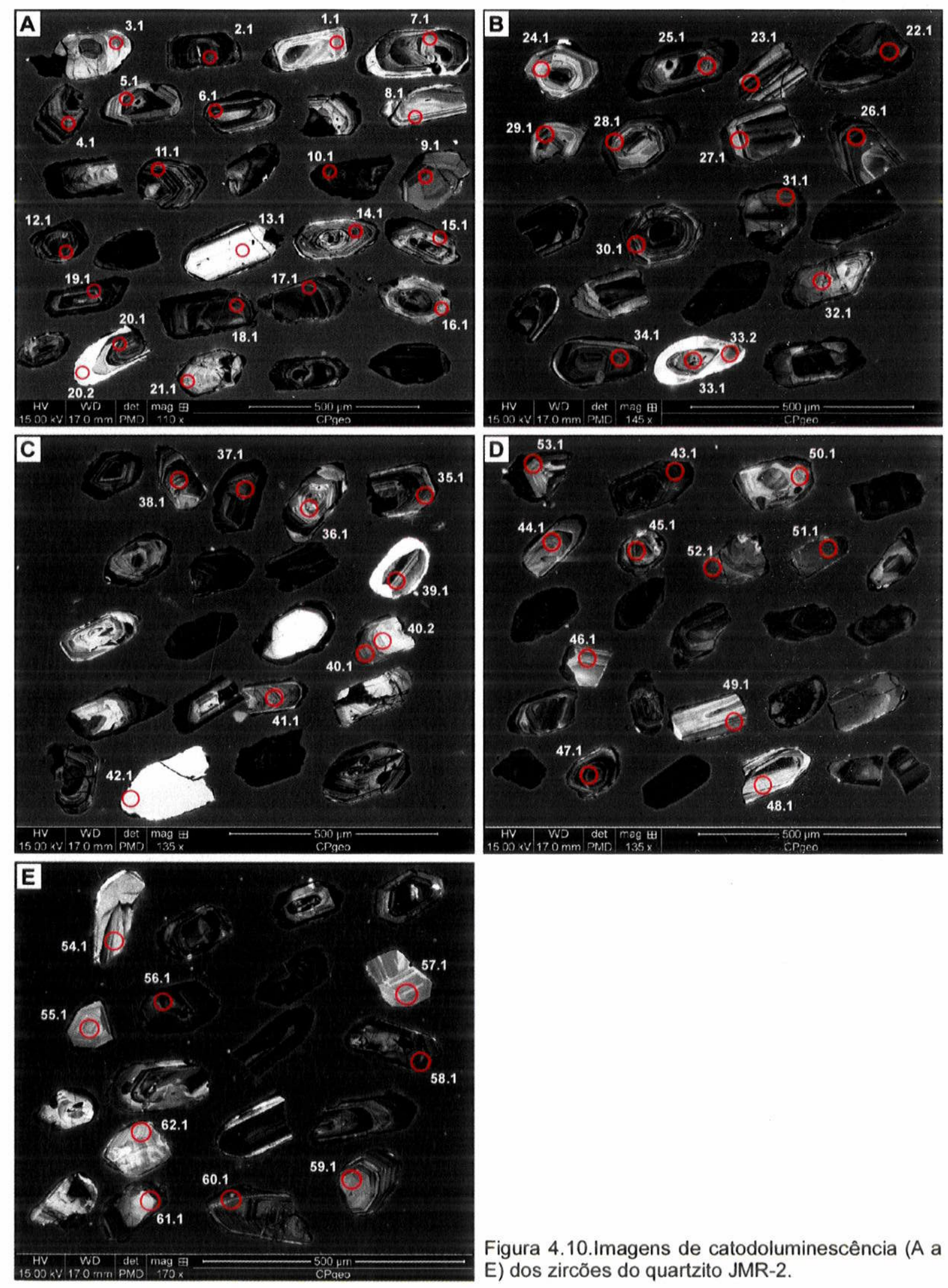

Figura 4.10.Imagens de catodoluminescência (A a E) dos zircões do quartzito JMR-2. 

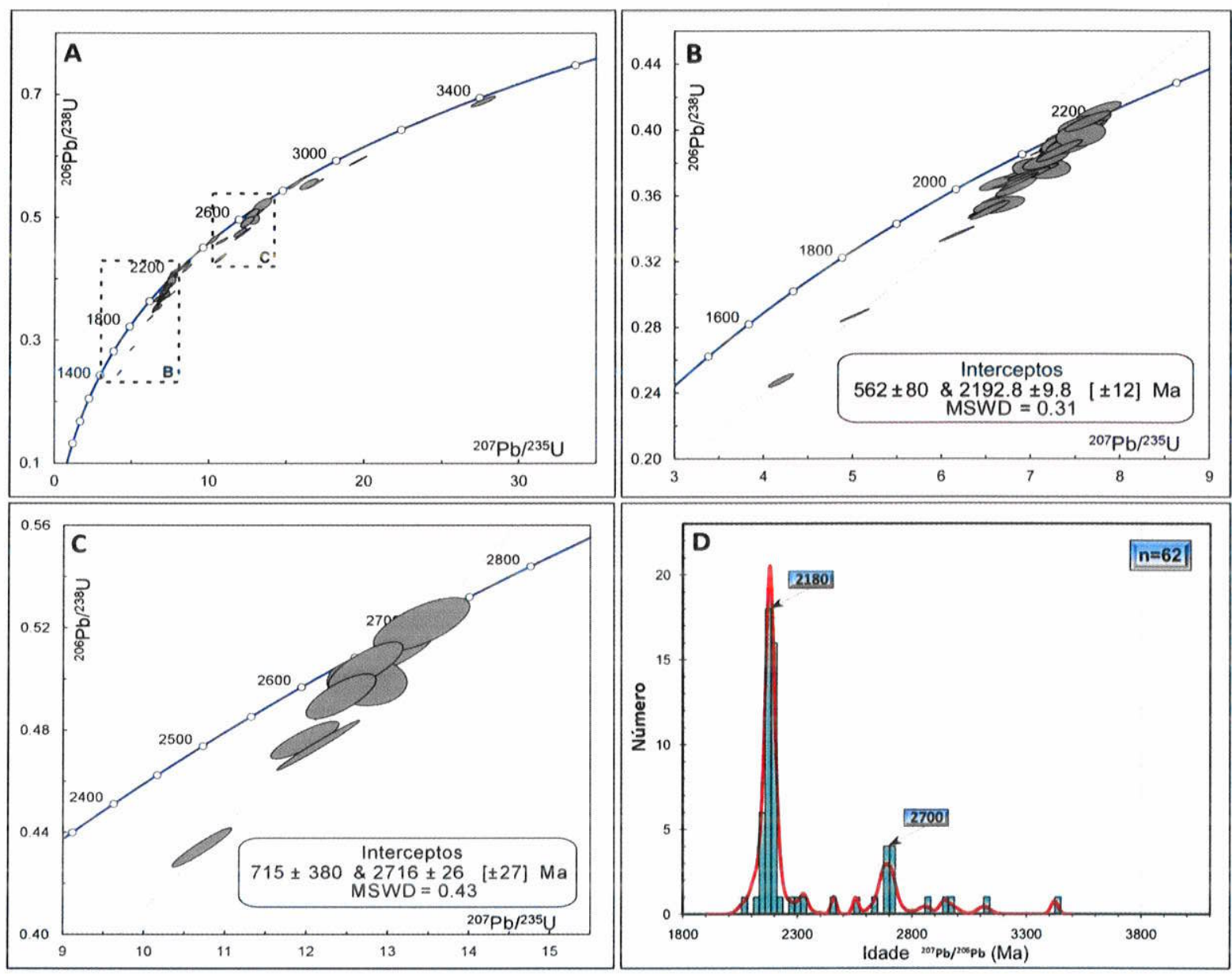

Figura 4.11. Diagramas Concórdia e histograma de densidade de probabilidade para o quartzito JMR-2: (A) Todas as análises incluídas, mostrando o agrupamento dominante entre 3,0 e 2,0 Ga; (B) conjunto de análises que define uma discórdia com intercepto superior em c. $2.2 \mathrm{Ga}$; (C) conjunto de análises agrupadas ao longo de uma discórdia com intercepto superior em c. $2.7 \mathrm{Ga}$; (D) histograma de densidade de probabilidade mostrando os picos definidos pelas idades ${ }^{207} \mathrm{~Pb} /{ }^{206} \mathrm{~Pb}$.

\subsubsection{Sequência Metasedimentar Seridó}

As rochas que caracterizam essa unidade ocorrem ao longo da Zona de Cisalhamento Patos, mais especificamente entre as cidades Cajazeiras e Coremas (Paraíba). Como mencionado no Capítulo I as semelhanças litológicas com o Grupo Seridó levou Medeiros et al. (2008) a correlacionar esse pacote de metasedimentos com o Grupo Seridó definido na região homônima. Nesse trabalho foram coletadas quatro amostras, sendo uma de um paragnaisse (Jucurutu), duas de quartzitos (Equador) e uma de um biotita xisto (Seridó). Desse último não foi possível recuperar zircões com qualidade para serem analisados, de forma que apenas as três amostras restantes têm seus resultados aqui apresentados. 

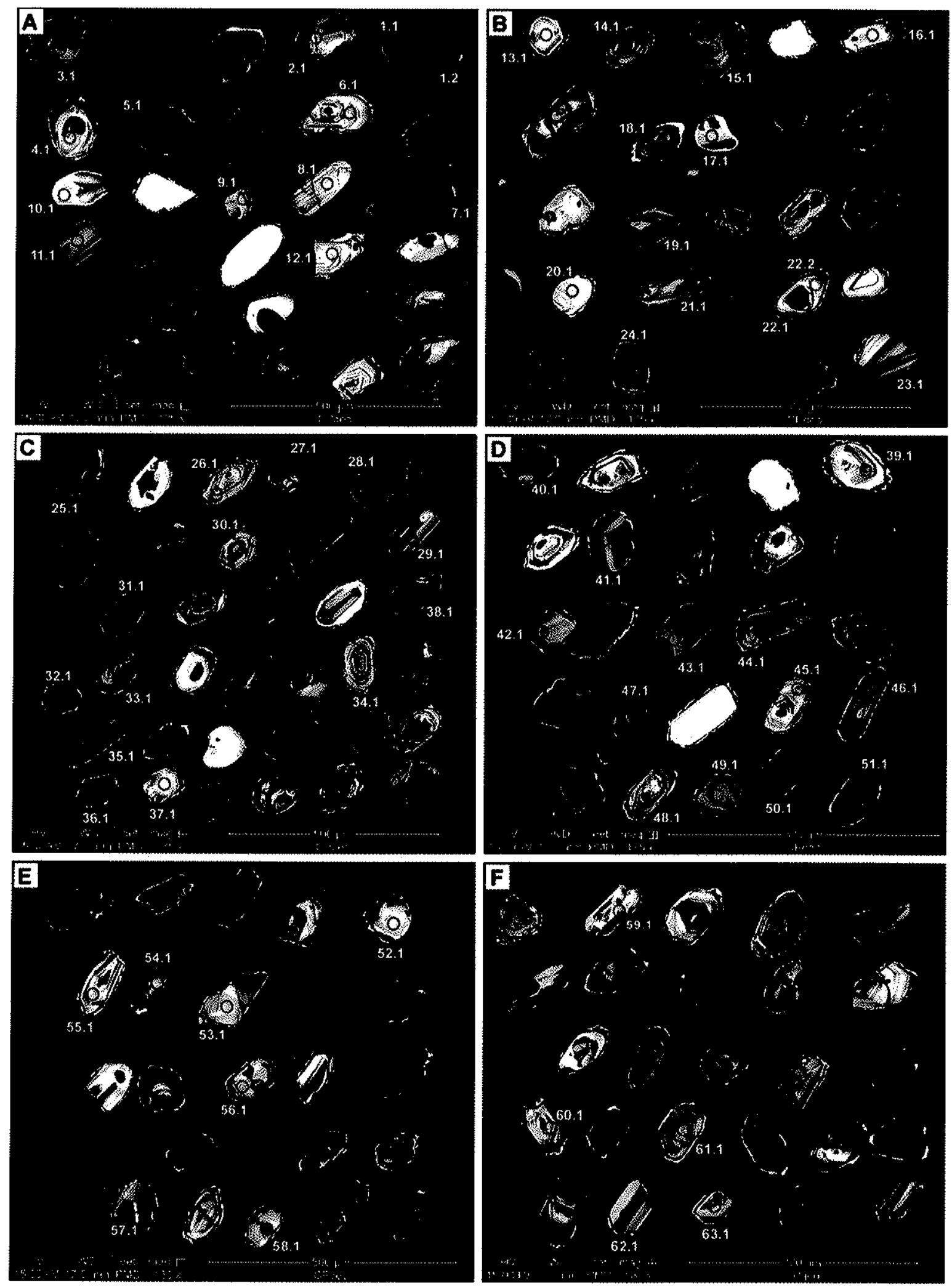

Figura 4.12. Imagens de catodoluminescência ( $A$ a F) dos zircões do biotita xisto PT-10. 

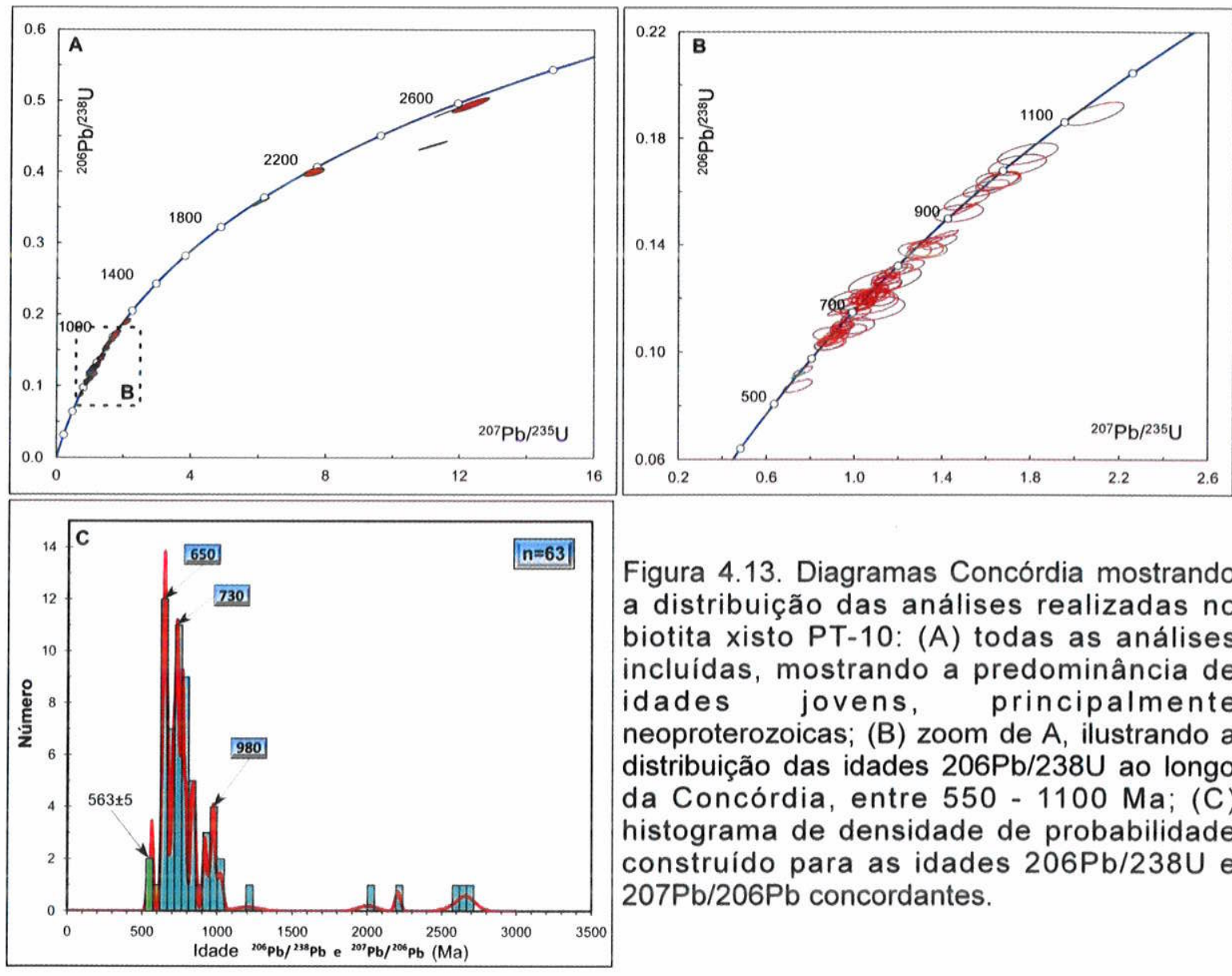

Figura 4.13. Diagramas Concórdia mostrando a distribuição das análises realizadas no biotita xisto PT-10: (A) todas as análises incluídas, mostrando a predominância de idades jovens, principalmente neoproterozoicas; (B) zoom de A, ilustrando a distribuição das idades $206 \mathrm{~Pb} / 238 \mathrm{U}$ ao longo da Concórdia, entre 550 - $1100 \mathrm{Ma}$; (C) histograma de densidade de probabilidade construido para as idades $206 \mathrm{~Pb} / 238 \mathrm{U}$ e $207 \mathrm{~Pb} / 206 \mathrm{~Pb}$ concordantes.

\subsubsection{Paragnaisse JMR-12}

A amostra analisada foi coletada em um corte da rodovia PB-348, 4,5 km a oeste da cidade de Coremas, próximo à barragem do açude. Consiste de um granada-biotita paragnaisse com textura granolepidoblástica e assembléia mineral constituída por quartzo $(40 \%)$, biotita $(40 \%)$, plagioclásio $(20 \%)$ e granada $(2 \%)$, tendo turmalina, apatita e zircão como as fases acessórias identificadas. A foliação é principalmente definida pela orientação preferencial da biotita.

Cerca de 80 grãos de zircão foram recuperados e montados para análise. Zonação com padrões oscilatório e setorizado são comuns tanto nos grãos com hábito prismático quanto naqueles com formas mais arredondadas. Grãos com discreto sobrecrescimento de baixa luminescência (alto $U$ ) e alguns poucos com núcleos metamitizados também foram observados (Figura 4.14 A-D). As análises foram feitas em 62 grãos, procurando-se priorizar os setores com crescimento ígneo.

A distribuição dos pontos analíticos no diagrama Concórdia mostra dispersão de uma parte menor dos grãos analisados entre c. 2,9 e 1,8 Ga, sendo que seis destes se alinharam definindo uma discórdia cujo intercepto superior é $2202 \pm 31$ Ma (MSWD =0,35; Figura 4.15A, B). O maior conjunto de análises distribuiu-se ao longo da Concórdia entre c. 1300 
até $600 \mathrm{Ma}$, com concentração mais expressiva entre c. 850 e 600 Ma (Figura 4.15C, D). O histograma de densidade de probabilidade ilustra a dominância de idades ${ }^{206} \mathrm{U} /{ }^{238} \mathrm{U}$ neoproterozoicas, com pico em torno de 800 - 700 Ma e contribuições mais modestas em c. 3,0 e 1,8 Ga (Figura 4.15E).
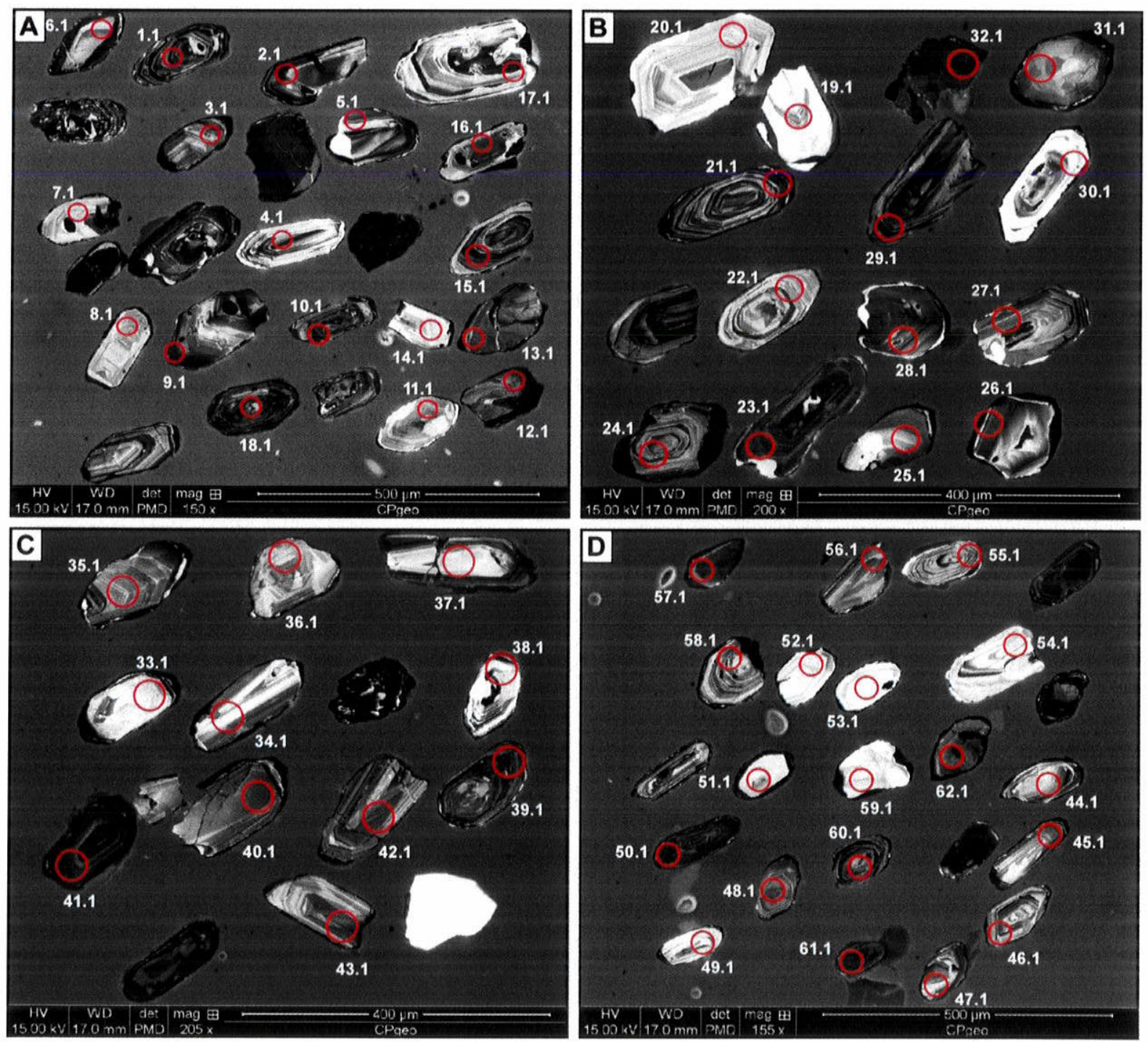

Figura 4.14. Imagens de catodoluminescência (A a D) dos zircões do paragnaisse JMR-12. 

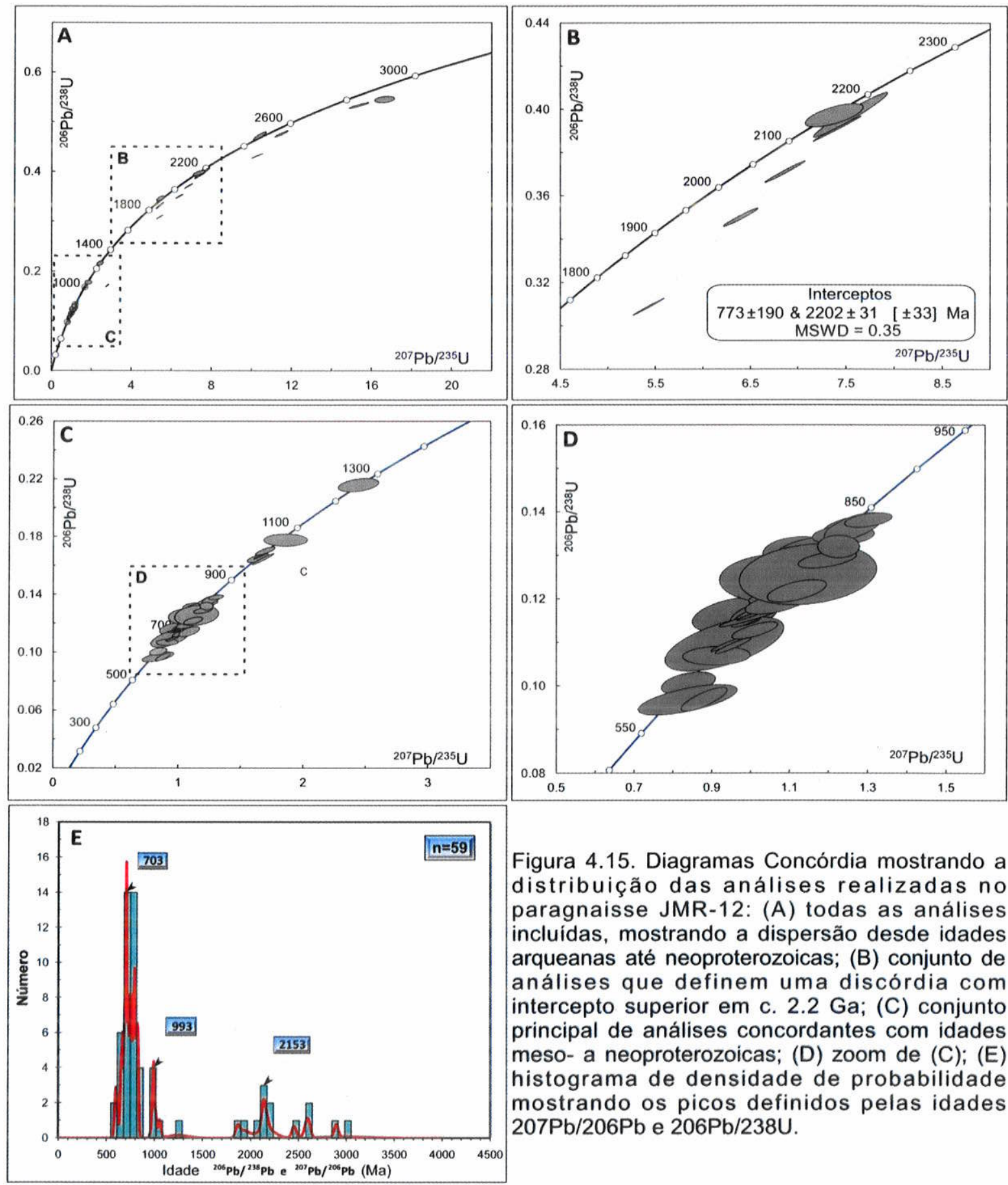

Figura 4.15. Diagramas Concórdia mostrando a distribuição das análises realizadas no paragnaisse JMR-12: (A) todas as análises incluídas, mostrando a dispersão desde idades arqueanas até neoproterozoicas; (B) conjunto de análises que definem uma discórdia com intercepto superior em c. $2.2 \mathrm{Ga}$; (C) conjunto principal de análises concordantes com idades meso- a neoproterozoicas; (D) zoom de (C); (E) histograma de densidade de probabilidade mostrando os picos definidos pelas idades $207 \mathrm{~Pb} / 206 \mathrm{~Pb}$ e $206 \mathrm{~Pb} / 238 \mathrm{U}$.

\subsubsection{Quartzitos JMR-8 e JMR-11}

Duas amostras da unidade quartzítica foram coletadas, uma na barragem do açude de Bom Jesus, próximo à cidade de Engenheiro Ávidos (amostra JMR-8) e a outra no entorno de Coremas (PB) na barragem do açude que abastece essa cidade (amostra JMR11). Ambas as amostras constituem muscovita quartzitos (quartzo + muscovita como 
principais fases na moda) com turmalina, monazita, zircão, epidoto e feldspato potássico como minerais acessórios.

As imagens de catodoluminescência das duas amostras mostram forte metamitização e fraturamento na maioria dos zircões recuperados. Por esse motivo os resultados analíticos das duas amostras (68 ao todo) foram plotados e interpretados em conjunto.

Os grãos analisados mostram morfologias prismáticas a arrendondadas e estruturas internas complexas evidenciadas por núcleos metamitizados, zonação tipo oscilatória, setorizada ou convoluta, micro-fraturas, além de sobrecrescimentos que, em geral, apresentam alto conteúdo de $U$ (baixa luminescência) (Figura 4.16A-E \& Figura 4.17 A-F).

No diagrama Concórdia os pontos analíticos distribuem-se preferencialmente entre 2,7 e 2,0 Ga, sendo que um pequeno conjunto de seis pontos concordantes se agrupa em c. 2,7 - 2,5 Ga (\#16.1, \#19.1, \#24.1, \#28.1 da amostra JMR-8 e \#26.1 da amostra JMR-11; Figura 4.18A), enquanto a maioria das análises define uma discórdia cujo intercepto superior é $2180 \pm 11 \mathrm{Ma}(M S W D=1,9, n=52$; Figura 4.18B). Apesar do erro elevado a idade de intercepto inferior em 576 Ma é controlada por três análises concordantes da amostra JMR11 (\#19.2, \#21.2, \#23.1), obtidas nas bordas desses grãos (Figura 4.17D \& 4.18C), sendo isses valores similares ao metamorfismo datado em c. $575 \mathrm{Ma}$ (Archanjo et al., 2012). No histograma de densidade de probabilidade é confirmada a dominância de zircões paleoproterozoicos, com pico em c. $2175 \mathrm{Ma}$, junto as bordas analisadas com pico c. 560 Ma (Figura 4.18D). 

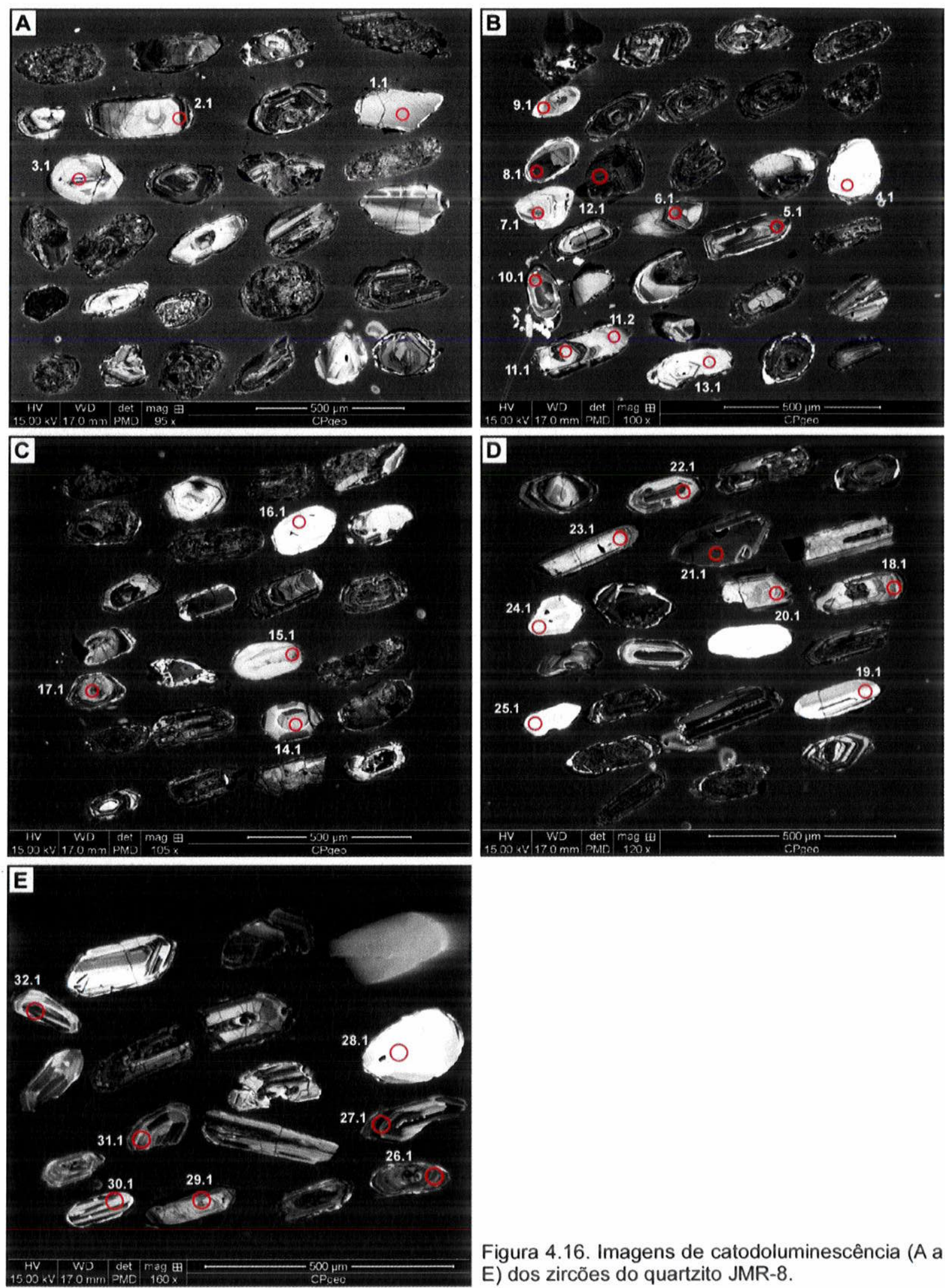

Figura 4.16. Imagens de catodoluminescência (A a E) dos zircões do quartzito JMR-8. 

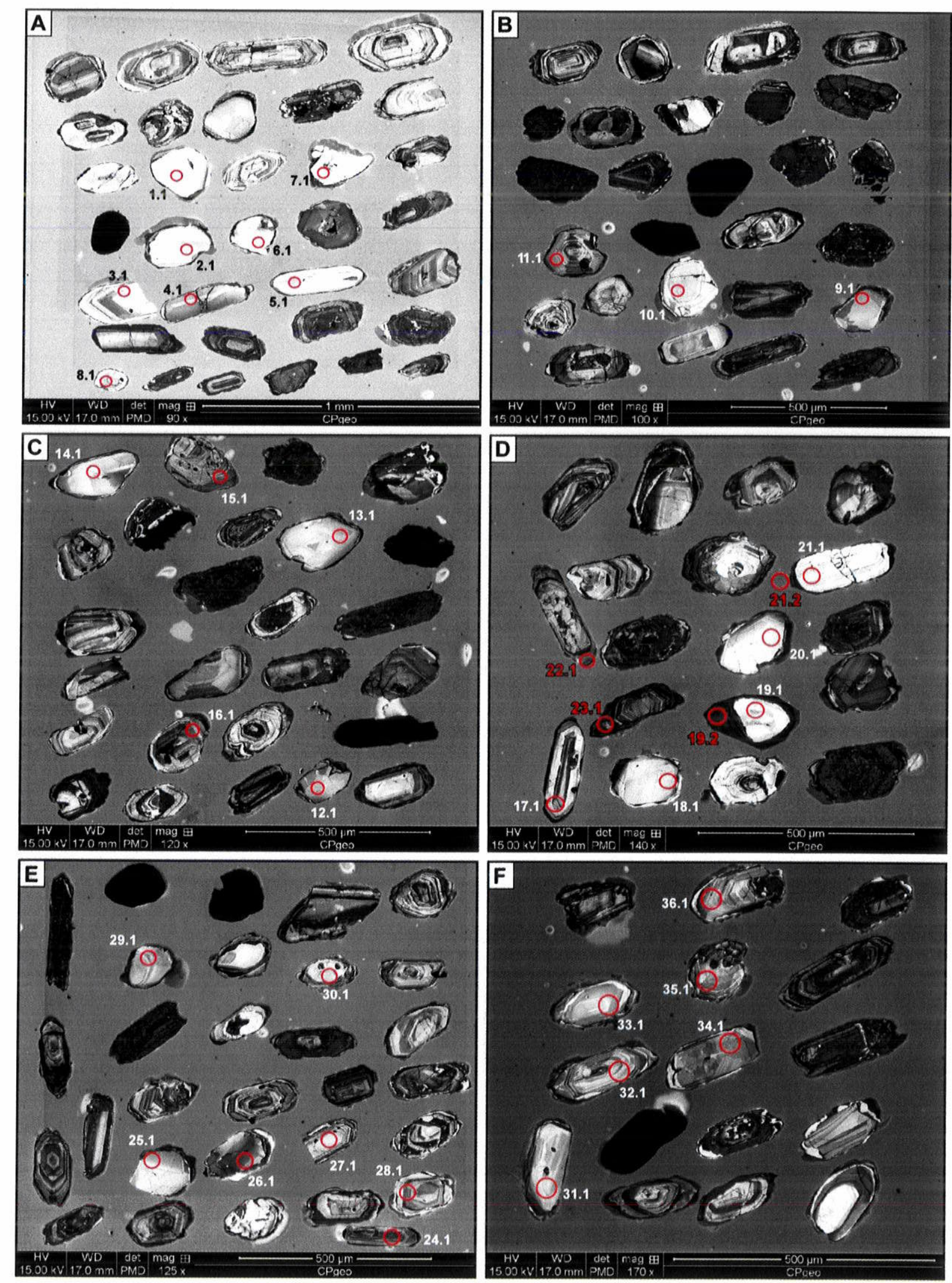

Figura 4.17. Imagens de catodoluminescência (A a D) dos zircões do quartzitos JMR-11. Em letra vermelha estão indicadas as análises feitas em bordas de grãos. 

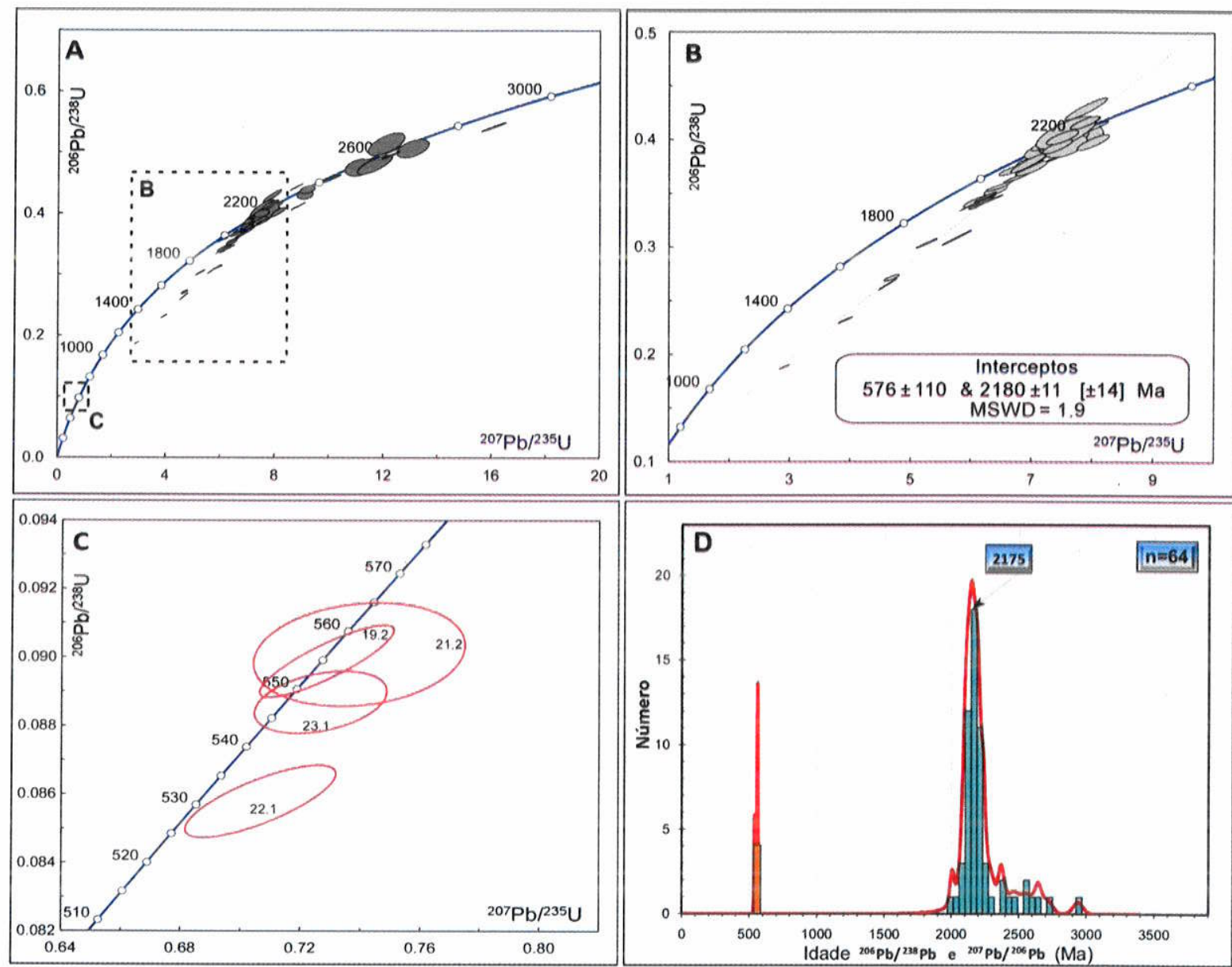

Figura 4.18. Diagramas Concórdia e histograma de densidade de probabilidade para os quartzitos JMR-8 e JMR-11: (A) todas as análises incluídas, mostrando o agrupamento dominante entre 2,0 e 2,7 Ga; (B) conjunto de análises que definem uma discórdia com intercepto superior em c. 2.2 Ga; (C) detalhe do conjunto de análises que controlam o intercepto inferior em c. $575 \mathrm{Ma}$, com destaque para um dos zircões com bordas neoproterozoicas da amostra JMR-11; (D) histograma de densidade de probabilidade mostrando os picos definidos pelas idades ${ }^{207} \mathrm{~Pb} /{ }^{206} \mathrm{~Pb}$ paleoproterozoicas e outro menor com as idades ${ }^{206} \mathrm{~Pb} /{ }^{238} \mathrm{U}$ neoproterozoicas.

\subsubsection{Bacias Paleozoicas}

\subsubsection{Arenito JMR-4 (Bacia de lara)}

A amostra foi coletada na BR-116, $1 \mathrm{Km}$ a sul da cidade de lara, consistindo em um arenito arcosiano lítico granulação grossa, com arcabouço dominado por quartzo (45\%), feldspatos $(22 \%)$ e fragmentos líticos $(33 \%)$ de natureza metamórfica e ígnea. Cerca de $40 \%$ da rocha é representada por cimento e poros.

Dessa amostra cerca de 120 grãos detríticos foram recuperados e montados para serem imageados por catodoluminiscência, os quais apresentam formas prismáticas a arredondadas. Os padrões de estruturas internas são aqueles também observados nas demais amostras estudadas - zonação tipo oscilatório, setorizado e/ou convoluto, além de sobrecrecimentos com alto teor de U. Um total de 70 análises foi feito em grãos distintos, a 
maioria em setores tipicamente ígneos (Figura 4.19A-D). As razões ${ }^{206} \mathrm{~Pb} /{ }^{238} \mathrm{U}$ e ${ }^{207} \mathrm{~Pb} /{ }^{235} \mathrm{U}$ são concordantes e distribuem-se preferencialmente em cinco intervalos na Concórdia: 2,2 2,1 Ga / 2,0 - 1,9 Ga / 1,8 - 1,7 Ga / 0,9 - 0,8 Ga / 0,65-0,55 Ga (Figura 4.20A-C), sendo que cerca de $60 \%$ das idades são neoproterozoicas principalmente agrupadas entre 650 - 565 Ma (Figura 4.20D). As idades mais jovens que $600 \mathrm{Ma}$ foram indiscriminadamente tomadas de setores com zonação ígnea e com evidente recristalização metamórfica em c. 580 -560 Ma (ver imagens CL na Figura 4.19 A-D).
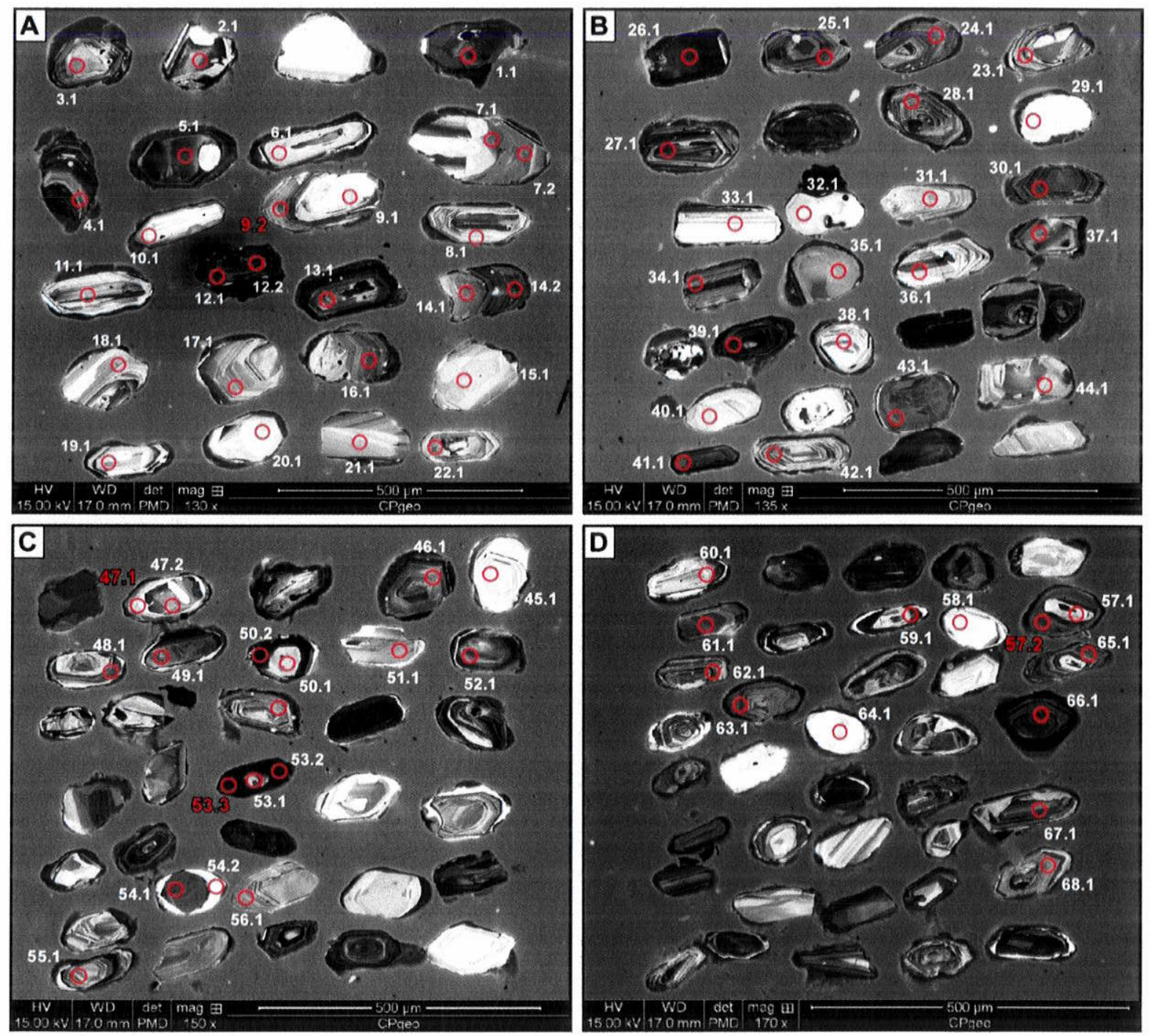

Figura 4.19. Imagens de catodoluminescência (A a D) dos zircões do arenito JMR-4. Em letra vermelha estão indicadas as análises feitas em bordas de grão com idades c. $560 \mathrm{Ma}$. 

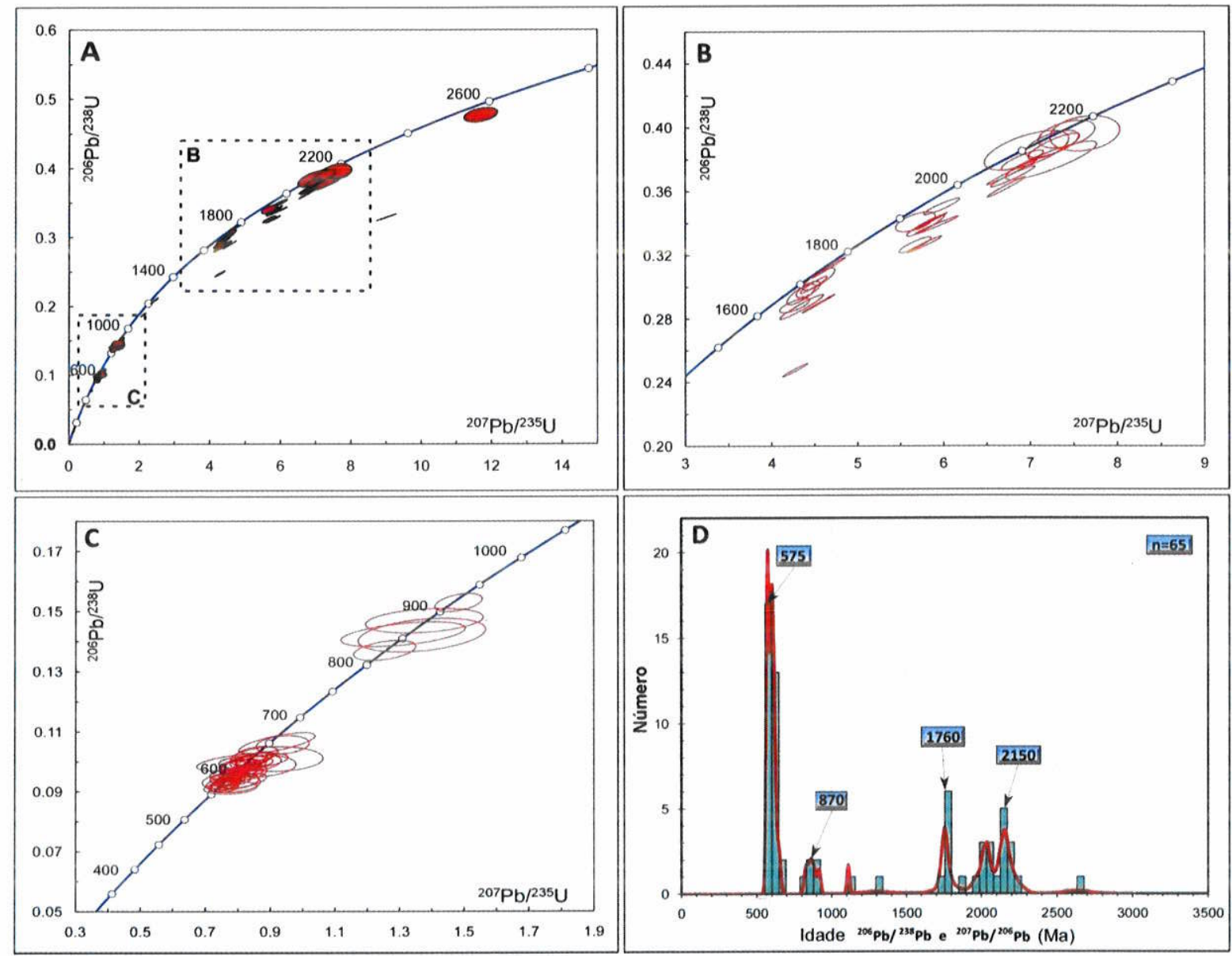

Figura 4.20. Diagramas Concórdia e histograma de densidade de probabilidade para o arenito JMR-4: (A) todas as análises incluídas, mostrando a dispersão desde idades paleoproterozoicas a neoproterozoicas e um único ponto com idade em $2632 \pm 84 \mathrm{Ma}$; (B) distribuição das populações de idades paleoproterozoicas; (C) distribuição de das populações de idades neoproterozoicas; (D) histograma de densidade de probabilidade mostrando os picos definidos pelas idades ${ }^{207} \mathrm{~Pb} /{ }^{206} \mathrm{~Pb}$ e ${ }^{206} \mathrm{~Pb} /{ }^{238} \mathrm{U}$.

\subsubsection{Arenito JMR-5 (Bacia de Barro)}

Essa amostra foi coletada na BR-230 dentro da área urbana da cidade de Barro (PB). Consiste em um arenito arcosiano de granulação grossa, grão suportado, bem selecionado, com grãos dominantemente subangulares a subarredondados. Cerca de $70 \%$ da rocha é representada pelo arcabouço (quartzo - 70\%, feldspatos - 30\% e fragmentos líticos - 1\%), o restante incluindo material intersticial e poros. Um total de 120 zircões detríticos foram recuperados e 75 grãos selecionados para análise. A morfologia dominante é prismática com terminações sub-arredondadas. As imagens de catodoluminescência mostram zonações oscilatória, setorizada e convoluta combinadas à bordas recristalizadas com teores de baixo $U$ (forte luminescência) e alto $U$ (fraca luminescência) (Figura 4.21A-E). As análises se distribuem de forma semelhante ao visto no arenito JMR-4 da bacia de lara (Figura 4.22A-F). No entanto, nesta amostra nota-se a presença significativa de zircões com idades ${ }^{207} \mathrm{~Pb} /{ }^{206} \mathrm{~Pb}$ entre $2,3-2,1 \mathrm{Ga}$, bem como idades paleoproterozoicas-neoarquenas 
(entre 3,3 - 2,4 Ga), e as idades mais jovens distribuem-se entre 1050 - $550 \mathrm{Ma}$, com maior concentração entre 650 e 550 Ma e entre 1050 - 950 Ma (Figura 4.22D).
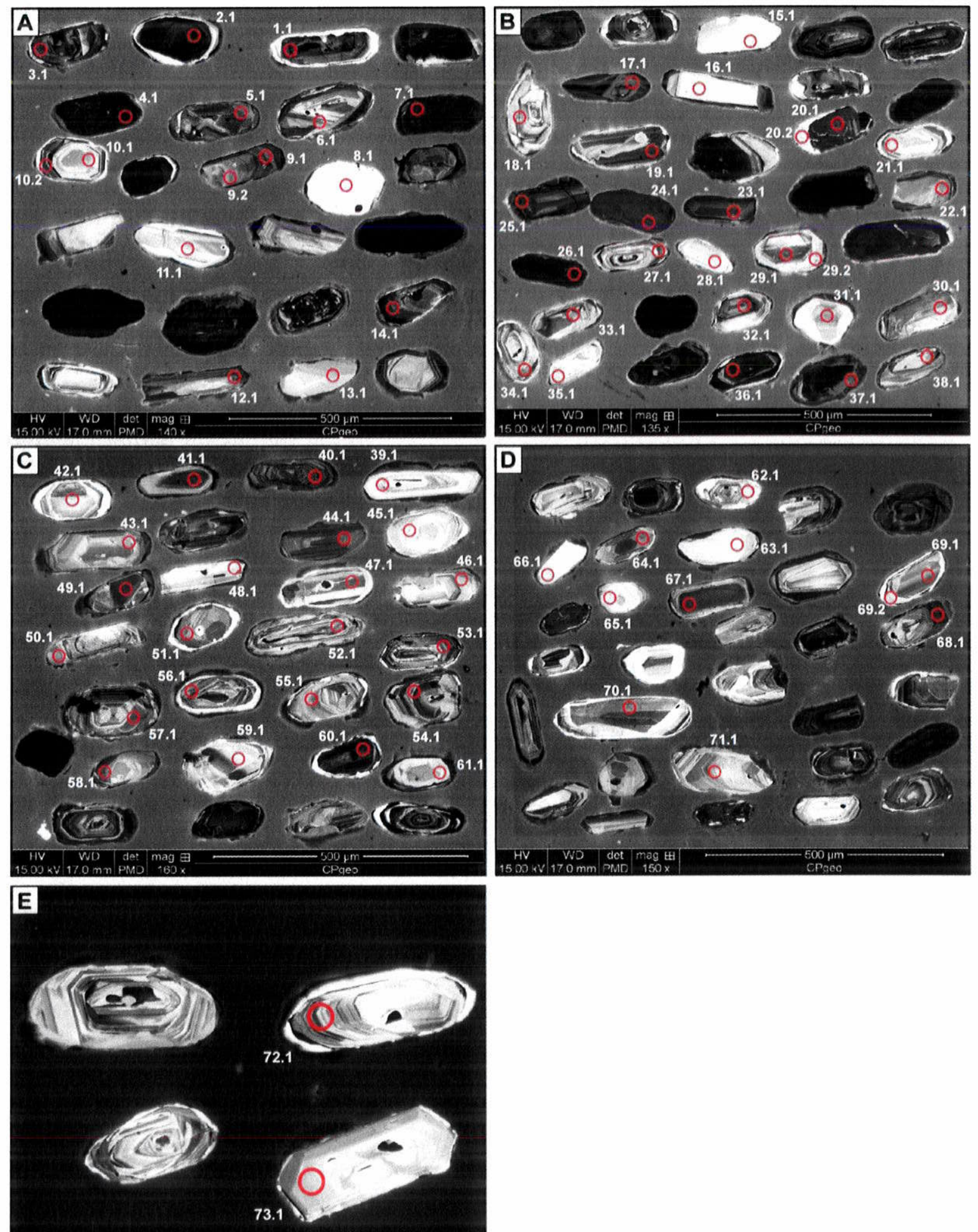

HV WD $\operatorname{det}$ nag $⿴ 囗 十$

Figura 4.21. Imagens de catodoluminescência (A a E) dos zircões do arenito JMR-5. 

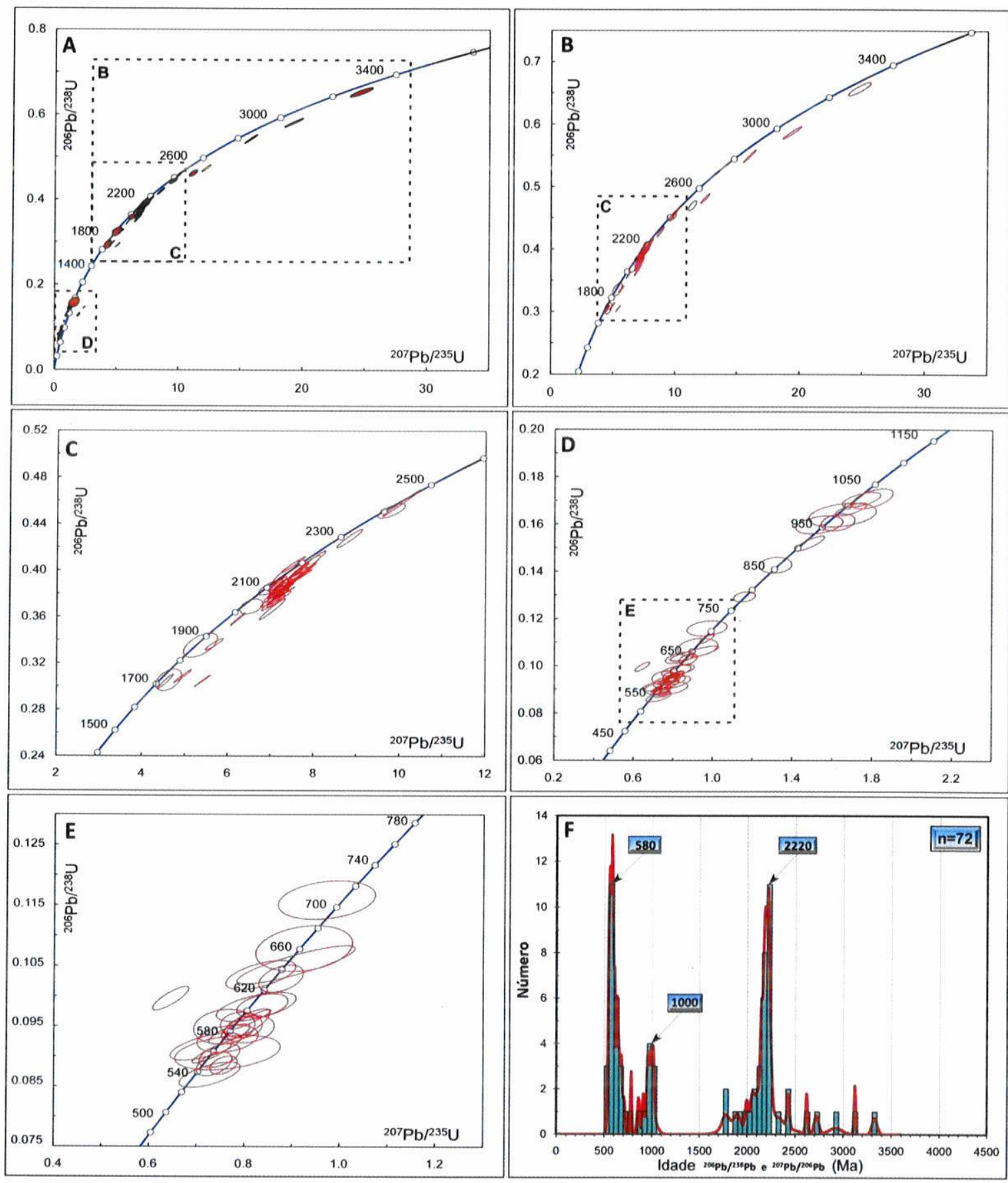

Figura 4.22. Diagramas Concórdia e histograma de densidade de probabilidade para o arenito JMR-5: (A) Todas as análises incluídas, mostrando o agrupamento em intervalos de idades concordantes neoproterozoicas e paleoproterozoicas; (B) zoom de A com destaque para as populações de idades paleoproterozoicas; (C) zoom de B; (D) zoom de A com destaque para a distribuição das análises ao longo da Concórdia em intervalos dentro do Neoproterozoico; (E) zoom de $\mathrm{D}$; $(\mathrm{F})$ histograma de densidade de probabilidade mostrando as maiores concentrações de idades no Neoproterozoico e Paleoproterozoico. 


\section{CAPÍTULO 5 - DISCUSSÕES E CONCLUSÕES}

\subsection{PROVENIÊNCIA DO GRUPO SERIDÓ}

Apesar do crescente acervo de dados geocronológicos que vêm sendo obtidos para a Província Borborema, são poucas as informações sobre proveniência das sequências metasedimentares precambrianas. Dentro desse tema de pesquisa destacamse as contribuições de Van Schmus et al. (2003) e Araujo et al. (2012), direcionadas ao estudo de sequências neoproterozoicas do setor setentrional da província. Os dados de Van Schmus e colaboradores, em particular, constituem uma referência para as discussões apresentadas neste trabalho uma vez que foram relevantes para definir a história deposicional do Grupo Seridó (Faixa Seridó).

O estudo de Van Schmus et al. (2003) foi direcionado ao uso dos métodos Sm/Nd (rocha total) e U/Pb in situ em zircão detrítico. Os dados $\mathrm{Sm} / \mathrm{Nd}$ regionais obtidos para os metapelitos das formações Jucurutu e Seridó são ilustrados no gráfico da Figura 4.1. O comportamento isotópico de $\mathrm{Nd}$ mostra a variação dos valores da idade modelo $\mathrm{t}_{\mathrm{DM}}$ entre 1,6 - 1,4 Ga para os paragnaisses Jucurutu os quais decrescem para valores entre 1,5 1,1 Ga nas nos biotita xistos da Formação Seridó. Esse padrão é considerado normal em uma sequência depositada durante um ciclo único de sedimentação, como defendido por Jardim de Sá et al. (1994) para o Grupo Seridó. No entanto, Van Schmus et al. (2003) não contemplaram a unidade quartzítica Equador, intermediária, de forma que só recentemente seu padrão de proveniência vem sendo discutido na literatura através dos dados obtidos por M.H. Hollanda e colaboradores. Os resultados ainda não foram publicados, mas algumas informações gerais constam no corpo desse capítulo para dar suporte às correlações litoestratigráficas entre as unidades estudadas e o Grupo Seridó.

As idades modelo $t_{D M}$ para os quartzitos e metaconglomerados da Formação Equador apontam para valores bem mais antigos quando comparados aos dos metapelitos, com valores consistentemente superiores a $2,5 \mathrm{Ga}$. Essa primeira aproximação é confirmada quando observadas as idades dos zircões detríticos que definem populações exclusivamente paleoproterozoicas e arqueanas, com picos das idades ${ }^{207} \mathrm{~Pb} /{ }^{206} \mathrm{~Pb}$ em c. 2,2 Ga, c. 2,7 - 2,4 Ga e c. 3,2 Ga. Em contraste, a proveniência dos zircões nas formações Seridó e Jucurutu se caracteriza pela dominância de populações neoproterozoicas com picos em 700-620 Ma, 840-760 Ma e entre 1000-900 Ma na primeira, enquanto que na Formação Jucurutu as idades são mais dispersas mas ainda no mesmo intervalo neoproterozoico (Van Schmus et al., 2003). Zircões paleoproterozoicos representam uma contribuição menor nestas duas unidades.

O contraste entre as assinaturas definidas para as unidades Seridó-Jucurutu e Equador necessariamente implica em uma revisão da posição estratigráfica dos quartzitos 
e metaconglomerados dentro do Grupo Seridó. No entanto, essa discussão não será abordada neste trabalho, que apenas fará uso das informações disponibilizadas por M.H. Hollanda para comentar sobre possíveis correlações regionais entre as sequências metasedimentares da Província Borborema oriental.

\subsection{CORRELAÇÃO ENTRE AS SEQUÊNCIAS METASEDIMENTARES ESTUDADAS E O GRUPO SERIDÓ}

Os dados $\mathrm{U} / \mathrm{Pb}$ in situ obtidos neste trabalho trazem uma importante contribuição para entender a evolução geológica das sequências metasedimentares neoproterozoicas que ocorrem ao longo da Zona de Cisalhamento Patos, uma estrutura de importância regional que subdivide os setores setentrional e central da Província Borborema. Nessa região afloram a sequência metasedimentar de Lavras da Mangabeira e uma outra sequência que tem sido interpretada pela CPRM (Medeiros et al., 2008) como correlata do Grupo Seridó dada as suas semelhanças litológicas - paragnaisses na base que gradam para biotita xisto no topo, com uma unidade intermediária quartzítica. Essa última sequência ocorre aflora entre as cidades de Cajazeiras e Coremas, na Paraíba.

Apesar do número reduzido de análises $\mathrm{Sm} / \mathrm{Nd}$ aqui apresentado, nota-se que os valores das idades $t_{D M}$ se aproximam quando comparadas os resultados das sequências estudadas com o Grupo Seridó (Figura 5.1). As idades $t_{D M}$ são consistentemente paleoproterozoicas-arqueanas entre 2,7 e 2,5 Ga para os quartzitos e metaconglomerados de Lavras da Mangabeira e de Cajazeiras-Coremas com valores > 2,5 Ga obtidos para as rochas da Formação Equador. Quando comparadas as assinaturas $\mathrm{U} / \mathrm{Pb}$ em zircões detríticos a estreita correlação é confirmada (Figura 5.1). Duas populações principais podem ser destacadas: uma em c. 2,2 Ga nas amostras JMR2 (Lavras da Mangabeira) e JMR-8/JMR-11 (Cajazeiras-Coremas) e outra em c. 2,4 Ga na amostra JMR-3 (Lavras da Mangabeira). Notadamente essas populações são também reconhecidas para os quartzitos Equador. Também fica evidente a presença comum de outras populações mais antigas em c. 2,7 Ga e menos importante em c. 3,4 - 3,2 Ga. Nos diagramas Concórdia ilustrados no Capítulo 4 todas essas populações são definidas por um padrão de alinhamento ao longo de discórdias individuais com intercepto inferior tendendo a idades neoproterozoicas. Isso sugere que a abertura parcial do sistema U/Pb nos zircões detríticos dessas unidades é uma feição pós-deposicional, provavelmente relacionada à forte deformação brasiliana vista em campo.

Com respeito às rochas metapelíticas estudadas, o paragnaisse amostrado na sequência Cajazeiras-Coremas guarda estreita correlação com a assinatura de proveniência U/Pb definida em Van Schmus et al. (2003) para a Formação Jucurutu (Figura 5.1). O maior aporte é retratado por idades entre 800 - $700 \mathrm{Ma}$, com contribuições 
menos expressivas em torno de $1000 \mathrm{Ma}$ e $600 \mathrm{Ma}$. Apenas cerca de $20 \%$ dos grãos retratam a proveniência mais antiga, entre idades paleoproterozoicas e arqueanas distribuídas em intervalos semelhantes a aqueles evidenciados nos quartzitos. Infelizmente não foi possivel recuperar zircões do biotita xisto amostrado dessa sequência, de forma que não foi possível a análise comparativa com a Formação Seridó.

Ao contrário da associação litoestratigráfica cartografada na região de CajazeirasCoremas, a sequência de Lavras da Mangabeira não inclui os paragnaisses basais. Lá são identificados apenas os quartzitos e metaconglomerados dispostos diretamente sobre o embasamento (Complexo Granjeiro), os quais estão sotopostos por metapelitos xistosos semelhantes à Formação Seridó do grupo homônimo. O padrão de proveniência dos biotita xistos também ficou restrito à análise de uma única amostra, mas os resultados foram claros em definir a estreita semelhança com a assinatura definida para a Formação Seridó (Van Schmus et al., 2003), ou seja, presença dominante de zircões neoproterozoicos com idades ${ }^{206} \mathrm{~Pb} /{ }^{238} \mathrm{U}$ mais jovens que c. $1000 \mathrm{Ma}$ e contribuição paleoproterozoica-arqueana menor que $5 \%$ da população total analisada (Figura 5.1).

Considerando que os dados de proveniência aqui apresentados podem ser usados como ferramenta de correlação litológica entre unidades geograficamente separadas por dezenas de quilômetros, mas inseridas em um mesmo contexto tectônico, esse trabalho propõe que as sequências metasedimentares de Lavras da Mangabeira e de CajazeirasCoremas representem partes desmembradas do Grupo Seridó ao longo da Zona de Cisalhamento Patos. Se consideradas isoladamente as unidades metapelíticas Jucurutu e Seridó em Cajazeiras-Coremas, o rejuvenescimento das idades $t_{D M} e$ das idades ${ }^{206} \mathrm{~Pb} /{ }^{238} \mathrm{U}$ em direção ao topo representa o padrão esperado de um ciclo deposicional contínuo sem mudanças significativas das fontes de sedimentos. No entanto, a presença de uma unidade intermediária com proveniência paleoproterozoica-arquena necessita de novas considerações sobre o empilhamento estratigráfico proposto por Medeiros et al. (2008). Dada a correlação com o Grupo Seridó as propostas de revisão litosestratigráficas necessariamente devem ser estendidas para a região de Cajazeiras-Coremas. $O$ mesmo aplica-se à sequência de Lavras da Mangabeira, muito embora lá os paragnaisses Jucurutu não sejam cartografados. É importante observar que essa unidade é lateralmente descontínua na Faixa Seridó, o que poderia explicar a sua ausência em Lavras da Mangabeira.

\subsection{ORIGEM PARA AS PROVÁVEIS FONTES DO GRUPO SERIDÓ}

Qualquer tentativa de correlacionar as fontes identificadas a partir das idades $U / P b$ em zircões detríticos com rochas de mesma idade hoje expostas deve ser cuidadosa. Nesse sentido, falta um banco de dados geocronológicos preciso sobre o precambriano 
da província, o conhecimento do cenário paleogeográfico de terrenos durante o Neoproterozoico e, principalmente, dados básicos de paleocorrentes hoje indisponíveis devido os efeitos da intensa deformação regional do Ciclo Brasiliano.

Mesmo considerando as limitações inerentes a estudos de proveniência de sucessões metasedimentares antigas é possível vincular algumas unidades hoje reconhecidas na Província Borborema setentrional (do ponto de vista geocronológico) com as fontes de sedimentos identificadas nas sequências estudadas. Quanto às contribuições paleoproterozoicas e arqueanas, sabe-se que o substrato de embasamento gnáissico de todo o setor setentrional é constituído por rochas ortoderivadas de idades $\mathrm{C}$. 2,25 - 2,1 Ga (Riaciano) e c. 2,4 - 2,3 Ga (Sideriano), representando períodos importantes de acresção crustal identificados nos domínios Ceará Central e Médio Coreaú (Fetter et al., 1999) e Rio Grande do Norte (Dantas, 1992; Souza et al., 2008; Hollanda et al., 2011) expostos como embasamento das faixas móveis meso- e neoproterozoicas. As idades mais antigas obtidas nos zircões detríticos se agrupam em definir uma outra população importante em c. 2,7 - 2,6 Ga que na Província Borborema tem sua representação nas rochas do Maciço de Tróia-Pedra Branca (Fetter, 1999; Fetter et al., 2000, 2003) e com menor contribuição nas rochas mais jovens do núcleo arqueano São José do Campestre (Dantas et al., 2004). Esse núcleo também poderia ser pensado como uma das possíveis fontes para a população de grãos arqueanos que é encontrada nas unidades quartzíticas em todas as sequências metasedimentares estudadas.

Quando analisadas as contribuições neoproterozoicas a conecção com fontes conhecidas na província é mais difícil. $O$ atual conhecimento de processos acrescionários neoproterozoicos (ou ainda da transição Meso-Neoproterozoico) aponta para a ocorrência ampla de terrenos com idades entre 1,05 - 0,95 Ga reconhecidos na Zona Transversal (terrenos Rio Capibaribe, Alto Pajeú; Van Schmus et al., 1995; Brito Neves et al., 2000; Kozuch., 2003) e no maciço Pernambuco-Alagoas a sul. No entanto, grande parte das idades neoproterozoicas obtidas nos zircões detríticos das unidades metapelíticas estão no intervalo entre 800 - 600 Ma e cujos representantes na Província Borborema ainda não são precisamente identificados. Idades nesse intervalo foram identificadas em vulcânicas da sequência Martinópole (Fetter et al., 2003) e, mais recentemente, em tipos plutônicos de ocorrência ainda pontual no Ceará Central (Araújo et al., 2012). Por outro lado, as idades em c. 600 Ma são reconhecidas principalmente no maciço de Santa Quitéria (Fetter et al., 1999, Santos et al., 1998, Prado et al., 1981).

Por fim, as idades ${ }^{206} \mathrm{~Pb} /{ }^{238} \mathrm{U}$ em torno de 590 - 570 Ma reconhecidas nas unidades neoproterozoicas representam um proporção menor na assinatura de proveniência das unidades metapelíticas, ainda menos importante quando considerado que parte das análises foi obtida em bordas recristalizadas e, portanto, representam prováveis idades de 
metamorfismo brasiliano nessas rochas. Apenas duas análises foram obtidas em setores aparentemente ígneos (com zonação oscilatória), sugerindo tratar-se de proveniência mais jovem. No entanto, dada a baixa representatividade dessas idades no conjunto total de dados qualquer interpretação baseada nessa informação ainda deve ser considerada inconclusiva.

\subsection{A TRANSIÇÃO NEOPROTEROZOICO-PALEOZOICO}

Os resultados apresentados neste trabalho contribuíram para o reconhecimento de variações importantes entre os padrões de proveniência identificados para as sequências neoproterozoicas e aqueles definidos para as duas sucessões sedimentares eopaleozoicas que afloram nas bacias de lara e Barro.

Em termos gerais a proveniência das unidades eo-paleozoicas se assemelha àquela das unidades pre-cambrianas dada a presença de dois conjuntos bem individualizados de idades U/Pb: um neoproterozoico entre c. 1000 - $600 \mathrm{Ma}$ e outro paleoproterozoico entre c. 2,5-1,8 Ga, com menor contribuição arqueana > 2,5 Ga. Destaca-se como diferença marcante a presença mais expressiva de zircões paleoproterozoicos-arqueanos nessas bacias quando comparadas com as proporções reconhecidas para as formações Seridó e Jucurutu (ver Figura 5.1). Se levado em conta que o embasamento antigo deveria estar pouco disponivel quando da deposição final do Grupo Seridó, representado pelos metapelitos da Formação Seridó (amostra PT-10 deste trabalho e dados de Van Schmus et al., 2003), seria esperado decréscimo ainda maior de contribuição dessa fonte nas bacias eo-paleozoicas ou mesmo a ausência completa de zircões antigos. No entanto, o componente paleoproterozoico-arqueano na Bacia de Barro representa mais que $50 \%$ do total de grãos analisados contra $40 \%$ do total na Bacia de lara.

Outra característica importante que pode ser observada a partir dos dados de proveniência $\mathrm{U} / \mathrm{Pb}$ é a presença de zircões muito jovens, com idades entre $600-550 \mathrm{Ma}$ especialmente encontrados no arenito da Bacia de lara e totalizando cerca de $85 \%$ dos zircões neoproterozoicos datados. Considerando que essa bacia está preservada de qualquer evento de deformação/metamorfismo regional e que o inicio da deposição é creditado ao siluro-devoniano, aquelas idades necessariamente refletem contribuição externa à bacia. Em adição, os spots analíticos foram feitos em setores ígneos indicando também que as idades obtidas devem ser interpretadas como de cristalização desses zircões.

Essa assinatura de proveniência permite concluir que as bacias eo-paleozoicas ao longo da Zona de Cisalhamento Patos tiveram sua deposição inicial controlada pelo aporte combinado de material fonte neoproterozoico de idades diversas, com especial 
contribuição de fontes c. $600-550 \mathrm{Ma}$, e de material sedimentar mais antigo de idades paleoproterozoicas-arqueanas. Nesse último caso, as contribuições poderiam representar a reciclagem das sucessões neoproterozoicas pre-existentes, mais especificamente das unidades quartzíticas visto a presença expressiva de zircões com idades $>2,0 \mathrm{Ga}$.

\subsection{CONCLUSÕES}

Dos resultados apresentados neste trabalho podemos concluir:

a. A assinatura isotópica $\mathrm{Sm} / \mathrm{Nd}$ em rocha total dada pelos valores das idades modelo $t_{\mathrm{DM}}$ estão em estreita sintonia com os padrões de idades $\mathrm{U} / \mathrm{Pb}$ em zircões detríticos, em todas as unidades estudadas, mostrando a inegável eficiência dessas ferramentas analíticas para o estudo de proveniência de sequências metasedimentares precambrianas.

b. A assinatura de proveniência das unidades quartzíticas tanto em Lavras da Mangabeira quanto em Cajazeiras-Coremas são semelhantes, com populações de zircões $>2,0 \mathrm{Ga}$, enquanto que as unidades metapeliticas das duas sequências mostram padrões de idades dominantemente neoproterozoicos com menor contribuição paleoproterozoica.

c. Os dados $\mathrm{Sm} / \mathrm{Nd}$ e $\mathrm{U} / \mathrm{Pb}$ permitem correlacionar perfeitamente as assinaturas de proveniência das sequências estudadas (Cajazeiras-Coremas e Lavras da Mangabeira) com aquela definida para o Grupo Seridó, indicam que as mesmas são parte de uma única bacia desmembrada pela deformação transcorrente da Zona de Cisalhamento Patos, em cerca de $300 \mathrm{~km}$.

d. O padrão de proveniência de unidades eo-paleozoicas apontam para a contribuição expressiva de fontes brasilianas de c. 600 - $550 \mathrm{Ma}$, combinadas com material provavelmente oriundo da reciclagem das sequências metasedimentares. neoproterozoicas. 


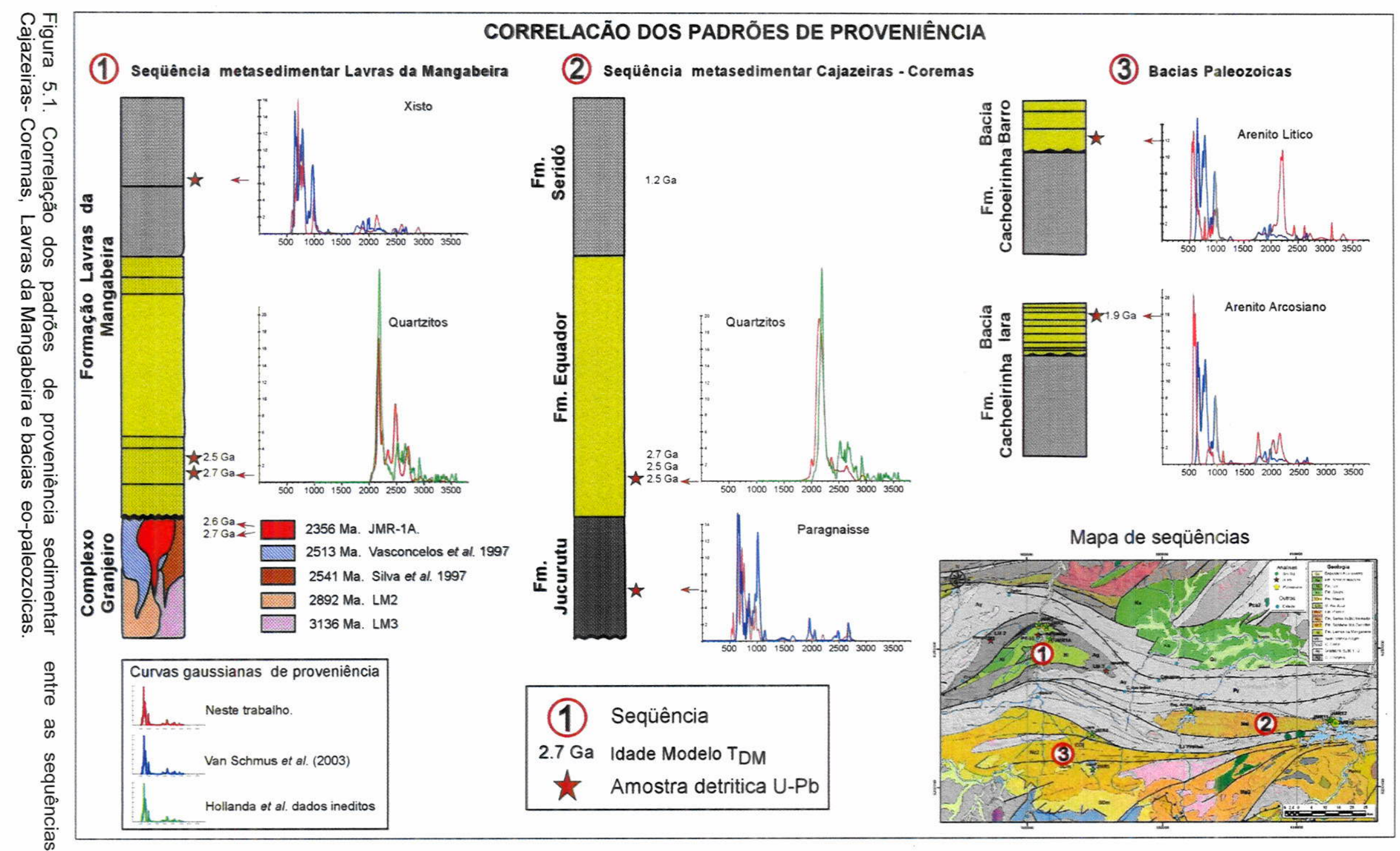




\section{Referências bibliográficas}

Almeida, F.F.M., Hasui, Y., Brito Neves B., \& Fuck, R., 1977. Províncias estruturais brasileiras. In: Simpósio de Geologia do Nordeste, 7, Campina Grande, Atas, p. 363391.

Almeida, F.F.M., Hasui, Y., Brito Neves B., \& Fuck, R.A., 1981. Brazilian structural provinces: an introduction. Earth Sciences Reviews, v. 17, p. 1-29.

Arai, M., 2006. Revisão Estratigráfica do Cretáceo Inferior das Bacias Interiores do Nordeste do Brasil. São Paulo, UNESP, Geociências, v. 25 (1), p. 7 -15.

Archanjo, C.J., \& Salim, J., 1986. Posição da Formação Seridó no contexto estratigráfico regional (RN-PB). In: Simpósio de Geologia do Nordeste, 12, Atas, p. 270-281.

Archanjo, C.J., Viegas, L.G., Hollanda, M.H.B.M., Souza, L.C., \& Liu, D., 2012. Timing of the HT/LP transpression on the Neoproterozoic Seridó Belt (Borborema Province, Brazil). Gondwana Research (In Press).

Arndt, N.T., \& Goldstein, S.L., 1987. Use and abuse of crust-formation ages. Geology, v. $15(10)$, p. 893-895.

Assine, M.L., 1992. Análise estratigráfica da bacia do Araripe, Nordeste do Brasil. Revista Brasileira de Geociências, v.22 (3), p. 289-300.

Baumgartner, R., Romer, R.L., Moritz, R., Sallet R., \& Chiaradia, M., 2006. Columbitetantalite-bearing granitic pegmatites from the Seridó Belt, northeastern Brazil: genetic constraints from $\mathrm{U}-\mathrm{Pb}$ dating and $\mathrm{Pb}$ isotopes. Canadian Mineralogist, v. 44:, p. 69 86.

Bizzi, L.A., Schobbenhaus, C., Vidotti, R.M., \& Gonçalves, J.H., 2003. In: Geologia, tectônica e recursos minerais do Brasil. Mapa Geológico 1: 2.500.000. CPRM Serviço Geológico do Brasil. Bacias Sedimentares Paleozóicas e Meso-Cenozóicas Interiores, $692 \mathrm{p}$.

Brito Neves, B.B. de., 1975. Regionalização geotectônica do Precambriano nordestino. Instituto de Geociências, Universidade de São Paulo, Tese de Livre Docência, 177 p.

Brito Neves, B.B. de., 1983. O mapa geológico do nordeste do Brasil, Escala 1/1.000.000. Tese de Livre Docência, Departamento de Geologia Geral, USP, São Paulo-SP, Brasil, $177 \mathrm{p}$.

Brito Neves, B.B., Santos, E.J., \& Van Schmus, W.R., 2000. Tectonic History of the Borborema Province, Northeast Brazil. In: Cordani, U.G., Milani, E. J., Thomaz Filho, A. Campos, D.A. (Eds.), Tectonic Evolution of South America, Rio de Janeiro, 31st International Geological Congress, p. 151-182.

Caby, R., 1985. New geodinamic concepts regarding the crustal evolution of the NE Brazil. Abstr. Conference Tectonics Geochemical. Early to Middle Proterozoic fold belts. BMR Record 1985/28. 
Caby, R., \& Arthaud, M.H., 1986. Major Precambrian nappes of the Brazilian belt, Ceará, northeast Brazil. Geology, v. 14, p. 871 874.

Caby, R., Arthaud, M.H., \& Vauchez, A., 1991. Crustal Evolution and the Brasiliano orogeny in Northeast Brazil. In: Dallmeyer, R.D., \& Lecorche, J.P. (eds). The West African Orogens and Circum Atlantic correlatives. Springer-Verlag, p. 373-397.

Caby, R., Arthaud, M.H., \& Archanjo, C.J., 1995. Lithostratigraphy and petrostructural characterization of supracrustal units in the Brasiliano Belt of Northeast Brazil: geodynamic implications. Journal of South American Earth Sciences, v. $8(3 / 4)$, p. $235-246$.

Carvalho, I.S., 1996. As pegadas de dinossauros da bacia do Uiraúna-Brejo das Freiras (Cretáceo Inferior, estado da Paraiba). In: Simpósio sobre o Cretáceo do Brasil, 4, Rio Claro, Boletim, p. 115-121.

Corfu, F., Hanchar, J.M., Hoskin, P.W.O., \& Kinny, P., 2003. Atlas of zircon textures. In: Hanchar, J.M., Hoskin, P.W.O. Zircon. Review in Mineralogy and Geochemistry, v. 53 , p. 426-466.

Corsini, M., Vauchez, A., \& Caby, R., 1996. Ductile duplexing at a bend of a continentalscale strike slip shear zone: example from NE Brazil. Journal of Structural Geology, v. 18, p. $358-394$

Dantas, E.L., 1992. Evolução tectono-magmática do maciço poli-diapírico São Vicente/Florania-RN. Dissertação de Mestrado, Universidade Estadual Paulista UNESP, Rio Claro, $206 \mathrm{p}$.

Dantas, E.L., 1997. Geocronologia U/Pb e $\mathrm{Sm} / \mathrm{Nd}$ de terrenos Arqueanos e Paleoproterozóicos do Maciço Caldas Brandão, NE Brasil. Tese de Doutorado. Universidade Estadual Paulista UNESP, Rio Claro-SP, 201 p.

Dantas, E.L., Van Schmus, W.R., Hackspacher, P.C., Fetter, A.H., Brito Neves, B.B.,Cordani, U., Nutman, A.P., \& Williams, I.S., 2004. The 3.4 e 3.5 Ga São José do Campestre massif, NE Brazil: remnants of the oldest crust in South America. Precambrian Research, v. 130, p. 113-137.

De Paolo, D.J., \& Wasserburg, G.J., 1976. Inferences about magma sources and mantle structure from variations of ${ }^{143} \mathrm{Nd} /{ }^{144} \mathrm{Nd}$. Geophysics Research Letters, v. 3, p. 743746.

Fetter, A. H., 1999. U-Pb and Sm-Nd constraints on the crustal framework and geologic history of Ceará State, NW Borborema Province, NE Brazil: Implications for the assembly of Gondwana. Tese de Doutorado, Univ. Kansas, $164 \mathrm{p}$.

Fetter, A.H., Van Schmus, W.R., Santos, T.J.S., Arthaud, M., \& Nogueira Neto, J.A., 2000. $\mathrm{U}-\mathrm{Pb}$ and $\mathrm{Sm}-\mathrm{Nd}$ geochronological constraints on the crustal evolution and basement architecture of Ceará State, NW Borborema Province, NE Brazil: implications for the 
existence of the Paleoproterozoic supercontinent Atlantica. Revista Brasileira de Geociencias, v. 30, p. 102-106.

Fetter, A.H., Saraiva dos Santos, T.J., Van Schmus, W.R., Hackspacher, P.C., Brito Neves, B.B., Arthaud, M.H., Nogueira Neto, J.A., \& Wernick, E., 2003. Evidence for Neoproterozoic Continental Arc Magmatism in the Santa Quitéria batholith of Ceará State, NW Borborema Province, NE Brazil: implications for the Assembly of West Gondwana. Gondwana Research, v. 6, p. 265-273.

Gomes, J.R. de C., Vasconcelos, A.M., \& Torres, P.F.M., 2000. Programa Levantamentos Geológicos Básicos do Brasil. Jaguaribe-SW, Jaguaribe SB.24-Z. Estado do Ceará, Escala 1:500000. Brasilia, CPRM.

Hackspacher, PC., Van Schmus, W.R. \& Dantas, E.L. 1990. Um embasamento Transamazônico na Província Borborema. Congresso Brasileiro de Geologia, 36, Natal, Anais, v. 6.

Hollanda, M.H.B.M., Pimentel, M.M., \& Jardim de Sá, E.F., 2003. Paleoproterozoic subduction-related metasomatic signatures in the lithospheric mantle beneath NE Brazil: Inferences from trace elements and $\mathrm{Sr}-\mathrm{Nd}-\mathrm{Pb}$ isotopic compositions of Neoproterozoic high-K igneous rocks. Journal of South American Earth Sciences, v. $15(8)$, p. 885-900.

Hollanda, M.H.B.M., Archanjo, C.J., \& Souza, L.C., 2010. Historia de proveniência do Grupo Seridó (Província Borborema), com base em dados isotópicos. In: Congresso Brasileiro de Geologia, 45, Belém, Anais, p. 87.

Hollanda, M.H.B.M., Archanjo, C.J., Souza, L.C., Dunyi, L., \& Armstrong, R., 2011. Longlived Paleoproterozoic granitic magmatism in the Seridó-Jaguaribe domain, Borborema Province-NE Brazil. Journal of South American Earth Sciences, v. 32, p. 287-300.

Jardim de Sá, E.F., \& Salim, J., 1980. Reavaliação dos conceitos estratigráficos na região do Seridó (RN-PB). Mineração e Metalurgia, Rio de Janeiro, v. 417, p. 16-28.

Jardim de Sá, E.F., Legrand, J.M., \& McReath, I., 1981. "Estratigrafia" de rochas granitóides na região do Seridó (RN-PB), com base em critérios estruturais. Revista Brasileira de Geociências, v. 11, p. 50-57.

Jardim de Sá, E.F., 1984. Geologia da região do Seridó: reavaliação de dados. Simpósio de Geologia do Nordeste, 11, Atas, p. 278-296.

Jardim de Sá, E.F., Macedo, M.H.F., Legrand, J.M., McReath, I., Galindo, A.C., \& Sá, J.M., 1987. Proterozoic granitoids in a polycyclic setting: the Seridó Region, NE Brazil. Intern. Symp. Granites Assoc. Mineraliz., Extended Abstracts, p. 103-110.

Jardim de Sá, E.F., 1994. A Faixa Seridó (Província Borborema, NE do Brasil) na Cadeia Brasiliana/Pan-Africana. Instituto de Geociências. Universidade de Brasília. Tese de 
Doutorado, $803 \mathrm{p}$.

Jardim de Sá, E.F., 1995. A faixa Seridó (Província Borborema, NE do Brasil) e o seu significado geodinâmico na Cadeia Brasiliano/Pan-Africana. In: Simpósio de Geologia do Nordeste, 16, Recife, Atas, Sociedade Brasileira de Geologia, Núcleo Nordeste (Boi. 14, v. 2), p. 394-398.

Jardim de Sá, E.F., Fuck, R.A., Macedo, M.H.F., Peucat, J.J., Kawashita, K., Souza, Z.S., \& Bertrand, J.M., 1995. Pré-brasiliano orogenic evolution in the Seridó Belt, NE Brazil: conflicting geochronological and structural data. Revista Brasileira de Geociências, v. 25 (4), p. 307-314.

Köppel V., \& Sommerauer J., 1974. Trace elements and the behaviour of the U-Pb system in inherited and newly formed zircons. Contribution Mineral Petrology, v. 43, p. 71-82. Kozuch, M., 2003. Isotopic and trace element geochemistry of early Neoproterozoic gneissic and metavolcanic rocks in the Cariris Velhos Orogen of Borborema Province, Brazil, and their bearing on tectonic setting. Tese (Doutorado), University of Kansas, $199 \mathrm{p}$.

Legrand, J.M., Liegeois, J.P., \& Deutsch, S., 1991. Datação U/Pb e Rb/Sr de Rochas Precambrianas da Região de Caicó. Reavaliação da Definição de um Embasamento Arqueano. In: XIV Simpósio de Geologia do Nordeste, Recife. Sociedade Brasileira de Geologia, Anais, p. 276-279.

Loios, V.A.P., 2009. Métodos de Preparação e Separação de Minerais no CPGeo -IGCUSP. Simpósio 45 Anos de Geocronologia no Brasil, Boletim de Resumos Expandidos.

Ludwig, K.R., 2003. Isoplot 3.00: A Geocrhronological Toolkit for Microsoft Excel ${ }^{\circledast}$ (Revised version). Berkeley Geochronological Center, Special Publ. 4, Berkeley, California, $70 p$.

Macedo, M.H.F., Jardim de Sá, E.F., \& Sá, J.M., 1984. Datações Rb-Sr em ortognaisses e a idade do Grupo Seridó. Simpósio de Geologia do Nordeste, 11, Atas, p. 253-262.

Mass, M.V.R., Oliveira C.G., Pires, A.C.B., \& Moraes, R.A,V., 2003. Aplicação da geofísica da geofísica aérea na Exploração Mineral e Mapeamento Geológico do setor sudoeste do Cinturão cuprifero Orós-Jaguaribe. Revista Brasileira de Geociências, $33(3), 279-288$.

Medeiros, V.C., 2004. Evolução geodinâmica e condicionamento estrutural dos terrenos Piancó-Alto Brígida e Alto Pajeú, Domínio da Zona Transversal, NE do Brasil, Natal. Tese de Doutorado, PPGG/UFRN, $200 \mathrm{p}$.

Medeiros, V.C., Amaral, C.A., Rocha, D.E.G.A., \& Santos, R.B., 2008. Geologia e Recursos Minerais da Folha Sousa SB.24-X-A. Escala 1:250.000. Estados da Paraíba, Rio Grande do Norte e Ceará. Recife, CPRM -Serviço Geológico do Brasil, 
2008. 312p il. + mapas.

Nasdala, L., Zhang, M., Kempe, U., Panezer, G., Gaft, M., Andrut, M., \& Plötze, M., 2003. Spectroscopic Methods Applied to Zircon. In: Hanchar, J.M., Hoskin, P.W.O. Zircon. Review in Mineralogy and Geochemistry, v. 53, p. 426-466.

Parente, C.V., 1984. Geologia da mineralização de cobre de Mandacaru-PI. Brasilia, Instituto de Geociências, UnB, Dissertação de Mestrado, 203 p.

Parente, C.V., Arthaud, M.H., \& de Oliveira, F.V.C., 1990. Geologia da bacia eopaleozoica de lara-CE. Revista de Geologia, v.3, p. $29-39$.

Petronilho, L.A., 2009. Método Sm-Nd no CPGeo-IGC-USP: Procedimentos Analíticos Atualmente em Rotina. Simpósio 45 Anos de Geocronologia no Brasil, Boletim de Resumos Expandidos.

Ponte, F.C., \& Appi, C.J., 1990. Proposta de revisão da coluna litoestratigráfica da Bacia do Araripe. In: Congresso Brasileiro de Geologia, 36, Natal, Anais, Sociedade Brasileira de Geologia, v. 1, p. 211-226.

Ponte F.C., Hashimoto, \& A.T., Dino, R. (Coords.), 1991. Geologia das bacias sedimentares mesozóicas do interior do Nordeste do Brasil. Rio de Janeiro: PETROBRAS/CENPES/DIVEX/SEBIPE, $278 \mathrm{p}$.

Prado, F. da S., Oliveira, A.A. de, Leite, E.A., Gomes, F.E.M., \& Colares, J.Q. dos S., 1980. Projeto Lavras da Mangabeira: Mapa geológico integrado. Escala 1:200.000. Fortaleza, DNPM/CPRM, 2v.

Prado, E.S, Mendona, J.C.G., Moraes, J.B.A., Nedeiros, M.F., Andrade, P.R.S. \& Medeiros, R.P. 1981. Projeto Martinópole. DNPM/CPRM, Relatório Final, v. 5.

Santos, E.J. dos, \& Brito Neves, B.B., 1984. Província Borborema. In: Almeida, F.F.M. de, Hasui, Y. O pré-cambriano do Brasil. São Paulo: Edgard Blucher, Cap.5, p. 123 -186.

Santos, E.J., Coutinho, M.G.N., Costa, M.P.A., \& Ramalho, R., 1984. A Região de Dobramentos Nordeste e a Bacia do Parnaiba, incluindo o Cratón de São Luis e as Bacias Marginais. In: Geologia do Brasil, eds. Schobbenchaus, C., Campos, D.A., Derze, G.R., Asmus, H.E., p. 131-189. Ministério das Minas e Energia-Departamento Nacional da Produção Mineral.

Santos, E.J., 1996. Ensaio preliminar sobre Terrenos e Tectónica Acrescionária na Província Borborema. In: Congresso Brasileiro de Geologia, 39, Salvador, 6, p. 4750.

Santos, E.J. dos, Oliveira, R.G., \& Paiva, I.P., 1997. Terrenos no Domínio Transversal da Província Borborema: controles sobre acresção e retrabalhamento crustais ao sul do Lineamento Patos. In: Simpósio de Geologia do Nordeste, 17, Fortaleza, Boletim 15, p. 141-144.

Santos, E.J., Brito Neves, B.B., Van Schmus, W.R., Oliveira, R.G., \& Medeiros, V.C., 
2000. An overall view on the displaced terrane arrangement of the Borborema Province, NE-Brazil. In: 31st International Geological Congress, 2000, Rio de Janeiro. Proceedings, in CD-Rom.

Sato, K., Siga Jr O., Sproesser, W., \& Onoe, A.T., 2009. Excimer Laser (193 クm) acoplado ao ICP-MS Neptune: primeiros resultados de análises isotópicas "In situ" de $\mathrm{U}, \mathrm{Pb}$, Lu e Hf em zircão, monazita e xenotima no CPGeo-IGc-USP. Simpósio 45 Anos de Geocronologia no Brasil, São Paulo, Boletim de Resumos Expandidos, p. 131-133

Sato, K., Tassinari, C.C.G., Kawashita, K., \& Petronitho, L., 1995. O Método Geocronológico Sm-Nd no IG/USP e suas Aplicações. Anais Academia Brasileira de Ciências, v. 67, p. 315-336.

Silva, L.C., McNaughton N., Vasconcelos, A.M., Gomes, J.R.C., \& Fletcher, I.R.C., 1997. U-Pb SHIMP ages in the southern State of Ceará, Borborema Province, NE Brazil: Archean TTG accretion and Proterozoic crustal reworking. In: International Symposium on Granites and Associated Mineralizations - ISGAM, 2, Salvador. Extended Abstract and Program, p. 280-281.

Souza, Z.S., 1991. Petrogénese des metagranitoides du Complexe de Caicó, Province Borborema (Etat du Rio Grande do Norte, Brésil), Mém. DESS, Inst, Géol., Univ. Rennes I, $87 \mathrm{p}$.

Souza, Z.S., Martin, H., Macedo, M.H.F., Peucat, J.J., \& Jardim de Sá, E.F., 1993. Um segment de croute continentale juvenile dáge protérozoique inferieur Du Complexe Caicó (Rio Grande do Norte, NR Brésil), Comptes Rendu Académie Sciences, Paris, T. Ill 316, p. 201-208.

Souza, Z.S., Martin, H., Peucat, J.J., Jardim de Sá, E.F., \& Macedo, M.H.F., 2007. Calcalkaline magmatism at the Archean-Proterozoic transition: the Caicó complex basement (NE Brazil). Journal of Petrology, v. 48, p. 2149-2185.

Stacey, J.S.\& Kramers, J.D., 1975. Approximation of terrestrial lead isotope evolution by a two-stage model. Earth and Planetary Science Letters, v. 26, p. 207-221.

Teixeira, A.L., Gaucher, C., Paim, P.S.G., Fonseca, M.M., Parente, C.V., Silva Filho, W.F., \& Almeida, A.R., 2004. Bacias do estágio de transição da Plataforma Sul-Americana. In: Mantesso-Neto, V., Bartorella, A., Carneiro, C.D.R., Brito Neves, B.B. (Orgs). Geologia do Continente Sul-Americano. Evolução da Obra De Fernando Flávio Marques de Almeida. São Paulo, Beca, Cap. 29, p. 487-536.

Van Schmus, W.R., Brito Neves, B.B., Hackspacher, P., \& Babinski, M., 1995. U/Pb and $\mathrm{Sm} / \mathrm{Nd}$ geochronologic studies of eastern Borborema Province, Northeastern Brazil: initial conclusions. Journal of South American Earth Sciences, v. 8 (3/4), p. 267-288.

Van Schmus, W.R., Brito Neves, B.B., Williams, I.S., Hackspacher, P., Ferrer, A.H., Dantas, E.L, \& Babinski,M., 2003. The Seridó group of the NE Brazil, a late 
Neoproterozoic pre-to syn- collisional basin in West Gondwana: insights from SHRIMP U-Pb detritical zircon ages and Sm-Nd crustal residence (Tdm) ages. Precambriam Research, v. 127, p. 287-327.

Van Schmus, W.R., Kozuch, M., \& Brito Neves, B.B. de, 2011. Precambrain history of the Zona Transversal of the Borborema Province, NE Brazil: Insights from Sm-Nd and U-Pb geochronology. Journal of South America Earth Sciences, v. 31, p. 227-252.

Vasconcelos, A.M., Gomes, I.P., \& Moura, C.A.V., 1997. Caracterização dos ortognaisses calcialcalinos da região de Granjeiro-sul do Estado do Ceará-Brasil. In: Simpósio de Geologia do Nordeste, 17, Fortaleza, Resumos Expandidos, Bol. 15, p. 137-138.

Vasconcelos, A. M., Prado, F.S., \& Gomes, E.M., 1998. Programa Levantamentos Geológicos Básicos do Brasil. Iguatu. Folha SB.24-Y-B. Estado do Ceará. Escala 1: 250.000. Geologia e Metalogênese. Brasília. CPRM, 148 p, 2 mapas.

Vauchez, A., Neves, S., Caby, R., Corsini, M., Egydio-Silva, M. Arthaud, M., \& Amaro, V., 1995. The Borborema shear zone systems, NE Brazil. Journal of South American Earth Sciences, v. 8, p. 247-266.

Vauchez, A., \& outros 11., 1991. The continental scale shear zones system of NE Brazil, an example of Panafrican intraplate tectonics. In: International Conference on Circum-Pacific Terranes, 4, Resumos Expandidos, Santiago, Universidad de Chile, v. 42, p. 233-237.

Wetherrill, G.W., 1956. Discordant uranium lead ages,I. Transactions, American Geophysical Union, v.37 (3), p. 320-326. 
ANEXO 1 
TABELA.2 RESULTADOS METODO ISOTOPICO SM-Nd

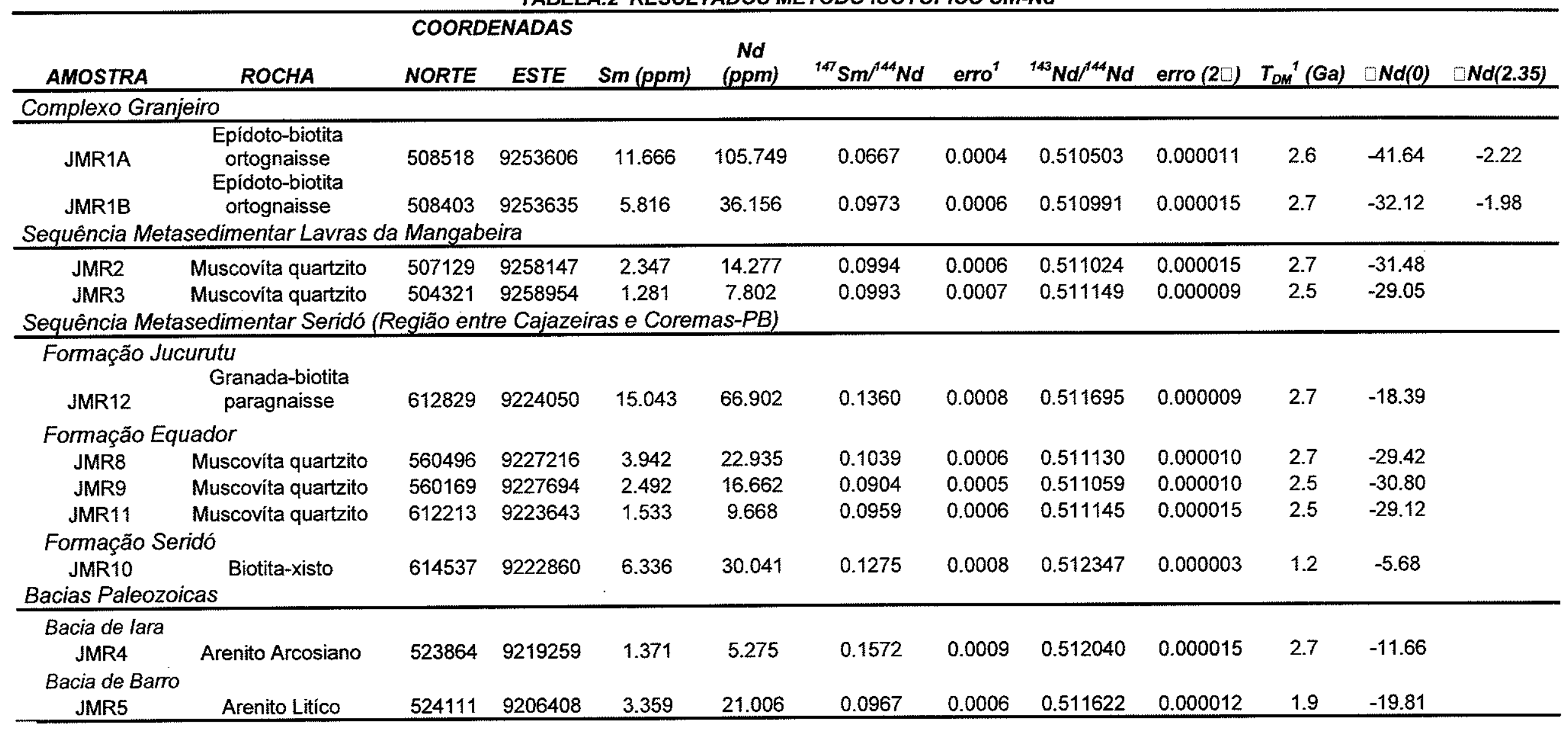

Tabela 2. Resultados isotópicos $\mathrm{Sm} / \mathrm{Nd}$ para amostras das sequências metasedimentares estudadas. 
ANEXO 2 


\section{Tabela 3- DADOS U/Pb in situ (MC) LA-ICPMS.}

Notas: As letras $\mathrm{C}=$ Centro (Setor com sobrecrescimento Igneo); $\mathrm{B} \times$ Borda. Indicam o local no grăo onde fol felta a analise. tho a coeficlente de correlaçáo

conc = porcentagem de concordancla entre as razoes ${ }^{207} \mathrm{~Pb}^{235} \mathrm{U}$ a ${ }^{206} \mathrm{~Pb} /{ }^{231} \mathrm{U}$

a Indlca aqueles anslisés concordantes com recristalizactoo ao redor de $576 \mathrm{Ma}$.

\begin{tabular}{|c|c|c|c|c|c|c|c|c|c|c|c|}
\hline \multirow[b]{2}{*}{ Spot } & \multirow[b]{2}{*}{ Local } & \multicolumn{4}{|c|}{ Razoes } & \multirow[b]{2}{*}{$p$} & \multirow[b]{2}{*}{ conc. } & \multicolumn{4}{|c|}{ Idades } \\
\hline & & ${ }^{207} \mathrm{~Pb} /{ }^{238} \mathrm{U}$ & $\pm 1 \sigma$ & ${ }^{206} \mathrm{~Pb}{ }^{238} \mathrm{U}$ & $\pm 1 \sigma$ & & & ${ }^{208} \mathrm{~Pb} /{ }^{230} \mathrm{U} \pm 10$ & ${ }^{207} \mathrm{~Pb} /{ }^{236} \mathrm{U} \pm 10$ & $\left.{ }^{207} \mathrm{~Pb}\right|^{208} \mathrm{~Pb} \pm 10$ & ${ }^{208} \mathrm{~Pb} / 232 \mathrm{Th} \pm 10$ \\
\hline 1.1 & c & 16,276 & 0.412 & 0.510 & 0.005 & 0.992 & $93.60 \%$ & $2656+22$ & $2832 \pm 26$ & $2960 \pm 20$ & $2465 \pm 41$ \\
\hline 2.1 & c & 19,790 & 0.527 & 0.597 & 0.006 & 0.977 & $97.90 \%$ & $3015 \pm 24$ & $3081 \pm 27$ & $3124 \pm 104$ & $2507 \pm 33$ \\
\hline 3.1 & c & 19,823 & 0.536 & 0.593 & 0.006 & 0.948 & $97.40 \%$ & $3002 \pm 25$ & $3082 \pm 27$ & $3135 \pm 107$ & $2575 \pm 35$ \\
\hline 4.1 & c & 16,119 & 0.415 & 0.515 & 0.005 & 0.992 & $92.60 \%$ & $2678 \pm 22$ & $2883 \pm 26$ & $3030 \pm 172$ & $2263 \pm 26$ \\
\hline 4.2 & $c$ & 6,148 & 0.171 & 0.254 & 0.003 & 0.980 & $68.80 \%$ & $1457 \pm 13$ & $1997 \pm 24$ & $2613 \pm 79$ & $349 \pm 11$ \\
\hline 5.1 & c & 15,371 & 0.421 & 0.504 & 0.006 & 0.912 & $92.50 \%$ & $2632 \pm 23$ & $2838 \pm 26$ & $2987 \pm 25$ & $2\{18 \pm 33$ \\
\hline 6.1 & c & 17,303 & 0.499 & 0.540 & 0,006 & 0.957 & $94.20 \%$ & $2785 \pm 25$ & $2951 \pm 26$ & $3067 \pm 16$ & $2547 \pm 35$ \\
\hline 6.2 & c & 17,316 & 0.419 & 0.562 & 0.006 & 0.999 & $97.40 \%$ & $2568 \pm 22$ & $2824 \pm 25$ & $3012 \pm 90$ & $2169 \pm 26$ \\
\hline 7.1 & C & 18,468 & 0.425 & 0.578 & 0,005 & 0.994 & $95.80 \%$ & $2876 \pm 23$ & $2952 \pm 25$ & $3004 \pm 103$ & $2956 \pm 52$ \\
\hline 8.1 & c & 13,280 & 0.340 & 0.444 & 0.005 & 0.993 & $87.00 \%$ & $2938 \pm 22$ & $3065 \pm 26$ & $3149 \pm 126$ & $2562 \pm 38$ \\
\hline 9.1 & c & 16,006 & 0.402 & 0.503 & 0.005 & 0.998 & $90.90 \%$ & $2370 \pm 20$ & $2699 \pm 25$ & $2956 \pm 49$ & $2262 \pm 46$ \\
\hline 10.1 & $\mathrm{c}$ & 18,155 & 0.489 & 0.561 & 0.006 & 0.902 & $95.70 \%$ & $2627 \pm 21$ & $2877 \pm 25$ & $3056 \pm 117$ & $2369 \pm 23$ \\
\hline 11.1 & C & 15,144 & 0.414 & 0.489 & 0.005 & 0.985 & $90.50 \%$ & $2872+25$ & $2998 \pm 26$ & $3083 \pm 42$ & $2741 \pm 56$ \\
\hline
\end{tabular}

4.3.1.2. Amostra JMR 1A: "Ortognalisse" grăos de zircáo lgneo

\begin{tabular}{|c|c|c|c|c|c|c|c|c|c|c|c|}
\hline \multirow[b]{2}{*}{ Spot } & \multirow[b]{2}{*}{ Local } & \multicolumn{4}{|c|}{ Razoes } & \multirow[b]{2}{*}{$p}$. & \multirow[b]{2}{*}{ conc. } & \multicolumn{4}{|c|}{ Idades } \\
\hline & & ${ }^{207} \mathrm{~Pb} /{ }^{235} \mathrm{U}$ & $\pm 1 \sigma$ & $\left.{ }^{206} \mathrm{~Pb}\right|^{2 \mathrm{sB}} \mathrm{U}$ & \pm 10 & & & ${ }^{208} \mathrm{~Pb} /{ }^{23 \mathrm{\theta}} \mathrm{U} \pm 1 \sigma$ & ${ }^{207} \mathrm{~Pb} /{ }^{235} \mathrm{U} \pm 1 \sigma$ & ${ }^{207} \mathrm{pb}{ }^{206} \mathrm{~Pb} \pm 10$ & ${ }^{208} \mathrm{~Pb} /{ }^{232} \mathrm{Tht} \pm 1 \mathrm{~g}$ \\
\hline 1.1 & c & 8.849 & 0.212 & 0.428 & 0.006 & 0.767 & $98.80 \%$ & $2295 \pm 28$ & $2322 \pm 21$ & $2346 \pm 21$ & $2556 \pm 95$ \\
\hline 2.1 & c & 4,379 & 0.105 & 0.240 & 0.003 & 0.999 & $79.20 \%$ & $1386 \pm 16$ & $1708 \pm 18$ & $2129 \pm 190$ & $2077 \pm 67$ \\
\hline 3.1 & C & 8,670 & 0.228 & 0.423 & 0.007 & 0.572 & $98.70 \%$ & $2274 \pm 31$ & $2303 \pm 23$ & $2330 \neq 29$ & $2655 \pm 130$ \\
\hline 4.1 & $c$ & 8,867 & 0.247 & 0.429 & 0,008 & 0.727 & $98.90 \%$ & $2299 \pm 33$ & $2324 \pm 25$ & $2346 \pm 27$ & $2831 \pm 125$ \\
\hline 5.1 & c & 8,821 & 0.205 & 0.427 & 0.006 & 0.861 & $98.70 \%$ & $2289 \pm 27$ & $2319 \pm 21$ & $2345 \pm 18$ & $2752 \pm 79$ \\
\hline 6.1 & $c$ & 8,665 & 0.213 & 0.418 & 0.006 & 0.677 & $97.80 \%$ & $2252 \pm 28$ & $2303 \pm 22$ & $2348 \pm 22$ & $2751 \pm 110$ \\
\hline 7.1 & $c$ & 8,767 & 0.212 & 0.428 & 0.006 & 0.613 & $99.20 \%$ & $2296+28$ & $2314 \pm 22$ & $2329 \pm 28$ & $2664 \pm 68$ \\
\hline 8.1 & c & 8,725 & 0.197 & 0.420 & 0.006 & 0.849 & $97.80 \%$ & $2259 \pm 26$ & $2309 \pm 20$ & $2354 \pm 17$ & $2763 \pm 74$ \\
\hline 9.1 & c & 8,720 & 0.187 & 0.424 & 0.006 & 0.869 & $98.60 \%$ & $2277 \pm 24$ & $2309 \pm 19$ & $2337 \pm 14$ & $2766 \pm 72$ \\
\hline 10.1 & c & 8.870 & 0.196 & 0.429 & 0.006 & 0.849 & $98.90 \%$ & $2298 \pm 26$ & $2324 \pm 20$ & $2347 \pm 12$ & $2890 \pm 78$ \\
\hline 11.1 & c & 8,939 & 0.218 & 0.430 & 0.007 & 0.770 & $98.80 \%$ & $2303 \pm 29$ & $2331 \pm 22$ & $2356 \pm 20$ & $2857 \pm 108$ \\
\hline 12.1 & c & 8,970 & 0.271 & 0,435 & 0.008 & 0.533 & $99.80 \%$ & $2329 \pm 37$ & $2334 \pm 27$ & $2339 \pm 38$ & $2747 \pm 168$ \\
\hline 13.1 & c & 8,514 & 0.235 & 0.414 & 0.007 & 0.552 & $97,50 \%$ & $2230 \pm 32$ & $2287 \pm 25$ & $2338 \pm 24$ & $2610 \pm 156$ \\
\hline 14.1 & c & 8,720 & 0.199 & 0.423 & 0.006 & 0.536 & $98.40 \%$ & $2273 \pm 24$ & $2309 \pm 20$ & $2341 \pm 25$ & $2414 \pm 142$ \\
\hline 15.1 & c & 8,949 & 0.190 & 0.432 & 0.005 & 0.869 & $99.10 \%$ & $2312 \pm 23$ & $2332 \pm 19$ & $2350 \pm 18$ & $2579 \pm 123$ \\
\hline 16.1 & c & 9,024 & 0.218 & 0.434 & 0.006 & 0.706 & $99.20 \%$ & $2321 \pm 27$ & $2340 \pm 22$ & $2357 \pm 29$ & $2775 \pm 117$ \\
\hline 17.1 & c & 8,634 & 0.231 & 0.414 & 0.007 & 0.808 & $97.00 \%$ & $2233 \pm 29$ & $2300 \pm 24$ & $2360 \pm 23$ & $2500 \pm 160$ \\
\hline 18.1 & $c$ & 8,749 & 0.204 & 0.421 & 0.006 & 0.403 & $98.00 \%$ & $2265 \pm 25$ & $2312 \pm 21$ & $2353 \pm 23$ & $2926 \pm 117$ \\
\hline 19.1 & c & 8,883 & 0.213 & 0.428 & 0.006 & 0.726 & $98.70 \%$ & $2296 \pm 26$ & $2326 \pm 21$ & $2352 \pm 23$ & $2903 \pm 120$ \\
\hline 20.1 & c & 8,560 & 0.217 & 0.415 & 0.006 & 0.622 & $97,60 \%$ & $2237 \pm 27$ & $2292 \pm 23$ & $2341 \pm 23$ & $2874 \pm 168$ \\
\hline 21.1 & c & 8,657 & 0.204 & 0.418 & 0.006 & 0.358 & $97.80 \%$ & $2252 \pm 25$ & $2302 \pm 21$ & $2347 \pm 20$ & $2784 \pm 147$ \\
\hline 22.1 & c & 8,846 & 0.190 & 0.428 & 0.005 & 0.255 & $98.80 \%$ & $2295 \pm 23$ & $2322 \pm 19$ & $2346 \pm 21$ & $2697 \pm 134$ \\
\hline 23.1 & C & 8,835 & 0.198 & 0.433 & 0.006 & 0.834 & $99.50 \%$ & $2320 \pm 24$ & $2331 \pm 20$ & $2340 \pm 22$ & $2894 \pm 139$ \\
\hline 24.1 & c & 8,954 & 0.170 & 0.431 & 0.005 & 0.863 & $99.10 \%$ & $2311 \pm 21$ & $2333 \pm 17$ & $2352 \pm 11$ & $2840 \pm 86$ \\
\hline 25.1 & c & 9,099 & 0.184 & 0.439 & 0.005 & 0.824 & $99.80 \%$ & $2343 \pm 22$ & $2348 \pm 18$ & $2351 \pm 15$ & $2879 \pm 105$ \\
\hline 26.7 & $\mathrm{C}$ & 8,877 & 0.226 & 0.428 & 0.006 & 0.770 & $98.70 \%$ & $2294 \pm 28$ & $2325 \pm 23$ & $2352 \pm 26$ & $2884 \pm 176$ \\
\hline
\end{tabular}




\begin{tabular}{|c|c|c|c|c|c|c|c|c|c|c|c|}
\hline Spot & Loca! & ${ }^{207} \mathrm{~Pb} /{ }^{208} \mathrm{U}$ & \pm 10 & ${ }^{206} \mathrm{~Pb} / f^{238} \mathrm{U}$ & $\pm 1 \sigma$ & $\rho$ & conc. & ${ }^{208} \mathrm{~Pb} /{ }^{23 \mathrm{a}} \mathrm{U} \pm 1 \mathrm{O}$ & ${ }^{207} \mathrm{pb} f^{235} \mathrm{U} \pm 10$ & ${ }^{207} \mathrm{~Pb}^{206} \mathrm{~Pb}_{\mathrm{b} \pm 10}$ & ${ }^{208} \mathrm{~Pb} /{ }^{252} \mathrm{Th} \pm 10$ \\
\hline 1.1 & $\mathrm{c}$ & 13,606 & 0.341 & 0.489 & 0.006 & 0.832 & $94.00 \%$ & $2564 \pm 24$ & $2722 \pm 24$ & $2842 \pm 82$ & $2762 \pm 46$ \\
\hline 1.2 & C & 14,551 & 0.332 & 0.517 & 0.006 & 0.997 & $78.00 \%$ & $810 \pm 9$ & $1010 \pm 18$ & $1474 \pm 139$ & $459 \pm 11$ \\
\hline 2.1 & C & 1,706 & 0.048 & 0.134 & 0.002 & 0.988 & $87.30 \%$ & $2199 \pm 24$ & $2259 \pm 26$ & $2313 \pm 33$ & $2182 \pm 77$ \\
\hline 3.1 & $c$ & 8,253 & 0.237 & 0.407 & 0.005 & 0.969 & $80.10 \%$ & $1875 \pm 19$ & $2290 \pm 24$ & $2684 \pm 126$ & $1736 \pm 38$ \\
\hline 4.1 & c & 8.540 & 0.243 & 0.338 & 0.004 & 0.999 & $81,60 \%$ & $1897 \pm 18$ & $2282 \pm 22$ & $2647 \pm 163$ & $1871 \pm 34$ \\
\hline 5.1 & C & 8,470 & 0.207 & 0.342 & 0.004 & 0.997 & $81.20 \%$ & $1671+16$ & $2019 \pm 22$ & $2395 \pm 120$ & $801 \pm 28$ \\
\hline 6.1 & c & 6,305 & 0.154 & 0.296 & 0.003 & 0.993 & $71.90 \%$ & $1217 \pm 12$ & $1615 \pm 21$ & $2181 \pm 196$ & $688 \pm 21$ \\
\hline 7.1 & $\mathrm{c}$ & 3,909 & 0.103 & 0.208 & 0.002 & 0.993 & $95.70 \%$ & $2159 \pm 23$ & $2254 \pm 25$ & $2341 \pm 34$ & $2317 \pm 57$ \\
\hline 8.1 & B & 8,208 & 0.228 & 0.398 & 0.005 & 0.994 & $85.60 \%$ & $1671 \pm 20$ & $1931 \pm 28$ & $2222 \pm 55$ & $1853 \pm 105$ \\
\hline 9.1 & B & 5,698 & 0.176 & 0.296 & 0.004 & 0.995 & $78.70 \%$ & $1380 \pm 15$ & $1709 \pm 22$ & $2141 \pm 93$ & $910 \pm 43$ \\
\hline 9.2 & C & 13,533 & 0.347 & 0.489 & 0.006 & 0.964 & $94.20 \%$ & $2564 \approx 24$ & $2717 \pm 24$ & $2833 \pm 12$ & $2868 \pm 50$ \\
\hline 10.1 & B & 4,386 & 0.122 & 0.239 & 0.003 & 0.979 & $79.90 \%$ & $1839 \pm 14$ & $2251 \pm 22$ & $2649 \pm 485$ & $1615 \pm 31$ \\
\hline$\$ 1.1$ & $\mathrm{C}$ & 8,180 & 0.143 & 0.330 & 0.003 & 0.999 & $96.40 \%$ & $2687 \pm 23$ & $2786+23$ & $2858 \pm 36$ & $2605 \pm 38$ \\
\hline
\end{tabular}

4.3.2 SEQUÉNCIA METASEDIMENTAR LAVRAS DA MANGABEIRA.

4.3.2.1. Amostra JMR 3: "Metaconglomerado" grăos de zirço detritico.

\begin{tabular}{|c|c|c|c|c|c|c|c|c|c|c|c|}
\hline \multirow[b]{2}{*}{ Spot } & \multirow[b]{2}{*}{ Local } & \multicolumn{4}{|c|}{ Razoes } & \multirow[b]{2}{*}{$\rho$} & \multirow[b]{2}{*}{ conc. } & \multicolumn{4}{|c|}{ Idades } \\
\hline & & $\left.{ }^{207} \mathrm{~Pb}\right|^{255} \mathrm{U}$ & \pm 10 & ${ }^{2010} \mathrm{~Pb} /{ }^{2039} \mathrm{U}$ & \pm 10 & & & ${ }^{208} \mathrm{~Pb} /{ }^{238} \mathrm{U} \pm 1 \sigma$ & ${ }^{207} \mathrm{~Pb} /{ }^{233} \mathrm{U} \pm 1 \sigma$ & ${ }^{207} \mathrm{~Pb}^{208} \mathrm{~Pb}^{2} 1 \mathrm{a}$ & $\left.{ }^{209} \mathrm{pb}\right|^{232} \mathrm{Th} \neq 1 \sigma$ \\
\hline 1.1 & C & 10,260 & 0.199 & 0.45 & 0.005 & 0.718 & $97.50 \%$ & $2396 \pm 19$ & $2458 \pm 17$ & $2510 \pm 13$ & $3589 \pm 76$ \\
\hline 2.1 & C & 12,376 & 0.250 & 0.482 & 0.005 & 0.672 & $96.20 \%$ & $2535 \pm 22$ & $2633 \pm 18$ & $2709 \pm 39$ & $3781 \pm 84$ \\
\hline 3.1 & C & 10,035 & 0.190 & 0.448 & 0.004 & 0.977 & $97.80 \%$ & $2385 \pm 18$ & $2438 \pm 17$ & $2482 \pm 15$ & $3663 \pm 67$ \\
\hline 4.1 & C & 9,685 & 0.196 & 0.373 & 0.004 & 0.995 & $83.80 \%$ & $2043 \pm 19$ & $2405 \pm 18$ & $2727 \pm 56$ & $3187 \pm 66$ \\
\hline 5.1 & C & 5,993 & 0.118 & 0.311 & 0.003 & 0.998 & $87.60 \%$ & $1743 \pm 14$ & $1974 \pm 16$ & $2226 \pm 27$ & $2454 \pm 55$ \\
\hline 6.1 & C & 7,415 & 0.138 & 0.371 & 0.003 & 0.974 & $93.80 \%$ & $2032 \pm 15$ & $2162 \pm 16$ & $2288 \pm 18$ & $3166 \pm 60$ \\
\hline 7.1 & $c$ & 9,542 & 0.188 & 0.424 & 0.004 & 0.756 & $95.20 \%$ & $2280 \pm 19$ & $2391 \pm 18$ & $2487 \pm 15$ & $3412 \pm 87$ \\
\hline 8.1 & $\mathrm{c}$ & 8,615 & 0.191 & 0.415 & 0.005 & 0.708 & $97.40 \%$ & $2239 \pm 22$ & $2298 \pm 19$ & $2350 \pm 26$ & $3308 \pm 100$ \\
\hline 9.1 & $\mathrm{C}$ & 9.189 & 0.187 & 0.353 & 0.004 & 0.994 & $80.90 \%$ & $1946 \pm\{7$ & $2357 \pm 17$ & $2734 \pm 48$ & $3259 \pm 58$ \\
\hline 10.1 & c & 8,819 & 0.162 & 0.414 & 0.004 & 0.828 & $96.20 \%$ & $2231 \pm 17$ & $2319 \pm 16$ & $2397 \pm 17$ & $2727 \pm 206$ \\
\hline 11.1 & $c$ & 10,348 & 0.215 & 0.454 & 0.005 & 0.620 & $97.80 \%$ & $2412 \pm 22$ & $2466 \pm 19$ & $2511 \pm 21$ & $3723 \pm 117$ \\
\hline 12.1 & C & 10,219 & 0.188 & 0.458 & 0.004 & 0.500 & $99.10 \%$ & $2432 \pm 18$ & $2454 \pm 17$ & $2473 \pm 13$ & $3695 \pm 61$ \\
\hline 13.1 & $\mathrm{c}$ & 6,568 & 0.126 & 0,339 & 0,003 & 0.996 & $91,20 \%$ & $1881 \pm 15$ & $2055 \pm 16$ & $2234 \pm 25$ & $2900 \pm 71$ \\
\hline 14.1 & $c$ & 10,363 & 0,301 & 0.453 & 0.007 & 0.345 & $97.50 \%$ & $2407 \pm 31$ & $2467 \pm 26$ & $2517 \pm 27$ & $3328 \pm 263$ \\
\hline 15.1 & C & 7,901 & 0.181 & 0.404 & 0.005 & 0.408 & $98.40 \%$ & $2184 \pm 22$ & $2219 \pm 20$ & $2252 \pm 16$ & $3048 \neq 113$ \\
\hline 16.1 & $\mathrm{C}$ & 7,826 & 0.166 & 0.401 & 0.005 & 0.914 & $98.20 \%$ & $2172 \pm 20$ & $2211 \pm 19$ & $2247 \pm 13$ & $3164 \pm 93$ \\
\hline$\$ 7.1$ & C & 8,797 & 0.215 & 0.423 & 0.006 & 0.078 & $98.00 \%$ & $2272 \pm 24$ & $2317 \pm 22$ & $2356 \pm 29$ & $2994 \pm 146$ \\
\hline 18.1 & C & 10,736 & 0.294 & 0.453 & 0.007 & 0.973 & $96.20 \%$ & $2407 \pm 29$ & $2500 \pm 23$ & $2577 \pm 30$ & $3252 \pm 243$ \\
\hline 19.1 & C & 10,466 & 0.262 & 0.447 & 0.006 & 0.945 & $96.00 \%$ & $2380 \pm 27$ & $2476 \pm 23$ & $2556 \pm 37$ & $3238 \pm 268$ \\
\hline 20.1 & B & 8,621 & 0.314 & 0.412 & 0.008 & 0.667 & $96.80 \%$ & $2225 \pm 35$ & $2298 \pm 33$ & $2364 \pm 53$ & $2254 \pm 1268$ \\
\hline 21 & $c$ & 10,377 & 0.240 & 0,456 & 0.006 & 0.415 & $98.00 \%$ & $2419 \pm 25$ & $2469 \pm 21$ & $2509 \pm 21$ & $3502 \pm 199$ \\
\hline 22.1 & c & 9,733 & 0.190 & 0.437 & 0.005 & 0.896 & $97.00 \%$ & $2338 \pm 20$ & $2409 \pm 18$ & $2470 \pm 15$ & $3330 \pm 89$ \\
\hline 23.1 & $c$ & 12,994 & 0.303 & 0.503 & 0.007 & 0.900 & $98.00 \%$ & $2626 \pm 28$ & $2678 \pm 22$ & $2719 \pm 24$ & $3649 \pm 167$ \\
\hline 24.1 & $c$ & 8,676 & 0.169 & 0.391 & 0.004 & 0.600 & $92.10 \%$ & $2129 \pm 18$ & $2304 \pm 17$ & $2463 \pm 26$ & $2010 \pm 27$ \\
\hline 25.1 & $c$ & 11.528 & 0.223 & 0.466 & 0.005 & 0.740 & $96.00 \%$ & $2466 \pm 20$ & $2566 \pm 18$ & $2646 \pm 76$ & $2235 \pm 27$ \\
\hline 26.1 & $c$ & 10,192 & 0.198 & 0.450 & 0.005 & 0.997 & $97.60 \%$ & $2395 \pm 20$ & $2452 \pm 18$ & $2500 \pm 28$ & $2412 \pm 41$ \\
\hline 27.1 & $\mathrm{C}$ & 8.713 & 0.178 & 0.418 & 0.005 & 0.001 & $97.50 \%$ & $2251+20$ & $2308 \pm 18$ & $2359 \pm 23$ & $2267 \pm 30$ \\
\hline 28.1 & $\mathrm{C}$ & 7.844 & 0.157 & 0.385 & 0.004 & 0.965 & $94.70 \%$ & $2099 \pm 18$ & $2213 \pm 18$ & $2320 \pm 17$ & $2103 \pm 34$ \\
\hline 29.7 & C & 23,665 & 0.463 & 0.636 & 0.007 & 0.552 & $87.40 \%$ & $3171 \pm 26$ & $3254 \pm 19$ & $3306 \pm 66$ & $3151+35$ \\
\hline 30.1 & c & 9,694 & 0.379 & 0.441 & 0.011 & 0.657 & $97.80 \%$ & $2353 \pm 50$ & $2406 \pm 35$ & $2451 \pm 63$ & $3179 \pm 1723$ \\
\hline 31.1 & $c$ & 10,182 & 0.221 & 0.452 & 0.005 & 0.235 & $98.00 \%$ & $2402 \pm 23$ & $2451 \pm 19$ & $2492 \pm 18$ & $2271 \pm 48$ \\
\hline 32.1 & $c$ & 10,256 & 0.212 & 0.453 & 0.005 & 0.989 & $97.90 \%$ & $2406 \pm 22$ & $2458 \pm 19$ & $2500 \pm 21$ & $2292 \pm 53$ \\
\hline 33,1 & 8 & 7,731 & 0.155 & 0.380 & 0.004 & 0.954 & $94.10 \%$ & $2074 \pm 18$ & $2200 \pm 18$ & $2319 \pm 33$ & $2062 \pm 77$ \\
\hline 34.1 & C & 10,041 & 0.201 & 0.450 & 0.005 & 0.827 & $98.30 \%$ & $2396 \pm 21$ & $2438 \pm 18$ & $2473 \pm 20$ & $2367 \pm 28$ \\
\hline 35.1 & C & 9,000 & 0.193 & 0.405 & 0.005 & 0.999 & $93.60 \%$ & $2192 \pm 22$ & $2338 \pm 20$ & $2467 \pm 93$ & $2211 \pm 56$ \\
\hline 35.2 & $c$ & 8,382 & 0.189 & 0.384 & 0.005 & 0.992 & $91.90 \%$ & $2095 \pm 22$ & $2273 \pm 20$ & $2436 \pm 37$ & $2254 \pm 58$ \\
\hline 36.1 & $\mathrm{C}$ & 8,158 & 0.165 & 0.418 & 0.005 & 0.945 & $100.20 \%$ & $2252 \pm 20$ & $2248 \pm 18$ & $2244 \pm 10$ & $2008 \pm 32$ \\
\hline
\end{tabular}




\begin{tabular}{|c|c|c|c|c|c|c|c|c|c|c|c|}
\hline 37.1 & C & 13,249 & 0.278 & 0.509 & 0.006 & 0.965 & $98.30 \%$ & $2652 \pm 25$ & $2697 \pm 19$ & $2731 \pm 20$ & $2427 \pm 46$ \\
\hline 38.1 & c & 8,188 & 0.175 & 0.418 & 0.005 & 0.968 & $99.90 \%$ & $2249 \pm 21$ & $2252 \pm 19$ & $2254 \pm 22$ & $2251 \pm 35$ \\
\hline 39,1 & B & 10,524 & 0.311 & 0.473 & 0.009 & 0.264 & $100.60 \%$ & $2495 \pm 38$ & $2482 \pm 27$ & $2470 \pm 38$ & $2245 \pm 5016$ \\
\hline 40.1 & c & 11,749 & 0.262 & 0.514 & 0.007 & 0.686 & $103.30 \%$ & $2671 \pm 27$ & $2584 \pm 20$ & $2516 \pm 14$ & $2285 \pm 79$ \\
\hline 41.1 & B & 9,061 & 0.171 & 0.419 & 0.004 & 0.999 & $96.10 \%$ & $2254 \pm 18$ & $2344 \pm 17$ & $2423 \pm 46$ & $879 \pm 44$ \\
\hline 42.1 & $\mathrm{c}$ & 6,854 & 0.136 & 0.388 & 0.004 & 0.953 & $101.00 \%$ & $2114 \pm 19$ & $2092 \pm 18$ & $2071 \pm 18$ & $2090 \pm 32$ \\
\hline 43.1 & $c$ & 8,396 & 0.170 & 0.430 & 0.005 & 0.704 & $101.40 \%$ & $2307 \pm 20$ & $2274 \pm 18$ & $2245 \pm 13$ & $2295 \pm 35$ \\
\hline 44.1 & $\mathrm{c}$ & 11,369 & 0.285 & 0.497 & 0.008 & 0.748 & $101.80 \%$ & $2600 \pm 32$ & $2553 \pm 23$ & $2517 \pm 22$ & $2235 \pm 128$ \\
\hline 45.1 & $c$ & 9,567 & 0.281 & 0.454 & 0.008 & 0.229 & $100.80 \%$ & $2413 \pm 36$ & $2394 \pm 26$ & $2377 \pm 48$ & $2194 \pm 133$ \\
\hline 46.1 & $c$ & 10,650 & 0.207 & 0.475 & 0.005 & 0.990 & $100.50 \%$ & $2505 \pm 21$ & $2493 \pm 18$ & $2483 \pm 12$ & $2412 \pm 42$ \\
\hline 47.1 & c & 14,343 & 0.284 & 0.553 & 0.006 & 0.921 & $102.30 \%$ & $2837 \pm 25$ & $2772 \pm 18$ & $2726 \pm 15$ & $2687 \pm 52$ \\
\hline 48.1 & $c$ & 11,214 & 0.293 & 0.491 & 0.008 & 0.831 & $101.40 \%$ & $2575 \pm 33$ & $2541 \pm 23$ & $2513 \pm 30$ & $2458 \pm 94$ \\
\hline 49.1 & $c$ & 8.171 & 0.168 & 0.416 & 0.004 & 0.870 & $99.70 \%$ & $2243 \pm 15$ & $2250 \pm 18$ & $2256 \pm 10$ & $2251 \pm 41$ \\
\hline 50.1 & $c$ & 10,734 & 0.224 & 0.471 & 0.004 & 0.900 & $99.50 \%$ & $2488 \pm 18$ & $2500 \pm 19$ & $2510 \pm 15$ & $2346 \pm 58$ \\
\hline 51.1 & $c$ & 10,649 & 0.194 & 0.478 & 0.004 & 0.995 & $101.00 \%$ & $2517 \pm 15$ & $2492 \pm 17$ & $2472 \pm 23$ & $2405 \pm 39$ \\
\hline 52.1 & $c$ & 13,604 & 0.255 & 0.521 & 0.004 & 0.890 & $99.20 \%$ & $2701 \pm 16$ & $2722 \pm 17$ & $2738 \pm 13$ & $2841 \pm 42$ \\
\hline 53.1 & $c$ & 9,513 & 0.298 & 0.441 & 0.007 & 0.270 & $98.50 \%$ & $2354 \pm 32$ & $2388 \pm 28$ & $2418 \pm 50$ & $2473 \pm 98$ \\
\hline 54.1 & $c$ & 9,724 & 0,196 & 0.445 & 0.004 & 0.972 & $98.40 \%$ & $2371 \pm 16$ & $2408 \pm 18$ & $2441 \pm 15$ & $7853 \pm 3469$ \\
\hline 55.1 & C & 10,673 & 0.272 & 0.468 & 0.006 & 0.001 & $99.20 \%$ & $2474 \pm 25$ & $2495 \pm 23$ & $2512 \pm 2 B$ & $2484 \pm 96$ \\
\hline 56.1 & C & 10,745 & 0.220 & 0.471 & 0.004 & 0.982 & $99.50 \%$ & $2487 \pm 18$ & $2501 \pm 19$ & $2512 \pm 12$ & $2405 \pm 53$ \\
\hline 57.1 & $c$ & $\$ 0,551$ & 0.197 & 0.470 & 0.003 & 0.836 & $100.00 \%$ & $2484 \pm 14$ & $2484 \pm 17$ & $2484 \pm 9$ & $2653 \pm 34$ \\
\hline 58.2 & $c$ & 8,998 & 0.223 & 0.412 & 0.005 & 0.892 & $85.10 \%$ & $2225 \pm 22$ & $2337 \pm 22$ & $2437 \pm 36$ & $1940 \pm 112$ \\
\hline 59.1 & $c$ & 9,090 & 0.191 & 0.436 & 0.004 & 0.136 & $99.50 \%$ & $2334 \pm 17$ & $2347 \pm 19$ & $2357 \pm 18$ & $2153 \pm 40$ \\
\hline 60.1 & c & 9,755 & 0.206 & 0.470 & 0.004 & 0.980 & $102.80 \%$ & $2481 \pm 19$ & $2411 \pm 19$ & $2353 \pm 13$ & $2319 \pm 37$ \\
\hline 61.1 & C & 8,339 & 0.171 & 0.422 & 0.004 & 0.846 & $100.10 \%$ & $2270 \pm 16$ & $2268+18$ & $2266 \pm 17$ & $1907 \pm 37$ \\
\hline & & \multicolumn{4}{|c|}{ Razoes } & & & \multicolumn{4}{|c|}{ Idades } \\
\hline Spot & Local & $\left.{ }^{207} \mathrm{~Pb}\right|^{238} \mathrm{U}$ & \pm 10 & ${ }^{208} \mathrm{~Pb}{ }^{239} \mathrm{U}$ & \pm 10 & D. & conc, & ${ }^{208} \mathrm{~Pb} /{ }^{258} \mathrm{U} \pm 1 \sigma$ & ${ }^{207} \mathrm{~Pb} / f^{238} \mathrm{U} \pm 1 \mathrm{~g}$ & ${ }^{207} \mathrm{~Pb} /{ }^{206} \mathrm{~Pb} \pm 1 \alpha$ & ${ }^{208} \mathrm{~Pb} / /^{232} \mathrm{Th} \pm 10$ \\
\hline 1.1 & C & 7,641 & 0.177 & 0.404 & 0.004 & 0.903 & $99.90 \%$ & $2187 \pm 19$ & $2189+20$ & $2192 \pm 20$ & $2430 \pm 88$ \\
\hline 2.1 & $c$ & 7,680 & 0.158 & 0.407 & 0.004 & 0.933 & $100.30 \%$ & $2201 \pm 17$ & $2194 \pm 18$ & $2187 \pm 11$ & $2479 \pm 54$ \\
\hline 3.1 & C & 12,499 & 0.255 & 0.491 & 0.005 & 0.994 & $97.40 \%$ & $2575 \pm 20$ & $2642 \pm 19$ & $2694 \pm 25$ & $3069 \pm 74$ \\
\hline 4.1 & C & 7.763 & 0.168 & 0.411 & 0.004 & 0.809 & $100.80 \%$ & $2221 \pm 18$ & $2203 \pm 19$ & $2187 \pm 20$ & $2472 \pm 67$ \\
\hline 5.1 & $\mathrm{C}$ & 7,639 & 0.169 & 0.405 & 0.004 & 0.886 & $100.20 \%$ & $2193 \pm 18$ & $2189 \pm 19$ & $2185 \pm 23$ & $2343 \pm 77$ \\
\hline 6.1 & c & 7,316 & 0.153 & 0.389 & 0.004 & 0.959 & $98.40 \%$ & $2117 \pm 16$ & $2150 \pm 18$ & $2783 \pm 17$ & $2160 \pm 49$ \\
\hline 7.1 & C & 13,119 & $0.28 B$ & 0.509 & 0.005 & 0.891 & $98.70 \%$ & $2653 \pm 22$ & $2688 \pm 20$ & $2714 \pm 16$ & $3009 \pm 115$ \\
\hline 8.1 & $\mathrm{C}$ & 7,580 & 0.174 & 0.400 & 0.004 & 0.871 & $99.30 \%$ & $2168 \pm 18$ & $2182 \pm 20$ & $2196 \pm 24$ & $2359 \pm 69$ \\
\hline 9.1 & $\mathrm{C}$ & 10,287 & 0.215 & 0.465 & 0.005 & 0.845 & $100.10 \%$ & $2462 \pm 19$ & $2460 \pm 19$ & $2459 \pm 12$ & $2875 \pm 58$ \\
\hline 10.1 & $\mathrm{C}$ & 6,646 & 0.132 & 0.359 & 0.003 & 0.994 & $95.70 \%$ & $1979 \pm 15$ & $2055 \pm 18$ & $2152 \pm 18$ & $2241 \pm 48$ \\
\hline 11.1 & $c$ & 7.575 & 0.159 & 0.376 & 0.004 & 0.998 & $94.10 \%$ & $2057 \pm 16$ & $2181 \pm 18$ & $2301 \pm 61$ & $2305 \pm 55$ \\
\hline$\$ 2.1$ & $c$ & 6.509 & 0.133 & 0.352 & 0.003 & 0.997 & $94.90 \%$ & $1946 \pm 15$ & $2047 \pm 19$ & $2150 \pm 51$ & $2448 \pm 61$ \\
\hline 13.1 & C & 13,432 & 0.328 & 0.519 & 0.006 & 0.953 & $99.40 \%$ & $2694 \pm 25$ & $2710 \pm 22$ & $2722 \pm 24$ & $3267 \pm 106$ \\
\hline 14.1 & $c$ & 27,655 & 0.534 & 0.689 & 0.006 & 0.908 & $99.20 \%$ & $3379 \pm 22$ & $3406 \pm 19$ & $3423 \pm 16$ & $3741 \pm 130$ \\
\hline 15.1 & $C$ & 7,098 & 0.152 & 0.377 & 0.003 & 0.983 & $97.00 \%$ & $2060 \pm 15$ & $2123 \pm 19$ & $2185 \pm 66$ & $2225 \pm 101$ \\
\hline 16.1 & $c$ & 7,340 & 0,166 & 0.390 & 0.004 & 0.985 & $98.50 \%$ & $2122 \pm 17$ & $2153 \pm 20$ & $2183 \pm 26$ & $2049 \pm 104$ \\
\hline 17.1 & $c$ & 7,328 & 0.150 & 0.382 & 0.003 & 0.843 & $99.00 \%$ & $2131 \pm 15$ & $2152 \pm 18$ & $2172 \pm 12$ & $2187 \pm 88$ \\
\hline 18.1 & $c$ & 7.348 & 0.154 & 0.392 & 0.003 & 0.825 & $99.00 \%$ & $2132 \pm 15$ & $2154 \pm 18$ & $2175 \pm 10$ & $2346 \pm 96$ \\
\hline 19.1 & $\mathrm{C}$ & 5,024 & 0.109 & 0.287 & 0.003 & 0.992 & $88.70 \%$ & $1627 \pm 12$ & $1823 \pm 17$ & $2055 \pm 15$ & $1594 \pm 74$ \\
\hline 20.3 & $c$ & 19,571 & 0.383 & 0.593 & 0.005 & 0.992 & $97.70 \%$ & $3001 \pm 20$ & $3070 \pm 18$ & $3115 \pm 28$ & $3368 \pm 127$ \\
\hline 20.2 & $\mathrm{~B}$ & 13,426 & 0.393 & 0.521 & 0.007 & 0.677 & $99.80 \%$ & $2705 \pm 29$ & $2710 \pm 27$ & $2713 \pm 34$ & $2954 \pm 131$ \\
\hline 21.1 & C & 7,587 & 0.183 & 0.403 & 0.004 & 0.558 & $100.00 \%$ & $2183 \pm 18$ & $2183 \pm 21$ & $2183 \pm 23$ & $2268 \pm 133$ \\
\hline 22.1 & $c$ & 6,630 & 0.133 & 0.368 & 0.003 & 0.806 & $97.80 \%$ & $2018 \pm 14$ & $2063 \pm 17$ & $2108 \pm 16$ & $2165 \pm 77$ \\
\hline 23.1 & $\mathrm{C}$ & 7,620 & 0.187 & 0.403 & 0.004 & 0.919 & $99.70 \%$ & $2181 \pm 19$ & $2187 \pm 21$ & $2192 \pm 28$ & $2686 \pm 161$ \\
\hline 24.1 & $\mathrm{c}$ & 7,400 & 0.162 & 0.391 & 0.004 & 0.934 & $98.50 \%$ & $2128 \pm 16$ & $2161 \pm 19$ & $2192 \pm 17$ & $2245 \pm 105$ \\
\hline 25.1 & $c$ & 7,576 & 0.168 & 0.400 & 0.004 & 0.948 & $99.50 \%$ & $2170 \pm 17$ & $2181 \pm 19$ & $2192 \pm 21$ & $2498 \pm 113$ \\
\hline 26.1 & $\mathrm{C}$ & 6,985 & 0.181 & 0.376 & 0.003 & 0.967 & $97.40 \%$ & $2038 \pm 17$ & $2107 \pm 20$ & $2176 \pm 15$ & $1785 \pm 35$ \\
\hline
\end{tabular}




\begin{tabular}{|c|c|c|c|c|c|c|c|c|c|c|c|}
\hline 27.4 & $c$ & 6,874 & 0.177 & 0.369 & 0.003 & 0.983 & $96.70 \%$ & $2849 \pm 21$ & $2925 \pm 20$ & $2978 \pm 29$ & $2529 \pm 43$ \\
\hline 28.1 & $c$ & 7,406 & 0.202 & 0.392 & 0.004 & 0.989 & $98.70 \%$ & $2510 \pm 21$ & $2603 \pm 21$ & $2676 \pm 29$ & $2058 \pm 40$ \\
\hline 29.1 & $c$ & 6,651 & 0.191 & 0.354 & 0.004 & 0.618 & $94.50 \%$ & $2609 \pm 26$ & $2661 \pm 24$ & $2701 \pm 67$ & $2497 \pm 51$ \\
\hline 30.1 & $c$ & 6,830 & 0.171 & 0.369 & 0.003 & 0.995 & $86.90 \%$ & $2084 \pm 18$ & $2133 \pm 21$ & $2180 \pm 13$ & $2043 \pm 37$ \\
\hline 31.1 & $c$ & 7,465 & 0.193 & 0.397 & 0.004 & 0.784 & $99.40 \%$ & $2501 \pm 28$ & $2616 \pm 26$ & $2706 \pm 53$ & $2380 \pm 49$ \\
\hline 32.1 & $c$ & 7,453 & 0.189 & 0.396 & 0,003 & 0.997 & $99.20 \%$ & $1870 \pm 14$ & $2000 \pm 19$ & $2138 \pm 39$ & $1495 \pm 21$ \\
\hline 33.1 & $c$ & 8,400 & 0.262 & 0.421 & 0.005 & 0.976 & $89.60 \%$ & $2\{24 \pm 17$ & $2142 \pm 20$ & $2159 \pm 34$ & $2050 \pm 33$ \\
\hline 33.2 & $B$ & 7,109 & 0.200 & 0.368 & 0.004 & 0.881 & $85.00 \%$ & $2130 \pm 17$ & $2155 \pm 20$ & $2179 \pm 18$ & $1843 \pm 27$ \\
\hline 34.1 & $c$ & 10,812 & 0.261 & 0.462 & 0.004 & 0.934 & $97.70 \%$ & $2132 \pm 20$ & $2162 \pm 23$ & $2191 \pm 25$ & $2018 \pm 48$ \\
\hline 35.1 & $c$ & 7,101 & 0.190 & 0.380 & 0.004 & 0.851 & $97.70 \%$ & $1983 \pm 15$ & $2068 \pm 19$ & $2154 \pm 22$ & $2042 \pm 23$ \\
\hline 36.1 & $c$ & 7,125 & 0.216 & 0.377 & 0.004 & 0.001 & $96.90 \%$ & $2845 \pm 25$ & $2900 \pm 22$ & $2939 \pm 20$ & $2615 \pm 48$ \\
\hline 37.1 & $c$ & 7,034 & 0.189 & 0.374 & 0.003 & 0.952 & $96.90 \%$ & $2250 \pm 19$ & $2292 \pm 21$ & $2329 \pm 16$ & $2177 \pm 37$ \\
\hline 38.1 & $c$ & 6.972 & 0.165 & 0.372 & 0.004 & 0.952 & $96.60 \%$ & $2038 \pm 17$ & $2107 \pm 20$ & $2176 \pm 15$ & $1785 \pm 35$ \\
\hline 39.1 & $c$ & 16,838 & 0.358 & 0.556 & 0.005 & 0.971 & $97.40 \%$ & $2849 \pm 21$ & $2925 \pm 20$ & $2978 \pm 29$ & $2529 \pm 43$ \\
\hline 40.1 & c & 11,992 & 0.278 & 0.476 & 0.005 & 0.850 & $96.40 \%$ & $2510 \pm 21$ & $2603 \pm 21$ & $2676 \pm 29$ & $2058 \pm 40$ \\
\hline 40.2 & C & 12,754 & 0.325 & 0.499 & 0.006 & 0.001 & $98.00 \%$ & $2609 \pm 26$ & $2661 \pm 24$ & $2701 \pm 61$ & $2497 \pm 51$ \\
\hline 41 & c & 7,172 & 0.171 & 0.382 & 0.004 & 0.753 & $97.70 \%$ & $2084 \pm 18$ & $2133 \pm 21$ & $2180 \pm 13$ & $2043 \pm 37$ \\
\hline 42.1 & $c$ & 12,155 & $0.33 B$ & 0.474 & 0.007 & 0.987 & $95.50 \%$ & $2501 \mp 28$ & $2616 \pm 26$ & $2706 \pm 53$ & $2380 \pm 49$ \\
\hline 43.1 & $c$ & 6.173 & 0.133 & 0.337 & 0.003 & 0.990 & $93.30 \%$ & $1870 \pm 14$ & $2000 \pm 19$ & $2138 \pm 39$ & $1495 \pm 21$ \\
\hline 44.1 & $c$ & 7,251 & 0.165 & 0.390 & 0.004 & 0.999 & $99.20 \%$ & $2124 \pm 17$ & $2142 \pm 20$ & $2159 \pm 34$ & $2050 \pm 33$ \\
\hline 45.1 & $c$ & 7,354 & 0.161 & 0.392 & 0.004 & 0.982 & $98.80 \%$ & $2130 \pm 17$ & $2155 \pm 20$ & $2179 \pm 18$ & $1843 \pm 27$ \\
\hline 46.1 & $c$ & 7,415 & 0.193 & 0.392 & 0.005 & 0.479 & $98.60 \%$ & $2132 \pm 20$ & $2162 \pm 23$ & $2191 \pm 25$ & $2018 \pm 48$ \\
\hline 47.1 & $c$ & 6,668 & 0.141 & 0.360 & 0.003 & 0.991 & $95.80 \%$ & $1983 \pm 15$ & $2068 \pm 19$ & $2154 \pm 22$ & $2042 \pm 23$ \\
\hline 48.1 & C & 16,409 & 0.388 & 0.555 & 0.006 & 0.803 & $98.10 \%$ & $2845 \pm 25$ & $2900 \pm 22$ & $2939 \pm 20$ & $2615 \pm 48$ \\
\hline 49.1 & $c$ & 8,558 & 0.205 & 0.418 & 0.004 & 0.947 & $98.20 \%$ & $2250 \pm 19$ & $2292 \pm 21$ & $2329 \pm 16$ & $2177 \pm 37$ \\
\hline 50.1 & $c$ & 7,480 & 0.192 & 0.396 & 0.005 & 0.935 & $99.00 \%$ & $2148 \pm 23$ & $2170 \pm 23$ & $2191 \pm 27$ & $1915 \pm 62$ \\
\hline 51.1 & $c$ & 7,427 & 0.168 & 0.393 & 0.004 & 0.917 & $88.80 \%$ & $2138 \pm 20$ & $2164 \pm 20$ & $2188 \pm 14$ & $2019 \pm 38$ \\
\hline 52.1 & $c$ & 6,840 & 0.151 & 0.365 & 0.004 & 0.870 & $95.90 \%$ & $2007 \pm 18$ & $2090 \pm 19$ & $2174 \pm 29$ & $1821 \pm 31$ \\
\hline 53.1 & $c$ & 4,194 & 0.095 & 0.248 & 0.003 & 0.914 & $84.10 \%$ & $1426 \pm 14$ & $1672 \pm 18$ & $1997 \pm 29$ & $1532 \pm 30$ \\
\hline 54.1 & $\mathrm{C}$ & 15,663 & 0.368 & 0.557 & 0.007 & 0.970 & $100.00 \%$ & $2855 \pm 29$ & $2856 \pm 22$ & $2857 \pm 28$ & $2688 \pm 66$ \\
\hline 55.1 & $c$ & 12,738 & 0.302 & 0.505 & 0.006 & 0.765 & $99.10 \%$ & $2636 \pm 26$ & $2660 \pm 22$ & $2679 \pm 19$ & $2538 \pm 72$ \\
\hline 56.1 & C & 6,506 & 0.139 & 0.352 & 0.004 & 0.995 & $94.80 \%$ & $1942 \pm 17$ & $2046 \pm 18$ & $2153 \pm 43$ & $1875 \pm 25$ \\
\hline 57.1 & c & 12,435 & 0.284 & 0.493 & 0.006 & 0.741 & $98.00 \%$ & $2585 \pm 25$ & $2637 \pm 21$ & $2678 \pm 21$ & $2436 \pm 67$ \\
\hline 58.1 & $c$ & 6,871 & 0.144 & 0.369 & 0.004 & 0.986 & $96.50 \%$ & $2022 \pm 17$ & $2094 \pm 18$ & $2166 \pm 28$ & $1874 \pm 28$ \\
\hline 59.1 & C & 7,566 & 0.184 & 0.397 & 0.005 & 0.293 & $98.80 \%$ & $2155 \pm 22$ & $2180 \pm 21$ & $2204 \pm 15$ & $2057 \pm 55$ \\
\hline 60.1 & c & 6,549 & 0.145 & 0.351 & 0.004 & 0.947 & $94.40 \%$ & $1940 \pm 18$ & $2052 \pm 19$ & $2167 \pm 13$ & $954 \pm 24$ \\
\hline 61.1 & $\mathrm{C}$ & 7,324 & 0.169 & 0.387 & 0.004 & 0.935 & $98.10 \%$ & $2110 \pm 20$ & $2151 \pm 20$ & $2190 \pm 10$ & $2\} 21 \pm 47$ \\
\hline 62.1 & C & 10,725 & 0.244 & 0.434 & 0.005 & 0.947 & $92.70 \%$ & $2324 \pm 23$ & $2499 \pm 21$ & $2645 \pm 38$ & $1754 \pm 45$ \\
\hline & & \multicolumn{4}{|c|}{ Razoes } & & & \multicolumn{4}{|c|}{ Idades } \\
\hline Spot & Local & ${ }^{207} \mathrm{~Pb}^{235} \mathrm{U}$ & س1 & ${ }^{200} \mathrm{~Pb} /{ }^{238} \mathrm{U}$ & \pm 10 & $\rho$ & conc. & ${ }^{208} \mathrm{~Pb} /{ }^{239} \mathrm{U} \pm 1 \mathrm{\sigma}$ & $\left.{ }^{207} \mathrm{~Pb}\right|^{235} \mathrm{U} \pm 10$ & ${ }^{207} \mathrm{~Pb} /{ }^{206} \mathrm{~Pb} \pm 10$ & $\left.{ }^{208} \mathrm{~Pb}\right|^{232} \mathrm{Th} \pm 1 \sigma$ \\
\hline 1.1 & $\mathrm{c}$ & 1,138 & 0.033 & 0.127 & 0.001 & 0.794 & $99.70 \%$ & $769 \pm 6$ & $771 \pm 15$ & $777 \pm 25$ & $759 \pm 15$ \\
\hline 1.2 & B & 1,069 & 0.029 & 0.120 & 0.001 & 0.937 & $99.10 \%$ & $731 \pm 6$ & $738 \pm 14$ & $758 \pm 31$ & $710 \pm 12$ \\
\hline 2.1 & $c$ & 0.995 & 0.066 & 0.130 & 0.002 & 0.277 & $95.70 \%$ & $671 \pm 11$ & $701 \pm 33$ & $796 \pm 229$ & $645 \pm 44$ \\
\hline 3.1 & $c$ & 1.145 & 0.044 & 0.127 & 0.002 & 0.272 & $99.70 \%$ & $772 \pm 8$ & $775 \pm 20$ & $782 \pm 70$ & $811 \pm 46$ \\
\hline 4.1 & c & 1.098 & 0.058 & 0.120 & 0.002 & 0.081 & $97.00 \%$ & $730 \pm 10$ & $752 \pm 28$ & $820 \div 182$ & $731 \pm 30$ \\
\hline 5.1 & $c$ & 1,150 & 0.039 & 0.128 & 0.001 & 0.822 & $99.80 \%$ & $775 \pm 7$ & $777 \pm 18$ & $781 \pm 29$ & $816 \pm 36$ \\
\hline 6.1 & $c$ & 0.891 & 0.048 & 0.103 & 0.002 & 0.424 & $97.80 \%$ & $632 \pm 9$ & $646 \pm 26$ & $696 \pm 107$ & $659 \pm 41$ \\
\hline 7.1 & $c$ & 0.744 & 0.021 & 0.091 & 0.001 & 0.961 & $99.70 \%$ & $563 \pm 5$ & $564 \pm 12$ & $570 \pm 185$ & $555 \pm 23$ \\
\hline 8.1 & $c$ & 1,788 & 0.090 & 0.174 & 0.003 & 0.584 & $99.40 \%$ & $1034 \pm\{4$ & $1041 \pm 33$ & $1054 \pm 93$ & $968 \pm 56$ \\
\hline 9.1 & $c$ & 1,600 & 0.070 & 0.161 & 0.002 & 0.662 & $99.30 \%$ & $963 \pm 11$ & $970 \pm 27$ & $985 \pm 83$ & $903 \pm 27$ \\
\hline 10.1 & $c$ & 1,390 & 0.056 & 0.143 & 0.002 & 0.930 & $97.20 \%$ & $860 \pm 10$ & $884 \pm 23$ & $946 \pm 80$ & $887 \pm 33$ \\
\hline 11.1 & $c$ & 1,207 & 0.042 & 0.131 & 0.001 & 0.567 & $98.50 \%$ & $792 \pm 8$ & $804 \pm 19$ & $837 \pm 74$ & $790 \pm 14$ \\
\hline 12.1 & $c$ & 1,477 & 0.073 & 0.152 & 0.002 & 0.380 & $99.10 \%$ & $912 \pm 12$ & $920 \pm 29$ & $941 \pm 170$ & $910 \pm 48$ \\
\hline 13.1 & $c$ & 1,140 & 0.110 & 0.127 & 0.003 & 0.593 & $99.40 \%$ & $767 \pm 18$ & $772 \pm 54$ & $787 \pm 361$ & $787 \pm 67$ \\
\hline
\end{tabular}




\begin{tabular}{|c|c|c|c|c|c|c|c|c|c|c|c|}
\hline 14.1 & $\mathrm{c}$ & 1,146 & 0.046 & 0.126 & 0.002 & 0,197 & $98.50 \%$ & $763 \pm 10$ & $775 \pm 22$ & $808 \pm 74$ & $843 \pm 25$ \\
\hline 15.1 & $\mathrm{C}$ & 1,072 & 0.054 & 0.121 & 0.002 & 0.549 & $99.50 \%$ & $735 \pm 11$ & $739 \pm 26$ & $751 \pm 91$ & $807 \pm 43$ \\
\hline 16.1 & $c$ & 1,041 & 0.106 & 0.119 & 0.003 & 0.230 & $100.00 \%$ & $723 \pm 17$ & $724 \pm 54$ & $724 \pm 291$ & $753 \pm 55$ \\
\hline 17.1 & $c$ & 2,092 & 0.086 & 0.189 & 0.003 & 0.718 & $97.40 \%$ & $1117 \pm 15$ & $1146 \pm 28$ & $1201 \pm 91$ & $1165 \pm 54$ \\
\hline 18.1 & $\mathrm{c}$ & 1,008 & 0.046 & 0.114 & 0.002 & 0.778 & $98.00 \%$ & $694 \pm 9$ & $708 \pm 22$ & $752 \pm 95$ & $348 \pm 14$ \\
\hline 19.1 & $c$ & 1,047 & 0.038 & 0.120 & 0.002 & 0.450 & $100.70 \%$ & $732 \pm 9$ & $727 \pm 18$ & $711 \pm 114$ & $805 \pm 27$ \\
\hline 20.7 & $\mathrm{C}$ & 1,085 & 0.097 & 0.116 & 0.003 & 0.338 & $94.80 \%$ & $708 \pm 16$ & $745 \pm 49$ & $860 \pm 296$ & $741 \pm 47$ \\
\hline 21.1 & $\mathrm{c}$ & 0.885 & 0.045 & 0.103 & 0.002 & 0.440 & $98,30 \%$ & $632 \pm 9$ & $643 \pm 24$ & $682 \pm 102$ & $676 \pm 25$ \\
\hline 22.1 & C & 1,513 & 0.068 & 0.157 & 0.002 & 0.684 & $100.40 \%$ & $938 \pm 13$ & $935 \pm 27$ & $927 \pm 98$ & $1074 \pm 19$ \\
\hline 22.2 & $B$ & 1,655 & 0.140 & 0.163 & 0.004 & 0.435 & $98.20 \%$ & $974 \pm 22$ & $991 \pm 52$ & $1030 \pm 247$ & $1038 \pm 33$ \\
\hline 23.1 & $c$ & 1,045 & 0.048 & 0.121 & 0.002 & 0.572 & $101.30 \%$ & $736 \pm 10$ & $726 \pm 23$ & $696 \pm 58$ & $807 \pm 38$ \\
\hline 24.1 & $c$ & 0.942 & 0.035 & 0.109 & 0.001 & 0.560 & $99.10 \%$ & $668 \pm 8$ & $674 \pm 18$ & $693 \pm 52$ & $759 \pm 24$ \\
\hline 25.1 & $c$ & 11,623 & 0.269 & 0.485 & 0.005 & 0.999 & $99.00 \%$ & $2549 \pm 21$ & $2574 \pm 22$ & $2594 \pm 74$ & $2182 \pm 61$ \\
\hline 26.1 & $c$ & 0.744 & 0.044 & 0.087 & 0.002 & 0.704 & $95.60 \%$ & $540 \pm 9$ & $564 \pm 25$ & $663 \pm 114$ & $240 \pm 19$ \\
\hline 27.1 & $c$ & 1,034 & 0.042 & 0.117 & 0.002 & 0.897 & $98.70 \%$ & $717 \pm 9$ & $720 \pm 21$ & $749 \pm 84$ & $342 \pm 24$ \\
\hline 28.1 & C & $\$, 175$ & 0.045 & 0.130 & 0.002 & 0.790 & $99.90 \%$ & $788 \pm 9$ & $788 \pm 21$ & $790 \pm 48$ & $741 \pm 50$ \\
\hline 29.1 & $\mathrm{C}$ & 1,651 & 0.065 & 0.164 & 0.002 & 0.652 & $98.70 \%$ & $977 \pm 12$ & $989 \pm 24$ & $1017 \pm 75$ & $905 \pm 42$ \\
\hline 30.1 & $c$ & 1,087 & 0.048 & 0.122 & 0.002 & 0.871 & $99.40 \%$ & $742 \pm 10$ & $747 \pm 23$ & $760 \pm 112$ & $625 \pm 51$ \\
\hline 31.1 & $c$ & 1,502 & 0.044 & 0.153 & 0.002 & 0.977 & $98.80 \%$ & $920 \pm 9$ & $931 \pm 17$ & $957 \pm 56$ & $831 \pm 26$ \\
\hline 32.1 & $c$ & 0.893 & 0.033 & 0.105 & 0.001 & 0.751 & $99.40 \%$ & $643 \pm 7$ & $647 \pm 17$ & $662 \pm 45$ & $628 \pm 78$ \\
\hline 33,1 & $c$ & 0.901 & 0.047 & 0.105 & 0.002 & 0.657 & $98.30 \%$ & $641 \pm 10$ & $652 \pm 25$ & $690 \pm 94$ & $616 \pm 42$ \\
\hline 34.1 & $\mathrm{c}$ & 0.903 & 0.045 & 0.106 & 0.002 & 0.943 & $99.40 \%$ & $649 \pm 9$ & $653 \pm 24$ & $666 \pm 273$ & $600 \pm 35$ \\
\hline 35.1 & $c$ & 0.903 & 0.038 & 0.106 & 0.002 & 0.924 & $99.70 \%$ & $650 \pm 8$ & $653 \pm 21$ & $661 \pm 294$ & $624 \pm 31$ \\
\hline 36.1 & $c$ & 7,660 & 0.064 & 0.164 & 0.002 & 0.597 & $98.60 \%$ & $979 \pm 12$ & $993 \pm 24$ & $1024 \pm 66$ & $973 \pm 32$ \\
\hline 37.1 & $c$ & 12,316 & 0.372 & 0.495 & 0.007 & 0.918 & $98.60 \%$ & $2591 \pm 30$ & $2628 \pm 28$ & $2657 \pm 47$ & $2249 \pm 121$ \\
\hline 38.1 & $c$ & 1,320 & 0.051 & 0.141 & 0.002 & 0.806 & $99.30 \%$ & $848 \pm 8$ & $854 \pm 22$ & $870 \pm 52$ & $792 \pm 12$ \\
\hline 39.1 & $c$ & 1,312 & 0.074 & 0.138 & 0.002 & 0.027 & $98.00 \%$ & $834 \pm 11$ & $851 \pm 32$ & $894 \pm 185$ & $743 \pm 36$ \\
\hline 40.1 & $c$ & 1,142 & 0.037 & 0.126 & 0.001 & 0.957 & $99.10 \%$ & $766 \pm 7$ & $773 \pm 17$ & $793 \pm 45$ & $707 \pm 12$ \\
\hline 41.1 & $\mathrm{C}$ & 1,082 & 0.053 & 0.120 & 0.002 & 0.648 & $98.00 \%$ & $729 \pm 8$ & $744 \pm 25$ & $788 \pm 105$ & $700 \pm 43$ \\
\hline 42.1 & $c$ & 0.991 & 0.068 & 0.118 & 0.002 & 0.353 & $102.40 \%$ & $716 \pm 10$ & $698 \pm 34$ & $644 \pm 155$ & $667 \pm 61$ \\
\hline 43.1 & c & 0.953 & 0.033 & 0.109 & 0.001 & 0.530 & $98.30 \%$ & $668 \pm 6$ & $679 \pm 17$ & $716 \pm 38$ & $632 \pm 18$ \\
\hline 44.1 & $\mathrm{C}$ & 0.958 & 0.053 & 0.116 & 0.002 & 0.894 & $\$ 03.50 \%$ & $707 \pm 8$ & $6 B 2 \pm 26$ & $602 \pm 117$ & $648 \pm 37$ \\
\hline 45.1 & c & 1,658 & 0.068 & 0.165 & 0.002 & 0.194 & $98.90 \%$ & $981 \pm 10$ & $992 \pm 25$ & $1017 \pm 62$ & $893 \pm 30$ \\
\hline 46.1 & $c$ & 0.883 & 0.030 & 0.104 & 0.001 & 0.731 & $99.00 \%$ & $636 \pm 6$ & $642 \pm 18$ & $664 \pm 82$ & $586 \pm 7$ \\
\hline 47.1 & $c$ & 1,159 & 0.039 & 0.124 & 0.001 & 0.741 & $96.50 \%$ & $754 \pm 7$ & $781 \pm 18$ & $860 \pm 46$ & $616 \pm 10$ \\
\hline 48.1 & $\mathrm{C}$ & 11,191 & 0.290 & 0.438 & 0.004 & 0.987 & $91.80 \%$ & $2340 \pm 18$ & $2539 \pm 23$ & $2702 \pm 58$ & $2371 \pm 27$ \\
\hline 49.1 & $c$ & 7,635 & 0.209 & 0.400 & 0.004 & 0.616 & $99.10 \%$ & $2169 \pm 18$ & $2188 \pm 24$ & $2207 \pm 18$ & $2010 \pm 52$ \\
\hline 50.1 & $c$ & 0.898 & 0.028 & 0.106 & 0.001 & 0.867 & $99.70 \%$ & $648 \pm 5$ & $650 \pm 15$ & $657 \pm 57$ & $579 \pm 11$ \\
\hline 51.1 & $\mathrm{C}$ & 1,294 & 0.039 & 0.137 & 0.002 & 0.414 & $98.30 \%$ & $828+8$ & $843 \pm 16$ & $880 \pm 93$ & $764 \pm 21$ \\
\hline 52.1 & $c$ & 1,742 & 0.087 & 0.170 & 0.003 & 0.503 & $98.80 \%$ & $1012 \pm 14$ & $1024 \pm 32$ & $1049 \pm 104$ & $976 \pm 82$ \\
\hline 53.1 & $\mathrm{c}$ & 1,230 & 0.060 & 0.132 & 0.002 & 0.674 & $97.80 \%$ & $796 \pm 10$ & $814 \pm 27$ & $862 \pm 148$ & $781 \pm 37$ \\
\hline 54.1 & $c$ & 0.931 & 0.034 & 0.107 & 0.001 & 0.750 & $97.80 \%$ & $653 \pm 7$ & $667 \pm 18$ & $717 \pm 92$ & $520 \pm 24$ \\
\hline 55.1 & $c$ & 0.767 & 0.029 & 0.093 & 0.001 & 0.608 & $99.10 \%$ & $573 \pm 6$ & $577 \pm 16$ & $597 \pm 130$ & $303 \pm 16$ \\
\hline 56.1 & $c$ & 0.884 & 0.047 & 0.107 & 0.002 & 0.175 & $301.60 \%$ & $654 \pm 9$ & $643 \pm 25$ & $606 \pm 189$ & $632 \pm 38$ \\
\hline 57.1 & $c$ & 0.977 & 0.053 & 0.108 & 0.002 & 0.455 & $95.20 \%$ & $659 \pm 9$ & $692 \pm 26$ & $799 \pm 175$ & $506 \pm 31$ \\
\hline 58.1 & $c$ & 1,017 & 0.057 & 0.118 & 0.002 & 0.460 & $101.20 \%$ & $721 \pm 10$ & $712 \pm 28$ & $684 \pm 142$ & $583 \pm 68$ \\
\hline 59.1 & $c$ & 6,086 & 0.163 & 0.358 & 0.004 & 0.994 & $99.20 \%$ & $1971 \pm 19$ & $1988 \pm 23$ & $2005 \pm 66$ & $1816 \pm 57$ \\
\hline 60.1 & $c$ & 1,391 & 0.051 & 0.141 & 0.002 & 0.720 & $96.00 \%$ & $850 \pm 10$ & $885 \pm 21$ & $873 \pm 97$ & $711 \pm 23$ \\
\hline 61.1 & $c$ & 1,098 & 0.041 & 0.122 & 0.002 & 0.705 & $98.30 \%$ & $739 \pm 8$ & $752 \pm 19$ & $790 \pm 88$ & $766 \pm 36$ \\
\hline 62.1 & $c$ & 0.924 & 0.042 & 0.108 & 0.002 & 0.868 & $99.10 \%$ & $658 \pm 8$ & $664 \pm 21$ & $685 \pm 201$ & $585 \pm 25$ \\
\hline 63.1 & $c$ & 1,329 & 0.051 & 0.138 & 0,002 & 0.085 & $97.30 \%$ & $835 \pm 10$ & $858 \pm 22$ & $917 \pm 91$ & $796 \pm 58$ \\
\hline
\end{tabular}

4.3.3 SEQUEENCIA METASEDIMENTAR SERIDO (reglao entre Coremas e Cajazeiras-PB)

4.3.3.1 Amostra JMR 12: "Paragnaisse" grăos de zircáo detrítico.

Razóes

Idades

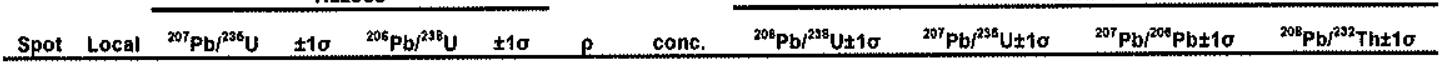




\begin{tabular}{|c|c|c|c|c|c|c|c|c|c|c|c|}
\hline 9.1 & $c$ & 1,678 & 0.058 & 0.165 & 0.003 & 0.971 & $98.10 \%$ & $981 \pm 14$ & $1000 \pm 21$ & $1041 \pm 74$ & $954 \pm 67$ \\
\hline 2.1 & $c$ & 0.881 & 0.039 & 0.097 & 0.002 & 0.800 & $92.60 \%$ & $596 \pm 10$ & $641 \pm 20$ & $805 \pm\{44$ & $522 \pm 19$ \\
\hline 3.1 & $c$ & 10,413 & 0.216 & 0.472 & 0,006 & 0.878 & $100.80 \%$ & $2492 \pm 23$ & $2472 \pm 19$ & $2455 \pm 23$ & $2543 \pm 79$ \\
\hline 4.1 & C & 1,090 & 0.055 & 0.114 & 0.002 & 0.619 & $93.00 \%$ & $697 \pm 13$ & $748 \pm 28$ & $902 \pm 146$ & $727 \pm 155$ \\
\hline 5.1 & c & 1,227 & 0.035 & 0.132 & 0.002 & 0.013 & $88.30 \%$ & $799 \pm 9$ & $813 \pm 16$ & $850 \pm 66$ & $750 \pm 55$ \\
\hline 6.1 & $c$ & 5,433 & 0.129 & 0.332 & 0.004 & 0.973 & $97.70 \%$ & $1846 \pm 20$ & $1890 \pm 19$ & $1937 \pm 40$ & $1750 \pm 108$ \\
\hline 7.1 & $\mathrm{c}$ & 1,148 & 0.116 & 0.126 & 0.005 & 0.200 & $98.30 \%$ & $762 \pm 26$ & $776 \pm 55$ & $814 \pm 362$ & $816 \pm 148$ \\
\hline 8.1 & $c$ & 0.933 & 0.102 & 0.110 & 0.004 & 0.604 & $100.20 \%$ & $670 \pm 23$ & $669 \pm 51$ & $664 \pm 417$ & $561 \pm 205$ \\
\hline 9.1 & $\mathrm{C}$ & 0.992 & 0.029 & 0.116 & 0.002 & 0.644 & $101.40 \%$ & $710 \pm 8$ & $699 \pm 14$ & $667 \pm 85$ & $624 \pm 34$ \\
\hline 10.1 & C & 0.985 & 0.031 & 0.116 & 0.002 & 0.939 & $101.80 \%$ & $708 \pm 8$ & $696 \pm 16$ & $656 \pm 68$ & $601 \pm 42$ \\
\hline 11.1 & $\mathrm{C}$ & 1,265 & 0.049 & 0.137 & 0.002 & 0.646 & $99.40 \%$ & $825 \pm 12$ & $830 \pm 22$ & $844 \pm 79$ & $868 \pm 59$ \\
\hline 12.1 & $c$ & 0.999 & 0.033 & 0.116 & 0.002 & 0.788 & $100.50 \%$ & $706 \pm 9$ & $703 \pm 16$ & $691 \pm 49$ & $730 \pm 56$ \\
\hline 13.1 & $c$ & 2,800 & 0.061 & 0.171 & 0.002 & 0.953 & $71.60 \%$ & $1018 \pm 10$ & $1355 \pm 15$ & $1936 \pm 74$ & $1409 \pm 171$ \\
\hline 14.1 & $c$ & 1,110 & 0.058 & 0.122 & 0.002 & 0.001 & $98.20 \%$ & $744 \pm 12$ & $757 \pm 28$ & $798 \pm 170$ & $784 \pm 44$ \\
\hline 15.1 & $\mathrm{c}$ & 1,172 & 0.028 & 0.131 & 0.001 & 0.607 & $100.90 \%$ & $794 \pm 6$ & $787 \pm 12$ & $767 \pm 37$ & $884 \pm 24$ \\
\hline 16.1 & C & 0.840 & 0.046 & 0.101 & 0.002 & 0.409 & $99.70 \%$ & $617 \pm 10$ & $619 \pm 25$ & $625 \pm 248$ & $455 \pm 72$ \\
\hline 17.1 & $\mathrm{C}$ & 6,866 & 0.141 & 0.371 & 0.003 & 0.988 & $97.10 \%$ & $2034 \pm 15$ & $2094 \pm 17$ & $2153 \pm 23$ & $2189 \pm 34$ \\
\hline 18.1 & $\mathrm{C}$ & 1,190 & 0.034 & 0.131 & 0.001 & 0.978 & $99.70 \%$ & $793 \pm 7$ & $795 \pm 16$ & $602 \pm 74$ & $747 \pm 72$ \\
\hline 19.1 & $c$ & 7,549 & 0.255 & 0.397 & 0.007 & 0.969 & $99.00 \%$ & $2157 \pm 32$ & $2178 \pm 31$ & $2199 \pm 70$ & $2145 \pm 178$ \\
\hline 20.1 & $c$ & 0.961 & 0.073 & 0.116 & 0.003 & 0.389 & $103.60 \%$ & $709 \pm 15$ & $683 \pm 39$ & $601 \pm 224$ & $851 \pm 195$ \\
\hline 21.1 & $c$ & 0.956 & 0.031 & 0.109 & 0.001 & 0.939 & $98.10 \%$ & $668 \pm 7$ & $681 \pm 15$ & $723+57$ & $522 \pm 32$ \\
\hline 22.1 & C & $\$ 1,494$ & 0.226 & 0.476 & 0.004 & 0.953 & $87.90 \%$ & $2510 \pm 18$ & $2564 \pm 18$ & $2606 \pm 23$ & $2662 \pm 35$ \\
\hline 23.1 & C & 6,398 & 0.122 & 0.350 & 0.003 & 0.974 & $85.10 \%$ & $1934 \pm 13$ & $2031 \pm 16$ & $2131 \pm 16$ & $2114 \pm 29$ \\
\hline 24.1 & C & $\$, 242$ & 0.038 & 0.137 & 0.002 & 0.616 & $100.70 \%$ & $825 \pm 8$ & $819 \pm 16$ & $804 \pm 62$ & $878 \pm 23$ \\
\hline 25.1 & $c$ & 5.455 & 0.130 & 0.346 & 0.004 & 0.642 & $101.10 \%$ & $1914 \pm 17$ & $1893 \pm 20$ & $1870 \pm 23$ & $2021 \pm 32$ \\
\hline 26.1 & $c$ & 0.682 & 0.022 & 0.076 & 0.001 & 0.987 & $88.50 \%$ & $470 \pm 5$ & $527 \pm 13$ & $783 \pm 96$ & $682 \pm 24$ \\
\hline 27.1 & $c$ & 0.902 & 0.039 & 0.106 & 0.001 & 0.783 & $99.80 \%$ & $651 \pm 7$ & $653 \pm 21$ & $657 \pm 71$ & $561 \pm 35$ \\
\hline 28.1 & 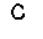 & 1,062 & 0.034 & 0.123 & 0.001 & 0.645 & $101.70 \%$ & $747 \pm 7$ & $734 \pm 16$ & $697 \pm 38$ & $689 \pm 26$ \\
\hline 29.1 & C & 0.937 & 0.026 & 0.109 & 0.001 & 0.958 & $89.60 \%$ & $669 \pm 6$ & $671 \pm 13$ & $679 \pm 39$ & $492 \pm 16$ \\
\hline 30.1 & $\mathrm{C}$ & 0.838 & 0.085 & 0.097 & 0.002 & 0.650 & $96.30 \%$ & $595 \pm 13$ & $618 \pm 46$ & $700 \pm 317$ & $478 \pm 156$ \\
\hline 37.1 & C & 1,069 & 0.054 & 0.119 & 0.002 & 0.590 & $98.10 \%$ & $724 \pm 9$ & $738 \pm 26$ & $780 \pm 112$ & $659 \pm 36$ \\
\hline 32.1 & $\mathrm{C}$ & 0.984 & 0.024 & 0.115 & 0.001 & 0.537 & $100.40 \%$ & $703 \pm 5$ & $700 \pm 12$ & $691 \pm 24$ & $674 \pm 26$ \\
\hline 33.1 & $\mathrm{c}$ & 2,443 & 0.108 & 0.216 & 0,003 & 0.383 & $100.40 \%$ & $1260 \pm 16$ & $1255 \pm 31$ & $1247 \pm 97$ & $1087 \pm 84$ \\
\hline 34.1 & C & 1,165 & 0.065 & 0.131 & 0.002 & 0.434 & $101.40 \%$ & $795 \pm 11$ & $784 \pm 30$ & $752 \pm 133$ & $626 \pm 66$ \\
\hline 35.1 & $\mathrm{C}$ & 1,641 & 0.060 & 0.165 & 0.002 & 0.660 & $99.80 \%$ & $985 \pm 10$ & $986 \pm 22$ & $988 \pm 45$ & $817 \pm 42$ \\
\hline 36.1 & C & $1,\{20$ & 0.050 & 0.122 & 0.002 & 0.575 & $97.10 \%$ & $740 \pm 9$ & $762 \pm 24$ & $827 \pm 85$ & $616 \pm 67$ \\
\hline 37.1 & $c$ & 1,140 & 0.081 & 0.125 & 0.002 & 0.508 & $98.50 \%$ & $760 \pm 13$ & $772 \pm 38$ & $806 \pm 187$ & $669 \pm 60$ \\
\hline 38.1 & $c$ & 1,012 & 0.039 & 0.113 & 0.001 & 0.723 & $96,90 \%$ & $688 \pm 7$ & $709 \pm 20$ & $778 \pm 79$ & $586 \pm 68$ \\
\hline 39.1 & $\mathrm{C}$ & 5,428 & 0.110 & 0.309 & 0.003 & 0.995 & $91.50 \%$ & $1735 \pm 13$ & $1889 \pm 18$ & $2063 \pm 72$ & $1077 \pm 41$ \\
\hline 40.1 & $c$ & 1,198 & 0,049 & 0.129 & 0.001 & 0.552 & $97.80 \%$ & $782 \pm 7$ & $799 \pm 22$ & $848 \pm 66$ & $862 \pm 36$ \\
\hline 41.1 & $\mathrm{C}$ & 1,106 & 0.028 & 0.126 & 0.001 & 0.985 & $100.80 \%$ & $762 \pm 5$ & $756 \pm 13$ & $737 \pm 26$ & $841 \pm 17$ \\
\hline 42.1 & $\mathrm{C}$ & 1,239 & 0.052 & 0.135 & 0,001 & 0.204 & $99.40 \%$ & $813 \pm 7$ & $818 \pm 23$ & $831 \pm 84$ & $822 \pm 55$ \\
\hline 43.1 & C & 1,006 & 0.029 & 0.113 & 0.001 & 0.921 & $97.30 \%$ & $688 \pm 5$ & $706 \pm 14$ & $766 \pm 44$ & $776 \pm 17$ \\
\hline 44.1 & c & 1,859 & 0.116 & 0.178 & 0.003 & 0.001 & $98.80 \%$ & $1054 \pm 15$ & $1066 \pm 41$ & $1092 \pm 148$ & $1207 \pm 73$ \\
\hline 45.1 & $c$ & 1,157 & 0.043 & 0.128 & 0.001 & 0.813 & $99.70 \%$ & $777 \pm 6$ & $780 \pm 20$ & $788 \pm 70$ & $845 \pm 22$ \\
\hline 46.1 & $c$ & 1,303 & 0.040 & 0.138 & 0.001 & 0.480 & $98.40 \%$ & $833 \pm 6$ & $846 \pm 17$ & $881 \pm 34$ & $944 \pm 17$ \\
\hline 47.1 & $c$ & 0.996 & 0.051 & 0.116 & 0.001 & 0.950 & $100.40 \%$ & $704 \pm 7$ & $701 \pm 26$ & $692 \pm 87$ & $790 \pm 26$ \\
\hline 48.1 & $c$ & $\$ .051$ & 0.036 & 0.120 & 0.001 & 0.001 & $99.80 \%$ & $727 \pm 5$ & $729 \pm 17$ & $734 \pm 65$ & $810 \pm 31$ \\
\hline 49.1 & $c$ & 15.373 & 0.334 & 0.533 & 0.004 & 0.947 & $97.00 \%$ & $2755 \pm 16$ & $2838 \pm 20$ & $2897 \pm 21$ & $3022 \pm 61$ \\
\hline 50.1 & $\mathrm{C}$ & 1,004 & 0.026 & 0.116 & 0.001 & 0.966 & $100.40 \%$ & $708 \pm 4$ & $705 \pm 13$ & $696 \pm 20$ & $759 \pm 18$ \\
\hline 51.1 & $c$ & 7,378 & 0.198 & 0.397 & 0.004 & 0.678 & $98.90 \%$ & $2156 \pm 16$ & $2158 \pm 24$ & $2160 \pm 28$ & $2455 \pm 66$ \\
\hline 52.1 & $c$ & 0.813 & 0.058 & 0.107 & 0.001 & 0.098 & $98.40 \%$ & $654 \pm 8$ & $658 \pm 30$ & $672 \pm 155$ & $712 \pm 62$ \\
\hline 53.1 & $c$ & 1,072 & 0.100 & 0,125 & 0.004 & $0.06 \theta$ & $102.40 \%$ & $757 \pm 21$ & $739 \pm 49$ & $685 \pm 309$ & $639 \pm 92$ \\
\hline 54.1 & $c$ & 7,410 & 0.166 & 0.391 & 0.004 & 0.997 & $98.40 \%$ & $2\{27 \pm 18$ & $2162 \pm 20$ & $2195 \pm 83$ & $2124 \pm 58$ \\
\hline 55.1 & $c$ & 1,103 & 0.035 & 0.124 & 0.001 & 0.708 & $99.90 \%$ & $754 \pm 7$ & $754 \pm 16$ & $756 \pm 52$ & $745 \pm 23$ \\
\hline 56.1 & $c$ & 1,696 & 0.053 & 0.170 & 0.002 & 0.789 & $100.50 \%$ & $1012 \pm 10$ & $1007 \pm 19$ & $995 \pm 45$ & $976 \pm 32$ \\
\hline
\end{tabular}




\begin{tabular}{|c|c|c|c|c|c|c|c|c|c|c|c|}
\hline 57.1 & $c$ & 1,656 & 0.035 & 0.167 & 0.001 & 0.978 & $100.20 \%$ & $993 \pm 7$ & 991 ะ 13 & $988 \pm 14$ & $986 \pm 15$ \\
\hline 58.1 & c & 1,239 & 0.037 & 0.136 & 0.001 & 0.693 & $100.20 \%$ & $820 \pm 8$ & $818 \pm 16$ & $8 \$ 4 \pm 39$ & $801 \pm 26$ \\
\hline 59.1 & C & 1,136 & 0.069 & 0.130 & 0.003 & 0.001 & $102.40 \%$ & $789 \pm 14$ & $770 \pm 32$ & $716 \pm 219$ & $810 \pm 47$ \\
\hline 60.1 & C & 10,284 & 0.192 & 0.432 & 0.003 & 0.997 & $93.90 \%$ & $2314 \pm 14$ & $2460 \pm 17$ & $2583 \pm 27$ & $2129 \pm 34$ \\
\hline 61.1 & c & 16,655 & 0.333 & 0.546 & 0.004 & 0.292 & $96.20 \%$ & $2807 \pm 18$ & $2915 \pm 18$ & $2990 \pm 238$ & $2637 \pm 98$ \\
\hline 62.1 & $C$ & 0.549 & 0.017 & 0,064 & 0.001 & 0.979 & $89.10 \%$ & $398 \pm 4$ & $444 \pm 10$ & $688 \pm 64$ & $633 \pm 21$ \\
\hline \multirow[b]{2}{*}{ Spot } & \multirow[b]{2}{*}{ Local } & \multicolumn{4}{|c|}{ Razoes } & \multirow[b]{2}{*}{$p$} & \multirow[b]{2}{*}{ conc. } & \multicolumn{4}{|c|}{ Idades } \\
\hline & & ${ }^{207} \mathrm{~Pb} /{ }^{23 s} \mathrm{U}$ & \pm 10 & ${ }^{208} \mathrm{~Pb} /{ }^{25 \mathrm{~B}_{\mathrm{U}}}$ & \pm 10 & & & ${ }^{206} \mathrm{~Pb}^{23 \mathrm{~B}} \mathrm{U} \pm 1 \mathrm{\sigma}$ & ${ }^{207} \mathrm{~Pb}^{235} \mathrm{U} \pm 1 \mathrm{\sigma}$ & ${ }^{207} \mathrm{~Pb} /{ }^{201} \mathrm{~Pb} \pm 10$ & ${ }^{208} \mathrm{~Pb} / /^{232} \mathrm{Th} \pm 1 \sigma$ \\
\hline 1.1 & C & 7,156 & 0.181 & 0.390 & 0.005 & 0.564 & $99.60 \%$ & $2122 \pm 23$ & $2131 \pm 22$ & $2139 \pm 31$ & $1722 \pm 92$ \\
\hline 2.1 & $c$ & 7,278 & 0.189 & 0.398 & 0.005 & 0.878 & $100.60 \%$ & $2160 \pm 24$ & $2146 \pm 22$ & $2132 \pm 32$ & $2154 \pm 126$ \\
\hline 3.1 & C & 7,567 & 0.169 & 0.403 & 0.004 & 0.994 & $100.10 \%$ & $2183 \pm 20$ & $2180 \pm 20$ & $2178 \pm 57$ & $1713 \pm 59$ \\
\hline 4.1 & c & 7,811 & 0.248 & 0.404 & 0.007 & 0.283 & $99.10 \%$ & $2188 \pm 33$ & $2209 \pm 28$ & $2228 \pm 53$ & $1811 \pm 200$ \\
\hline 5.1 & $c$ & 7.482 & 0.154 & 0.398 & 0.004 & 0.996 & $99.50 \%$ & $2160 \pm 18$ & $2170 \pm 19$ & $2181 \pm 35$ & $1635 \pm 45$ \\
\hline 6.1 & $c$ & 7,465 & 0.170 & 0.404 & 0.005 & 0.673 & $100.80 \%$ & $2185 \pm 20$ & $2168 \pm 20$ & $2152 \pm 33$ & $1810 \pm 114$ \\
\hline 7.1 & $\mathrm{C}$ & 7.901 & 0.231 & 0.429 & 0.007 & 0.926 & $103.60 \%$ & $2302 \pm 32$ & $2219 \pm 28$ & $2144 \pm 63$ & $2146 \pm 255$ \\
\hline 8.1 & C & 8,023 & 0.165 & 0.412 & 0.004 & 0.951 & $99.60 \%$ & $2225 \pm 17$ & $2233 \pm 18$ & $2241 \pm 11$ & $1622 \pm 42$ \\
\hline 9.1 & c & 9,106 & 0.197 & 0.431 & 0.005 & 0.249 & $98.30 \%$ & $2308 \pm 21$ & $2348 \pm 20$ & $2383 \pm 22$ & $1790 \pm 47$ \\
\hline 10.1 & C & 7,003 & 0.173 & 0.374 & 0.005 & 0.853 & $96.90 \%$ & $2046 \pm 22$ & $2111 \pm 21$ & $2175 \pm 45$ & $1643 \pm 102$ \\
\hline 11.1 & c & 7,421 & 0.203 & 0.397 & 0.006 & 0.592 & $99.60 \%$ & $2154 \pm 26$ & $2163 \pm 24$ & $2172 \pm 52$ & $1804 \pm\{52$ \\
\hline 11.2 & C & 7,434 & 0.183 & 0.400 & 0.005 & 0.522 & $100.10 \%$ & $2166 \pm 23$ & $2165 * 22$ & $2163 \pm 29$ & $1933 \pm 87$ \\
\hline 12.1 & $c$ & 5,267 & 0.117 & 0.304 & 0.003 & 0.980 & $91.30 \%$ & $1708 \pm 14$ & $1863 \pm 17$ & $2041 \pm 51$ & $1606 \pm 44$ \\
\hline 13.1 & $c$ & 6,958 & 0.198 & 0.378 & 0.006 & 0.920 & $98.30 \%$ & $2069 \pm 28$ & $2106 \pm 25$ & $2141 \pm 27$ & $1630 \pm 50$ \\
\hline 14.1 & $c$ & 7.433 & 0.194 & 0.395 & 0.006 & 0.512 & $99.10 \%$ & $2145 \pm 26$ & $2164 \pm 23$ & $2183 \pm 26$ & $216 B \pm 107$ \\
\hline 15.1 & $c$ & 5.771 & 0.164 & 0.309 & 0.005 & 0.995 & $88.70 \%$ & $1734 \pm 22$ & $1942 \pm 21$ & $2171 \pm 62$ & $1372 \pm 70$ \\
\hline 16.1 & $c$ & 13,074 & 0.398 & 0.507 & 0.010 & 0.514 & $98.50 \%$ & $2644 \pm 42$ & $2684 \pm 28$ & $2715 \pm 38$ & $2784 \pm 104$ \\
\hline 17.1 & C & 7,578 & 0.174 & 0.399 & 0.005 & 0.561 & $99.20 \%$ & $2164 \pm 23$ & $2182 \pm 20$ & $2498 \pm 23$ & $2125 \pm 54$ \\
\hline 18.1 & c & 7,579 & 0.179 & 0.399 & 0.005 & 0.792 & $99.10 \%$ & $2162 \pm 24$ & $2\{82 \pm 21$ & $2201 \pm 22$ & $1949 \pm 75$ \\
\hline 19.1 & C & 12,097 & 0.451 & 0.514 & 0.012 & 0.634 & $102.40 \%$ & $2674 \pm 53$ & $2611 \pm 34$ & $2563 \pm 58$ & $2380 \pm 234$ \\
\hline 20.1 & c & 7,552 & 0.196 & 0.398 & 0.006 & 0.556 & $99.10 \%$ & $2158 \pm 26$ & $2179 \pm 23$ & $2197 \pm 33$ & $2246 \pm 77$ \\
\hline 21.1 & C & 7,419 & 0.175 & 0.399 & 0.005 & 0.849 & $100.00 \%$ & $2163 \pm 23$ & $2163 \pm 21$ & $2162 \pm 19$ & $1931 \pm 38$ \\
\hline 22.1 & C & 7,684 & 0.173 & 0.402 & 0.005 & 0.611 & $99.30 \%$ & $2179 \pm 23$ & $2194 \pm 20$ & $2208 \pm 21$ & $2029 \pm 51$ \\
\hline 23.1 & C & 7,573 & 0.229 & 0.394 & 0.007 & 0.599 & $98.20 \%$ & $2142 \pm 31$ & $2181 \pm 27$ & $2219 \pm 39$ & $1830 \pm 115$ \\
\hline 24.1 & C & 11.087 & 0.347 & 0.476 & 0.009 & 0.349 & $99.20 \%$ & $2509 \pm 40$ & $2530 \pm 29$ & $2547 \pm 60$ & $2421 \pm 44$ \\
\hline 25.1 & C & 7,569 & 0.326 & 0.407 & 0.010 & 0.735 & $100.90 \%$ & $2201 \pm 46$ & $2181 \pm 38$ & $2161 \pm 61$ & $1965 \pm 107$ \\
\hline 26.1 & c & 8,194 & 0.186 & 0.439 & 0.005 & 0.391 & $99.60 \%$ & $2348 \pm 19$ & $2367 \pm 18$ & $2365 \pm 19$ & $2702 \pm 36$ \\
\hline 27,1 & $c$ & 6,242 & 0.119 & 0.347 & 0.003 & 0.973 & $95.30 \%$ & $1918 \pm 15$ & $2010 \pm 16$ & $2106 \pm 46$ & $2102 \pm 47$ \\
\hline 28.1 & c & 11,665 & 0.428 & 0.480 & 0.011 & 0.784 & $98.00 \%$ & $2527 \pm 45$ & $2577 \pm 33$ & $2617 \pm 72$ & $3085 \pm 132$ \\
\hline 29.1 & $c$ & 7,428 & 0.164 & 0.394 & 0.004 & 0.845 & $99.00 \%$ & $2141 \pm 20$ & $2164 \pm 19$ & $2185 \pm 22$ & $2384 \pm 63$ \\
\hline 30.1 & $c$ & 6,967 & 0.154 & 0.375 & 0.004 & 0.999 & $97.40 \%$ & $2053 \pm 19$ & $2107 \pm 20$ & $2160 \pm 183$ & $2416 \pm 73$ \\
\hline 31.1 & $c$ & 7,882 & 0.160 & 0.416 & 0.004 & 0.840 & $101.20 \%$ & $2244 \pm 18$ & $2217 \pm 18$ & $2193 \pm 18$ & $2509 \pm 53$ \\
\hline 32.1 & $\mathrm{C}$ & 7,514 & 0.176 & 0.403 & 0.005 & 0.794 & $100.30 \%$ & $2181 \pm 21$ & $2174 \pm 20$ & $2168 \pm 27$ & $2443 \pm 57$ \\
\hline
\end{tabular}

4.3.3.2.,li. Amostra JMR 11: "Quartzilto" gräos de zlrçáo detrítico.

\begin{tabular}{|c|c|c|c|c|c|c|c|c|c|c|c|}
\hline \multirow[b]{2}{*}{ Spot } & \multirow[b]{2}{*}{ Local } & \multicolumn{4}{|c|}{ Razoes } & \multirow[b]{2}{*}{$p$} & \multirow[b]{2}{*}{ conc. } & \multicolumn{4}{|c|}{ Idades } \\
\hline & & ${ }^{207} \mathrm{~Pb} / /^{256} \mathrm{U}$ & \pm 10 & ${ }^{200} \mathrm{~Pb} / /^{238} \mathrm{U}$ & \pm 10 & & & ${ }^{208} \mathrm{~Pb} /{ }^{298} \mathrm{U} \pm 1 \alpha$ & ${ }^{207} \mathrm{~Pb} /{ }^{236} \mathrm{U} \pm 1 \sigma$ & ${ }^{207} \mathrm{~Pb} /{ }^{206} \mathrm{~Pb} \pm 10$ & ${ }^{209} \mathrm{~Pb} / \mathrm{f}^{2 \mathrm{2} 2} \mathrm{Th} \pm 1 \sigma$ \\
\hline 1.1 & C & 7,629 & 0.213 & 0.406 & 0.008 & 0.294 & $98.30 \%$ & $2196 \pm 37$ & $2211 \pm 25$ & $2225 \pm 72$ & $2630 \pm 1444$ \\
\hline 2.1 & c & 6,185 & 0.141 & 0.342 & 0.005 & 0.934 & $94.60 \%$ & $1897 \pm 22$ & $2002 \pm 19$ & $2112 \pm 31$ & $4713 \pm 1351$ \\
\hline 3.1 & $\mathrm{c}$ & 6,715 & 0.153 & 0.364 & 0.005 & 0.985 & $96.30 \%$ & $1999 \pm 24$ & $2074 \pm 20$ & $2149 \pm 46$ & $4360 \pm 1243$ \\
\hline 4.1 & C & 7,049 & 0.134 & 0.380 & 0.003 & 0.946 & $98.10 \%$ & $2077 \pm 15$ & $2117 \pm 16$ & $2156 \pm 16$ & $4110 \pm 1289$ \\
\hline 5.1 & $c$ & 8,122 & 0.174 & 0.403 & 0.005 & 0.855 & $87.20 \%$ & $2182 \pm 22$ & $2244 \pm 19$ & $2302 \pm 28$ & $4723 \pm 1376$ \\
\hline 6.1 & $c$ & 4,659 & 0.101 & 0.264 & 0.004 & 0.997 & $84.80 \%$ & $1510 \pm 18$ & $1759 \pm 19$ & $2069 \pm 59$ & $3286 \pm 1171$ \\
\hline 7.1 & $c$ & 6.197 & 0.158 & 0.343 & 0.004 & 0.821 & $95.20 \%$ & $1899 \pm 18$ & $1992 \pm 21$ & $2090 \pm 43$ & $1675 \pm 113$ \\
\hline 8.1 & $\mathrm{C}$ & 3,922 & 0.081 & 0.232 & 0.002 & 0.988 & $81.50 \%$ & $1344 \pm 10$ & $1618 \pm 16$ & $1894 \pm 45$ & $1294 \pm 35$ \\
\hline 9.1 & $c$ & 6,677 & 0.140 & 0.372 & 0.003 & 0.842 & $98.40 \%$ & $2037 \pm 15$ & $2069 \pm 18$ & $2101 \pm 19$ & $2215 \pm 47$ \\
\hline
\end{tabular}




\begin{tabular}{|c|c|c|c|c|c|c|c|c|c|c|c|}
\hline 10.1 & $c$ & 7,530 & 0.161 & 0.386 & 0.004 & 0.954 & $96.70 \%$ & $2105 \pm 17$ & $2176 \pm 19$ & $2243 \pm 20$ & $1804 \pm 81$ \\
\hline$\$ 1.1$ & $\mathrm{C}$ & 6,959 & 0.134 & 0.378 & 0.003 & 0,351 & $98.10 \%$ & $2067 \pm 14$ & $2106 \pm 17$ & $2144 \pm 16$ & $2037 \pm 57$ \\
\hline$\$ 2.1$ & $c$ & 6,760 & 0.144 & 0.365 & 0.003 & 0.951 & $96.40 \%$ & $2006 \pm 16$ & $2080 \pm 19$ & $2154 \pm 40$ & $2362 \pm 69$ \\
\hline 13.1 & $\mathrm{C}$ & 6,411 & 0.128 & 0.353 & 0.003 & 0.721 & $95.80 \%$ & $1949 \pm 14$ & $2033 \pm 17$ & $2120 \pm 21$ & $1773 \pm 42$ \\
\hline 14.1 & $c$ & 7,305 & 0.198 & 0.399 & 0.005 & 0.975 & $100.60 \%$ & $2162 \pm 22$ & $2149 \pm 25$ & $2136 \pm 45$ & $1809 \pm 100$ \\
\hline 15.7 & $c$ & 4,685 & 0.086 & 0.272 & 0.002 & 0.836 & $86.90 \%$ & $1548 \pm 10$ & $1764 \pm 15$ & $2031 \pm 17$ & $1518 \pm 26$ \\
\hline 16.1 & $c$ & 6,368 & 0.115 & 0.345 & 0.003 & 0.994 & $94.00 \%$ & $1910 \pm 12$ & $2027 \pm 15$ & $2149 \pm 33$ & $2176 \pm 22$ \\
\hline 17.1 & $\mathrm{C}$ & 6,248 & 0.114 & 0.345 & 0.003 & 0.993 & $94.90 \%$ & $1911 \pm 13$ & $2011 \pm 15$ & $2114 \pm 28$ & $2188 \pm 31$ \\
\hline 18.1 & $C$ & 5,983 & 0.112 & 0.338 & 0.003 & 0.999 & $95.00 \%$ & $1877 \pm 13$ & $1973 \pm 17$ & $2075 \pm 137$ & $1282 \pm 77$ \\
\hline 19.1 & $c$ & 7,268 & 0.147 & 0.380 & 0.003 & 0.994 & $66.80 \%$ & $2077 \pm 15$ & $2144 \pm 18$ & $2209 \pm 28$ & $2428 \pm 51$ \\
\hline 19.2 & $\mathrm{BM}$ & 0.729 & 0.015 & 0.090 & 0.001 & 0.858 & $99.80 \%$ & $554 \pm 3$ & $556 \pm 8$ & $561 \pm 44$ & $518 \pm 84$ \\
\hline 20.1 & $c$ & 7,779 & 0.241 & 0.411 & 0.007 & 0.986 & $100.60 \%$ & $2218 \pm 32$ & $2205 \pm 28$ & $2194 \pm 85$ & $2015 \pm 164$ \\
\hline 21.1 & $\mathrm{C}$ & 8,859 & 0.180 & 0.413 & 0.004 & 0.996 & $95.70 \%$ & $2226 \pm 18$ & $2323 \pm 18$ & $2409 \pm 76$ & $2175 \pm 55$ \\
\hline 21.2 & $8 \pi$ & 0.740 & 0.023 & 0.090 & 0.001 & 0.180 & $98.80 \%$ & $555 \pm 5$ & $562 \pm 13$ & $588 \pm 103$ & $27 \pm 346$ \\
\hline 22.1 & $B^{p}$ & 0.707 & 0.017 & 0.086 & 0.001 & 0.768 & $97.70 \%$ & $530 \neq 4$ & $542 \pm 9$ & $594 \pm 66$ & $17 \pm 291$ \\
\hline 23.1 & $\mathrm{Br}^{\mathrm{L}}$ & 0.727 & 0.015 & 0.089 & 0.001 & 0.356 & $98.80 \%$ & $548 \pm 3$ & $554 \pm 8$ & $583 \pm 50$ & $348 \pm 149$ \\
\hline 24.1 & $\mathrm{C}$ & 2.819 & 0.061 & 0.189 & 0.002 & 0.996 & $78.10 \%$ & $1112 \pm 8$ & $1386 \pm 14$ & $1837 \pm 92$ & $1103 \pm 20$ \\
\hline 25.1 & $c$ & 16,068 & 0.304 & 0.543 & 0.005 & 0.987 & $97.00 \%$ & $2784 \pm 20$ & $2880 \pm 17$ & $2941 \pm 37$ & $2608 \pm 47$ \\
\hline 26.1 & $c$ & 12.262 & 0.226 & 0.496 & 0.004 & 0.980 & $98.90 \%$ & $2595 \pm 18$ & $2624 \pm 17$ & $2647 \pm 23$ & $2300 \pm 39$ \\
\hline 27.1 & $c$ & 7.111 & 0.137 & 0.376 & 0.003 & 0.999 & $96.80 \%$ & $2059 \pm 15$ & $2125 \pm 17$ & $2190 \pm 373$ & $1861 \pm 37$ \\
\hline 28.1 & $c$ & 6,226 & 0.113 & 0.342 & 0.003 & 0.980 & $94.20 \%$ & $1895 \pm 12$ & $2008 \pm 15$ & $2126 \pm 19$ & $1745 \pm 28$ \\
\hline 29.1 & $\mathrm{C}$ & 6.928 & 0.125 & 0.377 & 0.003 & 0.997 & $98.10 \%$ & $2063 \pm 13$ & $2102 \pm 16$ & $2140 \pm 21$ & $2019 \pm 37$ \\
\hline 30.1 & $c$ & 8.786 & 0.163 & 0.444 & 0.004 & 0.995 & $102.20 \%$ & $2367 \pm 16$ & $2316 \pm 17$ & $2270 \pm 37$ & $2097 \pm 37$ \\
\hline 31.1 & C & 7.513 & 0.182 & 0.400 & 0.004 & 0.458 & $99.70 \%$ & $2168 \pm 19$ & $2174 \pm 21$ & $2180 \pm 26$ & $1883 \pm 96$ \\
\hline 32.1 & $c$ & 6,543 & 0.140 & 0.367 & 0.003 & 0.887 & $98.10 \%$ & $2013 \pm 13$ & $2051 \pm 18$ & $2090 \pm 19$ & $1837 \pm 39$ \\
\hline 33.1 & c & 10,092 & 0.220 & 0.457 & 0.004 & 0.980 & $99.40 \%$ & $2427 \pm 19$ & $2443 \pm 20$ & $2456 \pm 36$ & $2152 \pm 81$ \\
\hline 34.1 & $c$ & 6,085 & 0.126 & 0.358 & 0.003 & 0.985 & $99.10 \%$ & $1970 \pm 12$ & $1988 \pm 18$ & $2006 \pm 15$ & $1737 \pm 45$ \\
\hline 35.1 & C & 5,901 & 0.126 & 0.312 & 0.003 & 0.975 & $88.60 \%$ & $1749 \pm 12$ & $1961 \pm 18$ & $2193 \pm 20$ & $1881 \pm 38$ \\
\hline 36.1 & c & 6,450 & 0.133 & 0.356 & 0.003 & 0.917 & $86.30 \%$ & $1964 \pm 12$ & $2039 \pm 18$ & $2115 \pm 20$ & $1692 \pm 38$ \\
\hline
\end{tabular}

4.3.4 BACIAS PALEOZOICAS

4.3.4.1. Amostra JMR 4: "Arenito Arcosjana" gráos de zlrcáo detritico.

\begin{tabular}{|c|c|c|c|c|c|c|c|c|c|c|c|}
\hline \multirow[b]{2}{*}{ Spot } & \multirow[b]{2}{*}{ Local } & \multicolumn{4}{|c|}{ Razoes } & \multirow[b]{2}{*}{$p$} & \multirow[b]{2}{*}{ conc. } & \multicolumn{4}{|c|}{ Idades } \\
\hline & & ${ }^{207} \mathrm{~Pb} / 236 \mathrm{U}$ & \pm 10 & ${ }^{206} \mathrm{~Pb} /{ }^{239} \mathrm{U}$ & \pm 10 & & & ${ }^{208} \mathrm{~Pb} /{ }^{23 \mathrm{i}} \mathrm{U} \pm 1 \sigma$ & ${ }^{207} \mathrm{~Pb} /{ }^{235} \mathrm{U} \pm 1 \sigma$ & $\left.{ }^{207} \mathrm{~Pb}\right|^{200} \mathrm{~Pb} \pm f o$ & ${ }^{208} \mathrm{~Pb} / /^{232} \mathrm{Th} \pm 10$ \\
\hline 1.1 & $c$ & 5,793 & 0.146 & 0.338 & 0.004 & 0.937 & $96.50 \%$ & $1878 \pm 21$ & $1945 \pm 21$ & $2016 \pm 14$ & $1975 \pm 24$ \\
\hline 2.1 & $c$ & 11,700 & 0.317 & 0.477 & 0.007 & 0.406 & $97.40 \%$ & $2515 \pm 29$ & $2580 \pm 25$ & $2632 \pm 84$ & $2434 \pm 74$ \\
\hline 3.1 & c & 4,546 & 0.126 & 0.290 & 0.004 & 0.997 & $94.10 \%$ & $1639 \pm 19$ & $1739 \pm 25$ & $1861 \pm\{59$ & $1484 \pm 51$ \\
\hline 4.1 & c & 0.759 & 0.029 & 0,092 & 0.001 & 0.215 & $98.60 \%$ & $565 \pm 7$ & $573 \pm 16$ & $605 \pm 74$ & $526 \pm 23$ \\
\hline 5.1 & C & 7,277 & 0.197 & 0.388 & 0.005 & 0.832 & $98.50 \%$ & $2113 \pm 25$ & $2145 \pm 24$ & $2177 \pm 25$ & $2065 \pm 69$ \\
\hline 6.1 & c & 4,669 & 0.128 & 0.312 & 0.004 & 0.994 & $99.50 \%$ & $1752 \pm 20$ & $1761 \pm 24$ & $1772 \pm 60$ & $1553 \pm 31$ \\
\hline 7.1 & C & 7.424 & 0.215 & 0.396 & 0.006 & 0.467 & $99.30 \%$ & $2148 \pm 26$ & $2163 \pm 26$ & $2178 \pm 56$ & $2138 \pm 82$ \\
\hline 7.2 & c & 7,315 & 0.189 & 0.390 & 0.005 & 0.941 & $98.70 \%$ & $2122 \pm 24$ & $2150 \pm 22$ & $2177 \pm 15$ & $2083 \pm 40$ \\
\hline 8.1 & c & 0.858 & 0.044 & 0.103 & 0.002 & 0.344 & $100.00 \%$ & $628 \pm 10$ & $628 \pm 24$ & $628 \div 122$ & $593 \pm 15$ \\
\hline 9.1 & $\mathrm{c}$ & 7,245 & 0.346 & 0.379 & 0.008 & 0.872 & $96.70 \%$ & $2071+37$ & $2142 \pm 41$ & $2210 \pm 56$ & $2248 \pm 153$ \\
\hline 9.2 & $8 x$ & 0.793 & 0.031 & 0.095 & 0.001 & 0.410 & $98.80 \%$ & $586 \pm 8$ & $593 \pm 17$ & $619 \pm 59$ & $617 \pm 19$ \\
\hline 10.7 & c & 0.821 & 0.078 & 0.106 & 0.002 & 0.705 & $98.10 \%$ & $650 \pm 13$ & $662 \pm 42$ & $705 \pm 166$ & $632 \pm 47$ \\
\hline 11.1 & C & 6,793 & 0.193 & 0.372 & 0.005 & 0.991 & $97.70 \%$ & $2037 \pm 24$ & $2084 \pm 24$ & $2131 \pm 55$ & $2158 \pm 48$ \\
\hline 12.1 & B & 0.645 & 0.019 & 0.078 & 0.001 & 0.938 & $95.30 \%$ & $482 \pm 6$ & $505 \pm 11$ & $611 \pm 46$ & $331 \pm 6$ \\
\hline 12.2 & C & 0.788 & 0.026 & 0.094 & 0.001 & 0.933 & $88.30 \%$ & $579 \pm 8$ & $589 \pm 15$ & $628 \pm 69$ & $580 \pm 10$ \\
\hline 13.1 & C & 0.766 & 0.030 & 0.093 & 0.002 & 0.533 & $99.20 \%$ & $572 \pm 8$ & $577 \pm 17$ & $595 \pm 86$ & $607 \pm 13$ \\
\hline 14.7 & C & 0.823 & 0.045 & 0.096 & 0.002 & 0.363 & $97.20 \%$ & $592 \pm 10$ & $609 \pm 25$ & $671 \pm 127$ & $635 \pm 48$ \\
\hline 14.2 & B & 0.794 & 0.032 & 0.097 & 0.002 & 0.507 & $101.00 \%$ & $599 \pm 9$ & $593 \pm 18$ & $570 \pm 80$ & $634 \pm 26$ \\
\hline 15.1 & c & 7,632 & 0.264 & 0.396 & 0.007 & 0.232 & $98.30 \%$ & $2151 \pm 33$ & $2188 \pm 31$ & $2223 \pm 55$ & $2225 \pm 114$ \\
\hline 16.1 & $c$ & 4,345 & 0.112 & 0.296 & 0.004 & 0.776 & $98.10 \%$ & $1669 \pm 21$ & $\{701 \pm 21$ & $1742 \pm 19$ & $1774 \pm 28$ \\
\hline 17.1 & C & 4,549 & 0.125 & 0.305 & 0.005 & 0.823 & $98.70 \%$ & $1716 \pm 22$ & $1739 \pm 22$ & $1767 \pm 30$ & $1829 \pm 34$ \\
\hline 18.1 & c & 0.864 & 0.077 & 0.099 & 0.002 & 0.185 & $95.70 \%$ & $605 \pm 13$ & $632 \pm 42$ & $728 \pm 197$ & $664 \pm 35$ \\
\hline
\end{tabular}




\begin{tabular}{|c|c|c|c|c|c|c|c|c|c|c|c|}
\hline 19.1 & c & 0.778 & 0.057 & 0.094 & 0.002 & 0.247 & $98.70 \%$ & $576 \pm 11$ & $584 \pm 33$ & $612 \pm 208$ & $612 \pm 16$ \\
\hline 20.1 & $c$ & 4,350 & 0.169 & 0.288 & 0,005 & 0.964 & $95.60 \%$ & $1629 \pm 26$ & $1702 \pm 33$ & $1793 \pm 101$ & $1734 \pm 82$ \\
\hline 21.1 & $\mathrm{C}$ & 0.939 & 0.054 & 0.106 & 0.002 & 0.211 & $96.20 \%$ & $647 \pm 11$ & $672 \pm 28$ & $758 \pm\{15$ & $678 \pm 11$ \\
\hline 22.1 & $c$ & 0.851 & 0.037 & 0.101 & 0.002 & 0.580 & $98.90 \%$ & $618 \pm 9$ & $625 \pm 20$ & $650 \pm 54$ & $590 \pm 24$ \\
\hline 23.1 & $\mathrm{c}$ & 0.866 & 0.045 & 0.100 & 0.002 & 0.383 & $96.50 \%$ & $611 \pm 9$ & $633 \pm 24$ & $712 \pm 180$ & $512 \pm 22$ \\
\hline 24.1 & $c$ & 0.760 & 0.033 & 0.092 & 0.001 & 0.585 & $99.00 \%$ & $568 \pm 8$ & $574 \pm 18$ & $597 \pm 86$ & $490 \pm 28$ \\
\hline 25.1 & $\mathrm{C}$ & 0.825 & 0.030 & 0.097 & 0.001 & 0.333 & $98.10 \%$ & $599 \pm 7$ & $610 \pm 16$ & $653 \pm 68$ & $506 \pm 13$ \\
\hline 26.1 & $\mathrm{C}$ & 4,429 & 0.094 & 0.299 & 0.003 & 0.701 & $98.00 \%$ & $1684 \pm 16$ & $\$ 717 \pm 17$ & $1758 \pm 14$ & $1439 \pm 33$ \\
\hline 27.1 & $c$ & 4,491 & 0.104 & 0.302 & 0.004 & 0.949 & $98.20 \%$ & $1698 \pm 17$ & $1729 \pm 19$ & $1766 \pm 24$ & $1448 \pm 34$ \\
\hline 28.1 & $c$ & 6,727 & 0.144 & 0.362 & 0.004 & 0.983 & $95.90 \%$ & $1993 \pm 19$ & $2076 \pm 19$ & $2159 \pm 15$ & $1663 \pm 52$ \\
\hline 29.1 & $c$ & 1,370 & 0.131 & 0.142 & 0,004 & 0.347 & $97.70 \%$ & $856 \pm 20$ & $876 \pm 55$ & $927 \pm 328$ & $656 \pm 76$ \\
\hline 30.1 & C & 0.775 & 0,024 & 0,094 & 0.001 & 0.771 & $99.10 \%$ & $577 \pm 6$ & $582 \pm 13$ & $604 \pm 111$ & $473 \pm 18$ \\
\hline 31.1 & C & 0.787 & 0.056 & 0.093 & 0.002 & 0.255 & $96.80 \%$ & $570 \pm 10$ & $589 \pm 32$ & $661 \pm 241$ & $477 \pm 58$ \\
\hline 32.1 & $\mathrm{C}$ & 6,963 & 0.321 & 0.385 & 0.008 & 0.626 & $99.70 \%$ & $2101 \pm 37$ & $2106 \pm 39$ & $2111 \times 88$ & $2015 \pm 316$ \\
\hline 33.1 & $\mathrm{C}$ & 2,417 & 0.075 & 0.208 & 0.003 & 0.976 & $97.80 \%$ & $1220 \pm 14$ & $1247 \pm 22$ & $1294 \pm 122$ & $998 \pm 55$ \\
\hline 34.1 & $c$ & 1,484 & 0.049 & 0.153 & 0.002 & 0.443 & $99.30 \%$ & $917 \pm 11$ & $923 \neq 19$ & $939 \pm 51$ & $803 \pm 29$ \\
\hline 35.1 & $c$ & 7,254 & 0.203 & 0.390 & 0.006 & 0.636 & $98.90 \%$ & $2120 \pm 25$ & $2143 \pm 24$ & $2165 \pm 35$ & $1869 \pm 179$ \\
\hline 36.1 & $c$ & 0.825 & 0.056 & 0.100 & 0.001 & 0.213 & $100.40 \%$ & $612 \pm 8$ & $610 \pm 30$ & $602 \pm 120$ & $725 \pm 23$ \\
\hline 37.1 & $c$ & 0.796 & 0.055 & 0.096 & 0.001 & 0.455 & $99.60 \%$ & $592 \pm 8$ & $594 \pm 31$ & $604 \pm 165$ & $640 \pm 34$ \\
\hline 38.1 & $\mathrm{c}$ & 1,312 & 0.128 & 0.142 & 0.003 & 0.485 & $100.80 \%$ & $858 \pm 15$ & $851 \pm 55$ & $832 \pm 306$ & $1007 \pm 95$ \\
\hline 39.1 & $\mathrm{C}$ & 2,098 & 0.049 & 0.188 & 0.002 & 0.945 & $86.70 \%$ & $1111 \pm 9$ & $1148 \pm 16$ & $12 \mathfrak{1} \pm 25$ & $1211 \pm 66$ \\
\hline 40.1 & $\mathrm{C}$ & 0.815 & 0.093 & 0.100 & 0.002 & 0.514 & $101.40 \%$ & $613 \pm 11$ & $605 \pm 49$ & $574 \pm 358$ & $728 \pm 67$ \\
\hline 41.1 & $c$ & 0.784 & 0.028 & 0.086 & 0.001 & 0.388 & $100.40 \%$ & $590 \pm 5$ & $587 \pm 15$ & $578 \pm 53$ & $679 \pm 9$ \\
\hline 42.1 & $c$ & 0.819 & 0.046 & 0.099 & 0.001 & 0.419 & $100.00 \%$ & $607 \pm 7$ & $607 \pm 25$ & $608 \pm 109$ & $727 \pm 19$ \\
\hline 43.1 & $c$ & 5,982 & 0.141 & 0.350 & 0.003 & 0.931 & $98.10 \%$ & $1936 \pm 16$ & $1973 \pm 20$ & $2011 \pm 25$ & $2245 \pm 57$ \\
\hline 44.1 & $c$ & 0.778 & 0.055 & 0.091 & 0.001 & 0.233 & $96.40 \%$ & $563 \pm 8$ & $584 \pm 31$ & $665 \pm\{44$ & $646 \pm 34$ \\
\hline 45.1 & $\mathrm{c}$ & 1,378 & 0.121 & 0.147 & 0.003 & 0.296 & $100.50 \%$ & $883 \pm 14$ & $879 \pm 51$ & $869 \pm 191$ & $1032 \pm 88$ \\
\hline 46.1 & $c$ & 4,269 & 0.117 & 0.289 & 0.003 & 0.746 & $96.80 \%$ & $1634 \pm 15$ & $1687 \pm 22$ & $1754 \pm 21$ & $1829 \pm 32$ \\
\hline 47.1 & $\mathrm{Bu}^{\mathrm{x}}$ & 0.758 & 0.060 & 0.093 & 0.002 & 0.192 & $100.20 \%$ & $573 \pm 8$ & $572 \pm 36$ & $568 \pm 268$ & $383 \pm 1329$ \\
\hline 47.2 & $\mathrm{c}$ & 5,923 & 0.169 & 0.339 & 0.004 & 0.886 & $95.60 \%$ & $1880 \pm 17$ & $1964 \pm 24$ & $2054 \pm 29$ & $2082 \pm 36$ \\
\hline 48.1 & $c$ & 5,780 & 0.133 & 0.327 & 0.003 & 0.978 & $93.60 \%$ & $1822 \pm 16$ & $1843 \pm 19$ & $2074 \pm 58$ & $1398 \pm 47$ \\
\hline 49.1 & $c$ & 5,670 & 0.125 & 0.326 & 0.003 & 0,888 & $94.40 \%$ & $1820 \pm 16$ & $1926 \pm 18$ & $2042 \pm 12$ & $1858 \pm 20$ \\
\hline 50.1 & $c$ & 5,675 & 0.153 & 0.341 & 0.004 & 0.619 & $98.10 \%$ & $1890 \pm 19$ & $1927 \pm 23$ & $1967 \pm 28$ & $1821 \pm 46$ \\
\hline 50.2 & B & 1,908 & 0.047 & 0.139 & 0.002 & 0.905 & $74,50 \%$ & $838 \neq 8$ & $1083 \pm 16$ & $1616 \pm 75$ & $417 \pm 18$ \\
\hline 51.1 & $c$ & 0.777 & 0.042 & 0.094 & 0.001 & 0.149 & $99.40 \%$ & $579 \pm 7$ & $583 \pm 23$ & $598 \pm 137$ & $542 \pm 13$ \\
\hline 52.1 & $c$ & 0.830 & 0.025 & 0.098 & 0.001 & 0.909 & $97.90 \%$ & $600 \pm 6$ & $613 \pm 13$ & $659 \pm 47$ & $605 \pm 11$ \\
\hline 53.1 & C & 9,006 & 0.188 & 0.329 & 0.003 & 0.998 & $75.90 \%$ & $1835 \pm 15$ & $2338 \pm 17$ & $2812 \pm 80$ & $24 \$ 6 \pm 27$ \\
\hline 53.2 & B & 1,669 & 0.046 & 0.125 & 0.001 & 0.996 & $72.60 \%$ & $756 \pm 7$ & $996 \pm 14$ & $1570 \pm 438$ & $1897 \pm 77$ \\
\hline 53.3 & $\mathrm{Br}^{\mathrm{n}}$ & 0.695 & 0.020 & 0.083 & 0.001 & 0.984 & $95.60 \%$ & $512 \pm 5$ & $536 \pm 12$ & $636 \pm 25$ & $236 \pm 43$ \\
\hline 54.1 & c & 5,860 & 0.125 & 0.341 & 0.003 & 0.997 & $96.80 \%$ & $1893 \pm 16$ & $1955 \pm 17$ & $2021 \pm 64$ & $1469 \pm 59$ \\
\hline 54.2 & B & 3,067 & 0.077 & 0.192 & 0.002 & 0.997 & $77.30 \%$ & $1134 \pm 11$ & $1424 \pm 18$ & $1889 \pm 112$ & $476 \pm 33$ \\
\hline 65.1 & C & 6,916 & 0.760 & 0.379 & 0.004 & 0.859 & $98.70 \%$ & $2073 \pm 19$ & $2100 \pm 20$ & $2127 \pm 17$ & $2112 \pm 43$ \\
\hline 56.1 & $c$ & 0.764 & 0.029 & 0.093 & 0.001 & 0.817 & $99.20 \%$ & $571 \pm 6$ & $576 \pm 16$ & $595 \pm 43$ & $530 \pm 28$ \\
\hline 57.1 & $c$ & 0.632 & 0.020 & 0.078 & 0.001 & 0.784 & $96.80 \%$ & $481 \pm 5$ & $497 \pm 12$ & $569 \pm 68$ & $253 \pm 6$ \\
\hline 57.2 & $8 x$ & 0.756 & 0.025 & 0.091 & 0.001 & 0.587 & $97.90 \%$ & $560 \pm 6$ & $571 \pm 14$ & $618 \pm 49$ & $453 \pm 20$ \\
\hline 58.1 & C & 0.817 & 0.048 & 0.094 & 0.002 & 0.550 & $95.00 \%$ & $576 \pm 9$ & $606 \pm 26$ & $717 \pm 152$ & $508 \pm 20$ \\
\hline 59.1 & $c$ & 6,805 & 0.170 & 0.369 & 0.004 & 0.966 & $97.00 \%$ & $2024 \pm 20$ & $2085 \pm 21$ & $2147 \pm 21$ & $1999 \pm 50$ \\
\hline 60.1 & c & 1.255 & 0.064 & 0.137 & 0.002 & 0.417 & $100.20 \%$ & $827 \pm 12$ & $825 \pm 28$ & $821 \pm 101$ & $758 \pm 23$ \\
\hline 61.1 & $\mathrm{c}$ & 0.841 & 0.042 & 0.101 & 0.002 & 0.613 & $99.70 \%$ & $617 \pm 9$ & $619 \pm 22$ & $627 \pm 102$ & $556 \pm 28$ \\
\hline 62.1 & $c$ & 0.774 & 0.033 & 0.094 & 0.001 & 0.523 & $99.30 \%$ & $577 \pm 7$ & $581 \pm 18$ & $598 \pm 88$ & $487 \pm 14$ \\
\hline 63.1 & $c$ & 0.818 & 0.036 & 0.099 & 0.001 & 0.129 & $100.00 \%$ & $606 \pm 8$ & $605 \pm 20$ & $607 \pm 86$ & $575 \pm 16$ \\
\hline 64.1 & c & 0.921 & 0.094 & 0.101 & 0.003 & 0.088 & $93.20 \%$ & $618 \pm 15$ & $663 \pm 48$ & $814 \pm 368$ & $564 \pm 43$ \\
\hline 65.1 & $c$ & 0.778 & 0.025 & 0.095 & 0.001 & 0.591 & $100.00 \%$ & $584 \pm 6$ & $584 \pm 14$ & $584 \pm 78$ & $459 \pm 67$ \\
\hline 66.1 & $c$ & 0.821 & 0.022 & 0.098 & 0.001 & 0.798 & $99.40 \%$ & $604 \pm 6$ & $608 \pm 12$ & $622 \pm 31$ & $557 \pm 13$ \\
\hline 67.1 & $c$ & 0.843 & 0.033 & 0.101 & 0.001 & 0.693 & $99.70 \%$ & $619 \pm 8$ & $620 \pm 18$ & $627 \pm 146$ & $504 \pm 13$ \\
\hline
\end{tabular}




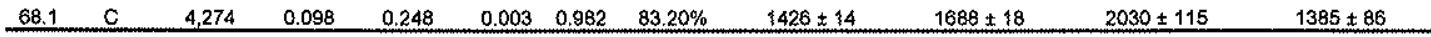
4.3.4.2. Amostra JMR 5: "Arenito Litico" gräos de zircăo detritico.

\begin{tabular}{|c|c|c|c|c|c|c|c|c|c|c|c|}
\hline \multirow[b]{2}{*}{ Spot } & \multirow[b]{2}{*}{ Local } & \multicolumn{4}{|c|}{ Razoes } & \multirow[b]{2}{*}{$\rho$} & \multirow[b]{2}{*}{ conc. } & \multicolumn{4}{|c|}{ Idades } \\
\hline & & ${ }^{207} \mathrm{~Pb} /{ }^{235} \mathrm{U}$ & \pm 10 & ${ }^{206} \mathrm{~Pb}^{238} \mathrm{U}$ & \pm 10 & & & ${ }^{200} \mathrm{~Pb} /{ }^{23 \theta} \mathrm{U} \pm 1 \mathrm{~g}$ & ${ }^{207} \mathrm{~Pb} /{ }^{235} \mathrm{U} \pm 10$ & ${ }^{207} \mathrm{~Pb} /{ }^{206} \mathrm{~Pb} \pm 1 \sigma$ & ${ }^{208} \mathrm{~Pb}$ / $^{252} \mathrm{Th} \pm 10$ \\
\hline 1.1 & c & 7,089 & 0.204 & 0.374 & 0.006 & 0.978 & $96.50 \%$ & $2049 \pm 28$ & $2122 \pm 25$ & $2194 \pm 14$ & $2186 \pm 27$ \\
\hline 2.1 & $c$ & 10,047 & 0.296 & 0.458 & 0.008 & 0.996 & $99.70 \%$ & $2432 \pm 33$ & $2438 \pm 26$ & $2444 \pm 84$ & $2561 \pm 36$ \\
\hline 3.1 & $\mathrm{C}$ & 7,044 & 0.203 & 0.367 & 0.006 & 0.975 & $95.00 \%$ & $2013 \pm 28$ & $2117 \pm 25$ & $2219 \pm 9$ & $1965 \pm 30$ \\
\hline 4.1 & $\mathrm{c}$ & 2,302 & 0.075 & 0.145 & 0.003 & 0.805 & $67.10 \%$ & $869 \pm 14$ & $1212 \pm 22$ & $1888 \pm 88$ & $596 \pm 11$ \\
\hline 5.1 & C & 7,732 & 0.219 & 0.396 & 0.007 & 0.999 & $97.80 \%$ & $2151 \pm 29$ & $2200 \pm 25$ & $2245 \pm 57$ & $2234 \pm 29$ \\
\hline 6.1 & C & 7.913 & 0.246 & 0.406 & 0.007 & 0.976 & $98.90 \%$ & $2\{97 \pm 32$ & $2221 \pm 27$ & $2243 \pm 16$ & $2377 \pm 28$ \\
\hline 7.1 & c & 7,339 & 0.210 & 0.399 & 0.007 & 0.963 & $100.40 \%$ & $2162 \pm 30$ & $2153 \pm 25$ & $2145 \pm 10$ & $2305 \pm 33$ \\
\hline 8.1 & $c$ & 1,950 & 0.286 & 0.173 & 0.007 & 0.341 & $93.20 \%$ & $1026 \pm 40$ & $1098 \pm 99$ & $1243 \pm 294$ & $1208 \pm 234$ \\
\hline 9.1 & C & 0.803 & 0.034 & 0.095 & 0.002 & 0.762 & $88.00 \%$ & $587 \pm 10$ & $598 \pm 19$ & $643 \pm 55$ & $602 \pm 15$ \\
\hline 9.2 & $B$ & 0.758 & 0.043 & 0.095 & 0.002 & 0.157 & $102.00 \%$ & $584 \pm 11$ & $573 \pm 24$ & $528 \pm 124$ & $619 \pm 19$ \\
\hline 10.1 & c & 7,778 & 0.253 & 0.402 & 0.007 & 0.951 & $98.80 \%$ & $2178 \pm 33$ & $2205 \pm 28$ & $2231 \pm 18$ & $2210 \pm 41$ \\
\hline 10.2 & B & 6,845 & 0.211 & 0.357 & 0.006 & 0.961 & $93.80 \%$ & $1966 \pm 28$ & $2091 \pm 27$ & $2216 \pm 12$ & $1470 \pm 38$ \\
\hline 11.1 & $c$ & 7,452 & 0.256 & 0.388 & 0.008 & 0.895 & $97.50 \%$ & $2114 \pm 34$ & $2167 \pm 29$ & $2217 \pm 24$ & $2259 \pm 64$ \\
\hline 12.1 & $c$ & 0.769 & 0.029 & 0.094 & 0.001 & 0.733 & $99.70 \%$ & $577 \pm 6$ & $579 \pm 16$ & $587 \pm 57$ & $474 \pm 15$ \\
\hline 13.1 & $c$ & 7,014 & 0.198 & 0.385 & 0.004 & 0.760 & $99.50 \%$ & $2101 \pm 20$ & $2113 \pm 24$ & $2124 \pm 23$ & $1786 \pm 42$ \\
\hline 14.1 & $c$ & 7,175 & 0.171 & 0.381 & 0.004 & 0.882 & $97.50 \%$ & $2080 \pm 16$ & $2133 \pm 21$ & $2184 \pm 13$ & $1828 \pm 33$ \\
\hline 15.1 & $c$ & 5,363 & 0.263 & 0.335 & 0.007 & 0.573 & $99.20 \%$ & $1863 \pm 33$ & $1878 \pm 43$ & $1895 \pm 101$ & $1549 \pm 78$ \\
\hline 16.1 & $C$ & 7,302 & 0.175 & 0.380 & 0.004 & 0.998 & $96.70 \%$ & $2078 \pm 16$ & $2149 \pm 21$ & $2217 \pm 61$ & $1567 \pm 27$ \\
\hline 17.1 & B & 1,694 & 0.052 & 0.166 & 0.002 & 0.728 & $98.60 \%$ & $992 \pm 10$ & $1006 \pm 19$ & $1037 \pm 31$ & $851 \pm 35$ \\
\hline 18.7 & $C$ & 7,270 & 0.192 & 0.387 & 0.004 & 0.719 & $98.20 \%$ & $2106 \pm 18$ & $2145 \pm 23$ & $2182 \pm 14$ & $1742 \pm 26$ \\
\hline 19.1 & C & 24,815 & 0.608 & 0.657 & 0.007 & 0.897 & $98.60 \%$ & $3254 \pm 27$ & $3300 \pm 24$ & $3329 \pm 27$ & $3224 \pm 99$ \\
\hline 20.7 & c & 5,685 & 0.141 & 0.336 & 0.003 & 0.940 & $96.80 \%$ & $1868 \pm 15$ & $1929 \pm 21$ & $1995 \pm 15$ & $1650 \pm 27$ \\
\hline 20.2 & B & 0.682 & 0.176 & 0.077 & 0.005 & 0.084 & $90.20 \%$ & $478 \pm 30$ & $528 \pm 113$ & $747 \pm 557$ & $41 \pm 59$ \\
\hline 21.3 & $\mathrm{C}$ & 19,434 & 0,502 & 0,586 & 0.007 & 0.979 & $97.00 \%$ & $2874 \pm 27$ & $3063 \pm 24$ & $3122 \pm 9$ & $2585 \pm 80$ \\
\hline 22.1 & c & 7,213 & 0.177 & 0.377 & 0.004 & 0.952 & $96.30 \%$ & $2060 \pm 17$ & $2138 \pm 22$ & $2213 \pm 13$ & $1754 \pm 37$ \\
\hline 23.1 & $c$ & 0.765 & 0.043 & 0.093 & 0.002 & 0.307 & $99.30 \%$ & $572 \pm 8$ & $576 \pm 24$ & $592 \pm 127$ & $463 \pm 35$ \\
\hline 24.1 & $c$ & 6,549 & 0.178 & 0.369 & 0.004 & 0.440 & $98.60 \%$ & $2023 \pm 19$ & $2052 \pm 23$ & $2081 \pm 29$ & $2822 \pm 76$ \\
\hline 25.1 & $c$ & 1,161 & 0.036 & 0.129 & 0.001 & 0.288 & $100.20 \%$ & $783 \pm 7$ & $782 \pm 17$ & $778 \pm 48$ & $934 \pm 50$ \\
\hline 26.1 & $c$ & 9,809 & 0.212 & 0.452 & 0.004 & 0.731 & $99.40 \%$ & $2401 \pm 18$ & $2416 \pm 19$ & $2429 \pm 13$ & $3287 \pm 86$ \\
\hline 27.1 & $C$ & 0.834 & 0.049 & 0.104 & 0.002 & 0.587 & $103.10 \%$ & $635 \pm 9$ & $615 \pm 27$ & $545 \pm 135$ & $832 \pm 43$ \\
\hline 28.1 & $c$ & 1,650 & 0.113 & 0.164 & 0.003 & 0.335 & $98.80 \%$ & $979 \pm 18$ & $889 \pm 43$ & $1012 \pm 140$ & $1146 \pm 65$ \\
\hline 29.1 & C & 0.972 & 0.067 & 0.116 & 0.002 & 0.264 & $102.50 \%$ & $707 \pm 12$ & $689 \pm 34$ & $633 \pm 161$ & $960 \pm 197$ \\
\hline 29.2 & 8 & 1.027 & 0.054 & 0.114 & 0.002 & 0.545 & $96.90 \%$ & $695 \pm 10$ & $717 \pm 27$ & $785 \pm 189$ & $717 \pm \$ 34$ \\
\hline 30.1 & $c$ & 1,535 & 0.078 & 0.160 & 0.003 & 0.371 & $101.20 \%$ & $955 \pm 13$ & $944 \pm 31$ & $917 \pm 87$ & $1282 \pm 56$ \\
\hline 31.1 & C & 0.812 & 0.051 & 0.093 & 0.002 & 0.562 & $95.00 \%$ & $574 \pm 9$ & $603 \pm 30$ & $715 \pm 237$ & $751 \pm 50$ \\
\hline 32.1 & C & 0.813 & 0.029 & 0.096 & 0.001 & 0.930 & $97.80 \%$ & $591 \pm 6$ & $604 \pm 16$ & $653 \pm 74$ & $703 \pm 23$ \\
\hline 33.1 & $C$ & 7,133 & 0.187 & 0.379 & 0.004 & 0.870 & $97.30 \%$ & $2072 \pm 19$ & $2128 \pm 23$ & $2182 \pm 28$ & $2884 \pm 76$ \\
\hline 34.1 & C & 1,745 & 0.064 & 0.171 & 0.002 & 0.619 & $99.00 \%$ & $1014 \pm 11$ & $1025 \pm 24$ & $1047 \pm 60$ & $1483 \pm 57$ \\
\hline 35.1 & $c$ & 0.728 & 0.043 & 0.087 & 0.001 & 0.640 & $96.70 \%$ & $537 \pm 8$ & $555 \pm 25$ & $630 \pm 159$ & $677 \pm 51$ \\
\hline 36.1 & $c$ & 5,416 & 0.126 & 0.305 & 0.003 & 0.996 & $90.40 \%$ & $1714 \pm 16$ & $1887 \pm 20$ & $2083 \pm 37$ & $2485 \pm 39$ \\
\hline 37.1 & $B$ & 2,760 & 0.061 & 0.162 & 0.002 & 0.994 & $67.10 \%$ & $965 \pm 9$ & $1344 \pm 16$ & $2013 \pm 97$ & $1050 \pm 10$ \\
\hline 38.1 & c & 4,848 & 0.139 & 0.308 & 0.004 & 0.985 & $95.60 \%$ & $1732 \pm 18$ & $1810 \pm 23$ & $1901 \pm 34$ & $2852 \pm 53$ \\
\hline 39.1 & C & 0.765 & 0.073 & 0.091 & 0.002 & 0.346 & $96.90 \%$ & $559 \pm 11$ & $576 \pm 42$ & $646 \pm 320$ & $768 \pm 85$ \\
\hline 40.1 & $\mathrm{C}$ & 0.732 & 0.027 & 0.091 & 0.001 & 0.876 & $100.10 \%$ & $558 \pm 6$ & $557 \neq 15$ & $555 \pm 47$ & $706 \pm 19$ \\
\hline 41.1 & C & 7,528 & 0.188 & 0.405 & 0.005 & 0.985 & $100.80 \%$ & $2192 \pm 21$ & $2176 \pm 23$ & $2160 \pm 42$ & $2699 \pm 86$ \\
\hline 42.1 & c & 7,651 & 0.210 & 0.394 & 0.005 & 0.993 & $97.60 \%$ & $2139 \pm 22$ & $2190 \pm 24$ & $2239 \pm 40$ & $3327 \pm 61$ \\
\hline 43.1 & $c$ & 0.825 & 0.056 & 0.098 & 0.002 & 0.596 & $98.80 \%$ & $604 \pm 9$ & $610 \pm 31$ & $636 \pm 197$ & $833 \pm 45$ \\
\hline 44.1 & C & 0.838 & 0.035 & 0.098 & 0.001 & 0.407 & $97.80 \%$ & $605 \pm 7$ & $618 \pm 19$ & $666 \pm 64$ & $905 \pm 29$ \\
\hline 45.1 & $c$ & 7,401 & 0.220 & 0.391 & 0.005 & 0.965 & $98.40 \%$ & $2\{27 \pm 23$ & $2161 \pm 26$ & $2193 \pm 19$ & $3223 \pm 86$ \\
\hline 46.1 & $c$ & 0.719 & 0.049 & 0.092 & 0.002 & 0.647 & $102.70 \%$ & $564 \pm 8$ & $549 \pm 28$ & $488 \pm 188$ & $834 \pm 53$ \\
\hline 47.1 & C & 7,029 & 0.176 & 0.375 & 0.004 & 0.959 & $97.00 \%$ & $2052 \pm 20$ & $2115 \pm 21$ & $2176 \pm 18$ & $3049 \pm 31$ \\
\hline
\end{tabular}




\begin{tabular}{|c|c|c|c|c|c|c|c|c|c|c|c|}
\hline 48.1 & $c$ & 0.908 & 0.082 & 0.105 & 0.002 & 0.852 & $98.20 \%$ & $644 \pm 12$ & $656 \pm 42$ & $695 \pm 284$ & $1146 \pm 91$ \\
\hline 49.1 & $\mathrm{c}$ & 1,487 & 0.050 & 0.152 & 0.002 & 0.645 & $98.50 \%$ & $911 \pm 11$ & $925 \pm 20$ & $957 \pm 144$ & $853 \pm 30$ \\
\hline 50.1 & $c$ & 0.748 & 0.029 & 0.090 & 0.001 & 0.467 & $98.00 \%$ & $555 \pm 7$ & $566 \pm 16$ & $611 \pm 118$ & $573 \pm 17$ \\
\hline 51.1 & c & 11.422 & 0.229 & 0.470 & 0.005 & 0.764 & $97.00 \%$ & $2481 \pm 22$ & $2558 \pm 18$ & $2619 \pm 11$ & $2474 \pm 28$ \\
\hline 52,1 & $c$ & 0.646 & 0.025 & 0.100 & 0.001 & 0.833 & $118.20 \%$ & $612 \pm 7$ & $505 t 15$ & $45 \pm 256$ & $522 \pm 9$ \\
\hline 53.1 & c & 12,446 & 0.249 & 0.481 & 0.005 & 0.963 & $95.80 \%$ & $2530 \div 22$ & $2638 \pm 18$ & $2722 \pm 24$ & $2444 \pm 28$ \\
\hline 54.1 & $\mathrm{C}$ & 7,173 & 0.145 & 0.384 & 0.004 & 0.949 & $98.10 \%$ & $2093 \pm 19$ & $2133 \pm 17$ & $2179 \pm \ddagger 2$ & $2057 \pm 27$ \\
\hline 55.1 & C & 7,123 & 0.141 & 0.374 & 0.004 & 0.928 & $96.20 \%$ & $2046 \pm 18$ & $2126 \pm 17$ & $2205 \pm 23$ & $2038 \pm 22$ \\
\hline 56.1 & c & 7,157 & 0.146 & 0.388 & 0.004 & 0.948 & $99.20 \%$ & $2115 \pm 19$ & $2131 \pm 18$ & $2146 \pm 12$ & $2165 \pm 31$ \\
\hline 57.1 & $c$ & 7,640 & 0.157 & 0.396 & 0.004 & 0.826 & $98.20 \%$ & $2151+20$ & $2189 \pm 18$ & $2225 \pm 13$ & $2137 \pm 26$ \\
\hline 58.1 & c & 0.757 & 0.019 & 0.089 & 0.001 & 0.411 & $95.40 \%$ & $546 \pm 6$ & $572 \pm 11$ & $675 \pm 63$ & $538 \pm 10$ \\
\hline 59.1 & $\mathrm{C}$ & 0.811 & 0.034 & 0.095 & 0.002 & 0.243 & $96.40 \%$ & $582 \pm 8$ & $603 \pm 19$ & $683 \pm 191$ & $559 \pm 23$ \\
\hline 60.1 & $c$ & 6.235 & 0.118 & 0.358 & 0.004 & 0.992 & $98.10 \%$ & $1971 \pm 17$ & $2009 \pm 16$ & $2048 \pm 20$ & $1880 \pm 23$ \\
\hline 61.1 & $c$ & 1,316 & 0.054 & 0.143 & 0.002 & 0.113 & $100.90 \%$ & $860 \pm 12$ & $852 \pm 23$ & $832 \pm 130$ & $858 \pm 36$ \\
\hline 62.1 & $\mathrm{C}$ & 1,801 & 0.068 & 0.771 & 0.003 & 0.557 & $97.20 \%$ & $1016 \pm 15$ & $1045 \pm 25$ & $1106 \pm 68$ & $935 \pm 21$ \\
\hline 63.1 & $\mathrm{C}$ & 4,628 & 0.199 & 0.305 & 0.006 & 0.452 & $97.90 \%$ & $1717 \pm 30$ & $1754 \pm 36$ & $1798 \pm 82$ & $1530 \pm 43$ \\
\hline 64.1 & $c$ & 16,020 & 0.348 & 0.549 & 0.007 & 0.986 & $97.90 \%$ & $2818 \pm 27$ & $2877 \pm 21$ & $2919 \pm 70$ & $2617 \pm 36$ \\
\hline 65.1 & $c$ & 0.925 & 0.067 & 0.108 & 0,003 & 0.246 & $99.30 \%$ & $660 \pm 14$ & $665 \pm 35$ & $680 \pm 277$ & $591 \pm 46$ \\
\hline 66.1 & $c$ & 0.972 & 0.026 & 0.112 & 0.001 & 0.850 & $98,90 \%$ & $682 \pm 8$ & $689 \pm 13$ & $713 \pm 33$ & $602 \pm 9$ \\
\hline 67.1 & c & 0.737 & 0.025 & 0.089 & 0.001 & 0.481 & $97,60 \%$ & $547 \pm 7$ & $560 \pm 14$ & $614 \pm 60$ & $467 \pm 9$ \\
\hline 68.1 & $c$ & 0.794 & 0.029 & 0.095 & 0.001 & 0.034 & $98.70 \%$ & $586 \pm 8$ & $583 \pm 16$ & $622 \pm 80$ & $553 \pm 14$ \\
\hline 69.1 & $c$ & 7,648 & 0.169 & 0.400 & 0.005 & 0.992 & $98.90 \%$ & $2166 \pm 22$ & $2190 \pm 20$ & $2212 \pm 22$ & $1934 \pm 22$ \\
\hline 69.2 & $B$ & 5,223 & 0.167 & 0.294 & 0.005 & 0.982 & $89,00 \%$ & $1663 \pm 23$ & $1856 \pm 25$ & $2079 \pm 67$ & $823 \pm 41$ \\
\hline 70.1 & $c$ & 0.877 & 0.031 & 0.103 & 0.002 & 0.414 & $98.70 \%$ & $631 \pm 8$ & $639 \pm 16$ & $668 \pm 236$ & $590 \pm 11$ \\
\hline 71.1 & $c$ & 1,628 & 0.056 & 0.161 & 0.002 & 0.276 & $98.00 \%$ & $961 \pm 13$ & $981 \pm 21$ & $1024 \pm 87$ & $901 \pm 23$ \\
\hline 72.1 & c & 8,840 & 0.201 & 0.428 & 0.005 & 0.963 & $98.90 \%$ & $2295 \pm 24$ & $2321 \pm 21$ & $2344 \pm 42$ & $2044 \pm 34$ \\
\hline 73.1 & $c$ & 4,552 & 0.120 & 0.304 & 0.004 & 0.968 & $98.30 \%$ & $1710 \pm 20$ & $1740 \pm 22$ & $1776 \pm 36$ & $1485 \pm 27$ \\
\hline
\end{tabular}


ANEXO 3 


\section{ANEXO 1. ANÁLISE PETROGRÁFICA}

Foram confeccionadas 11 seções delgadas das amostras estudadas para as análise petrográfica. As descrições são apresentadas abaixo.

\section{COMPLEXO DE EMBASAMENTO (COMPLEXO GRANJEIRO)}

\section{Ortognaisse JMR-1A}

Rocha de composição tonalítica, de textura grano-lepidoblástica constitulda essencialmente por quartzo $(25 \%)$, biotita $(30 \%)$, plagioclásio $(30 \%)$, álcali-feldspato $(4 \%)$, epídoto $(10 \%)$, titanita $(2 \%)$, e acessoriamente por hornblenda e minerais opacos. Apresenta-se moderadamente foliada, com uma foliação espaçada, do tipo xistosa. O domínio de micrólitos é definido por quartzo, plagioclásio e álcali-feldspato, enquanto o domínio de clivagem é caracterizado por biotita Fig.1.1 (A)(B).

Cristais de quartzo exibem feições de deformação tipo, extinção ondulante e subgrãos, ,estabelecendo contatos retos, denteados, e ligeiramente curvados e lobados entre si. Os gräos săo inequigranulares com tendência a formar uma trama hexagonal. Relações de contatos com cristais de plagioclásio e álcali-feldspatos são dominantemente retas, lobadas e denteadas, enquanto com cristais de biotita são retas e levemente curvas. Apresentam tamanhos máximos de $200 \mu \mathrm{m}$.

Os cristais de biotita apresentam-se com hábitos lamelares, são subedrais e anedrais, com tamanhos variando de $25 \mu \mathrm{m}$ a $1 \mathrm{~mm}$. Em geral possuem moderada orientação preferencial. Cristais de plagioclásio principalmente de tipo albita, apresentam hábitos granulares, tamanhos finos a médios e formas subédricas a anédricas. Exibem contatos retos entre si e com biotita. Apresentam orientação preferencial moderada, feições de fraturamento e alteração para sericita e minerais do grupo do epídoto principalmente espécie zoisita.

Os cristais de álcali-feldspato são subédricas e com tamanhos de $200 \mu \mathrm{m}$ a $400 \mu \mathrm{m}$. Encontram-se moderadamente orientados, estabelecendo contatos retos e curvos com plagioclásio e quartzo. Apresentam feições de faturamento e feições de alteração para caulinita.

Os cristais de epídoto apresentam tamanhos entre $30 \mu \mathrm{m}$ e $200 \mu \mathrm{m}$, são subédricas, hábito granular e moderada orientação preferencial. Estabelecem relações de contatos curvas e retas com cristais de quartzo e plagioclásio e curvas e irregulares com magnetita, óxidos de ferro e opacos, sendo o epidoto o produto de alteração. Fig 1.1. (C)(D)

Cristais de titanita são losangular e inequigranulares, subédricos a anédricos, e exibem tamanhos máximos de $350 \mu \mathrm{m}$, possuem fraca orientação preferencial e apresentam paragêneses com biotita e predominantemente com opacos (ilmenita?) da qual surgem como produto de alteração. Fig.1.1 (E)(F)(G). 
Os cristais de hornblenda são equigranulares e em geral possuem tamanhos médios de $250 \mu \mathrm{m}$, são euédricas a subédricas e com orientação preferencial moderada. Mostram relações de contatos serrilhadas e irregulares. Feições de alteração são caracterizadas por cristais de clorita (Fig.1.1 (C) e (D).

Minerais opacos exibem cristais euédricos hexagonais e retangulares, equigranulares, de magnetita(?) e/ou hematita(?). Em geral possuem tamanhos de $700 \mu \mathrm{m}$, e fraca orientação preferencial, desenvolvendo epídoto. Minerais opacos de caráter anedral, possivelmente ilmenita, alteram para titanita, e exibem contatos curvos.

\section{Ortognaisse JMR-1B}

Rocha de composicão tonalítico-granodiorítica, de textura grano-lepidoblástica, composta por quartzo $(25 \%)$, biotita $(26 \%)$, plagioclásio $(32 \%)$, álcali-feldspato $(6 \%)$, epídoto $(9 \%)$, titanita $(2 \%)$, e minerais opacos. Encontra-se moderadamente foliada, definindo uma foliação do tipo espaçada-xistosa, com cerca do $50 \%$ de volume de domínio de clivagem. 0 domínio de microlitos é definido predominantemente por quartzo e plagioclásio desenvolvendo uma textura granoblástica enquanto 0 domínio de clivagem é dominadamente por biotita exibindo um padrão anastomosado Fig.1.2 (A)(B).

Os cristais de quartzo possuem tamanhos médios de $200 \mu \mathrm{m}$, com formas subédricas, moderada orientação preferencial, e feições de deformação como extinção ondulante e subgrãos. Estabelecem relações de contatos levemente curvos, retos e moderadamente lobados. Sua tendência é de configurar uma trama poligonal com plagioclásio e álcalifeldspato.

Cristais de plagioclásio são inequigranulares e comumente mostram hábitos granulares, com tamanhos máximos de $250 \mu \mathrm{m}$. Apresentam formas subédricas, e moderada orientação preferencial. Possuem contatos curvos e retos com cristais de mesma espécie, e com álcalifeldspato e quartzo, configurando junções tríplices, semelhantes aquelas de texturas granoblásticas. Apresentam alteração para sericita, e localizadas texturas mirmequítica. Feições de deformação são caracterizadas por geminação deformacional.Fig.1.2 (C)(D) Os cristais de feldspato são inequigranulares, possuem tamanhos variando desde finos até grossos $(\sim 200 \mu \mathrm{m})$. Estabelecem contatos curvos com quartzo e plagioclásio. Geraimente mostram feições de alteração para grãos de aspecto sujo, possivelmente minerais argilosos 

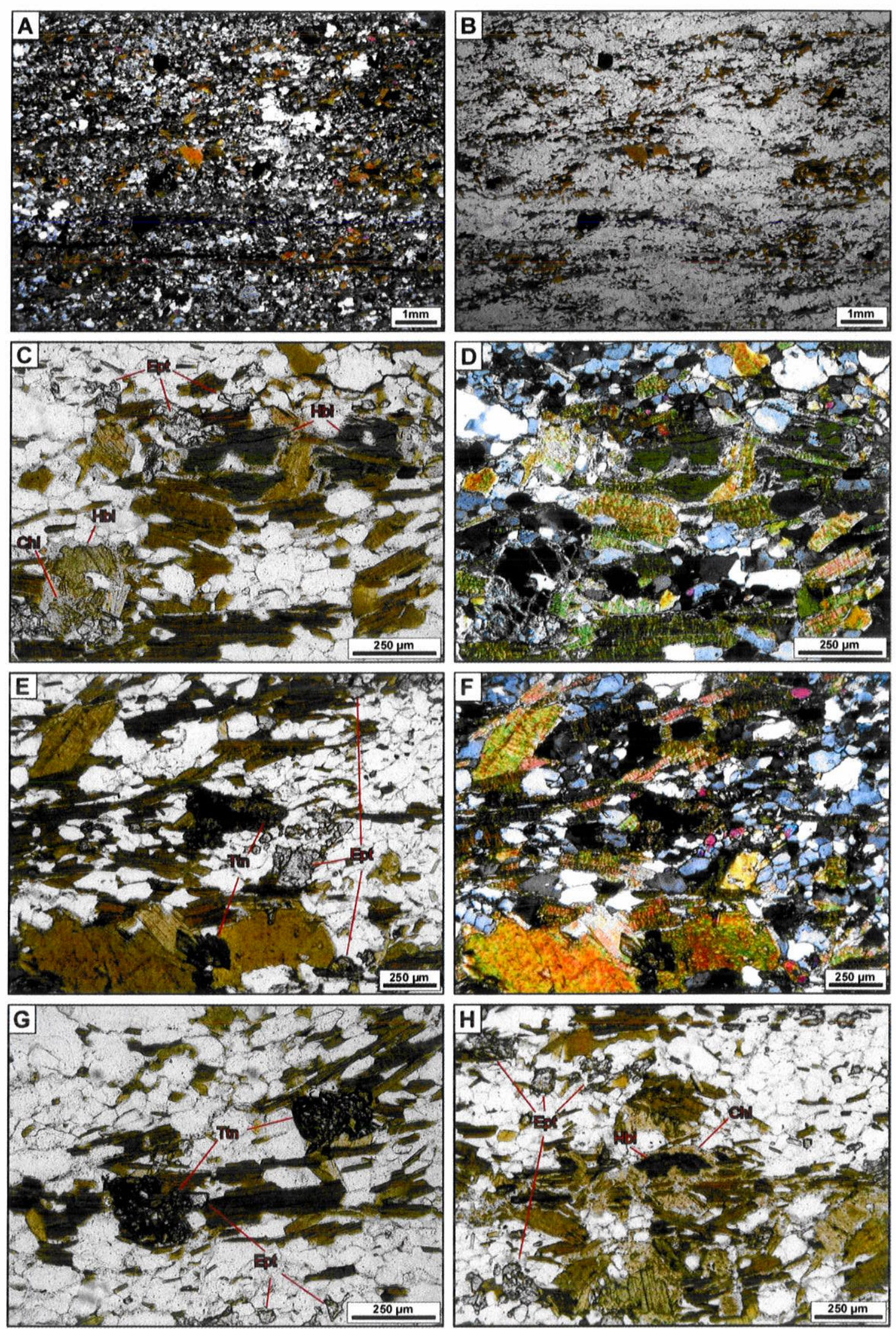

Figura 1.1 (A) (B) Microfotografías exibindo o aspecto da foliação e textura em nicóis cruzados e nicóis paralelos. (C)(D) Agregados minerais de hornblenda clorita e epídoto.(E) (F)Agregados de titanita e epídoto em nicóis paralelos e cruzados. (G) Agregados anedrais de titanita. (H) Agregados de epídoto e alteração de hornblenda a clorita. 
Biotita exibe cristais inequigranulares com formas subédricas e hábitos lamelares até tabulares nas frações mais grossas $\mathrm{Em}$ geral possuem moderada a forte orientação preferencial, estabelecendo com quartzo, plagioclásio e álcali-feldspato contatos retos, curvos a levemente denteados. Exibe feições de deformação como lamelas e extinção ondulante.

O epídoto ocorre geralmente em paragêneses com plagioclásio, biotita e minerais opacos, em agregados granulares irregulares com tamanhos entre $125 \mu \mathrm{m}-500 \mu \mathrm{m}$, configurando contatos comumente curvos. Fig.1.2 (E)(F).

Os cristais de titanita exibem formas subédricas, hábito losangular, e tamanhos que variam entre $30 \mu \mathrm{m}$ a $400 \mu \mathrm{m}$. Encontrassem em paragêneses com biotita por médio de contatos curvos e retos, e comumente exibem núcleos de minerais opacos (ilmenita?), indicando a transição transcorrida pelos efeitos de alteração. Fig.1.2 (G)(H).

Os cristais de feldspato são inequigranulares e possuem tamanhos variando desde finos até grossos, com tamanhos máximos de $200 \mu \mathrm{m}$. Estabelecem contatos curvos com quartzo e plagioclásio. Geralmente mostram feições de alteração para grãos de aspecto sujo, possivelmente minerais argilosos.

Minerais opacos são principalmente ilmenita. Esses cristais possuem formas anédricas e mostram diversos tamanhos (desde finos até grossos). Como feição de alteração ocorre a titanita.

\section{SEQUÊNCIA SUPRACRUSTAL LAVRAS DA MANGABEIRA.}

\section{Metaconglomerado JMR 3}

Rocha com textura porfiroblástica, exibindo texturas secundarias como granoblástica e lepidoblástica, constituída essencialmente por quartzo (90\%), muscovita (8\%), turmalina $(1 \%)$, e minerais opacos $(1 \%)$, e acessoriamente por titanita, monazita e biotita. Estes últimos minerais estão organizados em bandas dominadas por muscovita que em geral circundam porfiroblastos de quartzo. Fig.1.3 (A)(B).

Os cristais de quartzo ocorrem em geral sob a forma de porfiroblastos lenticulares do tipo phi $(\varphi)$ simétricos, com tamanhos médios a grossos (máximo $5 \mathrm{~mm}$ ), inequigranulares. Possuem forte orientação preferencial. Apresentam formas subédricas, estabelecendo relações de contatos retos, denteados, e levemente curvos, em textura granoblástica. Os cristais maiores exibem extinção ondulante, subgrãos e novos grãos, localizados principalmente nas bordas dos porfiroblastos. Neste setor encontram-se cristais de quartzo de hábito granular em tamanhos médios de $200 \mu \mathrm{m}$ com formas subédricas e contatos retos com a muscovita, desenvolvendo uma textura grano-lepidoblástica. Fig.1.3 (C). 

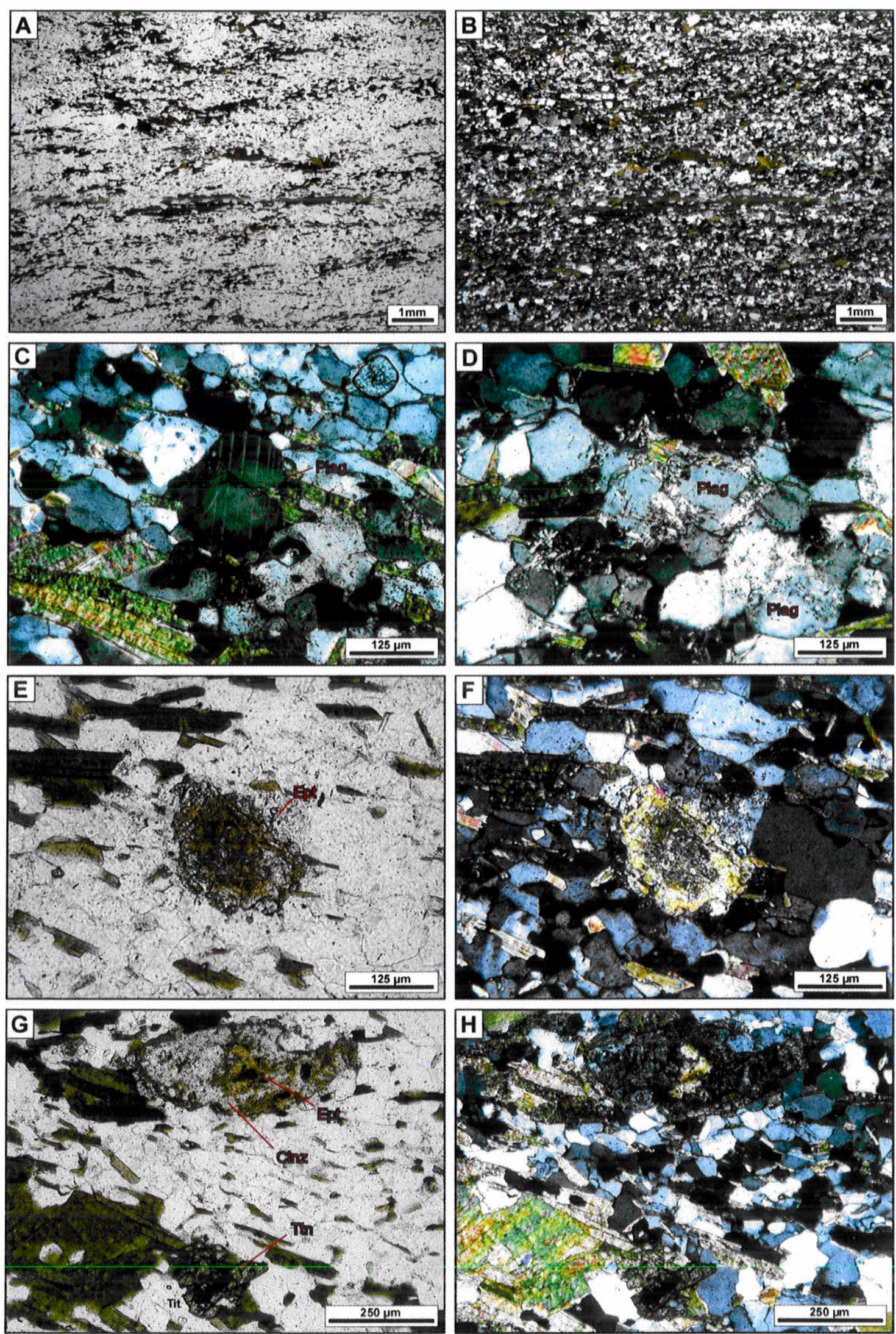

Figura 1.2 (A) (B) Fotomicrográficas com o aspecto da foliação e textura em nicóis paralelos e em nicóis cruzados. (C) cristais de plagioclásio zonado. (D) Plagioclásio alterado. (E) Agregados de epidoto em nicóis paralelos e nicóis cruzados. (G)(H) Titanita e epídoto em nicóis paralelos e cruzados. 
Os cristais de muscovita possuem hábito lamelar e tabular com formas euédricas a subédricas, e orientação preferencial forte. Apresentam contatos retos entre si e com quartzo. Ocorre em agregados de muscovita estabelecendo cordões tangenciais que bordejam os porfidoblastos de quartzo. Nestas faixas observa-se opacos e poucos cristais lamelares de biotita crescendo da muscovita .

Os cristais de turmalina possuem tamanhos entre $200 \mu \mathrm{m}$ e $600 \mu \mathrm{m}$, formas subédricas e anédricas, e hábito prismático. Apresentam orientação preferencial moderada a forte. Encontram-se comumente em paragêneses com muscovita e quartzo, estabelecendo contatos retos. Fig.1.3(D)(E)(F).

Minerais acessórios como titanita, monazita e biotita constituem aproximadamente $1 \%$ da composição da rocha. Os cristais de titanita são subequigranulares, subédricos, com tamanhos de $125 \mu \mathrm{m}$, em paragéneses com minerais opacos e muscovita. A monazita exibe tamanhos finos de $50 \mu \mathrm{m}$ até $100 \mu \mathrm{m}$ idiomórficos e alongados.

\section{Quartzito JMR2}

Rocha de textura granoblástica e grano-lepidoblástica, composta essencialmente de quartzo $(60 \%)$, plagioclásio $(10 \%)$, ortoclasio $(11 \%)$, microclínio $(8 \%)$, muscovita $(10 \%)$ e como acessórios epídoto, apatita e grafita(?). Minerais secundários são clorita e biotita, os quais são produto de alteração da muscovita. Apresenta foliação de tipo contínuo, definida pela muscovita e as feições de alteração do plagioclásio e álcali-felspato. Fig.1.4 (A)(B)

Os cristais de quartzo são subédricos a anédricos e exibem tamanhos médios de $250 \mu \mathrm{m}$, com orientação predominante entre incipiente e moderada. As relações de contatos são curvas, lobadas e retas entre si e entre cristais de álcali-feldspatos; e retas com cristais de muscovita, desenvolvendo uma fabrica inequigranular-interlobada. Exibe grãos com extinção ondulante, e subgrãos com inclusões de muscovita e grafita(?)

A muscovita possui variedades de tamanhos desde $10 \mu \mathrm{m}$ ate $600 \mu \mathrm{m}$, com formas subédricas a anédricas em hábito tabular e lamelar, com contatos retos e serrilhados entre si e principalmente com álcali-feldspato, plagioclásio e quartzo. Apresenta cristais inclusos no álcali-feldspato e exemplares que registram a transição a biotita.

Álcali-feldspato (ortoclásio?) ocorre em tamanhos médios, inequigranulares, com formas subédricas, e moderada orientação preferencial. Contem inclusões de muscovita e biotita estabelecendo contatos serrilhados dentro do cristal do álcali-feldspato, apresentando uma apariencia suja com feições de alteração de argilo minerais (caulinita?). Ocorre também microclínio exibindo cristais com tamanhos médios, anedrais, estabelecendo contatos denteados, curvos e lobados com quartzo e ortoclásio. Fig.1.4 (C)(D). 

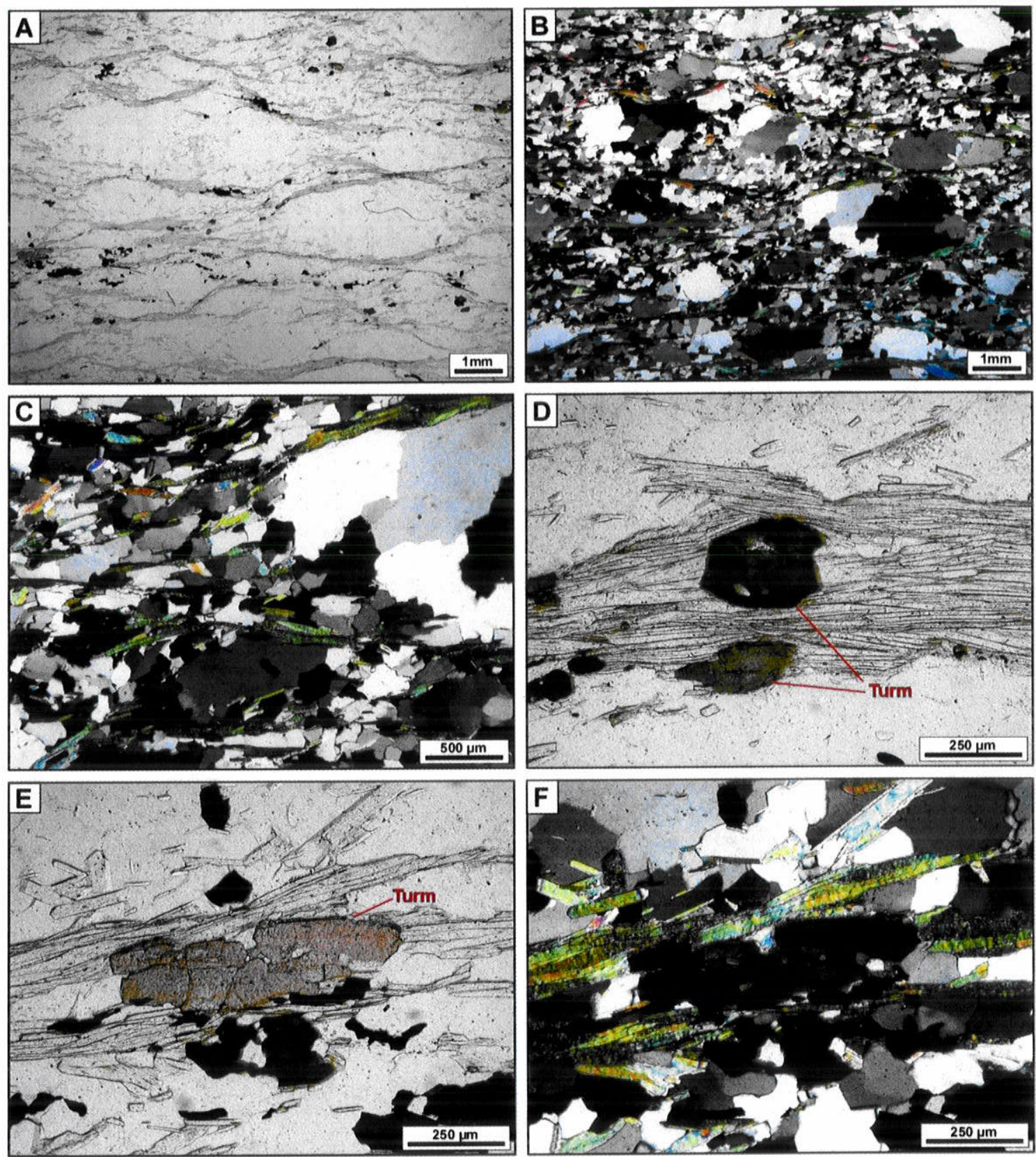

Figura 1.3. (A) Nicóis paralelos (B) Nicóis cruzados. Fotomicrográficas exibindo a textura porfidoblástica. (C) Porfidoblasto de quartzo exibindo contatos denteados e retos. (D) Turmalina euedral e subedral em agregado tabular de muscovita. (E) e (F) Turmalina subedral e anedrales com pleocroismo rosa e verde escuro.

Os cristais de plagioclásio são anedrais, com tamanhos médios de $200 \mu \mathrm{m}$, inequigranulares, estabelecendo contatos curvos, lobados e retos com quartzo e álcalifeldspato. Apresentam-se com orientação preferencial fraca e com feições de aiteração a sericita.

Os minerais acessórios (grafita(?), epídoto, e apatita) não ultrapassam 1\% da composição da rocha. A grafita(?) exibe hábito granular, tamanhos finos a médios e contatos irregulares com os outros minerais. Os cristais de epídoto são subeudrais, com hábito granular e 
tamanhos finos $(50 \mu \mathrm{m})$. Possuem relações de contatos curvas com os cristais de quartzo e álcali-feldspato. Os cristais de apatita são dominantemente euédricos, com tamanhos de aproximadamente $10 \mu \mathrm{m}$.
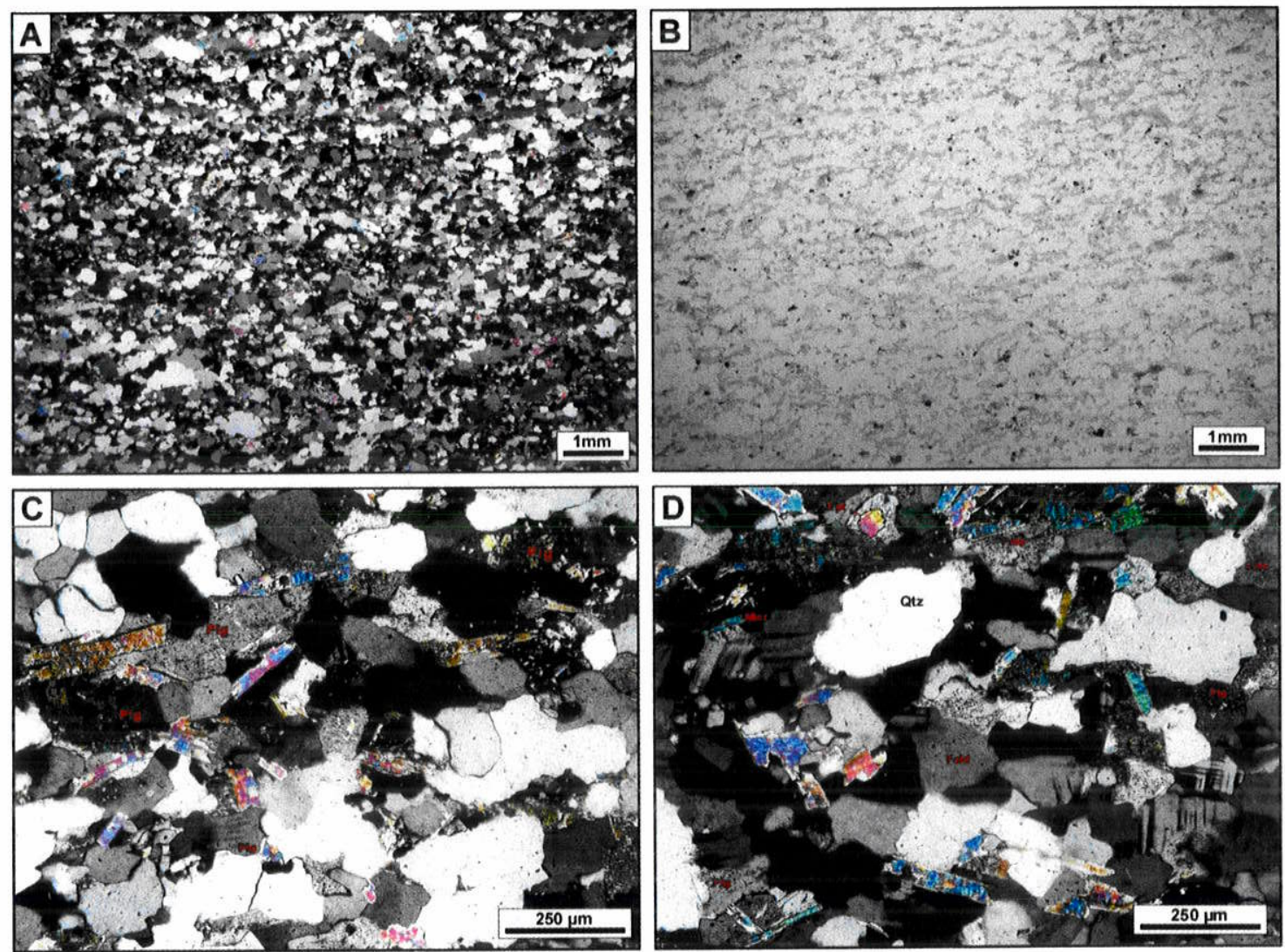

Figura 1.4.(A) (B) Foliação e textura grano-lepidoblástica em nicóis paralelos e nicóis cruzados. (C) Feldspato com inclusões de muscovita e relações de contato com quartzo e biotita. (D) cristais de microclínio e feldspato

\section{SEQUÊNCIA SUPRACRUSTAL SERIDÓ (região entre Coremas e Cajazeiras -PB)}

\section{Paragnaisse JMR 12}

Rocha com foliação contínua de caráter xistosa, composta por quartzo (40\%), biotita $(40 \%)$, plagioclásio $(20 \%)$, granada(2\%), e acessoriamente turmalina, apatita e zircão. Possui textura dominantemente grano-lepidoblástica. Apresenta-se moderadamente foliada, sendo a biotita o principal mineral que define a foliação Fig.1.5 (A)(B).

Os cristais de quartzo são inequigranulares, com formas subédrica e anédrica, com tamanhos máximos de $1.5 \mathrm{~mm}$, estabelecendo contatos retos e serrilhados com biotita, e lobados, denteados, curvos, e serrilhados entre si e com plagioclásio. Apresentam subgrãos, novos grãos e extinção ondulante como principais feições de deformação.

Os cristais de biotita são subédricas, com hábito acicular e predominantemente tabular e moderada orientação preferencial, caracterizando um arranjo lepidoblástico. Apresentam, 
tamanhos finos a médios $(<700 \mu \mathrm{m})$ e por vezes exibem formas alongadas. Localmente exibem contatos irregulares que configuram porções granulares.

Cristais equigranulares de granada possuem tamanhos médios $(<1 \mathrm{~mm})$, formas euédricas, e contatos levemente curvos e lobados com quartzo e plagioclásio, e retos e levemente serrilhados com biotita. Exibem inclusões de zircão, apatita, quartzo e minerais opacos alongados, indicando um evento dextral sintectônico. Fig.1.5 (C)(D).

Cristais de plagioclásio possuem tamanhos máximos de $500 \mu \mathrm{m}$, formas subédricas a anédricas, geralmente com hábito granular, exibindo orientação moderada e contatos denteados e serrilhados com biotita. Apresentam feições de deformação como geminações deformacionais.

Cristais de turmalina são euédricas, inequigranulares, com tamanhos máximos de $500 \mu \mathrm{m}$, e hábito prismático. Apresentam contatos curvos e retos com biotita e quartzo. Fig.1.5 (E)(F).

\section{Quartzito JMR 8}

Rocha composta essencialmente por quartzo $(90 \%)$, muscovita $(9 \%)$, e turmalina(1\%), e acessoriamente por titanita, epídoto, monazita e biotita. Geralmente apresenta textura porfiroblástica grossa, com porfidoblastos simétricos lenticulares, inequigranulares do tipo phi $(\varphi)$. Possuem tamanhos médios a grossos (máximo $5 \mathrm{~mm}$ ), assim como texturas granoblástica e grano-lepidoblástica, predominante nas granulações mais finas de quartzo. Fig.1.6 (A)(B).

Os cristais de quartzo são grãos inequigranulares com formas subédricas a anédricas, alongados, e com tamanhos médios entre $200 \mu \mathrm{m}-1.3 \mathrm{~mm}$. Mostram orientação preferencial forte. Os contatos são retos, curvos, e levemente lobados entre si. Os porfidoblastos são alongados com inclusões de muscovita acicular de $40 \mu \mathrm{m}$, e ocorre em tamanhos grossos máximos de $5.5 \mathrm{~mm}$. Apresentam feições de deformação como subgrãos, novos grãos e extinção ondulante.

Os cristais de muscovita são euédricas a subédricas, com tamanhos variados $(40 \mu \mathrm{m}-2$ $\mathrm{mm}$ ), hábito prismático, e orientação preferencial moderada a forte. Exibem contatos retos entre si, e com cristais de turmalina e quartzo. Comumente ocorrem sob a forma de faixas que bordejam cristais e porfiroblastos de quartzo. onde registrassem feições de deformação como extinção ondulante.

Os cristais de turmalina são inequigranulares, subédricos a anédricos, com tamanhos máximos de $850 \mu \mathrm{m}$, hábito prismático e orientação preferencial moderada. Encontram-se em paragêneses com quartzo e muscovita, onde desenvolvem contatos levemente retos com esses cristais Fig.1.6 (C)(D). 
Minerais acessórios como titanita, monazita e biotita perfazem menos de 1\% da composição da rocha. Os cristais de titanita são subequigranulares, subédricos, exibem tamanhos de $125 \mu \mathrm{m}$, e estão em paragêneses com minerais opacos e muscovita. A monazita exibe tamanhos médios de $50 \mu \mathrm{m}$ ate $80 \mu \mathrm{m}$, com formas euédrais alongados a subedrais. Encontra-se inclusa em quartzo e muscovita. A biotita apresenta uma variedade de tamanhos principalmente finos. O epídoto é anédrico, com tamanhos de $100 \mu \mathrm{m}$, constituindo a menor fração dos acessórios.
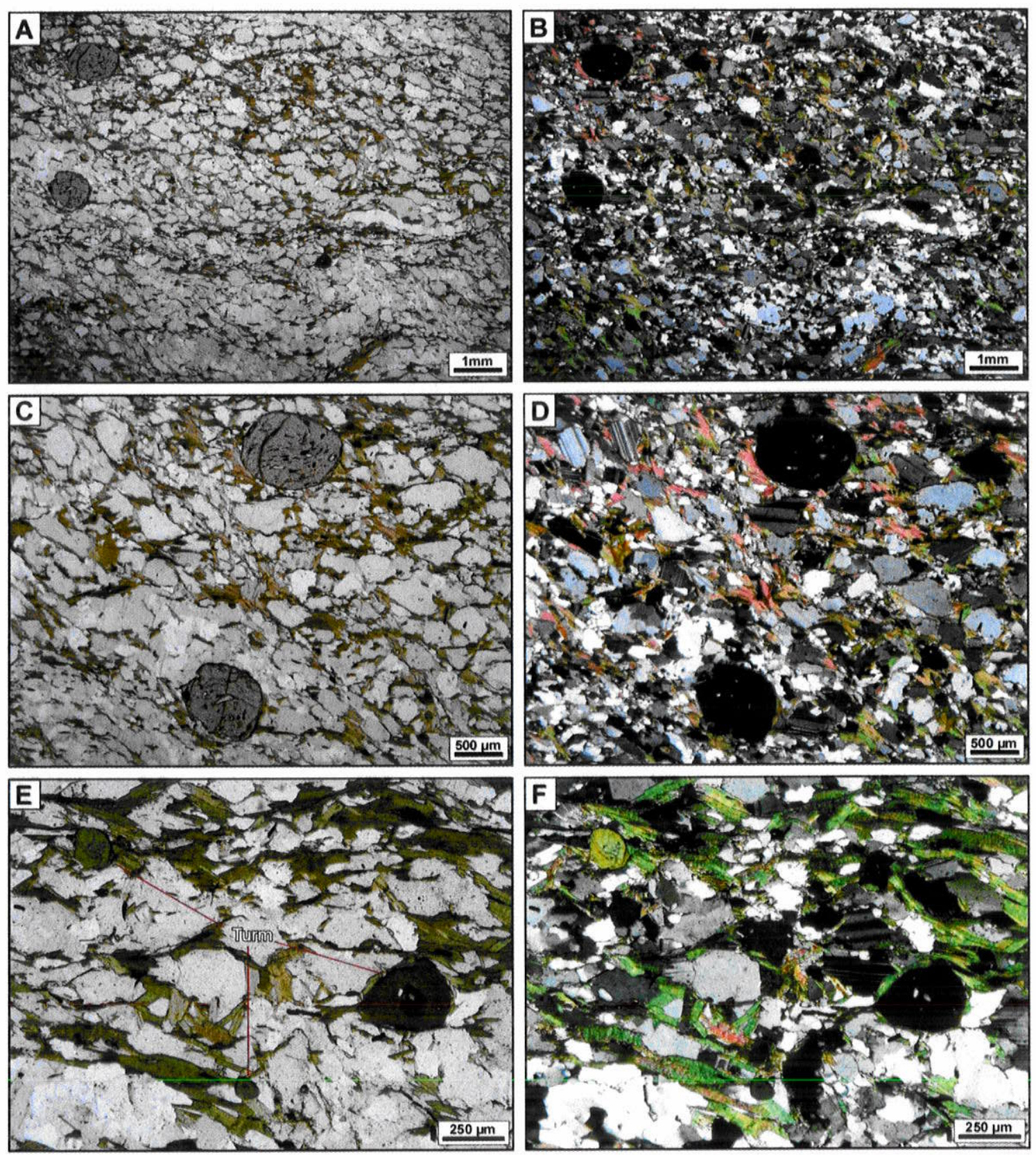

Figura 1.5. (A) (B) Textura geral da rocha. nicóis cruzados e nicóis paralelos e cruzados. (C) (D) cristais equigranulares de granada junto com plagioclásio. (E) (F) Nicóis paralelos e cruzados. Observa-se cristais inequigranulares de turmalina, cor verde oliva. 


\section{Quartzito JMR 11}

Rocha de textura granol-epidoblástica e granoblástica, constituída principalmente por quartzo $(88 \%)$, muscovita $(9 \%)$, microclínio $(2 \%)$, álcali-feldspato $(1 \%)$ e titanita. Apresenta-se moderadamente foliada, sendo essa trama do tipo espaçada, grossa, com aproximadamente $2 \%$ de domino de clivagem, relação anastomosada entre os domínios de clivagem, e com transição discreta entre os domínios de micrólitos e de clivagem Fig.1.7(A)(B).

Os cristais de quartzo configuram uma trama seriado-interlobada (seriates), com formas subédricas a anédricas e tamanhos médios a grossos $\leq 2 \mathrm{~mm}$., com orientação preferencial moderada. Apresenta contatos curvos e retos com cristais de muscovita; e predominantemente lobados, denteados, curvos e retos entre si e com microclínio e álcalifeldspato. Observa-se forte extinção ondulante, subgrãos e geralmente novos grãos como feições de deformação.
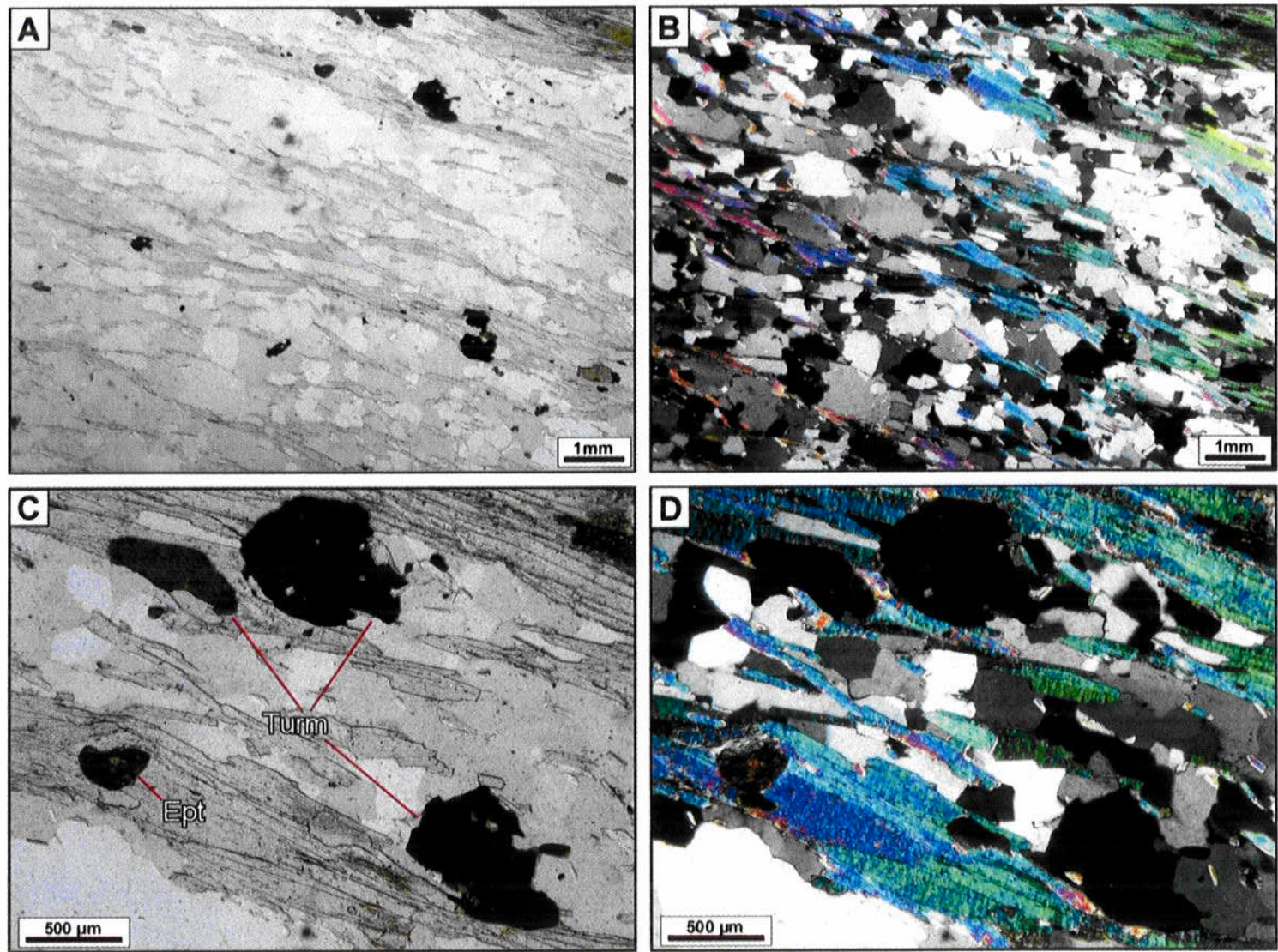

Figura 1.6. (A) Nicóis paralelos (B) Nicois cruzados. Microfotografias de textura porfidoblástica, e secundaria textura, grano-lepidoblástica com presença de turmalina. (C) (D) Cristais subeudrais e anedrais de turmalinas. Observe-se na parte inferior esquerda cristal de epídoto.

Cristais de muscovita definem o domínio de clivagem da rocha, exibindo tamanhos finos até grossos $(2 \mathrm{~mm})$, em hábito lamelar, subédricas e com orientação preferencial moderada a forte. Apresenta extinção ondulante, e cristais aciculais interdigitados de biotita em conjunto aos minerais opacos. Fig.1.7(C). 
Microclínio e álcali-feldspato ocorrem em tamanhos médios de $300 \mu \mathrm{m}$, com formas anédricas, orientação preferencial fraca. e exibindo argilo minerais e inclusões de opacos. Fig.1.7(D)(E). Os cristais de titanita são subedrais, com tamanhos máximos de $500 \mu \mathrm{m}$, associados geralmente a opacos, e estabelecendo relações de contatos curvas, retas e lobadas com quartzo e biotita. Fig.1.7(F)
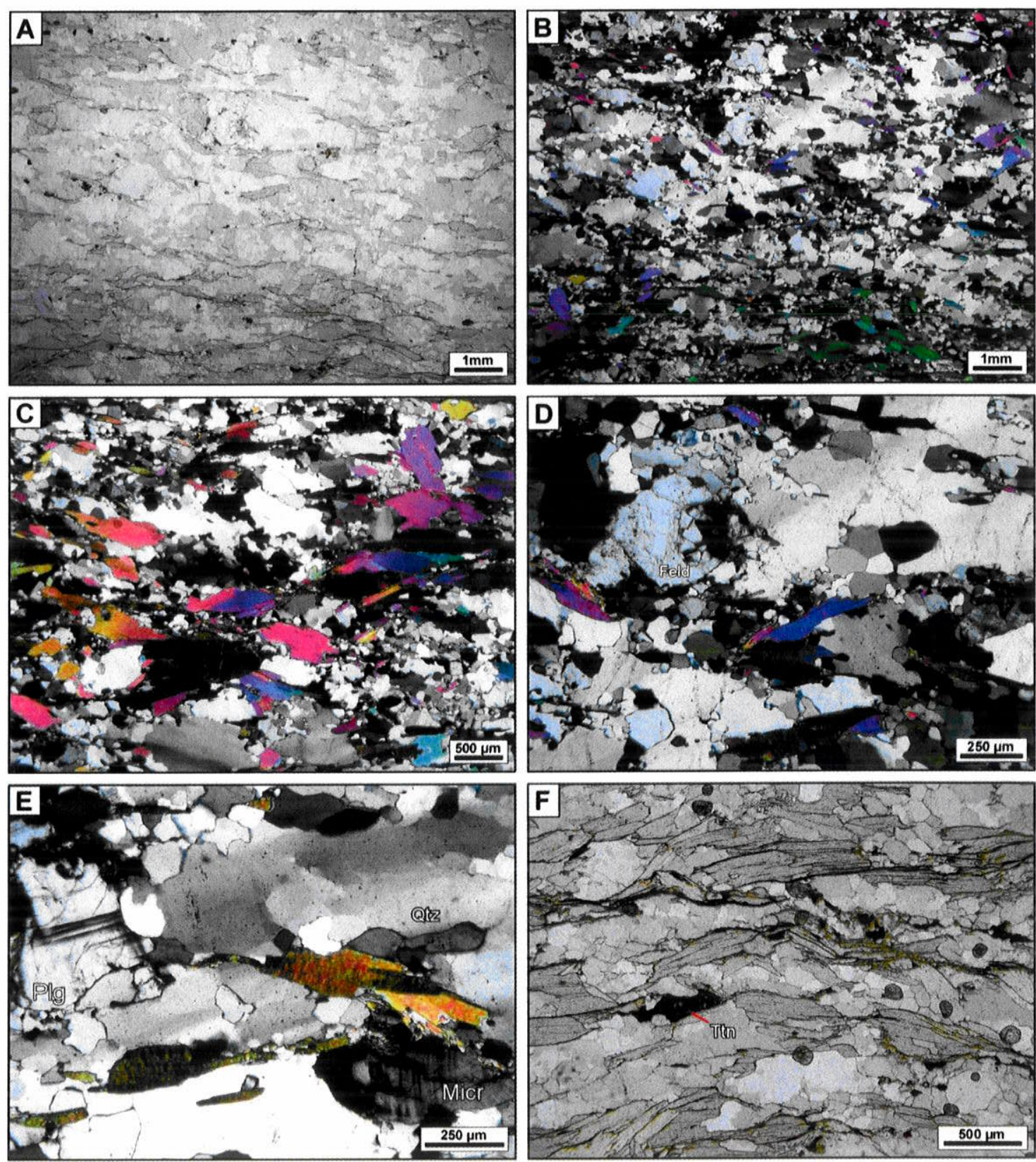

Figura 1.7. (A) (B) Microfotografias de textura grano-lepidoblástica em nicóis paralelos e nicóis cruzados. (C) Textura grano lepidoblástica com feições de extinção ondulante em biotita e novos grãos nos contatos entre quartzo. (D) Relacões de contatos entre feldspato e quartzo. (E) Relações de contatos entre microclínio, quartzo e biotita. (F) cristal de titanita com presença de turmalina (minerais escuros). (c)(d) Cristais subedrais e anedrais de turmalinas. Observe-se na parte inferior esquerda cristal de epídoto. 


\section{Quartzito JMR 9}

Rocha de textura dominantemente granoblástica, com textura grano-lepidoblástica localizada, levemente foliada, constituída por quartzo $(90 \%)$ e muscovita $(10 \%)$ e acessoriamente titanita. A foliação caracteriza-se como espaçada, paralela, com $1 \%$ de domínio de clivagem e com transição discreta entre os domínios de micrólitos e clivagens.

Fig. 1.8 (A)(B)

Os cristais de quartzo são subédricos, com tamanhos que variam entre $80 \mu \mathrm{m}$ e $2 \mathrm{~mm}$ (inequigranulares). Exibem contatos interlobados, denteados, retos, e curvos entre si. Com cristais de biotita estabelecem contatos retos e serrilhados, caracterizando uma textura granoblástica com leve tendência a grano-lepidoblástica. Estes cristais exibem inclusões de muscovita, forte extinção ondulante, novos grăos e predominantemente subgrãos como principais feições de deformação observadas.

Os cristais de muscovita apresentam formas euédricas a subédricas, em hábito lamelar e tabular, e tamanhos que variam desde $100 \mu \mathrm{m}$ até $1.5 \mathrm{~mm}$, com orientação preferencial moderada, onde os contatos dominantes entre si são de tipo reto e serrilhado. Fig. 1.6 (A)(C).

A titanita exibe hábito granular, em tamanhos de $125 \mu \mathrm{m}$, em formas subedricas, dentro de cristais lamelares de muscovita. Fig. 1.8 (C)(D).Localmente, apresenta feições de alteração caulinítica, Fig. 1.8 (B).

\section{Biotita xisto JMR 10}

Rocha composta essencialmente de quartzo $(50 \%)$, biotita $(30 \%)$, muscovita(10\%), plagioclásio $(10 \%)$, álcali-feldspato $(5 \%)$, e acessoriamente granada, apatita, epídoto e minerais opacos, desenvolvendo dominantemente uma textura grano-lepidoblástica. Mostrase fortemente foliada com uma foliação de caráter espaçado xistosa, com forma de domínios de clivagem regular e aproximadamente $40 \%$ de domínio de clivagem (descontinua), com relação espacial entre domínios de clivagem anastomosada, e transição gradacional entre micrólitos e clivagem. Fig.1.9 (A)(B).

Cristais de quartzo são inequigranulares, subédricos, com feições de deformação como extinção ondulante, subgrãos, ribbons e novos grãos. Possuem tamanhos variáveis (inequigranulares) com dimensões máximas de $500 \mu \mathrm{m}$ na matriz. Apresentam contatos curvos, lobados, e denteados com plagioclásio e álcali-feldspato, e com biotita contatos geralmente retos e curvos.

A biotita ocurre em companhia de quartzo, plagioclásio e álcali-feldspato, desenvolve localmente uma textura lepidoblástica entre cristais da mesma espécie e muscovita. Exibe 
cristais inequigranulares subedrais, que variam desde finos até grossos $(1 \mathrm{~mm})$. Possuem hábitos lamelares e inclusões de apatita.
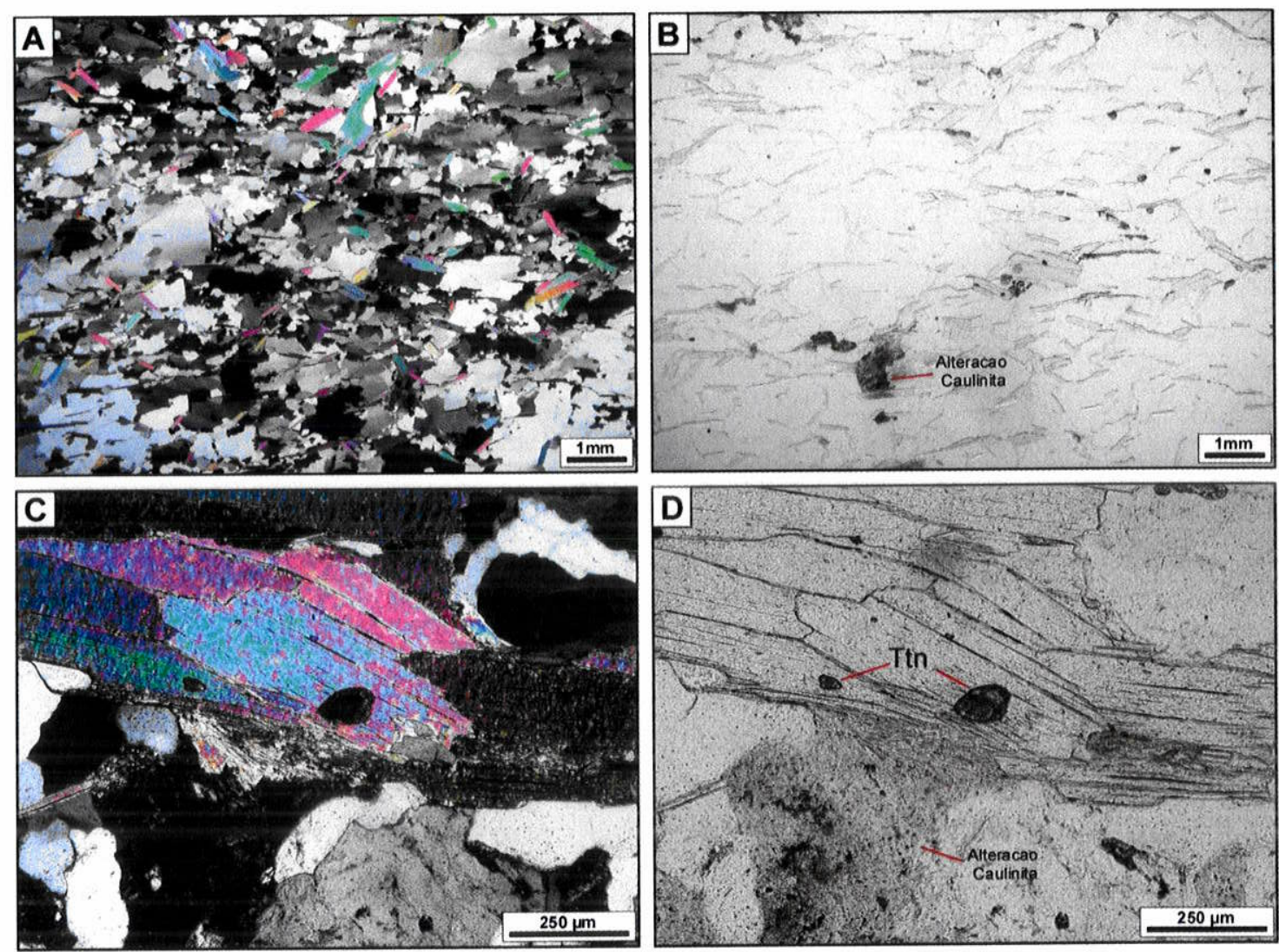

Figura 1.8. (A)(B) Microfotografias de textura grano-lepidoblástica em nicóis paralelos e nicóis cruzados. Observa-se a alteração caulinítica. (C)(D)Textura grano-lepidoblástica, microcristais de titanita.

Os cristais de plagioclásio são predominante equigranulares, subedrais, e com tamanhos que alcançam $500 \mu \mathrm{m}$. Exibem feições de fraturamento e geminações deformacionais. Feições de alteração são caracterizadas por grãos de aspecto sujo, suas relações de contatos com biotita variam de retas a ligeiramente denteadas. Os cristais de álcalifeldspato são predominantemente inequigranulares com tamanhos variando de $100 \mu \mathrm{m}$ até $500 \mu \mathrm{m}$. Possuem formas anédricas. Apresentam moderada orientação preferencial, e contatos denteados e interlobados entre si com quartzo e com plagioclásio. Com biotita exibem contatos denteados. Exibem feições de fraturamento e feições de alteração para cristais de aspecto sujo, possivelmente argilominerais como caulinita. Fig.1.9 (C)(D).

A muscovita possui tamanhos desde $10 \mu \mathrm{m}$ ate $600 \mu \mathrm{m}$, com formas subédricas e anédricas e hábito acicular. Apresenta contatos retos e serrilhados entre si e principalmente com álcali-feldspato, plagioclásio e quartzo. Ocorre por vezes inclusa no álcali-feldspato e/ou alterando-se para biotita. Fig.1.9 (E)(F).

Os minerais acessórios (granada, apatita e minerais opacos) juntos não ultrapassam 1\% de composição da rocha. A granada encontra-se em paragêneses com biotita, exibindo 
tamanho máximo de $500 \mu \mathrm{m}$ e hábito granular euedral. Os microcristais de apatita estão disseminados principalmente nos agregados cristalinos da biotita, desenvolvendo zonações concêntricas. Os minerais opacos ocorrem em cristais de hábito granular euédrico geralmente associados a biotita.
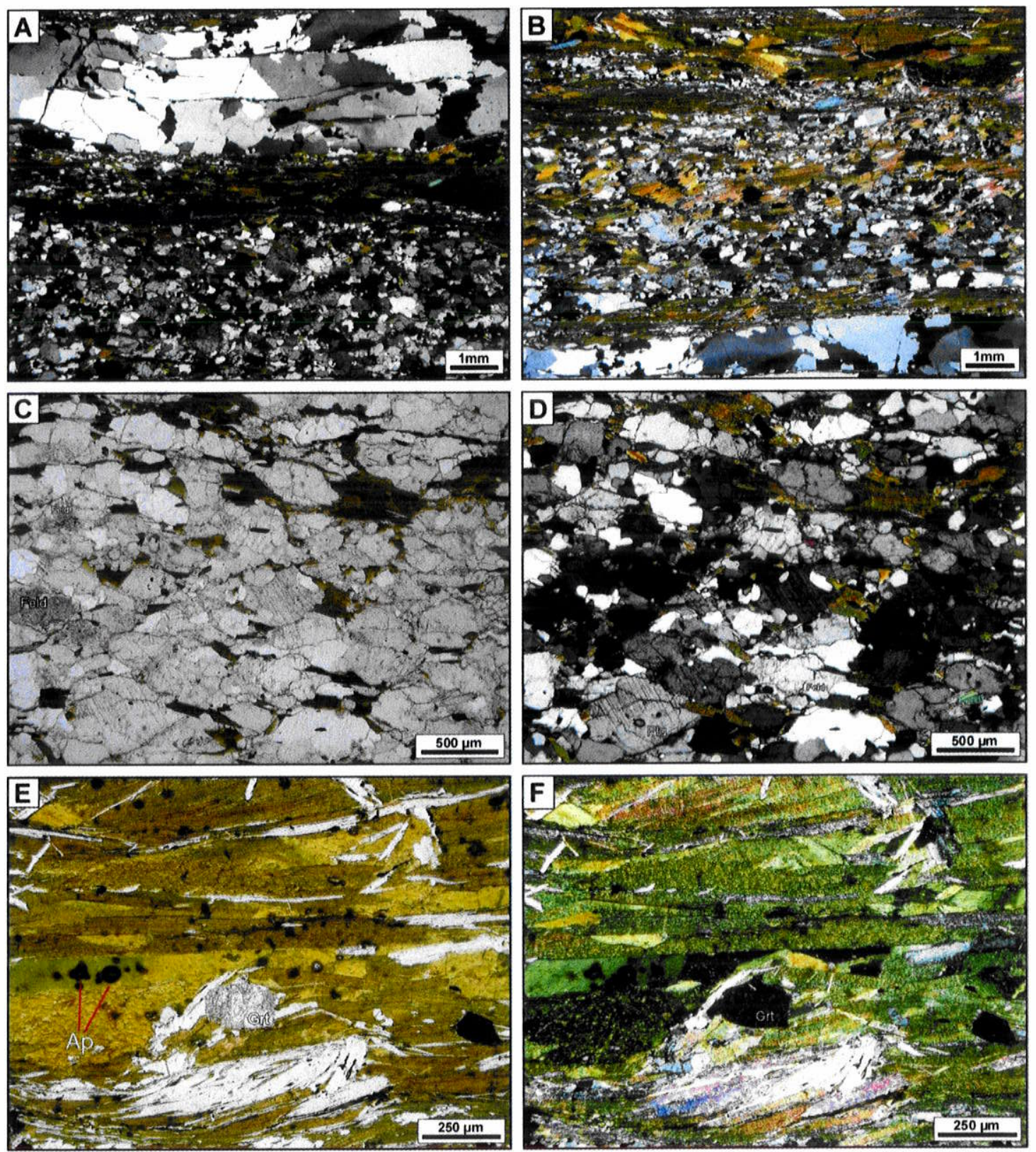

Figura 1.9. (A)(B) Micrólitos (Ribbon) e clivagem dominante na rocha. Nicóis cruzados e nicóis paralelos (C) (D) cristais de álcali-feldspato e plagioclásio. (E) (F) Textura lepidoblástica definida pela biotita e muscovita. Observe as zonações escuras efetuadas pela presença de apatita, além do cristal subedral de granada.

\section{Arenito JMR-4 (Bacia de lara)}

Rocha classificada como Arenito Litico (Filarenito), com 61.4\% de arcabouzo, 35,6\% de material intersticial, e $3 \%$ de porosidade. O arcabouço é composto principalmente por 
quartzo (45.6\%), feldspatos (21.6\%), variedade de fragmentos liticos $(32.9 \%)$, de tipo metamórfico quartzitico, vulcanico e ígneo, definindo uma granulacão grossa, cujos tamanhos médios dos grãos é aproximadamente de $0.5 \mathrm{~mm}$. Apresenta selecão é má, fabrica matriz soportada, com grãos de plagioclasio e fragmentos liticos dominantemente angulares junto a clastos de quartzo esferoidais maiores a $0.250 \mathrm{~mm}$.Fig 1.10 (A)(B)

O arcabouzo, encontra-se composta por graõs de quartzo monocristalino, fragmentos de quartzito, chert, volcânicos, fragmentos ígneos e sedimentares (chert). Predomina a ortoclasa, plagioclasio e em menor proporçao microclino. Este minerais encontra-se en diferentes grãos de alteracão sericitica e caolinitica.Fig 1.10 (C)(D)

A matriz apresenta fragmentos finos de quartzo, chert, feldespatos, liticos, opacos e predominantemente matriz caolinitica e sericitica, junto a matriz ferruginosa, opacos finos e setores silicificados.
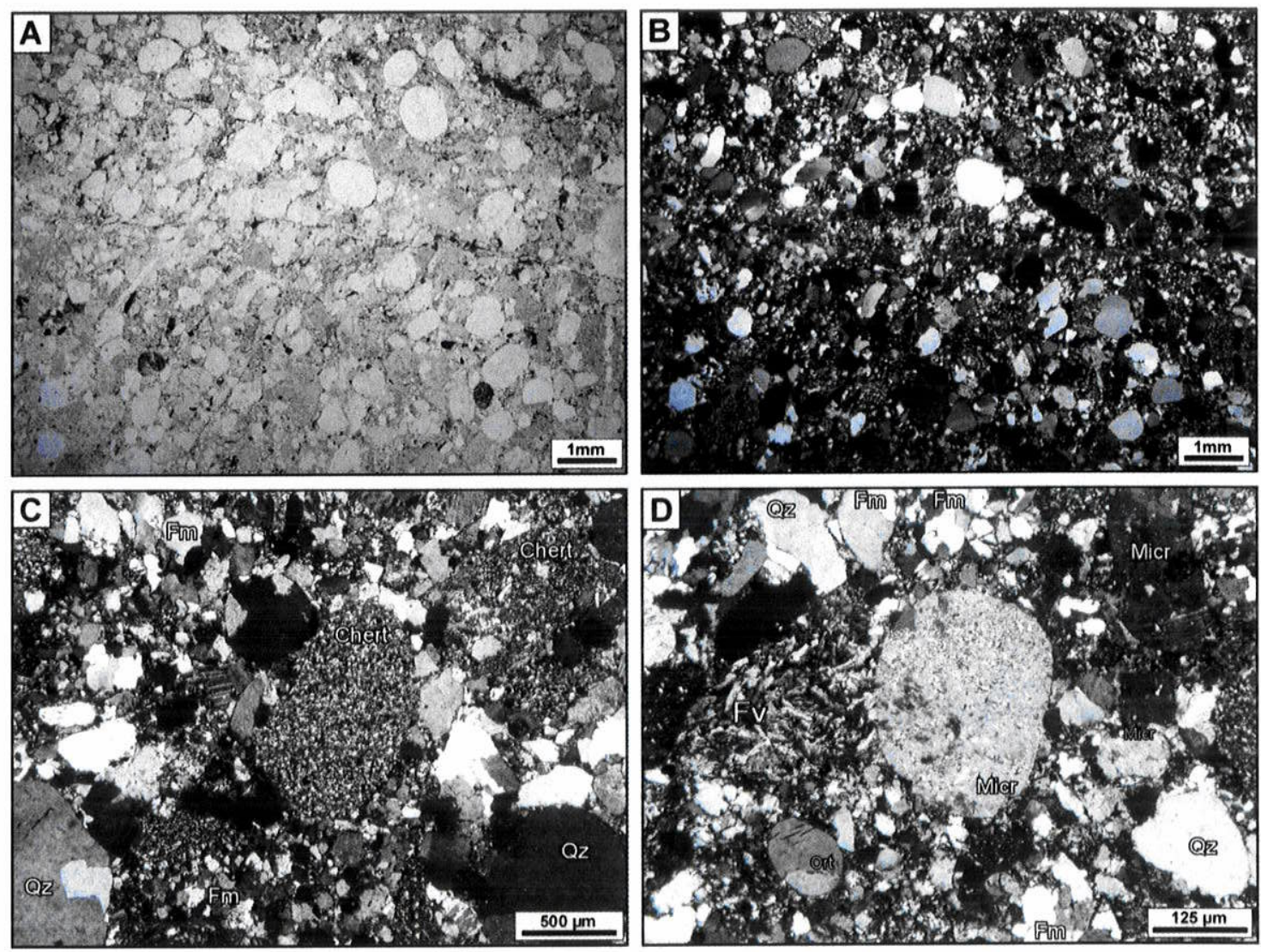

Figura 1.10 (A) (B)Microfotografias em nicóis paralelos e nicóis cruzados. Os cores marrão corresponde principalmentea matriz serititica, caolinitica, junto a fragmentos de feldspatos alterado.Apresenta-se clastos de quartzo redondados. (C) (D) Tipos de clastos. Fm: fragmento metamórfico de tipo quartzitico. Fv: fragmento vulcânico, Microclino alterado, fragmentos de chert.

\section{Arenito JMR-5 (Bacia de Barro)}

Rocha classificada como Arenito Arcosiano, composta essencialmente de quartzo (72\%), feldspato (28\%), e fragmentos líticos $(0.3 \%)$ de granulação media, com tamanos médios dos clastos de $0.25 \mathrm{~mm}$, relação soportada entre clastos, boa seleção, baixa esfericidade com 
grãos subangulares a subarredondados. Possui $58 \%$ de arcabouço, $22.9 \%$ de material intersticial, e 7.3\% de porosidade. Fig 1.11 (A)(B)

$O$ arcabouço encontra-se composta predominatemente por fragmentos de quartzitos, quartzo monocristalino com extinção ondulante. Apresenta-se pouco plagioclasio, mas clastos de Feldspatos são predominantemente de ortoclásio e microclino, exibindo moderada alteração de tipo sericitica, total e parcialmente no grão. Entre os fragmentos líticos apresentase esporadica turmalina cor marrão fortemente pleocroica, alem de presença de fragmentos micáceos. Fig 1.11 (C)(D)

A matriz é conformada por fragmentos finos de ortoclásio e microclino, com forte alteração sericitica. Esta alteração é acompanhada de setores com matriz ferruginosa e opacos de tamanho fino.
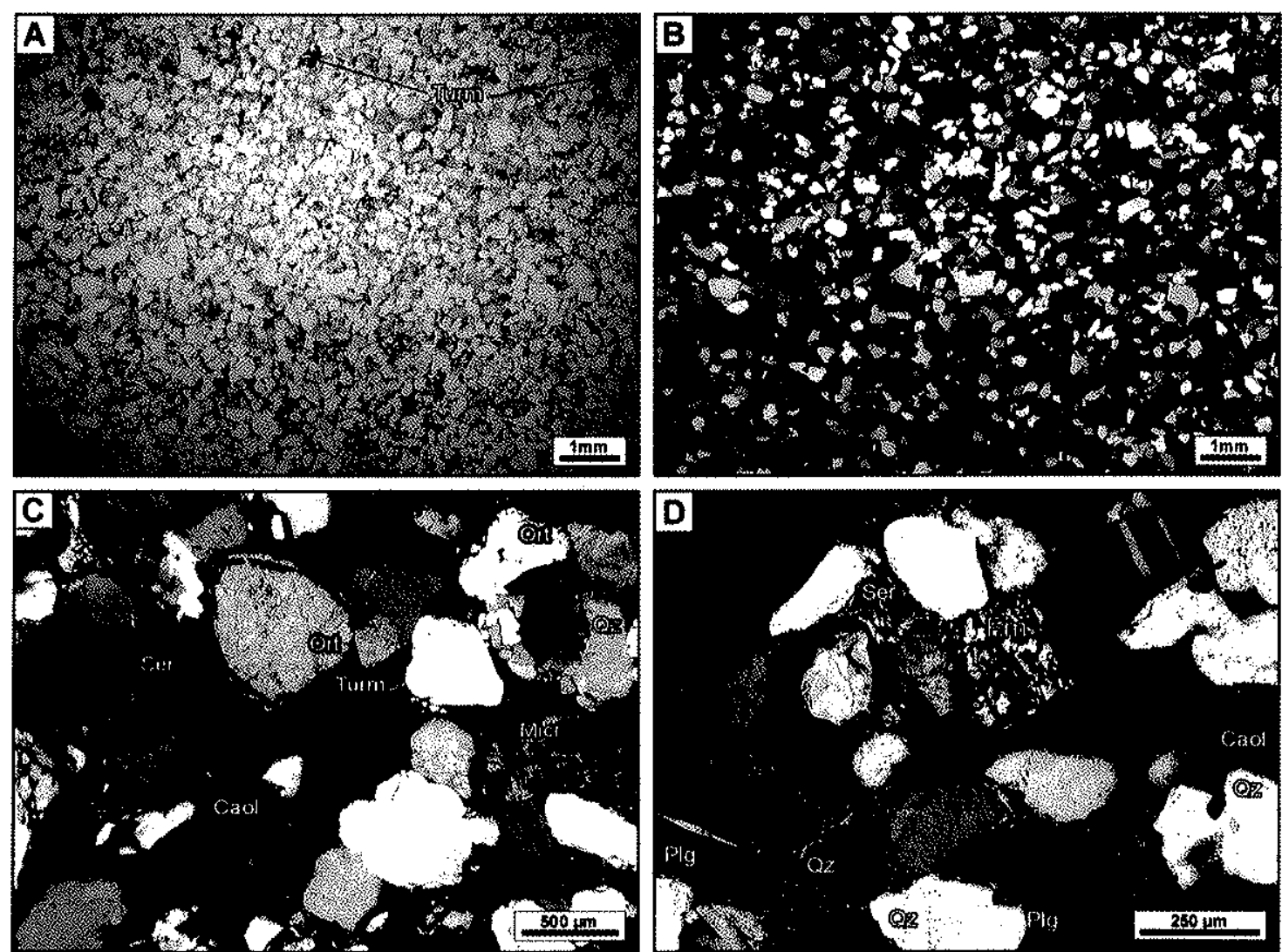

Figura 1.11 (A)(B)Microfotografias em nicóis paralelos e nicóis cruzados. Observa-se grãos de turmalina marrăo pleocroica. (C) (D) Tipos de clastos. Ort: ortoclasa, Micr; microclino. Plg= Plagioclásio. Fragmento metamórficos, de tipo quartzitico. 